\title{
Mining and residential development interact to produce highly impaired stream conditions in an intensively mined Appalachian watershed
}

Eric Richard Merriam

West Virginia University

Follow this and additional works at: https://researchrepository.wvu.edu/etd

\section{Recommended Citation}

Merriam, Eric Richard, "Mining and residential development interact to produce highly impaired stream conditions in an intensively mined Appalachian watershed" (2009). Graduate Theses, Dissertations, and Problem Reports. 2821.

https://researchrepository.wvu.edu/etd/2821

This Thesis is protected by copyright and/or related rights. It has been brought to you by the The Research Repository @ WVU with permission from the rights-holder(s). You are free to use this Thesis in any way that is permitted by the copyright and related rights legislation that applies to your use. For other uses you must obtain permission from the rights-holder(s) directly, unless additional rights are indicated by a Creative Commons license in the record and/ or on the work itself. This Thesis has been accepted for inclusion in WVU Graduate Theses, Dissertations, and Problem Reports collection by an authorized administrator of The Research Repository @ WVU. For more information, please contact researchrepository@mail.wvu.edu. 
Mining and Residential Development Interact to Produce Highly Impaired Stream Conditions in an Intensively Mined Appalachian Watershed

\title{
Eric Richard Merriam
}

\author{
A Thesis submitted to the \\ Davis College of Agriculture, Forestry, and Consumer Sciences \\ at West Virginia University \\ in partial fulfillment of the requirements \\ for the degree of
}

Master of Science

in

Wildlife and Fisheries Resources

\author{
J. Todd Petty, Ph.D., Chair \\ Michael P. Strager, Ph.D. \\ Stuart A. Welsh, Ph.D. \\ Wildlife and Fisheries Resources Program \\ Division of Forestry and Natural Resources
}
West Virginia University
Morgantown, WV

2009

Keywords: Mining, Multiple Interacting Stressors, Additive Effects, Landscape Indicators, Residential Development, Threshold Effects 


\section{Abstract \\ Mining and Residential Development Interact to Produce Highly Impaired Stream Conditions in an Intensively Mined Appalachian Watershed}

\section{Eric Richard Merriam}

Large scale surface mining in southern West Virginia causes significant alteration of headwater stream networks. It is unclear, however, the extent to which mining interacts with other stressors to determine physical, chemical, and biological conditions in aquatic systems downstream. Through a watershed scale assessment of Pigeon Creek, the specific objectives of this study were to: 1) quantify the direct and interactive effects of mining and residential development on in-stream conditions; and 2) identify landscape thresholds above which biological impairment occurs. Our results indicate high levels of impairment to habitat, water quality, and benthic invertebrate communities within this watershed. Statistical analyses indicate that degraded conditions were linked to both mining and residential development; however, residential development appeared to exhibit a stronger individual effect. Both mining and residential development resulted in a significant decrease in sensitive taxa. The impacts associated with residential development, however, also resulted in the proliferation of tolerant taxa. Both mining and residential development resulted in significant alterations to water chemistry, primarily through increases in dissolved ion concentrations and specific conductance. Changes in water quality resulting from mining, however, were more acute. Conversely, residential development resulted in more acute alterations to physical habitat, primarily through decreases in habitat complexity. Our results further suggest that the individual impacts associated with mining and residential development are additive, leading to highly degraded conditions downstream. The combined effects of mining and residential development were almost always worse than the individual effects of mining, but never worse than the individual effects of residential development. Thus, residential development appears to be the limiting factor in determining ecosystem impairment. Lastly, several community metrics exhibited potential threshold responses to relatively low levels of both total mining $(\sim 25 \%)$ and parcel density $\left(\sim 14\right.$ parcels $\left./ \mathrm{km}^{2}\right)$. These change points corresponded to conductivities of approximately $100 \mathrm{uS} / \mathrm{cm}$ and $60 \mathrm{uS} / \mathrm{cm}$, respectively. This study shows that effectively managing impacts from new mine development and watershed restoration efforts must address the prevalence of non-mining related impacts throughout this watershed. 


\section{Acknowledgments}

First and foremost, I would like to thank my graduate committee, Dr. J. Todd Petty, Dr. Michael Strager, and Dr. Stuart Welsh, for their assistance during my time at West Virginia University. They have not only provided invaluable guidance, but have been instrumental in providing me with the tools and information necessary to complete this project. I would especially like to thank Dr. Petty for being an excellent mentor. Without his constant support and enthusiasm, my success would not have been possible. I would also like to sincerely thank Dr. George Merovich for his help and guidance with many aspects of my research.

I am also indebted to the many people that have provided assistance in both the field and in the lab. Without each of these individuals, I would undoubtedly still be far from completion. Particularly, I would like to thank Megan Minter for her help with virtually all aspects of my data collection. Her friendship and good humor were instrumental in keeping me sane during our frequent trips into the field. I would like to thank Donna Hartman and Brandon Keplinger for their assistance and patience while helping me with macroinvertebrate identification. Many thanks are also extended to Mariya Schilz for her continued assistance with numerous aspects of my graduate career and her ability to keep everything and everybody in working order. Finally, I would like to thank the numerous other graduate and undergraduate students who have helped me with my research and/or provided invaluable friendships that have made my time at West Virginia University extremely enjoyable.

Last but not least, I would like to thank my family, whose love and support is the ultimate reason my completion was possible. They have provided me with every opportunity to succeed, and for that I am forever grateful. 


\section{Table of Contents}

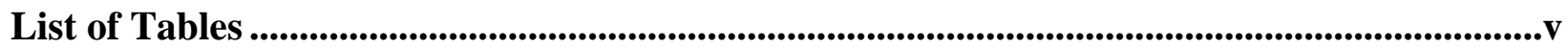

List of Figures.................................................................................................................................................... viii

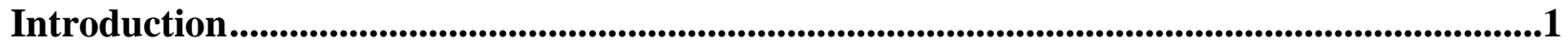

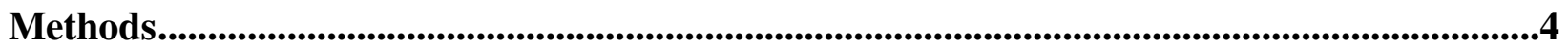

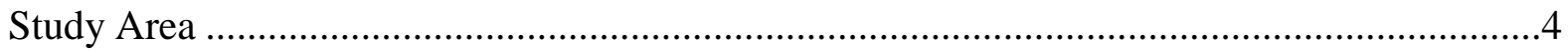

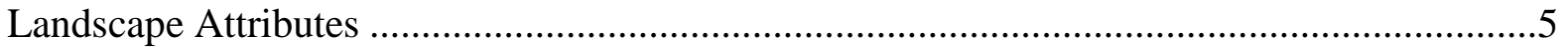

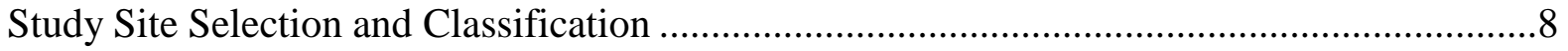

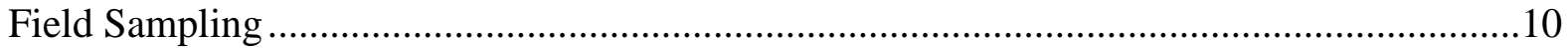

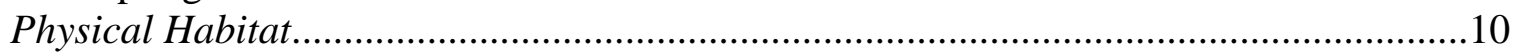

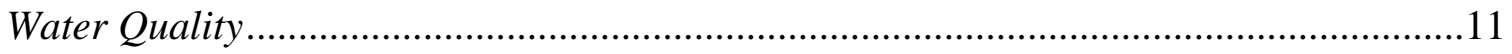

Benthic Macroinvertebrates...................................................................................13

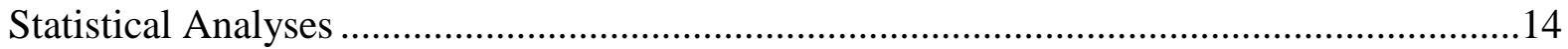

Quantifying Land Cover and In-stream Characteristics .............................................14

Direct Effects of Mining and Residential Development....................................................17

Interactive Effects of Mining and Residential Development.............................................18

Identification of Landscape Thresholds for Biological Impairment ..................................22

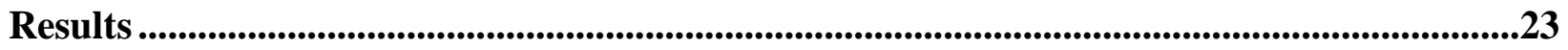

Quantifying Land Cover and In-stream Characteristics ....................................................23

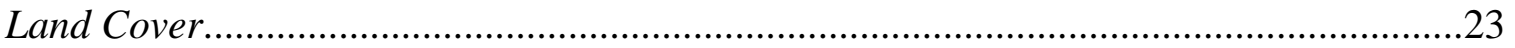

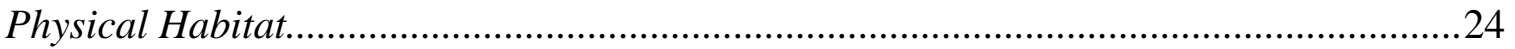

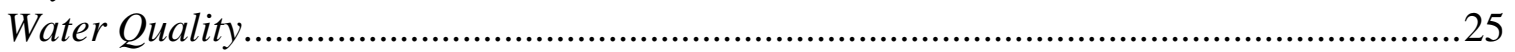

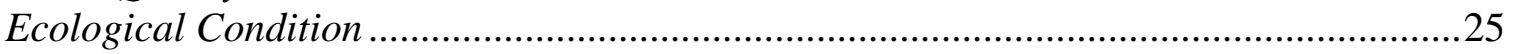

Direct Effects of Mining and Residential Development.......................................................26

Impacts Along the Mining and Residential Gradients................................................26

Impacts Across Combined Sites ................................................................................29

Interactive Effects of Mining and Residential Development....................................................

Identification of Landscape Thresholds for Biological Impairment .........................................42

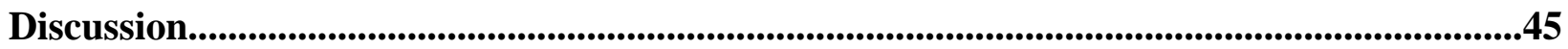

Direct Effects of Mining and Residential Development.......................................................45

Direct Effects of Residential Development ..................................................................45

Direct Effects of Mining ..............................................................................................4

Interactive Effects of Mining and Residential Development.................................................52

Identification of Landscape Thresholds for Biological Impairment......................................56

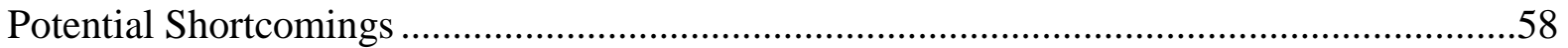

Macroinvertebrates as Indicators of Anthropogenic Disturbances .........................................60

Management Implications ..............................................................................................62

Literature Cited ........................................................................................................................................65 


\section{List of Tables}

Table 1: Geographic coordinates (expressed in decimal degrees), site type, basin area (BA), gradient, and level of mining and parcel density for each study site.

Table 2: Results from principal components analysis on land cover data. Each "PC" represents a principal component, or composite variable. Values represent variables that load significantly onto a given PC (loadings $\geq|0.4|)$.

Table 3: Combined Index (CI) values for all 41 study sites. Basin area (BA) in acres, cumulative mining density (CMD), cumulative parcel density (CPD), and combined index

(CI) score are given for each site. .78

Table 4: Results from principal components analysis on physical habitat data. Each "PC" represents a principal component, or composite variable. Values represent variables that load significantly onto a given PC (loadings $\geq|0.4|)$.

Table 5: Results from principal components analysis on water quality data from spring 2008. Each "PC" represents a principal component, or composite variable. Values represent variables that load significantly onto a given PC (loadings $\geq|0.4|$ ).

Table 6: Correlations between physical habitat variables and \% mining, parcel density, and CI score for the mining gradient, residential gradient, and large and small combined sites, respectively.

Table 7: Correlations between water quality variables and \% mining, parcel density, and CI score for the mining gradient, residential gradient, and large and small combined sites, respectively.

Table 8: Correlations between invertebrate metrics and \% mining, parcel density, and CI score for the mining gradient, residential gradient, and large and small combined sites, respectively.

Table 9: Correlations between physical habitat variables and $m$ WVSCI, EPT richness, E richness, \% Excluding Baetidae, and \%dominant along the residential gradient.

Table 10: Correlations between water quality variables and $m$ WVSCI, EPT richness, E richness,

$\%$ E excluding Baetidae, and \%dominant along the residential gradient. .86

Table 11: Correlations between physical habitat variables and $m$ WVSCI, EPT richness, E richness, \%E excluding Baetidae, and \%dominant along the mining gradient.

Table 12: Correlations between water quality variables and $m$ WVSCI, EPT richness, E richness,

$\%$ E excluding Baetidae, and \%dominant along the mining gradient. .89 
Table 13: Correlations between water quality variables and total richness, EPT richness, and P richness across the large combined sites.........................................................................

Table 14: Correlations between physical habitat variables and total richness, EPT richness, and P richness across the large combined sites.

Table 15: Correlations between water quality variables and total abundance (\#) and \%EPT excluding Baetidae across the small combined sites.

Table 16: Correlations between physical habitat variables and total abundance and \%EPT excluding Baetidae across the small combined sites.

Table 17: Results of Multivariate Analysis of Variance (MANOVA) tests used to identify multivariate differences between the mined, developed, large combined, and small combined sites with respect to physical habitat, water chemistry, and macroinvertebrate community structure.

Table 18: Means and standard errors (SE) for physical habitat variables across all sites and individual site types. Bolded variables and ANOVA results indicate significant differences $(p<0.05)$ between the mined, developed, small combined, and large combined site types (d.f. $=3,35$ for all analyses).

Table 19: Results of the Tukey's HSD tests used for pair-wise comparisons of the habitat variables found to significantly differ $(\mathrm{p}<0.05)$ between the mined, developed, small combined, and large combined sites.

Table 20: Means and standard errors (SE) for water quality variables across all sites and individual site types. Bolded ANOVA results indicate significant differences $(\mathrm{p}<0.05)$ between the mined, developed, small combined, and large combined site types (d.f. $=3$, 35 for all analyses).

Table 21: Results of the Tukey's HSD tests used for pair-wise comparisons of the water chemistry variables found to significantly differ $(\mathrm{p}<0.05)$ between the mined, developed, small combined, and large combined sites.

Table 22: Means and standard errors (SE) for habitat variables across all sites and individual site types. Bolded ANOVA results indicate significant differences $(\mathrm{p}<0.05)$ between the mined, developed, small combined, and large combined site types (d.f. $=3,35$ for all analyses).

Table 23: Results of the Tukey's HSD tests used for pair-wise comparisons of the macroinvertebrate community metrics found to significantly differ $(\mathrm{p}<0.05)$ between the mined, developed, small combined, and large combined sites.

Table 24: Results of partial Mantel tests run on the macroinvertebrate community, water quality (WQ), and physical habitat datasets in response to \% mining, parcel density (PD), and 
spatial location ( $\mathrm{x}$ - and $\mathrm{y}$-coordinates) across the mined, developed, small combined, and reference sites.

Table 25: Results of partial correlation analysis used to determine the relative influence of total $\%$ mining and parcel density $\left(\# / \mathrm{km}^{2}\right)$ on WQ PC1 and Habitat PC2.

Table 26: Results of ANCOVAs used to determine how community metrics varied with respect to site type, combined index (CI) scores, and their interaction.

Table 27: Results of ANCOVAs used to determine how community metrics varied with respect to site type, conductivity, and their interaction. 106

Table 28: Results of ANCOVAs used to determine how community metrics varied with respect to site types, \%Rapid Visual Habitat Assessment (RVHA), and their interaction.

Table 29: Maximum probability of a change point (PCP) associated with each macroinvertebrate community metric for each site type as identified by Bayesian Change Point (BCP) analysis. The maximum PCP is given along with the associated landscape metric score at which each max PCP occurred. Bolded values indicate possible change points with probabilities $\geq 0.300$. 108

Table 30: Maximum probability of a change point (PCP) associated with each macroinvertebrate community metric resulting from a conductivity gradient across each site type. The maximum PCP is given along with the associated conductivity at which each max PCP occurred. Bolded values indicate potential change points with probabilities $\geq 0.300$ .109 


\section{List of Figures}

Figure 1: Location of Pigeon Creek within West Virginia. 110

Figure 2: The Upper Pigeon Creek watershed (study basin) with respect to the Pigeon Creek watershed and its component 12-Digit HUCs.

Figure 3: Topography of the Upper Pigeon Creek watershed.

Figure 4: Mining within the Upper Pigeon Creek watershed.

Figure 5: Land Parcels within the Upper Pigeon Creek watershed.

Figure 6: Land use throughout the Upper Pigeon Creek watershed as defined by the 1992 National Land Cover Dataset (NLCD).

Figure 7: Land use within the Upper Pigeon Creek watershed as defined by the 1992 National Land Cover Dataset (NLCD) following the replacement of previously forested area by recent large-scale surface mining.

Figure 8: Study sites throughout the Upper Pigeon Creek watershed.

Figure 9: Scatter plot of study sites with respect to their influence from mining and residential development (parcel density). Sites falling within the boxes represent the mining and residential gradients. Reference sites were included in both gradients to represent optimal conditions.

Figure 10: Scatter plot of the first two landscape principal components (PCs). Sites are labeled by site type. Variables significantly loading onto a given PC (loadings $\geq|0.4|)$ are annotated along each axis.

Figure 11: Scatter plot of the 41 study sites with respect to their influence from total $\%$ mining and parcel density. The size of each character is relative to the combined index value associated with each site.

Figure 12: Scatter plot of the first two physical habitat principal components (PCs). Sites are labeled by site type. Variables significantly loading onto a given PC (loadings $\geq|0.4|$ ) are annotated along each axis.

Figure 13: Scatter plot of the first two water chemistry principal components (PCs) created using spring 2008 water chemistry data. Sites are labeled based on site type. Variables significantly loading onto a given PC (loadings $\geq|0.4|$ ) are annotated along each axis. ...122

Figure 14: Relationship between the modified West Virginia Stream Condition Index ( $m$ WVSCI) and true WVSCI scores calculated using a 200 individual subsample. 
Figure 15: Frequency distribution of West Virginia Stream Condition Index (WVSCI) categories throughout the study area. Modified West Virginia Stream Condition Index ( $m$ WVSCI) scores were corrected to approximate WVSCI scores by subtracting 8.81 points.

Figure 16: Box plot comparing \%sand across all site types.

Figure 17: Box plot comparing \%Rapid Visual Habitat Assessment (RVHA) scores across all site types.

Figure 18: Box plot comparing conductivity values across all site types.

Figure 19: Box plot comparing water quality principal component 1 (WQ PC1) scores across all site types.

Figure 20: Box plot comparing modified West Virginia Stream Condition Index ( $m$ WVSCI) scores across all site types.

Figure 21: Box plot comparing Ephemeroptera, Plecoptera, and Trichoptera richness (EPT) scores across all site types.

Figure 22: Mean Similarity dendrogram comparing site types based on macroinvertebrate community structure.

Figure 23: Scree plot used to determine the number of dimensions needed to construct the NMDS ordination.

Figure 24: Non-Metric Multidimensional Scaling (NMDS) ordination of sites based on genuslevel macroinvertebrate community data. NMDS scores from Axis 1 (x-axis) and Axis 2 (y-axis) are plotted. Taxa abundances and community metrics with high Spearman rank correlations $(\mathrm{p}<0.05)$ are annotated along each axis.

Figure 25: Non-Metric Multidimensional Scaling (NMDS) biplot separating sites based on genus-level macroinvertebrate community data. Individual community metrics were environmentally fitted to the NMDS ordination. Only metrics significantly correlated with the NMDS ordination $(\mathrm{p}<0.0001)$ were plotted.

Figure 26: Scatter plot between WQ Principal Component (PC) 1 and Habitat PC2. The arrows represent results of partial correlation analysis used to determine the influence of total mining $(\%)$ and parcel density $\left(\# / \mathrm{km}^{2}\right)$ on both the WQ and habitat PCs.

Figure 27: Relationship between the modified West Virginia Stream Condition Index ( $m$ WVSCI) and combined index (CI) score for each site type.

Figure 28: Relationship between Ephemeroptera, Plecoptera, and Trichoptera (EPT) richness and combined index $(\mathrm{CI})$ score for each site type.

Figure 29: Relationship between Ephemeroptera (E) richness and CI score for each site type. 
Figure 30: Relationship between \%dominant and combined index (CI) score for each site type.

Figure 31: Relationship between \%E excluding Baetidae and combined index (CI) score for each site type.

Figure 32: Relationship between the modified West Virginia Stream Condition Index ( $m$ WVSCI) and conductivity for each site type.

Figure 33: Relationship between Ephemeroptera, Plecoptera, and Trichoptera (EPT) richness and conductivity for each site type.

Figure 34: Relationship between Ephemeroptera richness and conductivity for each site type.

Figure 35: Relationship between \%dominant and conductivity for each site type.

Figure 36: Relationship between \%E excluding Baetidae and conductivity for each site type.

Figure 37: Relationship between the modified West Virginia Stream Condition Index $(m$ WVSCI) and \% Rapid Visual Habitat Assessment (RVHA) for each site type.

Figure 38: Relationship between Ephemeroptera, Plecoptera, and Trichoptera (EPT) richness and \%Rapid Visual Habitat Assessment (RVHA) for each site type.

Figure 39: Relationship between \%dominant and \%Rapid Visual Habitat Assessment (RVHA) for each site type.

Figure 40: Relationship between Ephemeroptera richness and \%Rapid Visual Habitat Assessment (RVHA) for each site type.

Figure 41: Relationship between \%E excluding Baetidae and \%Rapid Visual Habitat Assessment (RVHA) for each site type.

Figure 42: Multiple scatter plot showing the correlation between total \% mining and EPT richness for each site type. Linear regressions were constructed for the mined and combined sites to help identify and visualize differences in EPT richness across the two site types.

Figure 43: Relationship between parcel density and the deviation of the developed and combined sites from the mining regression. The $\mathrm{R}^{2}$ and $\mathrm{p}$-value are presented.

Figure 44: Multiple scatter plot showing the correlation between parcel density and EPT richness for each site type. Linear regressions were constructed for the developed and combined sites to help identify and visualize differences in EPT richness across the two site types. 
Figure 45: Relationship between total \%mining and the deviation of the mined and combined sites from the developed regression. The $\mathrm{R}^{2}$ and $\mathrm{p}$-value are presented.....

Figure 46: Results of Bayesian Change Point (BCP) analysis for the correlation between $\%$ Ephemeroptera excluding Baetidae and parcel density along the residential gradient.

Figure 47: Results of Bayesian Change Point (BCP) analysis for the correlation between \%EPT excluding Baetidae and parcel density along the residential gradient.

Figure 48: Results of Bayesian Change Point (BCP) analysis for the correlation between total abundance and parcel density along the residential gradient.

Figure 49: Results of Bayesian Change Point (BCP) analysis for the correlation between Ephemeroptera richness and total mining along the mining gradient.

Figure 50: Results of Bayesian Change Point (BCP) analysis for the correlation between $\%$ Ephemeroptera excluding Baetidae and total mining along the mining gradient.

Figure 51: Results of Bayesian Change Point (BCP) analysis for the correlation between total abundance and combined index (CI) score across the small combined sites.

Figure 52: Results of Bayesian Change Point (BCP) analysis for the correlation between Ephemeroptera richness and conductivity along the mining gradient.

Figure 53: Results of Bayesian Change Point (BCP) analysis for the correlation between \%E excluding Baetidae and conductivity along the mining gradient.

Figure 54: Results of Bayesian Change Point (BCP) analysis for the correlation between $\%$ tolerant and conductivity along the residential gradient.

Figure 55: Results of Bayesian Change Point (BCP) analysis for the correlation between $\%$ Chironomidae and conductivity along the residential gradient.

Figure 56: Results of Bayesian Change Point (BCP) analysis for the correlation between \%E excluding Baetidae and conductivity across all combined sites.

Figure 57: Results of Bayesian Change Point (BCP) analysis for the correlation between \%EPT excluding Baetidae and conductivity across all combined sites.

Figure 58: Results of Bayesian Change Point (BCP) analysis for the correlation between Ephemeroptera richness and conductivity across all combined sites.

Figure 59: Results of Bayesian Change Point (BCP) analysis for the correlation between $\%$ Hydropsychidae and conductivity across all combined sites. 
Figure 60: Results of Bayesian Change Point (BCP) analysis for the correlation between \% $\mathrm{E}$ excluding Baetidae and conductivity across the small combined sites. 


\section{Introduction}

Impacts resulting from changes in land use and land cover are considered by many to be the most important environmental issue currently facing natural ecosystems (Bruns et al. 2005). This is particularly true for freshwater ecosystems, where anthropogenic alterations and their corresponding stressors consistently produce the greatest impacts to aquatic resources (Vitousek 1994; Bruns et al. 2005).

Due to advances in Geographic Information Systems (GIS) technology, landscape-based indicators have been increasingly used to assess anthropogenic impacts on aquatic systems (Strayer et al. 2003; Allan 2004; Strager et al. 2009). For example, numerous studies have been conducted linking landscape-based indicators of urbanization (Fitzpatrick et al. 2003; Roy et al. 2003; Morse et al. 2004; Ourso and Frenzel 2003; Wang and Kanehl 2003), agriculture (Cuffney et al. 2000; King et al. 2005), and mining (Maret and MacCoy 2002; Maret et al. 2003; Bruns et al. 2005; Strager et al. 2009) to in-stream physical, chemical, and biological conditions. Furthermore, an increasing number of studies have used landscape indicators to aid in the management and restoration of watersheds impacted by anthropogenic stressors (Richards et al. 1994; Carlisle et al. 2009; Petty et al. unpublished manuscript). For example, Petty et al. (unpublished manuscript) used an index of mining intensity (Strager et al. 2009) to aid in both the development of spatially explicit restoration priorities and the determination of risks associated with new mine development on aquatic systems in north-central West Virginia.

The majority of studies linking landscape-based indicators to in-stream conditions have focused on the effects of a single anthropogenic land use. There is a growing body of literature, however, that suggests multiple anthropogenic stressors are more prevalent within natural systems, and that these multiple stressors interact to produce patterns of degradation that are 
unpredictable based on their known individual effects (e.g. Folt et al. 1999; Merovich and Petty 2007). Studies documenting the interactive effects of multiple stressors have predominately been laboratory experiments designed to manipulate levels of individual stressors (Folt et al. 1999; Porter et al. 1999; Clements 2004). Thus, watershed-scale field studies attempting to identify interactions between multiple stressors are very rare (but see Merovich and Petty 2007). Although understanding the effects of each individual stressor is extremely important, there has been a recent call in the literature to account for stressor interactions in ecological studies and subsequent restoration and conservation planning (Merovich and Petty 2007; Crain et al. 2008).

In the coalfields of southern West Virginia, large-scale surface mining (also known as mountaintop mining) and residential development act individually and in combination to severely degrade aquatic systems. Extensive research has been conducted regarding the direct effects of residential development on in-stream physical, chemical, and biological conditions. Numerous studies have documented changes in stream geomorphology, primarily through increased sedimentation and channel alteration (Paul and Meyer 2001; Ourso and Frenzel 2003; Roy et al. 2003; Wang and Kanehl 2003). Urbanization and residential development have also been shown to decrease habitat heterogeneity. For example, studies have documented decreases in large woody debris (LWD) and depth variability (see Allan et al. 2004). Water chemistry and quality also change considerably, primarily through increases in specific conductance, nutrient concentrations, and organic pollution (Paul and Meyer 2001; Roy et al. 2003; Allan 2004; Meyer et al. 2005; Voeltz et al. 2005). Lastly, through changes in the physical and chemical conditions, urbanization leads to considerable degradation of biological communities. This degradation occurs primarily through a decrease in sensitive taxa and a corresponding increase in tolerant taxa (Ourso and Frenzel 2003; Wang and Kanehl 2003; Roy et al. 2003; Fitzpatrick et al. 2003, 
Voeltz et al. 2005), which have commonly exhibited threshold relationships with landscape measures of urbanization (Ourso and Frenzel 2003; Roy et al. 2003; Morse et al. 2004).

Although there is a growing body of literature identifying the direct effects of mountaintop mining (Fulk et al. 2003; Hartman et al. 2005; Merricks et al. 2007; Pond et al. 2008), no study has attempted to relate a landscape-based measure of mining intensity to instream conditions. Studies in this region have either compared sites impacted by mining to regional reference sites (Fulk et al. 2003; Hartman et al. 2005; Merricks et al. 2007) or used measures of conductivity as an indicator of mining impairment (Pond et al. 2008). Regardless of study design, however, the observed impacts to in-stream conditions have been fairly consistent. Increased specific conductance has been consistently cited as one of the dominant impacts associated with mountaintop mining (Fulk 2003; Pond 2004; Hartman et al. 2005; Pond et al. 2008). Increases in the concentrations of several metals have also commonly been observed (Hartman et al. 2005; Merricks et al. 2007; Pond et al. 2008). The effects of mountaintop mining on physical habitat are less consistent. Both Merricks et al. (2007) and Hartman et al. (2005) observed no significant difference in habitat quality between mined and reference sites. In contrast, Pond et al. (2008) observed significant differences in several habitat variables, including embeddedness score and total Rapid Bioassessment Protocol score. Nevertheless, the effects of habitat on macroinvertebrate communities were not as great as those associated with water quality (Pond et al. 2008). The stressors associated with mountaintop mining alter macroinvertebrate community structure primarily through the loss of sensitive taxa, with Ephemeroptera taxa often showing the greatest response (Hartman et al. 2005; Pond et al. 2008). For example, Pond et al. (2008) observed a nonlinear threshold response in percent 
Ephemeroptera to specific conductance. In contrast, Merricks et al. (2007) failed to detect a significant difference in community structure below mined sites.

Despite abundant literature regarding the individual effects of both mining and residential development on aquatic systems, the pervasiveness of both stressors throughout southern West Virginia (Fulk 2003; Pond 2004) warrants a further look into their potential interactive effects on receiving waters. This is especially true if restoration and mitigation actions developed for this region are to be as beneficial and cost-effective as possible. Therefore, the overriding goal of this study was to determine the combined effects of mining and residential development on instream conditions in hopes of aiding in the development of watershed conservation plans. Through a watershed scale assessment of Pigeon Creek, the specific objectives of this study were to: 1) quantify the direct and interactive effects of mining and residential development on instream conditions; and 2) identify landscape thresholds above which biological impairment occurs.

\section{Methods}

Study Area

Pigeon Creek is a tributary to the Tug Fork River that drains approximately $370 \mathrm{~km}^{2}$ as it flows northwest through Mingo County, West Virginia (Figure 1). As defined by the National Resource Conservation Service (NRCS), the Pigeon Creek Watershed is classified as a 10-digit hydrologic unit (HUC) and is comprised of three separate 12-digit HUC subwatersheds - two of which intersect the study area of this project. The majority of the study basin is contained within the Headwaters of Pigeon Creek 12-digit HUC. However, the mouth of the study basin is located on Pigeon Creek directly above the confluence with Trace Fork, which is located in the subsequent Outlet of Pigeon Creek 12-digit HUC (Figure 2). This results in a study basin that 
drains an area of approximately $170 \mathrm{~km}^{2}$ into approximately $215 \mathrm{~km}$ of mapped stream channel (mapped streams defined by the 24K National Hydrology Dataset; Strager et al. 2009).

Land cover throughout the mountaintop mining region of southern WV is predominately forested, with mining and development being the two main land use practices, respectively (Pond 2004; Pond et al. 2008). Like many other areas within the region, land use patterns in the Upper Pigeon Creek watershed can largely be attributed to regional geology and topography. The underlying geology consists of Pennsylvanian Age sandstone, siltstone, and shale, with multiple seams of low sulfur coal (Pond 2004; Pond et al. 2008). Due to severe topography (Figure 3), development is largely confined to narrow floodplains, while mining is focused along ridgelines and headwater catchments of the surrounding mountains (Pond 2004).

\section{Landscape Attributes}

Cumulative landscape attributes were determined for the study area using segment-level watersheds (Strager et al. 2009). A stream segment was defined as the length of stream between the confluence of two mapped tributaries, as defined by the 1:24,000 National Hydrography Dataset (NHD). Each stream segment has an associated basin area, termed its reachshed (Strager et al. 2009). Arc View 3.3 (ESRI, Redlands, CA) was used to calculate the area of each landscape attribute for all reachsheds within the study area (Strager et al. 2009). The "Stream Watershed Tools" extension was then used in conjunction with flow tables developed by the WV Natural Resource Analysis Center (NRAC) to calculate a cumulative measure of each land use variable upstream of each pour point for all reachsheds.

Several data layers were used to characterize mining and residential development throughout the study area. All mining layers used in this study were originally developed by the West Virginia Department of Environmental Protection (WVDEP) at the 1:24000 scale (Figure 
4). Layers depicting abandoned mine lands (AML's) and valley fills (VF's) were obtained directly from the WV GIS Tech Center website and were published in 1996 and 2003, respectively. Layers depicting surface mines (SM), deep mines (DM), and other mine lands $(\mathrm{OM})$ were created using the mining permit boundaries layer obtained from the WVDEP website (http://gis.wvdep.org). Other mine lands were defined as areas within a given permit boundary not classified as any previous listed mining types. The mining permit boundaries layer is updated daily and provided data that was current up to the start of the project. Only mine lands that were currently or historically active were included in the final mining layers. A measure of total mining was calculated by summing the cumulative measures of abandoned mine lands, surface mines, deep mines, and other mines for each site. Valley fills were not included in this calculation because their area was included in the SM layer. The area of cumulative mining for each reachshed was then converted into a percentage of the total cumulative area.

To measure the extent of development throughout Upper Pigeon Creek, we used a data layer depicting floodplain structures along Pigeon Creek and its major tributaries, as well as a land parcels data layer. The floodplain structures data layer was developed by the Canaan Valley Institute (CVI) in Davis, WV from the 2003 Statewide Addressing and Mapping Board (SAMB) structures layer. The 2003 SAMB structures layer was created by the United States Geological Survey from 2003 SAMB aerial photography. Floodplain structures were believed to be a good measure of development within Upper Pigeon Creek because regional topography confines development to the floodplains. The land parcels data layer was developed by CVI from digital land records obtained from the West Virginia Department of Tax and Revenue and provided information on property locations and dimensions. Parcel data for Upper Pigeon Creek was created in 2004. 
The floodplain structures and land parcels data layers were compared both visually and quantitatively to identify their level of consistency with respect to their representation of development. It was determined that the two layers were highly consistent with one another. Most notably, the cumulative number of floodplain structures was highly correlated $(\mathrm{r}=0.99)$ with cumulative parcel frequency across all reachsheds in Upper Pigeon Creek. As a result of this redundancy, the land parcels layer was selected to represent development (Figure 5). The land parcels layer was chosen because it provided the most up-to-date information regarding development in the Upper Pigeon Creek watershed (the land parcels layer was created in 2004, while the floodplain structures layer was created in 2003). The final measure of development used during the study was a measure of cumulative parcel density $\left(\# / \mathrm{km}^{2}\right)$.

The 1992 National Land Cover Dataset (NLCD) was used to further characterize land cover patterns throughout the study watershed (Figure 6). The NLCD was developed by the Multi-Resolution Land Characteristics Consortium (MRLC) and obtained from the West Virginia GIS Tech Center website (http://wvgis.wvu.edu). In order to alleviate the problem of over-specification of land cover classifications (Thogmartin et al. 2004), several of the original land cover categories within the 1992 NLCD were combined. The original "pasture/hay", "row crops", and "mixed pasture/low intensity agriculture" categories were reclassified as agricultural land use. Similarly, the "mixed forest", "deciduous forest", and "evergreen forest" categories were combined to represent forested land cover. The remaining NLCD land cover types were maintained and represented "open water", "residential”, “commercial/residential”, "quarries/strip mines", and "transitional". Based on these categories, the following land cover variables were constructed: $\%$ Forested, $\%$ residential, $\%$ agriculture, and $\%$ barren $/$ mined. 
Discrepancies in land cover designations were observed between the NLCD and mining datasets. These discrepancies existed primarily between areas designated by the NLCD as forested and barren mine land. This is not surprising given the difference in age between each dataset and the variable nature of intensively mined landscapes. Inconsistencies between the datasets were identified by calculating the area of each land cover type within the NLCD that intersected the new surface mining layer. It was determined that approximately $99 \%$ of the area transformed by surface mining was forested prior to mining. Therefore, the NLCD was recalculated based on the assumption that new surface mines replaced only previously forested area (Figure 7). For each reachshed, the area of land designated by the NLCD as barren/mined was subtracted from the new surface mining layer, providing an estimate of the amount of forest lost due to recent surface mining. This number was then subtracted from the original measure of cumulative forest provided by the NLCD. Based on the recalculated NLCD, land cover throughout the study basin was observed to be predominately forested (approximately $80 \%$ ), with mining-related land use (approximately 18\%) and residential development (approximately $2 \%$ ) being the second and third most abundant, respectively.

\section{Study Site Selection and Classification}

Forty-three study sites were selected throughout Pigeon Creek based on their cumulative influence from residential development and coal mining practices (Table 1; Figure 8). Two sites (Big Muncy UNT L1 and Timothy Br.) were removed from the study because it was believed that their current land cover characteristics were not consistent with the information obtained from the land cover datasets (the catchments were mined immediately after our study began). Each of the remaining 41 study sites belonged to one of three categories or gradients (Figure 9). Ten sites made up a distinct residential gradient. These included sites with varying degrees of 
residential development (ranging from 8 to 86 parcels $/ \mathrm{km}^{2}$ ) and $<5 \%$ total cumulative mining. Thirteen sites were part of a mining gradient. These included sites with varying levels of cumulative $\%$ mining (ranging from 15 to $74 \%$ ) and a cumulative parcel density of $<7$ parcels $/ \mathrm{km}^{2}$ (Table 1; Figure 9). Two sites (Conley Br and UNT Hell Creek) were included as "reference" sites and were characterized by $0 \%$ mining and $<7$ parcels $/ \mathrm{km}^{2}$ (Table 1; Figure 9). Sites along the mining and residential gradients were selected to be independent of one another (i.e., they were not linked by flow).

The remaining 20 sites were those affected by a combination of residential development and coal mining activities (Table 1). These sites, referred to as combined sites, encompassed a wide range of basin areas ( 1 to $173 \mathrm{~km}^{2}$ ) and included both smaller tributaries and larger sites along the mainstem of Pigeon Creek and its major tributaries. Because this study was conducted in a single watershed, however, the larger combined sites were not completely independent of the smaller combined sites, or the sites along the mining and residential gradients. Therefore, in order to ensure independence among study sites, the combined sites were separated based on basin area into large and small combined sites. Small combined sites were those with basin areas falling within the range of the mining and residential gradients $\left(0.80\right.$ to $\left.9.00 \mathrm{~km}^{2}\right)$ and were not linked to other study sites by flow. Large combined sites were those with basin areas greater than the sites along the mining and residential gradients $\left(>9.00 \mathrm{~km}^{2}\right)$. This separation resulted in 8 small combined sites and 12 large combined sites (Table 1). Although the large combined sites were not independent of other sites, it was believed that they could offer valuable information on the combined effects of mining and residential development and were therefore retained in some of our analyses for comparative purposes. 


\section{Field Sampling}

Following protocols of Merovich and Petty (2007) and Freund and Petty (2007), reach lengths for each site were delineated as 40 times the mean stream width, with maximum and minimum reach lengths set as 300 and 150 meters, respectively. Within each reach, a series of physical, chemical, and biological measurements were taken in order to identify and characterize the overall condition of each site.

$\underline{\text { Physical Habitat }}$ - Habitat measurements were taken during periods of low flow throughout the summers of 2007 and 2008. Overall habitat quality was visually assessed using the rapid visual habitat assessment (RVHA) protocol developed by the U.S. Environmental Protection Agency (Barbour et al. 1999) and the Unified Stream Methodology (USM) developed by the U.S. Army Corps of Engineers and Virginia Department of Environmental Quality (USACE and VADEQ 2007). Bank stability and erosion potential were measured along each reach using the bank erosion hazard index (Rosgen 2001). Finally, we quantified a series of habitat complexity measures from data taken within the thalweg at evenly spaced points along each reach (Petty et al. 2001). Points were spaced every $1 / 2$ mean stream width for streams greater than five meters wide (Kaufmann et al. 1999) and every mean stream width for streams less than five meters wide. The following measurements were taken at each thalweg point: water depth, the channel unit type in which each point was located (riffle, run, pool, glide), distance to and characterization of the nearest retentive feature, and distance to and characterization of the nearest fish cover. A retentive feature was defined as any structure capable of retaining organic material during bankful conditions. Fish cover was defined as any structure within the active channel that was capable of completely concealing a $20 \mathrm{~cm}$ fish (Petty et al. 2001). 
Several other structural measurements were also taken at each site. An index of total retentiveness was developed and employed that scored each site on a scale from one to twenty based equally on the organic and inorganic retentiveness throughout the reach (Minter, unpublished). A large woody debris (LWD) count was conducted that placed each piece of LWD into one of twelve size categories based on diameter and length (Petty et al. 2001). A modified Wolman pebble count (Wolman, 1954) was conducted by sampling the substrate at 100 evenly spaced points in a zigzag pattern that spanned from bank to bank along the length of each reach. Lastly, canopy cover was measured every ten meters using a spherical densitometer. At each location, four separate readings were taken from the midpoint of the stream (upstream, right bank, downstream, left bank). All readings were combined to provide an average \% canopy cover for the entire study reach.

Water Quality - Following the recommendations of Petty and Barker (2004), water quality was sampled during three separate seasonal visits. These included two spring samples (May 2007 and 2008) and one autumn sample (November 2007). Two separate water samples were obtained during each seasonal visit. A $250 \mathrm{ml}$ filtered sample was collected for analysis of dissolved metals. A Nalgene polysulfone filter and receiver apparatus was used to filter each sample through a mixed ester cellulose membrane filter with a pore size of $0.45 \mu \mathrm{m}$. All filtered samples were immediately treated with 1:1 nitric acid to prevent the precipitation of dissolved metals. A 500ml unfiltered grab sample was also obtained at each site and analyzed for alkalinity and acidity (mg/l CaCO3), and series of dissolved compounds. All equipment and sample bottles were thoroughly rinsed before collection at each site to prevent cross contamination. All samples were immediately put on ice and stored at $4^{\circ} \mathrm{C}$ until all analyses were completed by the National Research Center for Coal and Energy (NRCCE) at West 
Virginia University (WVU). Duplicate samples were obtained at approximately $5 \%$ of all sites for quality assurance.

In the laboratory, filtered samples were measured for the following dissolved metals: Aluminum (Al), Barium (Ba), Cadmium $(\mathrm{Cd})$, calcium $(\mathrm{Ca})$, chlorine $(\mathrm{Cl})$, cobalt $(\mathrm{Co})$, chromium $(\mathrm{Cr})$, copper $(\mathrm{Cu})$, iron $(\mathrm{Fe})$, magnesium $(\mathrm{Mg})$, manganese $(\mathrm{Mn})$, nickel $(\mathrm{Ni})$, selenium (Se), sodium $(\mathrm{Na})$, and zinc $(\mathrm{Zn})$. Unfiltered grab samples were analyzed for alkalinity, acidity, sulfate $\left(\mathrm{SO}_{4}{ }^{-2}\right)$, nitrate $\left(\mathrm{NO}_{3}{ }^{-}\right)$, nitrite $\left(\mathrm{NO}_{2}{ }^{-}\right)$, ammonium $\left(\mathrm{NH}_{3}{ }^{+}\right)$, and total phosphorus (TP). All analyses were performed using EPA standard operating procedures (EPA, 1991). Cationic trace metal and TP concentrations were determined using inductively coupled plasma-atomic spectrometry (EPA 1991; method 200.7). $\mathrm{NH}_{3}{ }^{+}$concentrations were determined using automated colorimetry (EPA 1991; method 350.1). Concentrations of the anions $\mathrm{Cl}^{-}, \mathrm{SO}_{4}{ }^{2-}$ and $\mathrm{NO}_{2}{ }^{-}$and $\mathrm{NO}_{3}{ }^{-}$were measured using ion chromatography (EPA 1991; methods 325.2, 375.4, and 353.2, respectively). Alkalinity and acidity were measured by automated titration and reported as $\mathrm{CaCO}_{3}$ concentration (EPA 1991; methods 310.1 and 305.2, respectively). Variables present below detectable levels were standardized using one half the detection limits.

Instantaneous measures of temperature $\left({ }^{\circ} \mathrm{C}\right), \mathrm{pH}$, specific conductance $(\mu \mathrm{s} / \mathrm{cm})$, dissolved oxygen $(\mathrm{mg} / \mathrm{L})$, and total dissolved solids $(\mathrm{g} / \mathrm{L})$ were obtained at each site using a YSI 650 equipped with a 600XL sonde (Yellow Springs Instruments, Yellow Springs, OH, USA) that was calibrated daily. During November 2007, equipment constraints prevented field measurements of specific conductance, dissolved oxygen (DO), and total dissolved solids (TDS) at 16 sites. Laboratory measures were substituted for these variables. Average current velocity was also measured at each site using a digital Marsh-McBirney flow meter (Marsh-McBirney Incorporated, Frederick, MD), allowing for the calculation of discharge (m/s). 


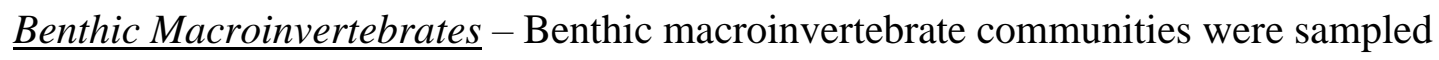
once from each study site in either May 2007 or May 2008 following modified procedures established by West Virginia Department of Environmental Protection's Watershed Assessment Program and the US Environmental Protection Agency's Rapid Bioassessment Protocols for wadeable streams (WVDEP 1996; Barbour et al. 1999; WVDEP 2003). Kick samples (net dimensions $335 \times 508 \mathrm{~mm}$ with $500 \mu \mathrm{m}$ mesh) were obtained from four representative riffles spanning the length of the reach. Kick sampling was conducted immediately upstream of the positioned kick net in an area of stream bed with dimensions equivalent to those of the kick net (335 x $508 \mathrm{~mm}$ ). Large substrate particles were removed from the bed, rubbed to dislodge any organisms present on their surfaces, and removed from the sampling area. The remaining substrate was vigorously kicked until the stream bed was completely disturbed. Macroinvertebrates from all four kick samples were then placed into a bucket equipped with a $0.500 \mu \mathrm{m}$ sieve, where large debris was checked for organisms and removed to facilitate macroinvertebrate sorting in the laboratory. All organisms and remaining debris were elutriated from heavier sediment particles, which were visually checked to ensure that all organisms were captured. Organisms and debris from all four kick samples were combined into a single composite sample for each study reach and preserved in $95 \%$ ethanol on site.

In the lab, each composite sample was filtered through a coarse, $2 \mathrm{~mm}$ sieve mounted on a $0.25 \mathrm{~mm}$ sieve. All organisms retained by the $2 \mathrm{~mm}$ sieve were identified and enumerated. Organisms retained by the $0.25 \mathrm{~mm}$ sieve were suspended in water and sub-sampled $\left(1 / 8^{\text {th }}\right.$ of total volume) using a Folsom plankton splitter (Model Number 1831-F10, Wildco Supply Company, Buffalo, NY). Individuals from a randomly selected $1 / 8^{\text {th }}$ sub-sample were identified, enumerated, and numerically scaled up to the original volume, providing an estimate 
of the number of different organisms present in the original $0.25 \mathrm{~mm}$ sample. This estimate was then added to the numbers of different organisms identified from the coarse sieve to arrive at an estimate of the total number of different organisms in the composite sample.

All macroinvertebrates were identified to the lowest possible taxonomic level, typically Genus, using Peckarsky et al. (1990) and Merritt and Cummins (1996). When an unknown or unusual specimen was encountered, the identification was cross checked with one or more individuals familiar with the aquatic macroinvertebrate fauna of West Virginia. A small percentage of samples were completely verified by other professionals for quality assurance. In addition, all macroinvertebrates are stored long-term as voucher specimens in the lab in polypropylene jars with $95 \%$ ethanol preservative.

\section{Statistical Analyses}

Quantifying Land Cover and In-stream Characteristics - Pearson correlation matrices were constructed to identify redundant variables $(r>0.9)$ present in the physical habitat, water chemistry, and land cover datasets. When necessary, variables were transformed to fulfill the assumption of linearity. Depending on data structure, variables were either log transformed or arcsine-root transformed. Redundant variables were removed from further analysis. We then used Principal Components Analysis (PCA), a parametric data reduction technique, to summarize patterns in the landscape, physical habitat, and water chemistry datasets (Merovich et al. 2007). PCA consolidates the total number of variables in each dataset into a series of independent principal components (PC's). Each PC represents a linear combination of variables that accounts for a certain percentage of the overall variation present in a given dataset. PC's with an eigenvalue $\geq 1$ were considered statistically significant (McCune and Grace 2002). Individual variables with factor loadings $\geq 0.4$ were regarded as explaining a statistically 
significant portion of the variation in a given PC (McCune and Grace 2002). A scatter plot of the first two PC's was then constructed for each dataset, allowing inter-site differences to be visualized (Merovich et al. 2007). Furthermore, site type was overlain on the PCA ordinations to help visualize differences in land cover and in-stream conditions between the five site types. Principal components analysis was conducted in the R Project for Statistical Computing Version 2.8.0 (R Development Core Team 2008) using the package LabDSV (Roberts 2007).

Land cover was further quantified through the calculation of an index that quantified the combined influence of mining and residential development for each site. Following the methods of Strager et al. (2009), the combined index (CI) was calculated to standardize the measures of mining and residential development. This allowed for the direct comparison of the individual and combined effects of mining and residential development on community structure. The (CI) compared the cumulative impact from mining and residential development for each reachshed to the maximum cumulative mining and residential development observed throughout the study watershed. CI scores for each reachshed were calculated as follows:

$$
\mathrm{CI}=\left[\left(\frac{\mathrm{CMD} i}{\max \mathrm{CMD}}+\frac{\mathrm{CPD} i}{\max \mathrm{PD}}\right) / 2\right] \times 100
$$

Where CMDi is the cumulative mining density for a given reachshed $i$, which was calculated as the total \% mining divided by 100 . CPD $i$ is the cumulative parcel density for a given reachshed i. $\max \mathrm{CMD}$ and $\max \mathrm{PD}$ are the maximum cumulative mining and parcel densities observed throughout the study watershed. CI scores for each reachshed ranged from zero to 100 and represented the percentage of the highest possible combined influence from mining and residential development in the Upper Pigeon Creek watershed. 
Variation in ecological condition and biological community structure was quantified using a series of family and genus-level macroinvertebrate community metrics. A modified West Virginia Stream Condition Index (denoted as $m$ WVSCI) was used to assess ecological condition at each site. The original WVSCI is a benthic macroinvertebrate index of biotic integrity (IBI) developed for West Virginia that uses a series of family-level community metrics to score each stream on a scale of 0 to 100 (Gerritsen et al. 2000). WVSCI scores are calculated using a subsample of 200 individuals. Each site falls within one of the following categories: poor, marginal, good, or excellent (Gerritsen et al. 2000). These categories correspond to WVSCI scores of $<55.0,55.0-69.9,70.0-85.0$, and $>85.0$, respectively. The $m$ WVSCI differs from the original WVSCI in that all individuals, not just a 200 individual subsample, were used in the $m \mathrm{WVSCI}$ calculation. For comparative purposes, $m \mathrm{WVSCI}$ scores were compared to true WVSCI scores.

Several metrics were created and assessed individually to further characterize differences in community structure between study sites. Genus-level community data was used to create several richness metrics that were measured as the total number of genera present at each site belonging to one or more of the following orders: Ephemeroptera $(\mathrm{E})$, Plecoptera $(\mathrm{P})$, Trichoptera (T), and Odonata (O). Richness metrics included EPTO, EPT, E, P, and T. Total richness was measured as the total number of genera present at each site. The relative abundance of EPT, E, Chironomidae, and Hydropsychidae individuals were calculated as the percentage of total individuals belonging to each group. The relative abundance of EPT and E were also calculated removing individuals belonging to the families Baetidae and Hydropsychidae. Several genera within these families are known to be tolerant to various stressors, and their inclusion could result in inflated abundance measurements (Pond et al. 2008). Percent generally 
tolerant, \%dominance, and a Modified Hilsenhoff biotic Index (MHI) were also used as defined by Gerritsen et al. (2000). A Pearson correlation matrix was constructed to identify redundant community metrics, which were removed from further analysis.

Direct Effects of Mining and Residential Development - The direct effects of mining and residential development were identified using Pearson correlations. Initially, correlations were performed using sites along the mining and residential gradients separately, allowing for the removal of possible confounding effects resulting from the presence of both stressors. Along their respective gradients, $\%$ mining and parcel density were correlated with physical habitat, water chemistry, and macroinvertebrate community metrics. Community metrics found to be significantly correlated with both mining and parcel density along their respective gradients were then correlated with individual physical and chemical variables, as well as their PCs, to identify the importance of physical habitat and water chemistry on structuring macroinvertebrate communities. Correlations were then performed on the large and small combined sites separately to identify direct impacts to in-stream conditions resulting from the combination of mining and residential development. Correlations on the combined sites were performed using the combined index (CI) as a predictor of in-stream conditions. Community metrics found to be significantly correlated with CI score were subsequently correlated with individual physical and chemical parameters. Variables were transformed when necessary to fulfill the underlying assumptions of parametric procedures.

Co-variation between land cover variables and in-stream physical, chemical, and biological conditions is a common issue in correlative analyses (Van Sickle 2003; King et al. 2005), and may lead to an overestimation of the importance of certain relationships or result in spurious associations (Bruns et al. 2005). Correlations using the linear principal components 
identified by PCA, however, take into consideration this co-variation and provide a good alternative to the significance testing of many bivariate correlations between land use and instream variables (Van Sickle 2003). Therefore, the cumulative measures of mining and parcel density were correlated with both the linear PCs and individual physical, chemical, and biological variables to determine and characterize their direct effects on in-stream conditions.

Interactive Effects of Mining and Residential Development - In order to understand how the direct effects of mining and residential development combine to influence aquatic systems, it is necessary to first characterize how each of the five site types (mined, developed, large combined, small combined, and reference) differ with respect to their in-stream conditions. Initially, simple descriptive statistics (mean, standard error) were calculated for all physical, chemical, and biological variables across each site type. We then used multivariate analysis of variance (MANOVA) to determine whether physical habitat, water chemistry, and macroinvertebrate community metrics differed significantly among the site types. MANOVA creates linear combinations of the original dependent variables that maximize differences among groups, thereby controlling for co-variation. Furthermore, MANOVA helps control for inflation of the type I error rate that occurs when performing multiple analyses of variance (ANOVAs) (Merovich et al. 2007). Wilks' test statistic was used for tests of significance. Once significant multivariate differences were observed, individual ANOVAs were then conducted to identify which variables resulted in the observed differences. Tukey's HSD was used for all post hoc pair-wise comparisons. Reference sites were not included in either the MANOVAs or subsequent ANOVAs due to small sample size $(n=2)$. However, box plots were constructed to aid in the visualization of the variation among site types and to show conditions relative to the 
two reference sites. Both the MANOVA and individual ANOVAs were conducted in the R Project for Statistical Computing Version 2.8.0 (R Development Core Team 2008).

Site types were also compared based on their overall macroinvertebrate community structure. Initially, mean similarity analysis (MEANSIM) was used to test for significant differences in overall community structure among site types. MEANSIM is a non-parametric test of significance between two or more groups based on a measure of distance between individual sites (Van Sickle and Hughes 2000). MEANSIM measures classification strength (CS) by subtracting the mean between-group similarity (Bbar) from the mean within-group similarity (Wbar). Significance is tested using a permutation procedure that identifies whether group structure is stronger than would be observed by chance alone (Van Sickle and Hughes 2000). The two reference sites were removed before MEANSIM was performed to ensure that the mining and residential gradients were independent. A MEANSIM dendrogram was then constructed to help visualize between- and within- group similarities (Van Sickle and Hughes 2000). MEANSIM was performed using the program MEANSIM6 (Van Sickle 1998).

Non-metric multidimensional scaling (NMDS) was then used to visualize and characterize any significant differences observed in the community structure between site types. This allowed for the identification of community response to the individual effects of mining and residential development and to their combined effects when both stressors are present. NMDS is a non-parametric ordination technique that uses an iterative solution to search for the ordination of $n$ sites within $k$ dimensions that best represents the data while reducing stress in the plot (McCune and Grace 2002). The number of dimensions that best represented the data without unnecessarily increasing $k$ was determined by examining a scree plot of stress as a function of $k$. A scatter plot using the first two NMDS dimensions was constructed to visualize spatial variation 
in invertebrate community structure. Sites that map closer together in the NMDS space are considered to be more similar than those mapping further apart (McCune and Grace 2002). The meaning of the each axis was determined and visualized using two separate techniques. First, Spearman rank correlations were conducted between the NMDS scores and individual genera and community metrics. Correlations were considered significant at an alpha level of 0.05 (Merovich and Petty 2007; McClurg et al. 2007). Individual taxa and community metrics were also environmentally fitted to the NMDS ordination. ANOSIM and NMDS were conducted in the R Project for Statistical Computing Version 2.8.0 (R Development Core Team 2008) using the package vegan (Oksanen et al. 2008).

Once differences in in-stream conditions were characterized among the five site types, a series of partial Mantel tests were conducted to determine the relative influence of mining and residential development on the observed conditions throughout the upper Pigeon Creek watershed. Mantel tests evaluate the correlation between two distance (or similarity) matrices through repeated randomization (McCune and Grace 2002). Partial Mantel tests are an extension of the Mantel test in that they determine the strength of the correlation between two similarity matrices after removing the effect of one or more matrices (McCune and Grace 2002; King et al. 2005). Thus, partial Mantel tests were used to determine the amount of variation in the in-stream conditions observed among study sites that could be explained by the individual effects of mining (total \% mining) and residential development (parcel density), while removing the effects of the competing predictor variable. Furthermore, King et al. (2005) observed that spatial autocorrelation in land cover classes accounted for significant variability in macroinvertebrate community structure. Consequently, King et al. (2005) warned that the variation explained by spatial location could be incorrectly attributed to land use variables. Therefore, partial Mantel 
tests were also used to remove the effects of spatial location ( $\mathrm{x}$ - and $\mathrm{y}$-coordinates) from each analysis and to identify whether spatial autocorrelation accounted for significant variation in the observed in-stream physical, chemical, and biological conditions.

Partial Mantel tests were performed on the macroinvertebrate community dataset, as well as the physical habitat and water chemistry datasets. The macroinvertebrate community dataset was transformed into a Bray-Curtis dissimilarity matrix, and the physical habitat and water chemistry datasets were transformed into similarity matrices using the Euclidean distance between site pairs. Partial Mantel tests were conducted using the mined, developed, small combined, and reference sites. The large combined sites were excluded from the partial Mantel tests because they were not completely independent of other study sites. Mantel tests were performed in the $\mathrm{R}$ language and environment ( $\mathrm{R}$ Development Core Team 2008) using the ecodist package (Goslee and Urban 2007).

To further characterize the relative effects of mining and residential development on instream physical and chemical conditions, partial correlation analysis was used to determine the effects of both percent mining and parcel density on the dominant water quality and physical habitat principal components. Partial correlation analysis is similar to the partial Mantel test in that it determines the strength of the correlation between two variables, while removing the effect of competing predictor variables. However, the partial correlation analysis differed from the partial Mantel tests in that individual vectors (i.e. individual PCs) were analyzed during the partial correlation, while matrices (i.e. entire datasets) were analyzed during the partial Mantel tests. Partial correlations were performed in the $\mathrm{R}$ language and environment ( $\mathrm{R}$ Development Core Team 2008) using the pcor function within the ggm package (Marchetti and Drton 2006). 
Lastly, a series of ANCOVAs were employed to identify the relationship between CI score and in-stream conditions across each site type. The $\mathrm{CI}$ allowed for the direct comparison of the impacts resulting from equivalent levels of mining, residential development, and their combination. ANCOVA tested whether the relationship between CI score and community structure differed across site types. Furthermore, ANCOVA tested whether site type and CI score interact to produce community degradation greater than would be expected given the individual effects of site type or CI score. Only small combined sites were used in the ANCOVAs and corresponding scatter plots. The removal of larger sites ensured that degraded conditions observed in combined sites were not the result of an accumulation of stressors occurring at a spatial scale much larger than those along the mined and combined gradients. Scatter plots and ANCOVAs were also conducted to look at the relationship between conductivity and community metrics and \%RVHA and community metrics across all three site types. This allowed for the comparison of the effects of water chemistry and habitat quality on community structure across each land use type. These results were then compared to those of the CI scatter plots and ANCOVAs to determine the relative importance of water chemistry and habitat quality on structuring macroinvertebrate communities.

\section{Identification of Landscape Thresholds for Biological Impairment - Previous research} has identified threshold responses in macroinvertebrate community structure to the stressors associated with both mining (Pond et al. 2008; Petty et al. unpublished manuscript) and urbanization (Morse et al. 2004; Ourso and Frenzel 2003; Roy et al. 2003). Therefore, Bayesian change-point analysis (BCP) was performed on individual community metrics to identify possible threshold responses along both the mining and residential gradients. $\mathrm{BCP}$ identifies the probability that a significant change has occurred at each data point in a given vector, with high 
probabilities signifying potential threshold responses. Probabilities are tested for statistical significance by a randomized permutation procedure. BCP was further used to detect threshold responses in community structure to the combination of mining and residential development within the combined sites. More specifically, BCP was used to identify threshold responses in community metrics to the combined index within all combined sites, as well as the small combined sites only. Lastly, following the identification of significant change points in response to the landscape indicators, BCP was used to identify change points in community structure to gradients in water chemistry and physical habitat variables. BCP was conducted in the R Project for Statistical Computing Version 2.8.0 (R Development Core Team 2008) using the package bcp (Erdman and Emerson 2008).

\section{Results}

Quantifying Land Cover and In-stream Characteristics

Land Cover-Percent Surface mining was found to be highly correlated with total \% mining ( $r=0.97)$ and was therefore removed from subsequent analyses. PCA identified two significant gradients (eigenvalue $\geq 1$ ) that accounted for approximately $67 \%$ of the variation in the land cover dataset (Table 2). PC1 represented a gradient of overall anthropogenic disturbance where increasing scores corresponded to an increase in both mining (\%OM, \%VF, $\% \mathrm{DM}, \% \mathrm{AML}$, and \% $\mathrm{TM}$ ) and residential development (PD, \% residential, and \% agriculture), and decreasing scores represented sites with a greater percentage of forested land cover (Table 2; Figure 10). PC2 also represented a gradient of anthropogenic land use, with increasing scores corresponding to an increase in residential development (PD, \%residential, and \%agriculture) and decreasing scores corresponding to an increase in various mining activities (\% TM, \%DM, and \%VF; Table 2; Figure 10). 
Combined index (CI) scores varied considerably throughout the study basin, with values ranging from 0 to 68 . The maximum and minimum CI scores across the study sites were 48 and 0, with combined sites accounting for nine of the top ten CI scores (Table 3; Figure 11). Following the removal of the large combined sites, mined sites accounted for six of the top ten CI scores, indicating that mined sites sampled during this study included some of the most intensively mined areas in the study watershed. However, small combined sites accounted for three of the top ten CI scores, including the highest score of 48 (Table 3).

Physical Habitat - The following habitat variables were identified as redundant and removed from further analysis and discussion: inorganic and organic retentiveness, which were highly correlated with total retentiveness ( $\mathrm{r}=0.91$ and 0.94 , respectively); $\mathrm{LWD} / \mathrm{m}^{2}$, which was highly correlated with $\mathrm{LWD} / \mathrm{m}(\mathrm{r}=0.92)$; and mean distance to fish cover (DFC), which was highly correlated with DFC/MSW (r=0.96). To remain consistent, mean distance to retentive feature (DRF) divided by MSW was used in place of mean DRF even though their correlation coefficient ( $\mathrm{r}=0.86)$ was slightly less than the cutoff of 0.9 . PCA identified five significant gradients (eigenvalue $\geq 1$ ) that accounted for approximately $80 \%$ of the total variation in the overall dataset (Table 4). PC1 represented a gradient where increasing factor scores corresponded to decreasing basin area and increasing structural complexity and substrate size. Conversely, negative factor scores represented increasing stream size and decreasing complexity and substrate size (Table 4; Figure 12). PC2 represented a gradient of habitat complexity and quality. Positive PC2 scores were associated with increasing habitat complexity (\#LWD/m, \#RF/m, and retentiveness) and overall habitat quality (\%RVHA and USM), where negative factor scores represented sites with decreasing structural complexity and substrate size (Table 4; 
Figure 12). The remaining three principal components were not significant in any subsequent analysis and were therefore removed from further discussion.

$\underline{\text { Water Quality }}$ - TDS was highly correlated with conductivity $(\mathrm{r}=0.99)$ and was therefore removed from subsequent analysis. Cadmium was not detected at any of the 41 study sites and was also removed from analyses. Initially, PCA was conducted using water quality data obtained from each season to take into consideration temporal variation. For each site, PCA scores from each season were averaged, providing a composite PC score. However, the high level of temporal variation observed among seasons distorted the spatial variation among sites, resulting in composite variables that were not independent of one another. Because the original objective was to determine spatial variation in water chemistry, only spring 2008 water quality was used in PCA and subsequent statistical analyses. PCA identified six statistically significant principal components (eigenvalue $\geq 1$ ) that explained approximately $80 \%$ of the total variation present within the water chemistry dataset (Table 5). PC1 represented a gradient where increasing factor scores corresponded to increasing conductivities and concentrations of dissolved parameters (Table 5; Figure 13). PC2 represented a gradient where increasing factor scores corresponded to increasing trace metal concentrations (Table 5; Figure 13). The remaining four axes were not statistically significant in any subsequent analyses and have therefore been removed from further discussion.

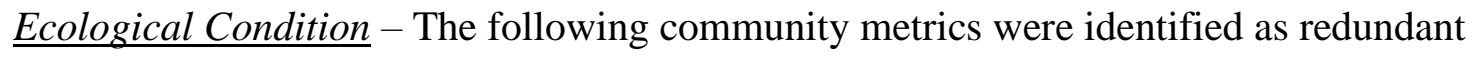
and removed from further analysis: MHI, which was redundant with \%tolerant ( $\mathrm{r}=0.93)$; EPTO richness, which was redundant with EPT richness ( $\mathrm{r}=0.97)$; and \%EPT excluding Baetidae and Hydropsychidae, which was redundant with \%EPT excluding Baetidae $(r=0.94)$. Ecological condition was highly variable throughout the study watershed, with $m$ WVSCI scores ranging 
from 23.7 to 90.1 . However, the average $m$ WVSCI score was 60.8 , indicating that many of the study sites were highly degraded. When predicting WVSCI using $m$ WVSCI scores $\left(\mathrm{R}^{2}=0.93\right.$; Figure 14), it was observed that $m$ WVSCI overestimated ecological condition by approximately nine percentage points. More specifically, the observed relationship was WVSCI = $1.00 m \mathrm{WVSCI}-8.81$. Upon further observation, the higher $m$ WVSCI scores appeared to be the result of an overestimation of total and EPT richness. After adjusting the $m$ WVSCI scores by 8.81 points to approximate WVSCI, it was determined that 35 sites (approximately $85 \%$ ) fell within the poor and marginal categories, while the remaining six sites were categorized as having good ecological condition (Figure 15). No study sites had macroinvertebrate communities that fell within the excellent category.

\section{Direct Effects of Mining and Residential Development}

Impacts Along the Mining and Residential Gradients - Significant negative correlations were observed between parcel density and five habitat variables (Table 6). LWD density, retentiveness, \%RVHA, CV depth, and \%canopy tended to decline in response to increased parcel density, indicating a significant decrease in habitat complexity and quality along the residential gradient. Along the mining gradient, a significant negative correlation was observed with \%bedrock (Table 6). However, this relationship was driven by three sites with a high proportion of bedrock and low total \% mining (Conley Br, UNT Hell Cr, and MF Elk Cr HW3). No significant relationships were detected between total mining and any of the remaining habitat complexity or quality measures (Table 6).

Conversely, both mining and residential development significantly altered water chemistry primarily through increases in the variables associated with WQ PC1 (Table 7). WQ PC1 was significantly correlated with both mining $(r=0.82)$ and parcel density $(r=0.70)$ along 
their respective gradients. Of the 12 variables significantly loading onto WQ PC1, eight were significantly correlated with total \%mining, while four were significantly correlated with parcel density (Table 7).

Both parcel density and \%mining also were significantly correlated with ecological conditions along their respective gradients (Table 8). This was evidenced by a significant negative response in $m \mathrm{WVSCI}$ to parcel density ( $\mathrm{r}=-0.73)$ and total mining $(\mathrm{r}=-0.64)$. Overall, 14 of the 15 community metrics (93\%) showed a greater response (i.e. higher correlation coefficient) to variation in parcel density as compared to total mining (Table 8). Significant responses to 10 macroinvertebrate metrics were observed along the residential gradient. Macorinvertebrate communities impacted by residential development were characterized by a significant decrease in sensitive taxa (EPT, E, and total richness) and a corresponding increase in tolerant taxa (\%Tolerant, \%Dominant, and \%Chironomidae). It is notable that neither \%E nor $\%$ EPT was significantly correlated with parcel density. However, when members of the family Baetidae were removed from the $\% \mathrm{E}(\mathrm{r}=-0.85)$ and \%EPT $(\mathrm{r}=-0.93)$ calculations, these were the strongest relationships observed (Table 8). Significant responses to six metrics were observed along the mining gradient (Table 8). Macroinvertebrate communities affected by mining were characterized by significant decreases in sensitive taxa, such as EPT richness, E richness, and \%E excluding Baetidae. Percent dominant and \%Hydropsychidae were positively correlated with total \% mining. However, mining related influences did not result in a proliferation of tolerant genera to the extent observed along the residential gradient.

Macroinvertebrate communities responded significantly to changes in both physical habitat (Table 9) and water chemistry (Table 10) along the residential gradient. With respect to physical habitat, $m$ WVSCI and \%E excluding Baetidae exhibited significant negative 
correlations with Habitat PC2 (Table 9). With respect to mWVSCI, similar relationships were observed between several individual habitat complexity and quality measures, such as retentiveness, \#RF/m, retentiveness, DRF/MSW, and USM. Percent E excluding Baetidae was also significantly correlated with USM, \%Canopy, and \%Bedrock (Table 9). In contrast, Ephemeroptera richness was not significantly correlated with any habitat variables (Table 9). Lastly, significant correlations were observed between \%dominant and USM, total retentiveness, and \%RVHA. With respect to water chemistry, \%E excluding Baetidae exhibited a significant negative correlation with WQ PC1 (Table 10). Furthermore, E richness and \%E excluding Baetidae exhibited significant negative correlations with Se and several variables loading into WQ PC1, such as conductivity, alkalinity, $\mathrm{SO}_{4}, \mathrm{NO}_{2}, \mathrm{Mg}$ and $\mathrm{Ca}$ (Table 10). EPT richness also exhibited negative correlations with Se and $\mathrm{NO}_{2}$ (Table 10). $m$ WVSCI exhibited a significant negative correlation with WQ PC1, and was further correlated with acidity, $\mathrm{pH}$, and TP. The significant correlations between $m \mathrm{WVSCI}$ and both acidity and $\mathrm{pH}$ were driven by only three sites along the parcel density gradient with detectable levels of acidity (Conley Br, Caney Br, and UNT Hell Cr). Percent dominant exhibited a similar correlation with acidity (Table 10).

Along the mining gradient, $m \mathrm{WVSCI}$, EPT richness, E richness, and \% E excluding Baetidae all exhibited significant positive correlations with \%bedrock (Table 11). Although \%bedrock exhibited a significant negative correlation along the mining gradient, the relationships between \%bedrock and each community metric were driven by three sites with a high proportion of bedrock and low total \% mining (Conley Br, UNT Hell Cr, and MF Elk Cr HW3). Percent E excluding Baetidae exhibited significant negative correlations with mean depth and \%gravel and a significant positive correlation with total retentiveness (Table 11). Percent dominant exhibited a significant positive correlation with \%sand and a negative 
correlation with \%boulder. Although several community metrics were significantly correlated with physical habitat along the mining gradient (Table 11), it is important to note that macroinvertebrate communities tended to responded stronger to physical habitat alterations along the residential gradient (Table 9).

With respect to water chemistry, $m$ WVSCI, EPT richness, E richness, \%E excluding Baetidae, and \%dominant all responded significantly to changes in WQ PC1 and several other variables significantly loading onto WQ PC1, such as alkalinity, conductivity, $\mathrm{SO}_{4}, \mathrm{Na}, \mathrm{Mg}, \mathrm{Fe}$, and $\mathrm{Cl}$ (Table 12). However, the strength and number of significant relationships observed for $m \mathrm{WVSCI}$ and \%dominant tended to be less than those observed for the remaining four metrics designed to specifically test for impacts to sensitive taxa (Table 12). Furthermore, it is notable that the correlation between $m \mathrm{WVSCI}$ and conductivity $(\mathrm{r}=-0.61 ; \mathrm{p}=0.027)$ along the mining gradient was not as significant as for EPT $(r=-0.66 ; p=0.01)$, E richness $(r=-0.73 ; p=0.004)$, and $\%$ E excluding Baetidae ( $\mathrm{r}=-0.79 ; \mathrm{p}=0.001)$. Lastly, it is important to point out that macroinvertebrate communities along the mining gradient responded more negatively to changes in water quality (Table 12), as compared to alterations to physical habitat (Table 11).

Impacts Across Combined Sites - The effects of mining and residential development impacted both water chemistry and physical habitat across the large and small combined sites. With respect to physical habitat, CI score was positively correlated with gradient and negatively correlated with DFC/MSW across the large combined sites (Table 6). Across the small combined sites, CI score was negatively correlated with MSW and positively correlated with habitat PC1 and \% boulder (Table 6). Water chemistry was significantly altered within the large combined sites, primarily through increases in WQ PC1 (Table 7). For example, significant positive correlations were observed between $\mathrm{CI}$ score and conductivity, $\mathrm{Ca}, \mathrm{Mg}, \mathrm{SO}_{4}, \mathrm{NO}_{3}$, and 
PC1 (Table 7). Furthermore, CI score was positively correlated with $\mathrm{pH}$ and negatively correlated with DO across large combined sites. In contrast, CI score was not significantly correlated with any water chemistry variables across the small combined sites (Table 7). However, correlations between $\mathrm{CI}$ score and $\mathrm{Ba}, \mathrm{Cr}$, and $\mathrm{Na}$ produced fairly high correlation coefficients $(r=-0.68)$, but small sample size $(n=8)$ resulted in decreased significance.

Macroinvertebrate community structure was impacted within both large and small combined sites. Total richness, EPT richness, and P richness all exhibited significant negative correlations with CI score across the large combined sites (Table 8), indicating a significant loss of sensitive taxa. Across the small combined sites, total abundance exhibited a significant negative correlation with CI score (Table 8). Conversely, \%EPT excluding Baetidae exhibited a significant positive correlation with CI score (Table 8). Upon further investigation, this pattern appeared to be the result of a loss in sensitive taxa and a greater increase in EPT taxa known to be tolerant to various stressors (e.g. Hydropsychidae and Leuctridae).

Macroinvertebrate communities within the large combined sites responded significantly to both water chemistry and physical habitat. Of the community metrics significantly differing across large combined sites, total richness, EPT richness, and P richness all exhibited significant positive correlations with DO (Table 13), indicating more complex communities in systems with higher DO concentrations. With respect to physical habitat, total richness exhibited significant negative correlations with habitat $\mathrm{PC} 2, \mathrm{BEHI}$, and the number of retentive features per meter (Table 14). Conversely, a significant positive correlation was observed between DRF/MSW and total and EPT richness (Table 14). Upon further investigation, these inverse relationships between taxa richness and measures of habitat complexity were the result of a stream size gradient. The larger sites along the Pigeon Creek mainstem tended to have the lowest total and 
EPT richness, as well as the greatest number of structures considered to be retentive features. No significant correlations were observed between P richness and any of the physical habitat variables across the large combined sites (Table 14).

Across the small combined sites, \%EPT excluding Baetidae exhibited a significant negative correlation with $\mathrm{Cr}$ concentration (Table 15). There was no significant relationship between total abundance and any water chemistry variable across the small combined sites (Table 15). With respect to physical habitat, total abundance exhibited a significant negative correlation with percent canopy cover and \% boulder, as well as a significant positive correlation with \%sand (Table 16). No significant correlations were observed between physical habitat and \%EPT excluding Baetidae.

\section{Interactive Effects of Mining and Residential Development}

MANOVA detected significant differences among the mined, developed, large combined, and small combined sites with respect to their physical habitat, water chemistry, and individual community metrics (Table 17). Following the significant multivariate tests, a series of ANOVAs were conducted to determine which individual variables were significantly different among the four site types. When comparing site types based on their physical characteristics, large combined sites had a significantly greater average MSW and mean depth, as well as a significantly lower average gradient, than all other site types (Tables 18 and 19). With respect to substrate composition, \% sand exhibited the most variation among the four site types (Table 18). Percent sand was significantly higher in the large combined sites as compared to the small combined and developed sites (Tables 18 and 19). Furthermore, small combined sites had a significantly greater proportion of sand as compared to the developed sites, and mined sites had a significantly greater percentage of sand as compared to the developed sites (Table 19). These 
differences in substrate composition were further evidenced when considering a box plot characterizing the differences in \% sand among each site type (Figure 16). Developed sites were characterized by the lowest mean $\%$ sand, which was lower than that observed in the two reference sites. The large combined and mined sites had the highest mean \%sand, with the large combined exhibiting the greatest proportion. Lastly, large combined sites were characterized by a significantly lower proportion of boulders as compared to developed sites (Tables 18 and 19).

Of the habitat complexity measures, DRF/MSW and DFC/MSW were significantly different among site types, with large combined sites exhibiting the lowest distances to each complexity measure (Tables 18 and 19). Although none of the remaining habitat complexity measures were significantly different among site types (Table 18), mined sites had the highest average $\mathrm{LWD} / \mathrm{m}$, as well as the highest overall retentiveness. Furthermore, mined sites had the highest mean \%RVHA and USM scores (Table 18), which were significantly different from those of small combined sites and large combined and developed sites, respectively (Table 19). This is further evidenced when looking at the box plot for \%RVHA (Figure 17). Although there was considerable within type variation, mined sites had an average \%RVHA score close to those of the reference sites, while the small combined sites had the lowest mean \%RVHA score. The large combined and developed sites had very similar mean \%RVHA scores. Lastly, the large combined sites had the lowest average PC1 score, which was significantly different from that of all other site types (Table 18; Figure 12). This was undoubtedly a result of their large size and low habitat complexity measures (Table 18). No significant difference was observed between the mined, small combined, and developed sites with respect to either habitat PC1 or PC2 (Table 19). However, mined sites had the highest average PC1 and PC2 scores (Table 18; Figure 12), suggesting that mined sites had the highest overall habitat complexity and quality. Developed 
sites tended to have low PC1 and PC2 scores, indicating poor overall habitat complexity and quality (Table 18; Figure 12).

When comparing site types based on water chemistry, 12 variables were found to be significantly different among the four site types (Table 20). Nine of these variables loaded significantly onto PC1, indicating that variation in its component variables (Table 5) dominates differences in water chemistry among the site types. Developed sites had an average PC1 score that was significantly lower than all other site types (Tables 20 and 21). Similar relationships were observed between several constituents of PC1, including alkalinity, conductivity, Ba, Ca, $\mathrm{Cl}, \mathrm{Mg}, \mathrm{SO}_{4}$, and $\mathrm{NO}_{3}$ (Table 21). $\mathrm{PCl}$ and several contributing variables (alkalinity, $\mathrm{Cl}$, and Na) differed significantly between mined and large combined sites, with large combined sites exhibiting higher values of each (Tables 20 and 21). Alkalinity and Na differed between the large and small combined sites, while no water chemistry variables were significantly different between mined and small combined sites (Table 21). Mined sites had the lowest average $\mathrm{pH}$ and $\mathrm{Cl}$ concentrations (Table 20), which were significantly different from large combined, and developed and large combined sites, respectively (Table 21). Overall, large combined sites had the highest values associated with 8 of the 12 variables differing significantly among the site types, including PC1 and seven of its constituents (Table 20). Developed sites had the lowest average values for each of these variables, while mined and small combined sites exhibited intermediate values. This pattern is evident when comparing both conductivity (Figure 18) and WQ PC1 (Figure 19) across each site type.

When comparing each site type based on macroinvertebrate community structure, nine metrics were observed to be significantly different (Table 22). The greatest difference in community structure was observed between the mined and large combined sites, with eight 
metrics differing significantly between them (Table 23). Of these, $m$ WVSCI, total richness, EPT richness, $\mathrm{P}$ richness, \%EPT and \%EPT no Baetidae were significantly higher in mined sites (Tables 22 and 23), indicating higher overall community complexity and health. Percent dominance and \%tolerant were significantly lower in mined sites as compared to large combined sites (Tables 22 and 23), further indicating healthier and more complex communities.

Furthermore, total richness and \%EPT (excluding Baetidae) were significantly greater in mined sites as compared to small combined and developed sites, respectively. Large combined sites had significantly fewer EPT and P taxa as compared to developed sites, as well as a significantly lower $m$ WVSCI as compared to small combined sites (Tables 22 and 23). Lastly, small combined sites had the highest average \%Hydropsychidae, which was significantly different from the developed sites. Overall, mined sites exhibited the highest value in terms of community health for nine of the 15 community metrics (Table 22). It is notable, however, that all three Ephemeropteran metrics (E richness, \%E, and \%E excluding Baetidae) were higher in either the developed or small combined sites (Table 22). Large combined sites exhibited the lowest value in terms of community health for 12 of the 15 community metrics (Table 22). Scores associated with developed and small combined sites tended to be intermediate to the mined and large combined sites. This pattern is evident when considering box plots of $m$ WVSCI (Figure 20) and EPT richness (Figure 21).

When comparing the mined, developed, small combined, and large combined sites based on macroinvertebrate community structure, MEANSIM detected statistical evidence $(\mathrm{p}=0.001)$ of greater site type classification strength (CS) than would be expected by chance alone. Thus, there appeared to be a significant difference in community structure between each site type. However, the CS value (0.040) was numerically low, indicating relatively high variation within 
one or more site types. The MEANSIM dendrogram suggests that sites along the residential and mining gradients had the lowest within-group similarity (Figure 22). In fact, developed sites exhibited within-group similarity that was less than the mean between-group similarity (Figure 22). Both the small and large combined sites exhibited individual within-group similarities that were greater than the mean within-group similarity, with the large combined sites exhibiting the strongest similarity (Figure 22).

The results of the NMDS ordination corroborated the patterns observed by MEANSIM. The number of NMDS dimensions (axes) that best represented the data was three, resulting in a stress of 15.62 (Figure 23). Axis 1 differentiated between diverse, ecologically complex communities with high numbers of sensitive genera and less complex communities dominated by tolerant taxa (Figure 24). Axis 2 separated sites based on their relative abundance of Ephemeroptera and certain Trichoptera and Plecoptera taxa. Mined sites appeared to have the highest community complexity, indicated by their high scores along Axis 1 and their separation from the other site types (Figure 24). However, there was considerable variation within the mined sites along axes. Conversely, large combined sites consistently grouped together, exhibiting a much greater loss of sensitive genera and a corresponding increase in dominant and tolerant taxa. This was signified by consistently low scores along Axis 1 (Figure 24). Significant overlap existed between the developed and small combined sites, which appeared to be characterized by a greater relative abundance of dominant and tolerant taxa as compared to mined sites. A biplot environmentally fitted with macroinvertebrate indices indicated that mined sites had the highest overall EPT, P, and T richness, as well as the highest WVSCI scores (Figure 25). Mined sites further separated from developed and small combined sites along axis 2, with 
mined sites exhibiting lower Ephemeroptera richness and relative abundance when excluding Baetidae (Figures 24 and 25).

The results of the partial Mantel tests suggest that both mining and residential development explain important variation in in-stream conditions within the upper Pigeon Creek watershed. Parcel density explained significant variation in macroinvertebrate community structure among the mined, developed, reference, and small combined sites (Table 24). In contrast, the partial Mantel test failed to detect a significant correlation between percent mining and the macroinvertebrate community dataset. With respect to water chemistry, percent mining explained a significant amount of the variation observed among study sites (Table 24).

However, the partial Mantel test failed to detect a significant correlation between parcel density and the water chemistry dataset. With respect to physical habitat, we were mainly interested in identifying the effects of mining and residential development on in-stream complexity and quality. Therefore, only variables significantly loading onto Habitat PC2 were included. Parcel density explained significant variation in the physical habitat characteristics observed among study sites, while the partial Mantel test failed to detect a significant correlation between percent mining and the physical habitat dataset (Table 24). During each analysis, similar relationships were observed before and after the effect of space was removed, and the individual effect of space was only significant when explaining variation in the water chemistry dataset (Table 24).

Similar results were obtained from the partial correlation analyses. After removing the effects of parcel density, total percent mining explained significant variation in WQ PC1 (Table 25). Although parcel density explained measurable variation in WQ PC1 $(r=0.34)$, this relationship was not statistically significant $(\mathrm{p}<0.05)$. Because we were mainly interested in the effects of mining and residential development on habitat complexity and quality, Habitat PC2 
was used in the partial correlation analysis. After removing the effects of total percent mining, parcel density explained significant variation in Habitat PC2 (Table 25). However, percent mining did not explain significant variation in Habitat PC2. The effects of water chemistry and physical habitat on each site type become evident when considering a scatter plot of WQ PC1 and Habitat PC2 (Figure 26). Both the mined and developed sites exhibited higher WQ PC1 scores as compared to the reference sites, with mining exhibiting a stronger partial correlation (Figure 26). However, developed sites consistently exhibited lower Habitat PC2 scores as compared to the reference sites, while mined sites often exhibited Habitat PC2 scores that exceeded those of the reference sites (Figure 26). Similar to the developed sites, the small combined sites tended to exhibit increased WQ PC1 scores and decreased Habitat PC2 scores as compared to the reference sites (Figure 26).

Analysis of covariance was conducted on the five community metrics found to be significantly correlated with both mining and parcel density along their respective gradients ( $m$ WVSCI, EPT richness, E richness, \%E excluding Baetidae, and \%dominant). For each variable, three separate ANCOVAs were conducted. In all analyses, site type was used as the treatment, and CI score, conductivity, and \%RVHA were held as individual covariates. With respect to $m$ WVSCI, ANCOVA detected a significant overall effect of CI score, as well as a significant difference between the three site types (Table 26). However, ANCOVA failed to detect a significant interaction between site type and CI score on $m$ WVSCI (Table 26). $m$ WVSCI decreased with increasing CI scores along both the mining and residential gradients, with developed sites exhibiting significantly lower $m$ WVSCI scores (Figure 26). Although $m$ WVSCI was slightly variable within the combined sites, scores within combined sites tended to be intermediate to those along the mined and developed gradients (Figure 26). Similarly, 
ANCOVA detected a significant overall effect of CI score and a significant difference between the three site types with respect to EPT richness. However, ANCOVA failed to detect an interaction between site type and CI score (Table 26). EPT richness decreased with increasing CI score along the mining and residential gradients and was significantly lower in sites affected by residential development (Figure 28). In combined sites, EPT scores tended to be similar to those observed along the residential gradient.

With respect to E richness, ANCOVA detected a significant CI effect, but failed to detect either a significant difference between the three site types or an interaction between CI score and site type (Table 26). Across all site types, E richness decreased with increasing CI score (Figure 29). Similarly, when run on \%dominant, ANCOVA detected a significant CI effect, but failed to detect either a significant difference between the three site types or an interaction between CI score and site type (Table 26). Percent dominant increased with increasing CI score along both the mining and residential gradients (Figure 30) and tended to decrease slightly in the combined sites. When conducted on \%E excluding Baetidae, ANCOVA detected a significant CI effect, but failed to detect a significant difference between the three site types (Table 26). Furthermore, ANCOVA detected a significant interaction between CI score and site type. This interaction was the result of a positive relationship between $\mathrm{CI}$ score and \%E excluding Baetidae within the combined sites, while a negative relationship existed within the mined and residential gradients. The positive relationship within the combined sites, however, was driven by a single site that was characterized by both a high \%E excluding Baetidae and a high CI score (Figure 31).

Relationships between conductivity and community metric scores across the three site types offered similar results. ANCOVA detected a significant overall relationship between $m$ WVSCI and conductivity, as well as a significant difference between each site type (Table 27). 
However, no interaction was detected between site type and conductivity. $m$ WVSCI decreased with increasing conductivity along the residential and mining gradients, with developed sites exhibiting much lower $m$ WVSCI scores that would be expected given their conductivity alone (Figure 32). $m$ WVSCI scores in combined sites tended to be intermediate to those along the residential and mining gradients (Figure 32). Similarly, ANCOVA detected a significant relationship between EPT richness and conductivity, as well as a significant difference in EPT richness among the three site types. Again, no significant interaction between site type and conductivity was detected (Table 27). Distinct negative relationships were observed between conductivity and EPT richness for both the mined and residential gradients, with developed sites exhibiting lower scores (Figure 33). Combined sites, however, exhibited EPT richness scores that were very similar to those along the residential gradient.

With respect to E richness, ANCOVA detected a significant relationship with conductivity, but was unable to detect either a significant difference between site types or a significant interaction between site type and conductivity (Table 27). Distinct negative relationships were observed between conductivity and E richness for all three site types, with mined sites exhibiting the highest scores, developed sites exhibiting the lowest scores, and combined sites exhibiting scores slightly intermediate to those along the mining and residential gradients (Figure 34). With respect to \%dominant, ANCOVA detected a significant overall effect of conductivity, but failed to detect either a significant difference between the three site types or a significant interaction between conductivity and site type (Table 27). Positive relationships were observed between conductivity and \%dominant for each site type, with the highest values being observed along the residential gradient (Figure 35). Mined and combined sites exhibited similar relationships between \%dominant and conductivity. Lastly, when 
conducted on \%E excluding Baetidae, ANCOVA detected a significant overall effect of conductivity, but failed to detect both a significant difference between site type and a significant interaction between conductivity and site type (Table 27). Percent E excluding Baetidae decreased with increasing conductivity across all three site types, with developed sites exhibiting the lowest scores (Figure 36). Again, mined and combined sites exhibited similar relationships.

The relationships between \%RVHA and community structure across the different site types were considerably different than those observed using CI score and conductivity. ANCOVA was only able to detect a significant difference between the three site types with respect to $m$ WVSCI and EPT richness (Table 28). $m$ WVSCI exhibited a slight increase with increasing \%RVHA score within the mined and combined sites, while the positive relationship between $m$ WVSCI and \%RVHA was much stronger within developed sites (Figure 37). $m$ WVSCI scores were consistently higher within mined sites as compared to the combined and developed sites (Figure 37). With respect to EPT richness, a slight positive relationship was observed with \%RVHA along the mining and developed gradients (Figure 38). Conversely, a slight negative relationship was observed between EPT richness and \%RVHA within combined sites (Figure 38). EPT richness scores were consistently higher in mined and developed sites as compared to the combined sites (Figure 38). Although ANCOVA observed a significant difference in $m$ WVSCI and EPT richness scores across the site types, there was not a significant effect of \%RVHA on either metric. ANCOVA only detected a significant effect of \%RVHA on $\%$ dominant, with \%dominant scores decreasing with increasing \%RVHA across all site types (Table 28; Figure 39). With respect to both E richness (Figure 40) and \%E excluding Baetidae (Figure 41), ANCOVA was unable to detect either a site type effect or an effect of \%RVHA (Table 28). No interactions between \%RVHA and site type were observed (Table 28). 
Because ANCOVA failed to detect an interaction between site type and each of the covariates, a series of analyses was conducted to identify and quantify the possible additive effects of mining and residential development. EPT richness was chosen for the analyses because it consistently showed the greatest difference between the three site types, as well as the strongest relationship with each of the covariates (Tables 26-28). Initially, a multiple scatter plot was created to compare the correlations of EPT richness and total \%mining for each individual site type. A linear regression was then calculated for the mined sites to identify the individual effect of mining on EPT richness. The deviation of the developed and combined sites from the mining regression was then calculated and regressed against parcel density, providing a measure of the additive effect of development. This process was then repeated by correlating EPT richness and parcel density for each site type. A regression was calculated for the combined sites, and the deviation of the mined and combined sites from the developed regression was calculated and regressed against total \% mining. This provided a measure of the additive effect of mining.

Based on the scatter plots of total \% mining and EPT richness across each site type, it was observed that the combined sites fell distinctly below the mined sites, indicating lower EPT richness when both mining and residential development were present (Figure 42). Furthermore, the deviation of the developed and combined sites from the mining regression was related to parcel density $\left(\mathrm{R}^{2}=0.22 ; \mathrm{p}=0.080\right.$; Figure 43$)$. Although this is not significant at an alpha level of 0.05 , there does appear to be a distinct positive relationship between parcel density and the deviation from the mining regression, indicating a measurable additive effect of parcel density. A similar pattern was observed when looking at the relationship between EPT richness and parcel density for each site type, with the combined sites falling distinctly below developed sites 
(Figure 44). This indicates lower EPT richness when both mining and residential development are present. The deviation of the mined and combined sites from the parcel density regression was significantly related to total mining $\left(\mathrm{R}^{2}=0.30 ; \mathrm{p}=0.018\right.$; Figure 45$)$, indicating an additive effect of mining.

Identification of Landscape Thresholds for Biological Impairment

Along the residential gradient, BCP identified a considerably high maximum probability (> 0.30) of a change point for the relative abundances of E and EPT excluding Baetidae, as well as total abundance (Table 29). With respect to \%E excluding Baetidae, the maximum probability (0.884) of a threshold response occurred at a parcel density of 14.36 parcels $/ \mathrm{km}^{2}$ (Table 29; Figure 46). Furthermore, there appeared to be a less significant, but still substantial (0.368), probability at a parcel density of 6.13 parcels $/ \mathrm{km}^{2}$ (Figure 46). The maximum probability of a threshold response associated with \%EPT excluding Baetidae (0.402) occurred at a parcel density of 1.25 parcels $/ \mathrm{km}^{2}$ (Table 29; Figure 47), indicating an immediate drop in EPT abundance with minimal residential development. Furthermore, there was a less significant probability of a threshold response (0.282) in \%EPT excluding Baetidae at a parcel density of 14.36 (Figure 47). Lastly, there was a 0.968 probability of a change point in total abundance at a parcel density of 16.58 (Table 29; Figure 48). Upon further investigation, the three sites above the parcel density threshold had the highest Chironomidae abundances, as well as high numbers of other tolerant taxa, such as several genera in the family Baetidae. However, there were no sites along the residential gradient with parcel densities between 16.58 and $43.60 \# / \mathrm{km}^{2}$.

BCP identified potential threshold responses to both Ephemeroptera richness and Ephemeroptera relative abundance excluding Baetidae (Table 29) along the mining gradient. The potential change point occurred at $26.18 \%$ total mining for both metrics, with change point 
probabilities of 0.362 and 0.454 , respectively. Considerable variation existed in both metrics below the potential threshold of $26.18 \%$, indicating that both good and bad conditions occurred in systems with lower levels of total mining. However, once this threshold was reached, both Ephemeroptera richness and relative abundance excluding Baetidae remained low and exhibited much less variation (Figures 49 and 50, respectively).

$\mathrm{BCP}$ identified potential threshold responses in \%EPT and \%E excluding Baetidae, total abundance, and Plecoptera richness to CI score when all combined sites were used (Table 29). However, the potential change points identified for each of these four metrics were the result of various outliers, and did not represent true threshold responses. When only the small combined sites were included in the analyses, the potential threshold observed for \%E excluding Baetidae was the result of the same outlier (Curry Branch) that produced the high probability when all combined sites were used. Curry Branch had the highest CI score of all combined sites (Table 3) and high abundances of E and EPT individuals when excluding Baetidae. Therefore, this relationship did not represent a true threshold response and is not considered further. The high probability associated with total abundance $(0.326)$ occurred at a combined index score of 18.18 and corresponded to a substantial drop in total abundance (Table 29; Figure 51). Although each of these combined sites had parcel densities above the total abundance threshold observed along the parcel density gradient, mining-related influences appear to inhibiting the proliferation of tolerant genera (i.e. chironomids) observed along the parcel density gradient.

$\mathrm{BCP}$ offered very similar results when looking at community response to conductivity across each site type. Along the mining gradient, $\mathrm{BCP}$ identified a high probability of a change point in both Ephemeroptera richness (Figure 52) and \%E excluding Baetidae (Table 30; Figure 53). For both metrics, the potential change point occurred at a conductivity of $104 \mathrm{uS} / \mathrm{cm}$, which 
corresponded to the threshold observed at $26.18 \%$ total mining (Table 29). Along the residential gradient, potential change points occurred for both \%tolerant (Figure 54) and \%Chironomidae (Table 30; Figure 55). For each metric, the potential threshold occurred at a conductivity of 58 $\mathrm{uS} / \mathrm{cm}$. This conductivity corresponds to a parcel density of 14.36 parcels $/ \mathrm{km}^{2}$, which is where a potential threshold occurred for both \% E and \%EPT excluding Baetidae.

$\mathrm{BCP}$ identified a high probability of a change point $(\geq 0.30)$ for Ephemeroptera richness, Plecoptera richness, total abundance, \%EPT, \%EPT excluding Baetidae, \%E excluding Baetidae, $\%$ Tolerant, and \%Hydropsychidae across all combined sites (Table 30). However, the change points associated with Plecoptera richness, total abundance, \%EPT, and \%tolerant were the result of outliers, and did not represent true threshold responses. With respect to \% (Figure 56) and \%EPT excluding Baetidae (Figure 57), BCP identified a potential threshold response at a conductivity of $168 \mathrm{uS} / \mathrm{cm}$ (Table 30). This change point corresponded to Curry Branch. Although Curry Branch resulted in a parcel density threshold that did not represent a true change point in community structure, the observed change points for $\% \mathrm{E}$ and $\% \mathrm{EPT}$ excluding Baetidae across the combined sites appear to be the result of increased specific conductance. With respect to Ephemeroptera richness, $\mathrm{BCP}$ identified a potential change point at a specific conductance of 437 uS/m (Table 30; Figure 58). Lastly, BCP identified a potential change point in $\%$ Hydropsychidae at a specific conductance of $555 \mathrm{uS} / \mathrm{cm}$ (Table 30). Considerable variation existed in \%Hydropsychidae below this threshold (Figure 59). However, once this threshold was reached, the relative abundance of hydropsychids remained low. When considering only the small combined sites, BCP identified a potential threshold for \%E excluding Baetidae at a specific conductance of $168 \mathrm{uS} / \mathrm{cm}$ (Table 30; Figure 60). 


\section{Discussion}

Direct Effects of Mining and Residential Development

Direct Effects of Residential Development - When occurring in isolation of other known stressors, residential development resulted in significant impacts to in-stream conditions within the upper Pigeon Creek watershed. Residential development resulted in significant alterations to water chemistry, primarily through increases in parameters associated with Principal Component 1 (i.e. specific conductivity and ion concentrations). For example, parcel density was significantly correlated with WQ PC1 ( $\mathrm{r}=0.70)$ and five variables loading significantly into PC1, with correlation coefficients ranging from 0.63 to 0.78 . However, it should be noted that changes in water quality resulting from residential development were not as acute as those resulting from mining. On the other hand, residential development resulted in more acute alterations to physical habitat than mining, primarily through decreases in habitat complexity. Along the residential gradient, significant correlations were observed for four habitat complexity and quality variables, with correlation coefficients ranging from -0.63 to -0.81 .

Residential development resulted in a significant decrease in ecological condition, as identified by a significant decrease in $m$ WVSCI $(r=-0.73)$. The impacts associated with residential development resulted in both a significant decrease in sensitive taxa, as well as significant increases in tolerant taxa. Overall, ten community metrics were significantly correlated with cumulative parcel density (coefficients ranging from 0.64 to -0.93 ) - five of which indicated a decrease in sensitive taxa and four indicated an increase in tolerant taxa. Significant correlations between several macroinvertebrate community metrics and in-stream measures of physical habitat and water chemistry provided mechanisms by which residential development may be altering biological communities. Communities appear to be responding 
significantly to changes in both habitat quality and water chemistry. For example, \%E excluding Baetidae was significantly correlated with four measures of physical habitat, including habitat PC2, with correlation coefficients ranging from 0.63 to 0.76 . With respect to water chemistry, $\%$ E excluding Baetidae was significantly correlated with nine variables, including WQ PC1, with correlation coefficients ranging from -0.64 to -0.86 .

These results add to a growing list of studies identifying significant correlations between landscape-based indicators of urban development and in-stream conditions. Significant correlations have been observed between in-stream conditions and percent impervious surface area (Morse et al. 2004; Ourso and Frenzel 2003; Wang and Kanehl 2003) and percent urban landcover (Fitzpatrick et al. 2003; Roy et al. 2003). Furthermore, Tate et al. (2005) developed a multimetric urban intensity index that incorporated aspects of land use, infrastructure, and socioeconomic variables. However, a search of existing literature suggested that few, if any, previous studies have used parcel density as a sole measure of residential development. The results of this study suggest that cumulative parcel density may be a good indicator of the impacts associated with residential development and urbanization. This is true, at least, in regions similar to the coalfields of southern West Virginia where development is largely confined to narrow floodplains directly adjacent to the stream channel.

With respect to biological communities, this study supports numerous others that have observed both a significant decrease in sensitive taxa and a corresponding increase in tolerant taxa with increasing urban development (Ourso and Frenzel 2003; Wang and Kanehl 2003; Roy et al. 2003; Fitzpatrick et al. 2003, Voeltz et al. 2005). For example, in their review of urbanized systems, Paul and Meyer (2001) noted that all studies looking at the effects of urbanization through gradient analysis observed significant decreases in sensitive taxa, while most observed 
significant increases in tolerant organisms. Although direct causal relationships cannot be inferred from correlative studies between landscape-based indicators and in-stream biological conditions (Roy et al. 2003; Van Sickle 2003; King et al. 2005), the observed relationships between parcel density and in-stream physical and chemical conditions provide pathways through which development affects ecological conditions.

Numerous studies have documented changes in physical habitat in response to urbanization (Allan 2004; Roy et al. 2003; Ourso and Frenzel 2003; Paul and Meyer 2001). However, many of these studies have focused on impacts to channel geomorphology resulting from sedimentation and channel alteration (Paul and Meyer 2001; Roy et al. 2003; Ourso and Frenzel 2003; Wang and Kanehl 2003), with few studies taking into consideration other important aspects of habitat complexity (but see Allan 2004). The present results suggest a considerable decrease in habitat complexity measures not typically considered by many of the previous studies of urbanizing systems. Three of the five habitat variables found to be significantly correlated with cumulative parcel density along the residential gradient were direct measures of habitat complexity (\#LWD/m, retentiveness, CV depth). Furthermore, the significant correlations observed between the measures of habitat complexity and quality and several macroinvertebrate community metrics is consistent with numerous studies (see Richards and Host 1994). For example, Sudduth and Meyer (2006) observed a strong correlation between macroinvertebrate richness and biomass and the percentage of stream bank covered with roots or woody debris in urban systems.

The results of this study are generally consistent with others documenting changes in water chemistry in response to urban and residential development. Increased ion concentrations and specific conductance are extremely common in urbanized systems and are often used as 
indicators of urban impact (see Paul and Meyer 2001; Roy et al. 2003; Voeltz et al. 2005). For example, specific conductance was consistently identified by multiple regressions as an important predictor of macroinvertebrate community indices in response to urban development (Roy et al. 2003). Increases in nutrient concentrations are also consistently observed in urbanized systems (Paul and Meyer 2001; Roy et al. 2003; Allan 2004). This has been attributed to increases in wastewater and fertilizers (Paul and Meyer 2001; Allan 2004) and a decrease in the capacity of aquatic systems to uptake nutrients with increasing urbanization (Meyer et al. 2005). Although nitrate and ammonium were significantly elevated in developed sites, these increases were not as drastic as observed in previous literature. The fact that cumulative parcel density was correlated with numerous physical and chemical variables supports the conclusion that the effects of development permeate multiple scales to impact biotic communities (see Roy et al. 2003).

Direct Effects of Mining - When occurring in isolation, mining also resulted in significant impacts to in-stream conditions. With respect to water chemistry, mining resulted in a significant increases in the parameters associated with Principal Component 1 (i.e. specific conductivity and ion concentrations). For example, mining was significantly correlated with WQ PC1 (r=0.90) and eight variables loading significantly into PC1, with correlation coefficients ranging from 0.68 to 0.91 . Unlike residential development, mining did not appear to directly impact physical habitat. Total \% mining was significantly correlated with \%bedrock. However, mining was not significantly correlated with any other measure of habitat complexity or quality.

As with residential development, mining resulted in a significant decrease in ecological condition, as determined by a significant decrease in mWVSCI $(r=-0.64)$ along the mining gradient. However, the strength and number of significant relationships between the community 
metrics were less than was observed along the parcel density gradient. Significant correlations were observed for six community metrics, with correlation coefficients ranging between 0.56 0.64. Mining resulted in a significant decrease in sensitive genera. However, there was not as profound of an increase in tolerant taxa as was observed along the residential gradient. Significant correlations between several macroinvertebrate community metrics and in-stream measures of physical habitat and water chemistry provided mechanisms by which mining may be altering biological communities. Along the mining gradient, macroinvertebrate communities responded more significantly to water chemistry, as compared to physical habitat. For example $\%$ E excluding Baetidae was significantly correlated with 10 water chemistry variables, including WQ PC1, with correlation coefficients ranging from -0.57 to -0.86 . Although $\% \mathrm{E}$ excluding Baetidae was significantly correlated with four habitat metrics, none of these variables (with the exception of \%bedrock) were significantly correlated with total \% mining. Therefore, although physical habitat may be influencing communities along the mining gradient, mining does not directly impact physical habitat.

The results presented here add to a growing list of studies linking landscape-based measures of mining to in-stream conditions (Maret and McCoy 2002; Maret et al. 2003; Bruns et al. 2005; Petty et al. unpublished manuscript). For example, Petty et al. (unpublished manuscript) observed significant correlations between an index of mining intensity (see Strager et al. 2009) and water chemistry and macroinvertebrate communities in the Cheat River watershed. Maret and MacCoy (2002) and Maret et al. (2003) observed significant relationships between mine density and in-stream physical, chemical, and biological conditions in the Coeur d'Alene watershed. However, this study is the only known study to use a landscape-based indicator of mining in the primary mountaintop mining region of West Virginia. Other studies in 
the region have either compared known mining sites to reference conditions (Merricks et al. 2007) or used water chemistry parameters as indicators of mining influence (Pond et al. 2008). However, of the four variables significantly correlated with the mining gradient, the correlations observed using total percent mining were just as strong (or stronger) than the observed correlations with conductivity and sulfate. Therefore, it appears that the measure of total percent mining was a good indicator of mining-related influences.

The results of this study are consistent with numerous others that have identified changes in water chemistry as the dominant stressor in systems affected predominately by coal mining activities (DeNicola and Stapleton 2002; Petty and Barker 2004; Pond et al. 2008; Fulk et al. 2003; Freund and Petty 2007). Most notably, this study adds to a growing body of literature identifying increases in specific conductance as an important predictor of ecological condition in systems impacted by large-scale surface mining in the mountaintop mining region of West Virginia (Fulk 2003; Pond 2004; Hartman et al. 2005; Pond et al. 2008). Dramatic increases in specific conductance have been consistently observed in streams impacted by mountaintop mining (Pond et al. 2008; Merricks et al. 2007; Hartman et al. 2005). For example, Hartman et al. (2005) observed conductivities in mined sites that were 2-21 times higher than those observed in paired reference sites. Many of the ions recognized by previous studies (Hartman et al. 2005; Pond et al. 2008) to be toxic to aquatic organisms (i.e. $\mathrm{SO}_{4}, \mathrm{Mg}, \mathrm{Na}, \mathrm{Cl}, \mathrm{Ca}, \mathrm{HCO}_{3}$ ) were found to be significant contributors to WQ PC1 and conductivity within Pigeon Creek.

Increases in ionic strength have been shown to cause significant impairment to macroinvertebrate communities, primarily through decreases in sensitive taxa (Garcia-Criado et al. 1999; Kennedy et al. 2002; Pond et al. 2008). For example, Pond et al. (2008) noted a significant response in 17 of 19 community metrics to increases in specific conductance. The 
results presented here support numerous other studies that observed Ephemeropteran as being among the most sensitive invertebrate taxa to increases in ionic strength (Pond et al. 2008; Hartman et al. 2005; Garcioa-Criado et al. 1999; Kennedy et al. 1999). However, the range of conductivities where impairment occurs has varied considerably between studies. For example, Garcia-Criado et al. (1999) observed significant decreases in sensitive taxa in a system where the max observed conductivity was 470uS/cm. However, Kennedy et al. (1999) did not see a significant decrease in sensitive taxa in conductivities less than $\sim 3700 \mathrm{uS} / \mathrm{cm}$. Within the range of conductivities observed, the results of this study are generally consistent with those of Pond et al. (2008) and Garcia-Criado et al. (1999). Substantial drops in E richness were observed at conductivities $\sim 150$. Furthermore, with the exception of one site, the original WVSCI scored all sites along the mining gradient with conductivities greater than $\sim 150 \mathrm{uS} / \mathrm{cm}$ as impaired $(<68)$.

Based on the data obtained, however, it is difficult to discern the individual effects of increased specific conductance and other mining-related stressors, such as increased heavy metal concentrations. Magnesium, which has been shown to be toxic to aquatic macroinvertebrates (see Hartman et al. 2005), was found to be significantly elevated along the mining gradient. Numerous other studies have linked increased metal concentrations to benthic macroinvertebrate toxicity in streams impacted by mining (Clements et al. 2000; DeNicola and Stapleton 2002; Clements 2004). Although this issue has been raised by multiple authors (Pond et al. 2008; Merricks et al. 2007; Hartman et al. 2005), studies attempting to describe the relationship between biological conditions and in-stream conditions are not designed to determine causative agents of impairment (Freund and Petty 2007; Maret and MacCoy 2002). Furthermore, it may be likely that the interactive effects of increased specific conductance and increased metal 
concentrations are responsible for the altered macroinvertebrate communities observed along the mining gradient (Merovich and Petty 2007; Clements 2004).

Interactive Effects of Mining and Residential Development

Results of this study suggest that when both mining and residential development occur in combination, their individual impacts combine additively to degrade ecological conditions.

Several results support this conclusion. First, ANCOVA failed to detect a significant interaction between site type and CI score, conductivity, and \%RVHA for essentially all of the community metrics analyzed. Therefore, site type did not interact with the covariates to produce conditions in combined sites that were worse than expected given independent levels of mining and residential development. Furthermore, when examining the relationship between EPT richness and total \%mining for each site type, the deviation of the developed and combined sites from the mining regression was correlated with parcel density. This indicates that parcel density has an individual effect that is added to the effects associated with mining. Similarly, when examining the relationship between EPT richness and parcel density for each site type, the deviation of the mined and combined sites from the parcel density regression was significantly correlated with total \%mining. This indicates that the individual effects of mining are added to the effects associated with parcel density.

As indicated by the ANCOVAs, however, the combined effects of mining and residential development were consistently worse than the individual effects of mining, but never worse than the individual effects of residential development. At equivalent CI scores and conductivities, residential development consistently resulted in conditions that were worse than the individual effects of mining. However, combined sites tended to have community metric scores that fell somewhere near those of residential development or intermediate to mining and development. 
For example, with respect to $m \mathrm{WVSCI}$ and E richness, conditions in combined sites were intermediate to those along the mined and developed gradients when holding CI score and conductivity as covariates. When considering EPT richness, however, conditions in the combined sites were consistently as bad as those along the developed gradient. Lastly, \%dominant and \%E excluding Baetidae in combined sites tended to be similar to those observed along the mining gradient. Collectively, these results suggest an additive effect where the combination of mining and residential development produces an overall effect that is most often greater than that of mining alone, but not greater than the individual effects of residential development. This conclusion is further supported by the results of the Mantel test suggesting that parcel density explains more variation in macroinvertebrate community structure among study sites.

The response of macroinvertebrate communities to the combined impacts of mining and residential development appears to fit the antagonistic additive model as described by Folt et al. (1999). This is to say that when the stressors associated with mining and residential development are combined, their individual impacts are the same as when either stressor occurs alone, but their combined effects are less severe than the sum of their individual effects (Folt et al. 1999). Several explanations can be offered for this pattern of degradation. First, because linear relationships were observed for individual community metrics along both the mining and residential gradients, the degree of degradation is directly related to the cumulative amounts of each stressor. The combined index suggests that when occurring at equivalent amounts, the stressors associated with residential development result in greater community degradation than those associated with mining. When mining and residential development are combined at an equivalent CI score, the individual amounts of each stressor are reduced, leading to an 
intermediate level of community degradation. For example, if two CI units of mining produce a deleterious effect of 10 and two CI units of residential development produce a deleterious effect of 20, a combination of one $\mathrm{CI}$ unit of both mining and residential development will produce a deleterious effect of 15 .

Further explanation for the pattern of community response observed in the presence of both mining and residential development can be made with respect to the stressors associated with each land use and the tolerances of individual taxa along each gradient. Although mining results in a greater increase in conductivity as compared to residential development, both land use practices result in conductivities that exceed a critical threshold of community degradation. Consequently, the high conductivities associated with both mining and residential development may impact macroinvertebrate communities in essentially the same manner. Unlike mining, however, residential development also results in a significant reduction in habitat complexity and quality, which may remove habitat requirements necessary for the survival of certain taxa and facilitate the proliferation of other tolerant taxa. Furthermore, organic pollution commonly associated with urbanization and residential development (see Paul and Meyer 2001) may remove taxa that were initially tolerant to increased conductivities. Therefore, the stressors associated with residential development may result in communities that are already tolerant to the dominant stressors associated with large-scale surface mining (i.e. increased specific conductance). Communities along the mining gradient, however, may not be tolerant to certain stressors associated with residential development (i.e. decreased habitat quality). Consequently, when the stressors associated with mining and residential development are added, communities are worse than those impacted by mining alone, but not worse than those impacted by development alone. This conclusion is further supported by results of the Mantel tests 
suggesting that mining explained more variation in the water chemistry dataset, while residential development explained more variation in habitat quality and complexity.

To our knowledge, our study is one of the first to examine the interactive effects of mining and residential development on aquatic systems. Several studies (Pond 2004; Fulk et al. 2003), however, have compared conditions in sites impacted by the combination of mining and residential development to those in sites impacted by each individual stressor and regional reference sites. Consistent with the current results, both studies observed worse community degradation in sites impacted by both stressors as opposed to mined or reference sites (Pond 2004; Fulk et al. 2003). However, Pond et al. (2004) was unable to detect patterns that could distinguish combined sites from either mined or residential sites. Results of this study provide such a pattern, indicating that the individual effects of each stressor combine additively to degrade aquatic systems, with the severity of degradation being directly related to the relative amounts of each stressor.

Field studies regarding the effects of multiple stressors on aquatic systems are rare (but see Merovich and Petty 2007). Furthermore, few studies have observed an additive effect between two anthropogenic stressors on aquatic communities. In a field experiment within the Cheat River watershed, Merovich and Petty (2007) observed a strong interactive effect of acid mine drainage and thermal effluent from a coal-fired power plant on macroinvertebrate community structure. Furthermore, numerous studies have observed significant interactions between multiple anthropogenic stressors by manipulating the amounts of each stressor in a laboratory experiment. For example, Clements et al. (2004) observed a strong interaction between multiple metals that drastically increased invertebrate drift. Furthermore, Porter et al. 
(1999) observed a significant interaction between temperature and salinity on coral reef production.

\section{Identification of Landscape Thresholds for Biological Impairment}

Through change point analysis, potential threshold levels were observed for total \%mining, parcel density, and the combined index. First, substantial drops in both Ephemeroptera richness and abundance excluding Baetidae were observed when mining-related land cover accounted for approximately $25 \%$ of the cumulative area upstream of a given site. The same pattern was observed using specific conductance as the predictor variable, with the threshold level occurring at approximately $100 \mathrm{uS} / \mathrm{cm}$. Residential development resulted in a substantial decrease in \%E excluding Baetidae at approximately 14 parcels $/ \mathrm{km}^{2}$. Percent EPT excluding Baetidae exhibited the same parcel density threshold. However, it also exhibited a sharp decline at a parcel density of approximately 1 parcel $/ \mathrm{km}^{2}$, indicating an immediate change in community structure as you cross from an undeveloped to a developed watershed. Lastly, a threshold was observed for total abundance at a parcel density of approximately 17 parcels $/ \mathrm{km}^{2}$. When using conductivity as the predictor along the residential gradient, sharp increases in \%tolerant and \%Chironomidae were observed at levels as low as $58 \mathrm{uS} / \mathrm{cm}$. Because this proliferation of tolerant taxa occurs at such a low conductivity, it is more likely the result of either organic enrichment (Paul and Meyer 2001; Roy et al. 2003; Allan 2004) or the habitat related increases observed for these community metrics. Regardless, the significant drop in Ephemeroptera and EPT abundances when excluding Baetidae appears to be the result of both a loss of the sensitive taxa, as well as the proliferation of tolerant organisms such as chironomids.

Within the combined sites, sharp declines were observed in both $\% \mathrm{E}$ and $\% \mathrm{EPT}$ excluding Baetidae at a conductivity of approximately $150 \mathrm{uS} / \mathrm{cm}$. This was observed for both 
all combined sites and the small combined sites only. However, a discrepancy was observed between conductivity and CI score. Curry Branch, which was characterized by the highest observed CI score, had a relatively low conductivity $(150 \mathrm{uS} / \mathrm{cm})$ and high percentages of $\mathrm{E}$ and EPT when excluding Baetidae. This highlights one of the issues surrounding landscape indicators, where in-stream conditions might not reflect the land use patterns of the surrounding landscape for any of a number of reasons, not the least of which is that the landscape indicators are not exact measures of true anthropogenic stress. Furthermore, when all combined sites were used, BCP identified a sharp decline in Ephemeroptera richness at a specific conductance of 437 $\mathrm{uS} / \mathrm{m}$. Although this is substantially higher than the conductivity threshold observed along the mining gradient, the relationship between conductivity and E richness remains relatively consistent between the mined and large combined sites. Therefore, it is possible that two distinct conductivity thresholds exist for many Ephemeroptera taxa; the first threshold occurring at approximately $100 \mathrm{uS} / \mathrm{cm}$, with the second occurring at approximately $400 \mathrm{uS} / \mathrm{cm}$.

These findings add to a growing body of literature documenting landscape conditions that produce threshold changes in aquatic systems. Numerous studies have observed thresholds associated with urbanization (Ourso and Frenzel 2003; Roy et al. 2003; Morse et al. 2004; King et al. 2005). For example, King et al. (2005) identified a threshold where greater than approximately 20-30\% development within the surrounding watershed resulted in a sharp change in macroinvertebrate community structure. Roy et al. (2003) observed a threshold of 15-20\% urban land cover beyond which sensitive taxa were removed from the system. Similarly, several studies have observed thresholds associated with \%impervious surface area (Ourso and Frenzel 2003; Morse et al. 2004). 
Studies documenting threshold changes along a mining gradient, however, are rare. The results of this study are similar to those of Pond et al. (2008) who observed a sharp non-linear decline in \%Ephemeroptera in response to specific conductance. Furthermore, Petty et al. (unpublished manuscript) observed multiple threshold levels for the West Virginia Stream Condition Index (WVSCI) in response to a mining index within the Cheat River watershed in north central West Virginia. Three separate thresholds were identified at approximately 2\%, $18 \%$, and $30 \%$ mining, which corresponded to shifts in ecological condition from exceptional to moderate, moderate to impaired, and impaired to highly impaired, respectively. To our knowledge, however, our study is one of the first to identify landscape thresholds associated with the combination of more than one stressor.

\section{Potential Shortcomings}

As a result of the short time scale of this study, it is unknown whether our data accurately represents long term trends of in-stream conditions characteristic of Pigeon Creek. Temporal variability with respect to physical habitat, water chemistry, and biological condition has long been associated with riverine systems (Merovich et al. 2007; McClurg et al. 2007). More specifically, because of the high level of seasonal variation observed in the water chemistry dataset, only data from spring 2008 was used in all statistical analysis. Examination of previous studies in the primary mountaintop mining region of West Virginia indicate that the water chemistry values obtained in spring 2008 are well within normal range of conditions for this region (Merricks et al. 2007; Pond et al. 2008).

Furthermore, landscapes impacted by current mountaintop mining activities are highly dynamic, changing considerably in short periods of time. Therefore, the landscape variables used during this study may not have accurately reflected the landscape at the time of in-stream 
sampling (Pond et al. 2008). However, the mining permits layer obtained from the WVDEP is updated daily and provides up-to-date information regarding not only permitted areas, but also on mining activity at each permitted location. Only sites that were actively or historically mined were included in the mining layer. This provided the most accurate representation of mining, given the outdated imagery available for the region (Pond et al. 2008). Furthermore, two sites were removed from the mining gradient because the accuracy of their landscape data was in question. Although this decreased the sample size of our mining gradient, the removal of these two sites helped ensure an accurate relationship between total percent mining and in-stream variables. Lastly, variables calculated from the 1992 NLCD were updated using the current mining layer, providing landscape information consistent with the mining layer.

Also, it should be noted that parcel density may not be the most accurate measure of development in all systems. The unique pattern of development in Upper Pigeon Creek resulted in a strong correlation between floodplain structures and parcel density. This is because severe regional topography confines development to narrow floodplains, while the surrounding landscape is largely undevelopable. As a result of the lack of developable land, the floodplain tends to be parceled into small plots that are developed with individual structures. Conversely, the surrounding landscape is parceled into a small number of large parcels that contribute relatively little to the total number of parcels within Upper Pigeon Creek. This results in a high consistency between land parcels and the number of associated structures within the floodplain. However, in many highly urbanized or developed systems, development is not confined by topography and occurs throughout the surrounding watershed. In these systems, large plots of land are often divided into smaller parcels that may or may not be developed. Therefore, in many systems, parcel density may not be the most accurate measure of development. As a 
result, background research should be conducted to find an appropriate landscape measure of development.

This study was designed as a watershed-scale analysis of multiple stressors. However, due to feasibility, only one watershed was examined. The use of multiple sites within one watershed raises the issue of study site independence. To the best of our ability, the residential and mining gradients were constructed using sites that were independent of one another. After constraining combined sites based on basin area, five of the eight sites were completely independent of the mining and residential gradients, which helped to ensure independence among each site type. Furthermore, constraining the combined sites helped to ensure that degraded conditions in sites impacted by both mining and residential development were not the result of an accumulation of stressors occurring at spatial scales greater than those along each individual gradient. Lastly, the Mantel tests conducted to identify spatial autocorrelation among site types concluded that spatial location within the study basin accounted for very little of the variation observed in the physical habitat, water chemistry, and macroinvertebrate community structure.

\section{Macroinvertebrates as Indicators of Anthropogenic Disturbances}

The results of this study support the conclusion that macroinvertebrate communities are good indicators of local conditions in systems impacted by anthropogenic stressors (Resh et al. 1996; Rosenberg and Resh 1996; Freund and Petty 2007; Merovich and Petty 2007). However, this study also suggests that some indices may be inaccurate or inappropriate in certain situations. For example, no significant correlation was observed for either \%EPT or \%E along the mining or residential gradients. However, following the removal of the family Baetidae from the $\%$ EPT and $\%$ E calculations, their correlations with mining and parcel density were 
considerably stronger. Furthermore, \%Hydropsychidae exhibited a significant positive relationship with total $\%$ mining. Based on these findings, it appears that $\% \mathrm{E}, \% \mathrm{EPT}$, and multimetric indices that incorporate these metrics (i.e. WVSCI) may underestimate impairment in these systems. This is further evidenced by the observation that the correlations between $m \mathrm{WVSCI}$ and conductivity were not as strong as those for EPT and E richness.

These results are consistent with several studies conducted in mined watersheds. For example, Pond et al. (2008) concluded that WVSCI may be underestimating impairment in sites impacted by mountaintop mining. When comparing WVSCI to a genus-level multimetric index, they found that WVSCI misclassified 18\% of moderately impaired sites (Pond et al. 2008). Furthermore, Garcia-Criado et al. (1999) and Pond et al. (2008) observed high abundances of several tolerant taxa (Baetidae, Nemouridae, Leuctridae, Hydropsychidae) below sites impacted by mining.

In the Cheat River watershed in north-central West Virginia, Freund and Petty (2007) and Merovich and Petty (2007) found WVSCI to be highly responsive to a range of AMD stressor levels. This suggests that the stressors associated with mining-related discharge (DeNicola and Stapleton 2002; Maret et al. 2003; Clements 2004) in streams located in north-central West Virginia (Freund and Petty 2007; Merovich and Petty 2007) affect macroinvertebrate communities in a much different way than the stressors associated with mountaintop mining in the southern coalfields of West Virginia. Therefore, the community metrics used in each of these systems must be strongly considered before a decision is made regarding the level of impairment. Invertebrate metrics that clearly identify impairment to AMD related stressors may not provide accurate results in the southern coalfields of West Virginia. 


\section{Management Implications}

The overriding goal of this study was to determine the combined effects of mining and residential development on in-stream conditions in hopes of aiding in the development of sound mitigation and restoration plans. This study offered several important conclusions that help in the attainment of this goal. First, the results of this study suggest that the landscape measures used in this study are good indicators of in-stream conditions. Therefore, managers can use mapped land use patterns to predict in-stream conditions and identify streams in need of restoration, saving valuable time and resources. Streams targeted for restoration based off landscape modeling, however, should be field validated before restoration actions are undertaken. The importance of field validation was highlighted in this study. Curry Branch, which had the highest CI score of all combined sites, was characterized by in-stream chemical and biological conditions that did not reflect the surrounding land use. The relationship between land cover and in-stream conditions, however, remained consistent for the remaining study sites.

Second, this study offered insight into the attributes of these systems where restoration will be most beneficial. For example, in systems impacted solely by mining practices, decreasing the specific conductance and dissolved ion concentrations will most likely result in the greatest restoration benefit in this region. However, as pointed out by several authors (Hartman et al. 2005; Merricks et al. 2007; Pond et al. 2008), more research is needed to determine the direct impacts of ionic strength versus individual constituents and metals in these systems. This study further suggests that enhancing habitat quality in streams directly impacted by mountaintop mining would not result in a significant increase in ecological condition. Conversely, systems impacted by residential development would benefit from restoring both water chemistry and physical habitat toward natural conditions. Reducing both high 
conductivities and potential organic pollution would undoubtedly enhance the ecological conditions in developed systems. Furthermore, increasing structural complexity and decreasing the amount of sand and fine substrates will help prevent the proliferation of tolerant taxa.

Most importantly, restoration in systems impacted by a combination of mining and residential development will not be effective unless the impacts of both stressors are addressed. However, because the individual effects of residential development appear to be the limiting factor in determining degradation, restoration actions aimed at alleviating these impacts may be, at least initially, the most beneficial. Furthermore, such actions will need to be conducted at the watershed scale if restoration is to be successful. This becomes evident when considering the pervasiveness of both mining and residential development throughout the study area and the highly degraded conditions within the large combined sites.

However, we were unable to discern whether poor conditions within the large combined sites were purely the result of an accumulation of stressors originating from streams similar to those along the mining and residential gradients. Numerous deep mines are known to exist within the study area, and several smaller tributaries draining deep mines were observed to have conductivities exceeding those along both the mining and residential gradients (personal observation). Collectively, such tributaries drain a relatively small proportion of the study basin. However, small streams draining deep mines could be contributing a disproportionate amount to the high conductivities and poor ecological conditions observed along the Pigeon Creek mainstem. Although this issue was beyond the scope of the current study, future research will be necessary to identify the importance of current and historic deep mining activities in determining ecological degradation in highly impaired systems within the coal fields of southern West Virginia. Such research could have huge implications regarding future restoration activities. 
Furthermore, a comparison of the impacts associated with large scale surface mining and deep mining within southern West Virginia may help direct future mining policy and permit issuing. Lastly, the identification of several critical thresholds for community degradation along both the mining and residential gradients will aid in the development of restoration goals. These thresholds offer a standard to which restoration goals and efforts must meet for restoration to be successful. For example, along the residential gradient, a threshold of approximately 15 parcels $/ \mathrm{km}^{2}$ was observed for several community metrics along the residential gradient, with several lesser thresholds also being identified (approximately six and 1parcels $/ \mathrm{km}^{2}$ ). Therefore, restoration actions in these systems should be targeted to restore conditions to those found in systems with at least 15 parcels $/ \mathrm{km}^{2}$. More importantly, however, the combination of accurate landscape modeling and the known thresholds for ecological condition can help managers identify if a proposed mining or development plan will result in an objectionable drop in ecological condition. Therefore, managers will be able to better predict the impacts of future mining and residential development. 


\section{Literature Cited}

Allan, J. D. 2004. Landscapes and riverscapes: The influence of land use on stream ecosystems. Annual Review of Ecology, Evolution, and Systematics 35:257-284.

Barbour, M. T., J. Gerritsen, B. D. Snyder, and J. B. Stribling. 1999. Rapid bioassessment protocols for use in streams and wadeable rivers: periphyton, benthic macroinvertebrates, and fish. $2^{\text {nd }}$ Edition. EPA 841-B-99-002. Office of Water, US Environmental Protection Agency, Washington, D.C.

Bopp, J. A. 2002. Combined effects of water chemistry, canopy cover, and stream size on benthic macroinvertebrates along a Central Appalachian stream continuum. Master's Thesis, West Virginia University.

Bruns, D. A. 2005. Macroinvertebrate response to land cover, habitat, and water chemistry in a mining-impacted river ecosystem: A GIS watershed analysis. Aquatic Sciences 67:403423.

Carlisle, D. M., J. Falcone, and M. R. Meador. 2009. Predicting the biological condition of streams: use of geospatial indicators of natural and anthropogenic characteristics of watersheds. Environmental Monitoring and Assessment 151: 143-160. 
Clements, W. H. 2004. Small-scale experiments support causal relationships between metal concentration and macroinvertebrate community responses. Ecological Applications 14:954-967.

Clements, W. H, D. M. Carlisle, J. M. Lazorchak, and P. C. Johnson. 2000. Heavy metals structure benthic communities in Colorado mountain streams. Ecological Applications 10:626-638.

Crain, M. C., K. Kroeker, B. S. Halpern. 2008. Interactive and cumulative effects of multiple human stressors in marine systems. Ecology Letters 11:1304-1315.

Cuffney, T. F., M. R. Meador, S. D. Porter, M. E. Gurtz. 2000. Responses of physical, chemical, and biological indicators of water quality to a gradient of agricultural land use in the Yakima River Basin, Washington. Environmental Monitoring and Assessment 64(1):259-270 .

DeNicola, D. M. and M. G. Stapleton. 2002. Impact of acid mine drainage on benthic communities in streams: the relative roles of substratum vs. aqueous effects. Environmental Pollution 119:303-315.

EPA. 1991. Methods for the determination of metals in environmental samples. EPA 600-91010. United States Environmental Protection Agency Office of Research and Development, Washington DC, 20460. 
Erdman, C. and J. W. Emerson. 2008. bcp: A Package for Performing a Bayesian Analysis of Change Point Problems. R package version 2.1.

Fitzpatrick, A. F., M. A. Harris, T. L. Arnold, K. D. Richards. 2004. Urbanization influences on aquatic communities in northeastern Illinois streams. Journal of the American Water Resources Association 40(2):461-475.

Folt, C. L., C. Y. Chen, M. V. Moore, and J. Burnaford. 1999. Synergism and antagonism among multiple stressors. Limnology and Oceanography 44:864-877.

Freund, J. G. and J. T. Petty. 2007. Response of fish and macroinvertebrate bioassessment indices to water chemistry in a mined Appalachian watershed. Environmental Management 39:707-720.

Friendly, M. and J. Fox. 2008. candisc: Generalized Canonical Discriminant Analysis. R package version $0.5-13$.

Fulk, F., B. Autrey, J. Hutchens, J. Gerritsen, J. Burton, C. Cresswell, and B. Jessup. 2003. Ecological assessment of streams in the coal mining region of West Virginia using data collected by the U.S. EPA and environmental consulting firms. National Exposure Research Laboratory, US Environmental Protection Agency, Cincinnati, Ohio. 
Garcia-Criado, F., A. Tome, F. J. Vega, and C. Antolin. 1999. Performance of some diversity and biotic indices in rivers affected by coal mining in northwestern Spain. Hydrobiologia 394:209-217.

Gerritsen, J., J. Burton, and M. T. Barbour. 2000. A stream condition index for West Virginia wadeable streams. Tetra Tech, Inc., Owings Mills, Maryland. (Available from: http://www.wvdep.org/Docs/536_WV-Index.pdf)

Goslee, S.C. and D.L. Urban. 2007. The ecodist package for dissimilarity-based analysis of ecological data. Journal of Statistical Software 22(7):1-19

Hair, J. F., Jr., R. E. Anderson, R. L. Tatham, and W. C. Black. 1995. Multivariate data analysis with readings, 4th edition. Prentice Hall, Upper Saddle River, NJ.

Hartman, K. J., J.D. Kaller, J. W. Howell, and J. A. Sweka. 2005. How much do valley fills influence headwater streams? Hydrobiologia 532:91-102.

Kaufmann et al., 1999. Quantifying Physical Habitat in Wadable Streams. EPA/620/R-99/003. U.S. Environmental Protection Agency, Washington, D.C.

Kennedy, A. J., D. S. Cherry, R. J. Currie. 1999. Field and laboratory assessment of a coal processing effluent in the Leading Creek watershed, Meigs County, Ohio. Archives of Environmental Contamination and Toxicology 44:324-331. 
King, R. S., M. E. Baker, D. F. Whigham, D. E. Weller, T. E. Jordan, P. F. Kazyak, and M. K. Hurd. 2005. Spatial considerations for linking watershed land cover to ecological indicators in streams. Ecological Applications 15(1):137-153.

Marchetti, G. M. and Drton, M. 2006. ggm: Graphical Guassian Models. R package version 1.0.2.

Maret, T. R. and D. E. MacCoy. 2002. Fish assemblages and environmental variables associated with hard-rock mining in the Coeur d'Alene River basin, Idaho. Transactions of the American Fisheries Society 131:865-884.

Maret, T. R., D. J. Cain, D. E. MacCoy, T. M. Short. 2003. Response of benthic invertebrate assemblages to metal exposure and bioaccumulation associated with hard-rock mining in northwestern streams, USA. Journal of the North American Benthological Society 22:598-620.

McClurg S. E., J. T. Petty, P. M. Mazik, and J. L. Clayton. 2007. Stream ecosystem response to limestone treatment in acid impacted watersheds of the Allegheny Plateau. Ecological Applications 17(4):1087-1104.

McCune, B. and J.B. Grace. 2002. Analysis of Ecological Communities. MjM Software Design, Gleneden Beach, Oregon. 
Merovich, G. T., J. M. Stiles, J. T. Petty, P. F. Ziemkiewicz, and J. B. Fulton. 2007. Water chemistry-based classification of streams and implications for restoring mined Appalachian watersheds. Environmental Toxicology and Chemistry 26(7): 1361-1369.

Merovich, G. T. and J. T. Petty. 2007. Interactive effects of multiple stressors and restoration priorities in a mined Appalachian watershed. Hydrobiologia 575:13-31.

Merricks, T. C, D. S. Cherry, C. E. Zipper, R. J. Currie, T. W. Valenti. 2007. Coal-mine hollow fill and settling pond influences on headwater streams in southern West Virginia, USA. Environmental Monitoring and Assessment 129:359-378.

Merritt, R. W., and K. W. Cummins. 1996. An introduction to the aquatic insects of North America, Third edition. Kendall/Hunt Publishing Co., Dubuque, IA.

Meyer, J. L., J. P. Michael, and W. K. Taulbee. 2005. Stream ecosystem function in urbanizing landscapes. Journal of the North American Benthological Society 24(3):602-612.

Morse, C. C., A. D. Huryn, and C. Cronan. 2004. Impervious surface area as a predictor of the effects of urbanization on stream insect communities in Maine, U.S.A. Environmental Monitoring and Assessment 89(1):95-127. 
Oksanen, J., R. Kindt, P. Legendre, B. O’Hara, G. L. Simpson, P. Solymos, H. Henry, H. Stevens, and H. Wagner. 2008. vegan: Community Ecology Package. R package version $1.15-0$.

Ourso, R. T. and S. A. Frenzel. 2003. Identification of linear and threshold responses in streams along a gradient of urbanization in Anchorage, Alaska. Hydrobiologia 501:117-131.

Paul, M. J. and J. L. Meyer. 2001. Streams in the urban landscape. Annual Review of Ecology and Systematics 32:333-365.

Peckarsky, B. L., P. R. Fraissinet, M. A. Penton, and J. Conklin, D. J. 1990. Freshwater macroinvertebrates of Northeastern North America. Cornell University Press, Ithaca.

Petty, J. T. and J. Barker. 2004. Water quality variability in tributaries of the Cheat River, a mined Appalachian watershed, 2004 National Meeting of the American Society of Mining and Reclamation and the $25^{\text {th }}$ West Virginia Surface Mine Drainage Task Force. American Society of Mining and Reclamation, Morgantown, WV, 1484-1504.

Petty, J. T., J. Freund, P. Lamothe, P. Mazik. 2001. Quantifying instream habitat in the upper Shavers Fork basin at multiple spatial scales. Proceedings of the Annual Conference of the Southeastern Association of Fish and Wildlife Agencies 55:81-94. 
Pond, G. J. 2004. Effects of surface mining and residential land use on headwater stream biotic integrity in the eastern Kentucky coalfield region. Kentucky Department of Environmental Protection, Division of Water, Frankfort, Kentucky. (Available from: http://www.water.ky.gov/NR/rdonlyres/ED76CE4E-F46A-4509-8937-1A5DA40F3838 /0/coal_mining1.pdf and http://www.water.ky.gov/NR/rdonlyres/ ED76CE4E-F46A4509-8937-1A5DA40F3838/0/coal_mining2.pdf)

Pond. G. J., M. E. Passmore, F. A. Borsuk, L. Reynolds, and C. J. Rose. 2008. Downstream effects of mountaintop coal mining: comparing biological conditions using family- and genus-level macroinvertebrate bioassessment tools. Journal of the North American Benthological Society 27(3):717-737.

Porter, J. W., S. K. Lewis, and K. G. Porter. 1999. The effect of multiple stressors on the Florida Keys coral reef ecosystem: A landscape hypothesis and physiological test. Limnology and Oceanography 44(3):941-949.

Resh, V. H., M. J. Meyers, and M. J. Hannaford. 1996. Macroinvertebrates as biotic indicators of environmental quality. In Hauer, F. R. and G. A. Lamberti (eds), Methods in Stream Ecology. Academic Press, San Diego, CA, USA, 647-667.

Richards, C. \& G. Host. 1994. Examining land use influences on stream habitats and macroinvertebrates: a GIS approach. Water Resources Bulletin 30(4): 729-738. 
Roberts, D. W. 2007. labdsv: Ordination and Multivariate Analysis for Ecology. R package version 1.3-1.

Rosenberg, D. M. and V. H. Resh. 1996. Use of aquatic insects in biomonitoring. In Merritt, R. W. and K. W. Cummins (eds), An Introduction to the Aquatic Insects of North America. Kendall/Hunt Publishing Company, Dubuque, IA, 87-97.

Rosgen, D. L. 2001. A practical method of computing stream bank erosion rate. Wildland Hydrology, Inc. Pagosa Springs, CO.

Roy, A. H., A. D. Rosemond, M. J. Paul, D. S. Leigh, and J. B. Wallace. 2003. Stream macroinvertebrate response to catchment urbanization (Georgia, U.S.A). Freshwater Biology 48:329-346.

Strager, M. P., J. T. Petty, J. M. Strager, and J. Barker-Fulton. 2009. A spatially explicit framework for quantifying downstream hydrologic conditions. Journal of Environmental Management 90:1854-1861.

Strayer, D. L., R. E. Beighley, L. C. Thompson, S. Brooks, C. Nilsson, G. Pinay, R. J. Naiman. 2003. Effects of land cover on stream ecosystems: roels of empirical models and scaling issues. Ecosystems 6:407-423. 
Sudduth, E. B. and J. L. Meyer. 2006. Effects of bioengineered streambank stabilization on bank habitat and macroinvertebrates in urban streams. Environmental Management 38(2):218-226.

Tate, C. M., Cuffney, T. F., G. McMahon, E. M. P. Giddings, J. F. Coles, and H. Zappia. 2005. Use of an urban intensity index to assess urban effects on streams in three contrasting environmental settings. American Fisheries Society Symposium 47:291-315.

Thogmartin, E. W, A. L. Gallant, M. G. Knutson, T. J. Fox, and M. J. Suarez. 2004.

Commentary: A cautionary tale regarding use of the National Land Cover Dataset 1992. Wildlife Society Bulletin 32:970-978.

USACE (United States Army Corps of Engineers, Norfolk Division) and VADEQ (Virginia Department of Environmental Quality). 2007. Unified stream methodology for use in Virginia. (Available from: http://www.nao.usace.army.mil/technical\%20services/ Regulatory\%20branch/USM/USM_Final_Draft.pdf)

Wang, L. and P. Kanehl 2003. Influences of watershed urbanization and instream habitat on macroinvertebrates in cold water streams. Journal of the American Water Resources Association 39(5):1181-1196. 
Van Sickle, J. 1998. Documentation for MEANSIM, Version 6.0. Western Ecology Division, ESEPA-NHEERL, Corvallis, Oregon (Available from: http://www.epa.gov/wed/pages/ models/dendro/meansim6.htm)

Van Sickle, J. 2003. Analyzing correlations between stream and watershed attributes. Journal of the American Water Resources Association 39(3):717-726.

Van Sickle, J. and R. M. Hughes. 2000. Classification strengths of ecoregions, catchments and geographic clusters for aquatic vertebrates in Oregon. Journal of the North American Benthological Society 19(3):370-384.

Vitousek, P. M. 1994. Beyond global warming: Ecology and global change. Ecology 75(7):1861-1876.

Voelz, N. J. 2005. The effects of urban areas on benthic macroinvertebrates in two Colorado plains rivers. Environmental Monitoring and Assessment 101:175-202.

WVDEP. 1996. An ecological Assessment of the Cheat River Watershed. Report Number 0502004-1996. West Virginia Division of Environmental Protection Charleston, WV.

WVDEP. 2003. Benthic invertebrate sampling, processing, and analysis standard operating procedures. West Virginia Division of Environmental Protection. 
Table 1: Geographic coordinates (expressed in decimal degrees), site type, basin area (BA), gradient, and level of mining and parcel density for each study site. Site types include: R=reference, $\mathrm{M}=$ mined, $\mathrm{D}=$ developed, $\mathrm{CS}=$ combined small, and $\mathrm{CL}=$ combined large.

\begin{tabular}{|c|c|c|c|c|c|c|c|}
\hline Site & Latitude & Longitude & Type & $\mathrm{BA}\left(\mathrm{km}^{2}\right)$ & Gradient $(\%)$ & $\%$ Mining & Parcel Density $\left(\# / \mathrm{km}^{2}\right)$ \\
\hline UNT Hell Cr & 37.73370 & -82.22839 & $\mathrm{R}$ & 0.80 & 2.50 & 0.00 & 1.25 \\
\hline Conley Br & 37.75463 & -82.23496 & $\mathrm{R}$ & 0.98 & 2.30 & 0.00 & 6.13 \\
\hline MF Elk Cr HW1 & 37.71807 & -82.10173 & M & 0.84 & 6.00 & 59.46 & 3.56 \\
\hline MF Elk Cr HW2 & 37.71452 & -82.09896 & M & 0.91 & 3.75 & 73.84 & 1.10 \\
\hline UNT Big Muncy Br & 37.64025 & -82.03339 & M & 0.98 & 3.30 & 29.44 & 1.02 \\
\hline LF Elk Cr HW3 & 37.74125 & -82.10713 & M & 1.09 & 2.60 & 14.59 & 0.92 \\
\hline Ashcamp Hollow & 37.68964 & -82.06154 & M & 1.39 & 6.00 & 60.72 & 2.15 \\
\hline MF Elk Cr HW3 & 37.71428 & -82.09930 & M & 1.55 & 2.30 & 26.18 & 1.94 \\
\hline LF Elk Cr HW2 & 37.73223 & -82.11040 & M & 2.12 & 3.50 & 56.87 & 1.41 \\
\hline LF Elk Cr HW1 & 37.73227 & -82.11068 & M & 2.85 & 2.67 & 32.53 & 1.05 \\
\hline Spring Br & 37.68810 & -82.09171 & M & 3.76 & 2.00 & 59.11 & 2.13 \\
\hline Rockhouse $\mathrm{Cr} 4$ & 37.68979 & -82.06117 & M & 6.55 & 1.00 & 47.70 & 5.50 \\
\hline LF Elk Cr & 37.73027 & -82.13232 & $\mathrm{M}$ & 8.22 & 0.50 & 32.59 & 5.35 \\
\hline Billy Curry Br & 37.73796 & -82.17216 & $\mathrm{D}$ & 0.87 & 3.00 & 0.00 & 44.58 \\
\hline Caney Br & 37.75981 & -82.21418 & $\mathrm{D}$ & 1.88 & 5.67 & 0.00 & 14.36 \\
\hline Stone Coal Br & 37.70265 & -82.18616 & $\mathrm{D}$ & 2.92 & 1.50 & 0.00 & 85.87 \\
\hline Pigeon Roost $\mathrm{Cr}$ & 37.72112 & -82.19350 & $\mathrm{D}$ & 3.30 & 1.75 & 0.00 & 43.60 \\
\hline Millstone $\mathrm{Br}$ & 37.72861 & -82.18741 & $\mathrm{D}$ & 3.43 & 2.00 & 0.53 & 14.30 \\
\hline Pigeon $\mathrm{Cr} 8$ & 37.64383 & -82.00616 & $\mathrm{D}$ & 3.72 & 2.25 & 3.48 & 11.30 \\
\hline Hell Cr 2 & 37.73661 & -82.21521 & $\mathrm{D}$ & 4.84 & 2.75 & 0.00 & 8.27 \\
\hline Hell Cr 1 & 37.74278 & -82.21559 & $\mathrm{D}$ & 8.98 & 1.17 & 0.00 & 16.58 \\
\hline LF Oldfield Br & 37.67531 & -82.11005 & CS & 0.99 & 4.00 & 58.78 & 9.07 \\
\hline UNT Rockhouse Cr & 37.69799 & -82.07196 & CS & 1.25 & 6.00 & 39.25 & 14.42 \\
\hline Curry Br & 37.70045 & -82.15173 & CS & 1.33 & 1.75 & 47.08 & 56.21 \\
\hline RF Oldfield Br & 37.67476 & -82.10995 & CS & 1.43 & 2.00 & 32.62 & 18.86 \\
\hline Big Muncy Br & 37.64302 & -82.03341 & CS & 4.44 & 2.50 & 9.61 & 40.75 \\
\hline Fivemile $\mathrm{Cr}$ & 37.73970 & -82.14667 & $\mathrm{CS}$ & 4.51 & 1.83 & 20.58 & 17.97 \\
\hline MF Elk Cr & 37.72987 & -82.13375 & CS & 7.35 & 1.00 & 24.18 & 32.54 \\
\hline Pigeon $\mathrm{Cr} 7$ & 37.65256 & -82.02809 & $\mathrm{CS}$ & 10.09 & 1.67 & 8.90 & 24.28 \\
\hline Elk Cr 3 & 37.73429 & -82.14214 & CL & 19.03 & 1.00 & 23.53 & 17.34 \\
\hline Rockhouse Cr 3 & 37.69148 & -82.10297 & CL & 20.87 & 1.00 & 41.05 & 23.48 \\
\hline Elk Cr 2 & 37.73397 & -82.15679 & CL & 25.78 & 1.00 & 21.05 & 19.35 \\
\hline Elk Cr 1 & 37.73361 & -82.18985 & CL & 31.93 & 0.67 & 17.05 & 27.28 \\
\hline Pigeon Cr 6 & 37.65683 & -82.09528 & CL & 32.65 & 1.33 & 17.56 & 52.71 \\
\hline Rockhouse $\mathrm{Cr} 2$ & 37.70763 & -82.13727 & $\mathrm{CL}$ & 33.24 & 1.25 & 38.16 & 47.36 \\
\hline Rockhouse $\mathrm{Cr} 1$ & 37.71105 & -82.17550 & $\mathrm{CL}$ & 41.77 & 1.38 & 34.21 & 66.71 \\
\hline Pigeon Cr 5 & 37.67691 & -82.17599 & CL & 51.39 & 1.50 & 17.86 & 92.59 \\
\hline Pigeon $\mathrm{Cr} 4$ & 37.70583 & -82.18530 & $\mathrm{CL}$ & 65.67 & 1.00 & 17.20 & 92.36 \\
\hline Pigeon Cr 3 & 37.74188 & -82.19684 & CL & 151.92 & 1.00 & 20.50 & 72.35 \\
\hline Pigeon Cr 2 & 37.74980 & -82.22135 & $\mathrm{CL}$ & 165.41 & 1.00 & 19.16 & 71.64 \\
\hline Pigeon Cr 1 & 37.76449 & -82.23473 & $\mathrm{CL}$ & 173.29 & 1.00 & 18.29 & 70.36 \\
\hline
\end{tabular}


Table 2: Results from principal components analysis on land cover data. Each "PC" represents a principal component, or composite variable. Values represent variables that load significantly onto a given PC (loadings $\geq|0.4|$ ). \% Var Exp=\% of the variance in the overall dataset explained by each PC, $\mathrm{OM}=$ Other Mines, $\mathrm{VF}=$ Valley Fills, DM=Deep Mines, $\mathrm{AML}=\mathrm{Abandoned}$ Mine Lands, and TM=Total Mining.

\begin{tabular}{lcc}
\hline & PC1 & PC2 \\
\hline Eigenvalue & 3.35 & 2.67 \\
\% Var Exp & 37 & 30 \\
\%OM & 0.54 & $\cdot$ \\
\%VF & 0.71 & -0.55 \\
\%DM & 0.71 & -0.43 \\
\%AML & 0.63 &. \\
\%TM & 0.41 & -0.69 \\
Parcel Density & 0.45 & 0.80 \\
\% Residential & 0.68 & 0.66 \\
\% Agriculture & 0.51 & 0.60 \\
\% Forest & -0.74 &. \\
\hline
\end{tabular}


Table 3: Combined Index (CI) values for all 41 study sites. Basin area (BA) in acres, cumulative mining density (CMD), cumulative parcel density (CPD), and combined index (CI) score are given for each site.

\begin{tabular}{|c|c|c|c|c|c|}
\hline Site & Type & $\mathrm{BA}\left(\mathrm{km}^{2}\right)$ & CMD & CPD & $\mathrm{CI}$ \\
\hline UNT Hell Cr & $\mathrm{R}$ & 0.80 & 0.00 & 0.01 & 0 \\
\hline Conley $\mathrm{Br}$ & $\mathrm{R}$ & 0.98 & 0.00 & 0.02 & 2 \\
\hline LF Elk Cr HW3 & $\mathrm{M}$ & 1.09 & 0.15 & 0.00 & 8 \\
\hline MF Elk Cr HW3 & $\mathrm{M}$ & 1.55 & 0.26 & 0.01 & 15 \\
\hline UNT Big Muncy Br & M & 0.98 & 0.29 & 0.00 & 16 \\
\hline LF Elk Cr HW1 & M & 2.85 & 0.33 & 0.00 & 18 \\
\hline LF Elk Cr & M & 8.22 & 0.33 & 0.02 & 20 \\
\hline Rockhouse Cr 4 & M & 6.55 & 0.48 & 0.02 & 28 \\
\hline LF Elk Cr HW2 & M & 2.12 & 0.57 & 0.01 & 31 \\
\hline Spring $\mathrm{Br}$ & $\mathrm{M}$ & 3.76 & 0.59 & 0.01 & 33 \\
\hline MF Elk Cr HW1 & $\mathrm{M}$ & 0.84 & 0.59 & 0.01 & 33 \\
\hline Ashcamp Hollow & $\mathrm{M}$ & 1.39 & 0.61 & 0.01 & 34 \\
\hline MF Elk Cr HW2 & $\mathrm{M}$ & 0.91 & 0.74 & 0.00 & 40 \\
\hline Hell Cr 1 & $\mathrm{D}$ & 4.84 & 0.00 & 0.03 & 3 \\
\hline Caney Br & $\mathrm{D}$ & 1.88 & 0.00 & 0.06 & 6 \\
\hline Millstone $\mathrm{Cr}$ & $\mathrm{D}$ & 3.43 & 0.01 & 0.06 & 6 \\
\hline Pigeon $\mathrm{Cr} 8$ & $\mathrm{D}$ & 3.72 & 0.03 & 0.05 & 6 \\
\hline Hell Cr 2 & $\mathrm{D}$ & 8.98 & 0.00 & 0.07 & 7 \\
\hline Pigeon Roost $\mathrm{Cr}$ & $\mathrm{D}$ & 3.30 & 0.00 & 0.18 & 17 \\
\hline Billy Curry Br & $\mathrm{D}$ & 0.87 & 0.00 & 0.18 & 18 \\
\hline Stone Coal Br & $\mathrm{D}$ & 2.92 & 0.00 & 0.35 & 34 \\
\hline Pigeon $\mathrm{Cr} 7$ & $\mathrm{CS}$ & 10.09 & 0.09 & 0.10 & 14 \\
\hline Fivemile $\mathrm{Cr}$ & $\mathrm{CS}$ & 4.51 & 0.21 & 0.07 & 18 \\
\hline Big Muncy Br & $\mathrm{CS}$ & 4.44 & 0.10 & 0.16 & 21 \\
\hline RF Oldfield Br & $\mathrm{CS}$ & 1.43 & 0.33 & 0.08 & 25 \\
\hline MF Elk Cr & $\mathrm{CS}$ & 7.35 & 0.24 & 0.13 & 26 \\
\hline UNT Rockhouse Cr & $\mathrm{CS}$ & 1.25 & 0.39 & 0.06 & 27 \\
\hline LF Oldfield Br & $\mathrm{CS}$ & 0.99 & 0.59 & 0.04 & 35 \\
\hline Curry Br & $\mathrm{CS}$ & 1.33 & 0.47 & 0.23 & 48 \\
\hline Elk Cr 2 & $\mathrm{CL}$ & 25.78 & 0.21 & 0.08 & 19 \\
\hline Elk Cr 3 & $\mathrm{CL}$ & 19.02 & 0.24 & 0.07 & 20 \\
\hline Elk Cr 1 & CL & 31.92 & 0.17 & 0.11 & 20 \\
\hline Pigeon Cr 6 & CL & 32.64 & 0.18 & 0.21 & 30 \\
\hline Rockhouse Cr 3 & $\mathrm{CL}$ & 20.86 & 0.41 & 0.10 & 31 \\
\hline Pigeon Cr 1 & $\mathrm{CL}$ & 173.26 & 0.18 & 0.28 & 38 \\
\hline Pigeon $\mathrm{Cr} 2$ & CL & 165.38 & 0.19 & 0.29 & 39 \\
\hline Rockhouse Cr 2 & CL & 33.23 & 0.38 & 0.19 & 39 \\
\hline Pigeon $\mathrm{Cr} 3$ & $\mathrm{CL}$ & 151.89 & 0.21 & 0.29 & 40 \\
\hline Rockhouse Cr 1 & CL & 41.76 & 0.34 & 0.27 & 45 \\
\hline Pigeon $\mathrm{Cr} 4$ & $\mathrm{CL}$ & 65.66 & 0.17 & 0.37 & 46 \\
\hline Pigeon $\mathrm{Cr} 5$ & $\mathrm{CL}$ & 51.38 & 0.18 & 0.37 & 46 \\
\hline
\end{tabular}


Table 4: Results from principal components analysis on physical habitat data. Each "PC" represents a principal component, or composite variable. Values represent variables that load significantly onto a given PC (loadings $\geq|0.4|$ ). \% Var Exp=\% of the variance in the overall dataset explained by each PC. $\mathrm{LWD}=$ large woody debris, $\mathrm{RF}=$ retentive features, $\mathrm{MSW}=$ mean stream width, $\mathrm{DRF}=$ distance to retentive feature, DFC=distance to fish cover, BEHI=Bank Erosion Hazard Index, USM=Unified Stream Method, RVHA=Rapid Visual Habitat Assessment, $\mathrm{CV}=$ coefficient of variation.

\begin{tabular}{|c|c|c|c|c|c|}
\hline & PC1 & PC2 & PC3 & $\mathrm{PC} 4$ & PC5 \\
\hline Eigenvalue & 5.18 & 4.63 & 1.77 & 1.59 & 1.04 \\
\hline$\%$ Var Exp & 29 & 26 & 10 & 9 & 6 \\
\hline MSW & -0.89 & . & . & . & . \\
\hline Gradient & 0.77 & . & . & . & . \\
\hline Mean Depth & -0.85 & . & . & . & . \\
\hline CV Depth & 0.53 & . & . & -0.45 & . \\
\hline \#LWD/m & 0.47 & 0.69 & . & . & . \\
\hline \#RF/m & . & 0.84 & . & . & . \\
\hline DRF/MSW & . & -0.80 & . & . & . \\
\hline DFC/MSW & 0.73 & -0.56 & . & . & . \\
\hline Retentiveness & 0.45 & 0.72 & . & . & . \\
\hline$\%$ RVHA & . & 0.68 & . & 0.50 & . \\
\hline USM & 0.59 & 0.62 & . & . & . \\
\hline BEHI & . & . & 0.77 & . & . \\
\hline$\%$ Clay/Silt & . & 0.45 & . & -0.58 & -0.52 \\
\hline$\%$ Sand & -0.55 & 0.60 & . & . & . \\
\hline$\%$ Gravel & . & . & 0.70 & . & . \\
\hline$\%$ Cobble & 0.57 & . & . & 0.52 & . \\
\hline$\%$ Boulder & 0.66 & -0.40 & . & . & . \\
\hline$\%$ Bedrock & . & . & -0.72 & . & 0.52 \\
\hline
\end{tabular}


Table 5: Results from principal components analysis on water quality data from spring 2008. Each "PC" represents a principal component, or composite variable. Values represent variables that load significantly onto a given PC (loadings $\geq|0.4|)$. \% Var Exp $=\%$ of the variance in the overall dataset explained by each $\mathrm{PC}$. $\mathrm{DO}=$ dissolved oxygen, $\mathrm{TP}=$ total phosphorus, and all elements and compounds are listed using their chemical abbreviations and formulas (e.g. $\mathrm{Al}=\mathrm{Aluminum}$ and $\mathrm{SO}_{4}=$ Sulfate).

\begin{tabular}{|c|c|c|c|c|c|c|}
\hline & $\mathrm{PC} 1$ & $\mathrm{PC} 2$ & PC3 & PC4 & PC5 & PC6 \\
\hline Eigenvalue & 7.65 & 5.25 & 2.46 & 1.44 & 1.29 & 1.09 \\
\hline$\%$ Var Exp & 32 & 22 & 10 & 6 & 5 & 5 \\
\hline Alkalinity & 0.92 & . & . & . & . & . \\
\hline Acidity & -0.65 & . & . & . & . & . \\
\hline $\mathrm{pH}$ & . & . & . & 0.46 & 0.58 & . \\
\hline Conductivity & 0.96 & . & . & . & . & . \\
\hline $\mathrm{Al}$ & . & 0.43 & 0.61 & . & . & . \\
\hline $\mathrm{Ba}$ & 0.72 & . & -0.47 & . & . & . \\
\hline $\mathrm{Ca}$ & 0.90 & . & . & . & . & . \\
\hline $\mathrm{Cl}$ & 0.57 & . & . & . & 0.53 & . \\
\hline $\mathrm{Co}$ & . & 0.88 & . & . & . & . \\
\hline $\mathrm{Cr}$ & . & 0.82 & -0.45 & . & . & . \\
\hline $\mathrm{Cu}$ & . & 0.95 & . & . & . & . \\
\hline $\mathrm{Fe}$ & 0.46 & 0.58 & 0.56 & . & . & . \\
\hline $\mathrm{Mg}$ & 0.87 & . & . & . & . & . \\
\hline $\mathrm{Mn}$ & . & 0.62 & . & . & . & . \\
\hline $\mathrm{Na}$ & 0.90 & . & . & . & . & . \\
\hline $\mathrm{Ni}$ & . & 0.91 & . & . & . & . \\
\hline $\mathrm{Se}$ & . & . & . & -0.67 & 0.46 & . \\
\hline $\mathrm{Zn}$ & . & 0.74 & . & . & . & . \\
\hline $\mathrm{SO} 4$ & 0.90 & . & . & . & . & . \\
\hline $\mathrm{NO} 2$ & 0.44 & . & . & -0.47 & . & 0.44 \\
\hline NO3 & 0.68 & . & . & . & . & . \\
\hline NH3 & . & . & . & 0.42 & . & 0.63 \\
\hline $\mathrm{TP}$ & . & 0.43 & 0.46 & . & . & . \\
\hline
\end{tabular}


Table 6: Correlations between physical habitat variables and \% mining, parcel density, and CI score for the mining gradient, residential gradient, and large and small combined sites, respectively. Correlation coefficients (r) and $p$-values are displayed. Bolded values are significant at $\alpha=0.05$. $\mathrm{LWD}=$ large woody debris, $\mathrm{RF}=$ retentive features, $\mathrm{MSW}=$ mean stream width, $\mathrm{DRF}=$ distance to retentive feature, $\mathrm{DFC}=$ distance to fish cover, BEHI=Bank Erosion Hazard Index, USM=Unified Stream Method, RVHA=Rapid Visual Habitat Assessment, CV=coefficient of variation.

\begin{tabular}{lllllllll}
\hline & \multicolumn{2}{l}{ Residential Gradient } & \multicolumn{2}{c}{ Mining Gradient } & \multicolumn{2}{c}{ Small Combined } & \multicolumn{2}{c}{ Large Combined } \\
& $\mathrm{r}$ & $\mathrm{p}$-value & $\mathrm{r}$ & $\mathrm{p}$-value & $\mathrm{r}$ & $\mathrm{p}$-value & $\mathrm{r}$ & $\mathrm{p}$-value \\
\hline MSW & -0.15 & 0.687 & 0.36 & 0.225 & $\mathbf{- 0 . 7 5}$ & $\mathbf{0 . 0 3 2}$ & 0.35 & 0.266 \\
Gradient & -0.25 & 0.483 & 0.22 & 0.468 & 0.14 & 0.748 & $\mathbf{0 . 5 8}$ & $\mathbf{0 . 0 5 0}$ \\
Mean Depth & 0.29 & 0.409 & 0.28 & 0.363 & -0.23 & 0.591 & 0.20 & 0.535 \\
CV Depth & $\mathbf{- 0 . 8 1}$ & $\mathbf{0 . 0 0 4}$ & -0.30 & 0.313 & 0.19 & 0.650 & 0.09 & 0.771 \\
LWD/m & $\mathbf{- 0 . 6 6}$ & $\mathbf{0 . 0 3 7}$ & 0.31 & 0.309 & 0.06 & 0.891 & -0.43 & 0.160 \\
RF/m & -0.42 & 0.230 & -0.11 & 0.726 & -0.16 & 0.705 & 0.54 & 0.072 \\
DRF/MSW & 0.47 & 0.171 & -0.08 & 0.798 & 0.43 & 0.291 & -0.56 & 0.059 \\
DFC/MSW & 0.35 & 0.320 & -0.40 & 0.176 & 0.54 & 0.172 & $\mathbf{- 0 . 6 5}$ & $\mathbf{0 . 0 2 1}$ \\
Retentiveness & $\mathbf{- 0 . 6 5}$ & $\mathbf{0 . 0 4 4}$ & -0.07 & 0.832 & 0.26 & 0.534 & 0.57 & 0.055 \\
\%RVHA & $\mathbf{- 0 . 6 3}$ & $\mathbf{0 . 0 5 3}$ & -0.06 & 0.852 & 0.02 & 0.969 & 0.28 & 0.380 \\
USM & -0.59 & 0.070 & 0.01 & 0.981 & -0.12 & 0.783 & -0.35 & 0.261 \\
BEHI & 0.10 & 0.785 & -0.20 & 0.518 & 0.21 & 0.622 & 0.24 & 0.461 \\
\% Clay/Silt & 0.005 & 0.990 & 0.18 & 0.553 & -0.17 & 0.694 & 0.36 & 0.246 \\
\% Sand & -0.59 & 0.071 & 0.29 & 0.339 & -0.70 & 0.052 & 0.08 & 0.799 \\
\% Gravel & 0.09 & 0.807 & 0.49 & 0.087 & -0.62 & 0.100 & 0.24 & 0.451 \\
\% Cobble & 0.02 & 0.957 & -0.36 & 0.229 & 0.41 & 0.314 & 0.26 & 0.406 \\
\% Boulder & 0.22 & 0.546 & -0.46 & 0.115 & $\mathbf{0 . 8 7}$ & $\mathbf{0 . 0 0 5}$ & 0.37 & 0.241 \\
\% Bedrock & -0.39 & 0.267 & $\mathbf{- 0 . 5 6}$ & $\mathbf{0 . 0 4 5}$ & -0.05 & 0.899 & -0.37 & 0.242 \\
\% Canopy & $\mathbf{- 0 . 6 5}$ & $\mathbf{0 . 0 4 2}$ & -0.03 & 0.913 & 0.63 & 0.096 & -0.42 & 0.175 \\
Habitat PC1 & -0.20 & 0.574 & -0.25 & 0.402 & $\mathbf{0 . 7 3}$ & $\mathbf{0 . 0 3 9}$ & 0.11 & 0.742 \\
Habitat PC2 & -0.62 & 0.055 & 0.23 & 0.450 & -0.29 & 0.474 & 0.50 & 0.098 \\
\hline
\end{tabular}


Table 7: Correlations between water quality variables and \% mining, parcel density, and CI score for the mining gradient, residential gradient, and large and small combined sites, respectively. Correlation coefficients $(r)$ and $p$-values are displayed. Bolded values are significant at $\alpha=0.05$. Spaces held by a "." indicate correlations where one variable did not vary among study sites. DO=dissolved oxygen, TP=total phosphorus, and all elements and compounds are listed using their chemical abbreviations and formulas (e.g. Al=Aluminum and $\mathrm{SO}_{4}=\mathrm{Sulfate}_{\text {) }}$.

\begin{tabular}{|c|c|c|c|c|c|c|c|c|}
\hline & \multicolumn{2}{|c|}{ Mining Gradient } & \multicolumn{2}{|c|}{ Residential Gradient } & \multicolumn{2}{|c|}{ Large Combined } & \multicolumn{2}{|c|}{ Small Combined } \\
\hline & $\mathrm{r}$ & p-value & $\mathrm{r}$ & p-value & $\mathrm{r}$ & p-value & $\mathrm{r}$ & p-value \\
\hline Alkalinity & 0.74 & 0.004 & 0.78 & 0.008 & 0.45 & 0.146 & -0.54 & 0.165 \\
\hline Acidity & -0.83 & $<0.001$ & -0.73 & 0.017 & . & . & . & . \\
\hline $\mathrm{pH}$ & -0.16 & 0.604 & 0.61 & 0.061 & 0.63 & 0.028 & 0.09 & 0.833 \\
\hline DO & -0.32 & 0.282 & -0.59 & 0.073 & -0.83 & $<0.001$ & 0.38 & 0.357 \\
\hline Conductivity & 0.91 & $<0.0001$ & 0.69 & $\mathbf{0 . 0 2 3}$ & 0.66 & 0.019 & -0.45 & 0.261 \\
\hline $\mathrm{Al}$ & 0.24 & 0.432 & 0.32 & 0.360 & 0.31 & 0.331 & $<0.0001$ & 1.000 \\
\hline $\mathrm{Ba}$ & 0.68 & 0.010 & 0.27 & 0.451 & -0.39 & 0.210 & -0.68 & 0.064 \\
\hline $\mathrm{Ca}$ & 0.84 & $<0.001$ & 0.56 & 0.092 & 0.83 & $<0.001$ & -0.35 & 0.397 \\
\hline $\mathrm{Cl}$ & 0.40 & 0.176 & 0.13 & 0.717 & 0.53 & 0.074 & -0.20 & 0.633 \\
\hline $\mathrm{Co}$ & -0.01 & 0.970 & -0.28 & 0.434 & 0.18 & 0.568 & 0.44 & 0.270 \\
\hline $\mathrm{Cr}$ & -0.02 & 0.949 & -0.23 & 0.532 & 0.17 & 0.596 & -0.68 & 0.063 \\
\hline $\mathrm{Cu}$ & 0.14 & 0.647 & -0.23 & 0.524 & 0.13 & 0.683 & 0.33 & 0.430 \\
\hline $\mathrm{Fe}$ & 0.30 & 0.319 & $<0.0001$ & 1.000 & 0.24 & 0.448 & $<0.0001$ & 1.000 \\
\hline $\mathrm{Mg}$ & 0.81 & $<0.001$ & 0.52 & 0.126 & 0.85 & $<0.001$ & -0.25 & 0.550 \\
\hline $\mathrm{Mn}$ & 0.44 & 0.131 & $<0.0001$ & 1.000 & 0.13 & 0.689 & $<0.0001$ & 1.000 \\
\hline $\mathrm{Na}$ & 0.79 & 0.002 & 0.43 & 0.216 & 0.22 & 0.498 & -0.68 & 0.061 \\
\hline $\mathrm{Ni}$ & 0.11 & 0.726 & -0.22 & 0.544 & 0.13 & 0.683 & . & . \\
\hline $\mathrm{Se}$ & 0.05 & 0.880 & 0.51 & 0.128 & 0.39 & 0.207 & 0.29 & 0.484 \\
\hline $\mathrm{Zn}$ & 0.33 & 0.275 & 0.26 & 0.464 & 0.03 & 0.933 & -0.01 & 0.982 \\
\hline SO4 & 0.89 & $<0.0001$ & 0.63 & 0.053 & 0.82 & 0.001 & -0.36 & 0.374 \\
\hline NO2 & 0.21 & 0.491 & 0.63 & 0.049 & 0.45 & 0.146 & 0.09 & 0.831 \\
\hline NO3 & 0.55 & 0.051 & 0.44 & 0.207 & 0.77 & 0.004 & 0.39 & 0.339 \\
\hline NH3 & 0.22 & 0.471 & 0.35 & 0.319 & -0.42 & 0.174 & 0.46 & 0.248 \\
\hline
\end{tabular}


Table 7: Continued

\begin{tabular}{lllllllll}
\hline & \multicolumn{2}{l}{ Mining Gradient } & \multicolumn{2}{c}{ Residential Gradient } & \multicolumn{2}{c}{ Large Combined } & \multicolumn{2}{c}{ Small Combined } \\
& $\mathrm{r}$ & $\mathrm{p}$-value & $\mathrm{r}$ & $\mathrm{p}$-value & $\mathrm{r}$ & $\mathrm{p}$-value & $\mathrm{r}$ & $\mathrm{p}$-value \\
\hline TP & 0.28 & 0.354 & 0.58 & 0.078 & 0.28 & 0.386 & -0.38 & 0.348 \\
WQ PC1 & $\mathbf{0 . 9 0}$ & $<\mathbf{0 . 0 0 0 1}$ & $\mathbf{0 . 7 0}$ & $\mathbf{0 . 0 2 4}$ & $\mathbf{0 . 5 9}$ & $\mathbf{0 . 0 4 6}$ & -0.37 & 0.368 \\
WQ PC2 & 0.10 & 0.748 & -0.20 & 0.583 & 0.10 & 0.754 & 0.18 & 0.664 \\
\hline
\end{tabular}


Table 8: Correlations between invertebrate metrics and \% mining, parcel density, and CI score for the mining gradient, residential gradient, and large and small combined sites, respectively. Correlation coefficients $(\mathrm{r})$ and $\mathrm{p}$-values are displayed. Bolded values are significant at $\alpha=0.05$. $m$ WVSCI=modified West Virginia stream condition index, $\mathrm{E}=$ Ephemeroptera, $\mathrm{P}=$ Plecoptera, $\mathrm{T}=$ Trichoptera, and $\mathrm{B}=\mathrm{Baetidae}$. All richness measures were calculated using genus-level identifications.

\begin{tabular}{|c|c|c|c|c|c|c|c|c|}
\hline & \multicolumn{2}{|c|}{ Mining Gradient } & \multicolumn{2}{|c|}{ Residential Gradient } & \multicolumn{2}{|c|}{ Large Combined } & \multicolumn{2}{|c|}{ Small Combined } \\
\hline & $\mathrm{r}$ & $\mathrm{p}$-value & $\mathrm{r}$ & $\mathrm{p}$-value & $\mathrm{r}$ & $\mathrm{p}$-value & $\mathrm{r}$ & p-value \\
\hline$m \mathrm{WVSCI}$ & -0.64 & 0.019 & -0.73 & 0.017 & -0.46 & 0.137 & 0.12 & 0.782 \\
\hline Total Richness & -0.30 & 0.324 & -0.69 & 0.027 & -0.67 & 0.018 & -0.29 & 0.480 \\
\hline EPT Richness & -0.58 & 0.036 & -0.74 & 0.015 & -0.71 & 0.009 & -0.11 & 0.789 \\
\hline E Richness & -0.56 & 0.047 & -0.72 & 0.019 & -0.53 & 0.079 & -0.20 & 0.635 \\
\hline P Richness & -0.32 & 0.282 & -0.41 & 0.235 & -0.73 & 0.007 & -0.62 & 0.102 \\
\hline T Richness & -0.43 & 0.141 & -0.59 & 0.074 & -0.33 & 0.300 & 0.08 & 0.845 \\
\hline Total \# & -0.11 & 0.728 & 0.71 & 0.020 & -0.45 & 0.144 & -0.88 & 0.004 \\
\hline$\%$ EPT & -0.16 & 0.592 & -0.51 & 0.131 & -0.43 & 0.167 & -0.30 & 0.465 \\
\hline$\%$ EPT (no B) & -0.33 & 0.276 & -0.93 & $<0.001$ & -0.54 & 0.069 & 0.82 & 0.013 \\
\hline$\% \mathrm{E}$ & -0.03 & 0.923 & -0.25 & 0.490 & -0.37 & 0.237 & -0.40 & 0.332 \\
\hline$\% \mathrm{E}($ no B $)$ & -0.57 & 0.041 & -0.85 & 0.002 & -0.33 & 0.290 & 0.68 & 0.066 \\
\hline$\%$ Tolerant & 0.44 & 0.131 & 0.64 & 0.046 & 0.28 & 0.376 & 0.01 & 0.986 \\
\hline$\%$ Dominant & 0.58 & 0.036 & 0.75 & 0.012 & 0.32 & 0.309 & -0.14 & 0.739 \\
\hline \%Chironomidae & 0.45 & 0.123 & 0.65 & 0.043 & 0.06 & 0.855 & -0.59 & 0.125 \\
\hline \%Hydropsychidae & 0.57 & 0.043 & -0.15 & 0.669 & -0.43 & 0.158 & 0.57 & 0.142 \\
\hline
\end{tabular}


Table 9: Correlations between physical habitat variables and $m$ WVSCI, EPT richness, E richness, \%E excluding Baetidae (B), and \%dominant along the residential gradient. Correlation coefficients ( $\mathrm{r}$ ) and $\mathrm{p}$-values are displayed. Bolded values are significant at $\alpha=0.05$. LWD=large woody debris, $\mathrm{RF}=$ retentive features, $\mathrm{MSW}=$ mean stream width, $\mathrm{DRF}=$ distance to retentive feature, $\mathrm{DFC}=$ distance to fish cover, $\mathrm{BEHI}=\mathrm{Bank}$ Erosion Hazard Index, USM=Unified Stream Method, RVHA=Rapid Visual Habitat Assessment, CV=coefficient of variation.

\begin{tabular}{|c|c|c|c|c|c|c|c|c|c|c|}
\hline & \multicolumn{2}{|c|}{$m \mathrm{WVSCI}$} & \multicolumn{2}{|c|}{ EPT Richness } & \multicolumn{2}{|c|}{ E Richness } & \multicolumn{2}{|c|}{$\% \mathrm{E}($ no B $)$} & \multicolumn{2}{|c|}{$\%$ Dominant } \\
\hline & $\mathrm{r}$ & $\mathrm{p}$-value & $\mathrm{r}$ & p-value & $\mathrm{r}$ & p-value & $\mathrm{r}$ & $\mathrm{p}$-value & $\mathrm{r}$ & $\mathrm{p}$-value \\
\hline MSW & 0.05 & 0.886 & -0.02 & 0.951 & 0.03 & 0.941 & 0.14 & 0.700 & -0.09 & 0.797 \\
\hline Gradient & 0.36 & 0.314 & 0.40 & 0.253 & 0.22 & 0.536 & 0.39 & 0.261 & 0.13 & 0.731 \\
\hline Mean Depth & -0.57 & 0.083 & -0.39 & 0.272 & -0.22 & 0.537 & -0.34 & 0.342 & 0.20 & 0.586 \\
\hline CV Depth & 0.53 & 0.114 & 0.52 & 0.125 & 0.54 & 0.107 & 0.56 & 0.090 & -0.50 & 0.144 \\
\hline $\mathrm{LWD} / \mathrm{m}$ & 0.53 & 0.119 & 0.44 & 0.200 & 0.42 & 0.230 & 0.45 & 0.194 & -0.42 & 0.223 \\
\hline $\mathrm{RF} / \mathrm{m}$ & 0.69 & 0.028 & 0.40 & 0.253 & 0.24 & 0.497 & 0.57 & 0.085 & -0.31 & 0.382 \\
\hline DRF/MSW & -0.76 & 0.011 & -0.57 & 0.089 & -0.45 & -0.188 & -0.62 & 0.055 & 0.46 & 0.177 \\
\hline DFC/MSW & -0.50 & 0.146 & -0.34 & 0.335 & -0.25 & 0.483 & -0.48 & 0.156 & 0.26 & 0.478 \\
\hline Retentiveness & 0.81 & 0.005 & 0.58 & 0.078 & 0.57 & 0.086 & 0.62 & 0.056 & -0.79 & 0.006 \\
\hline$\%$ RVHA & 0.62 & 0.057 & 0.35 & 0.328 & 0.45 & 0.197 & 0.51 & 0.130 & -0.74 & 0.015 \\
\hline USM & 0.74 & 0.015 & 0.65 & 0.042 & 0.58 & 0.078 & 0.76 & 0.011 & -0.68 & $\mathbf{0 . 0 3 0}$ \\
\hline BEHI & -0.25 & 0.483 & -0.32 & 0.371 & -0.25 & 0.494 & -0.20 & 0.575 & 0.47 & 0.166 \\
\hline$\%$ Clay/Silt & -0.03 & 0.943 & -0.11 & 0.755 & -0.11 & 0.766 & 0.05 & 0.897 & 0.27 & 0.445 \\
\hline$\%$ Sand & 0.46 & 0.180 & 0.22 & 0.544 & 0.16 & 0.660 & 0.40 & 0.250 & -0.23 & 0.520 \\
\hline$\%$ Gravel & -0.04 & 0.918 & -0.29 & 0.421 & -0.36 & 0.313 & -0.26 & 0.474 & 0.20 & 0.579 \\
\hline$\%$ Cobble & -0.09 & 0.797 & -0.19 & 0.604 & -0.02 & 0.963 & -0.08 & 0.827 & -0.29 & 0.423 \\
\hline$\%$ Boulder & -0.03 & 0.940 & 0.12 & 0.750 & 0.07 & 0.843 & -0.23 & 0.530 & -0.12 & 0.734 \\
\hline$\%$ Bedrock & 0.20 & 0.577 & 0.35 & 0.323 & 0.41 & 0.240 & 0.65 & 0.042 & -0.06 & 0.863 \\
\hline$\%$ Canopy & 0.43 & 0.219 & 0.44 & 0.202 & 0.53 & 0.119 & 0.71 & 0.022 & -0.60 & 0.069 \\
\hline Habitat PC1 & 0.28 & 0.440 & 0.31 & 0.379 & 0.29 & 0.412 & 0.16 & 0.663 & -0.33 & 0.348 \\
\hline Habitat PC2 & 0.74 & 0.016 & 0.47 & 0.168 & 0.40 & 0.251 & 0.63 & 0.500 & -0.48 & 0.159 \\
\hline
\end{tabular}


Table 10: Correlations between water quality variables and $m$ WVSCI, EPT richness, E richness, \%E excluding Baetidae (B), and \%dominant along the residential gradient. Correlation coefficients $(r)$ and $p$-values are displayed. Bolded values are significant at $\alpha=0.05$. $D O=d i s s o l v e d$ oxygen, $\mathrm{TP}=$ total phosphorus, and all elements and compounds are listed using their chemical abbreviations and formulas (e.g. $\mathrm{Al}=\mathrm{Aluminum}$ and $\mathrm{SO}_{4}=$ Sulfate).

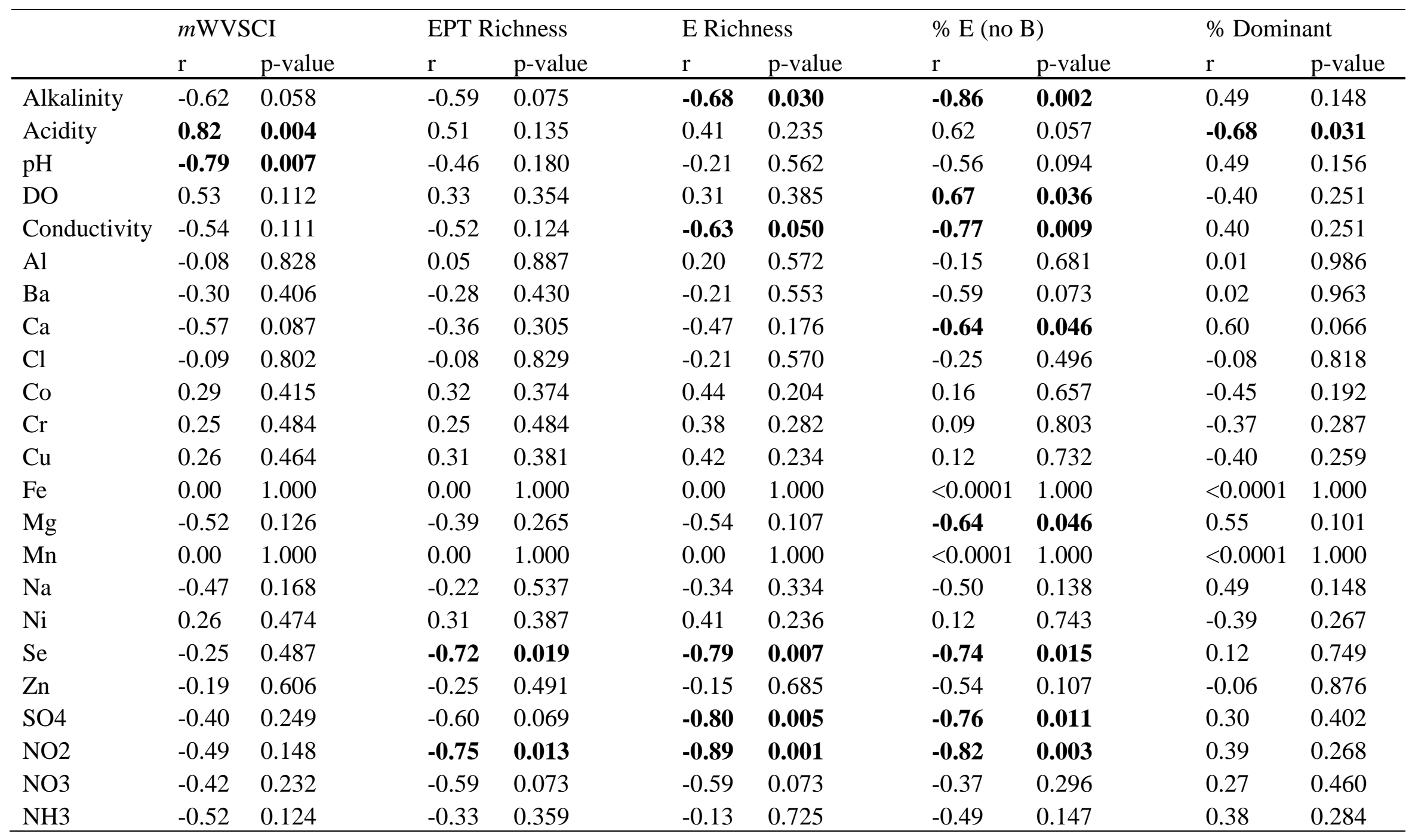


Table 10: Continued

\begin{tabular}{lllllllllll}
\hline & \multicolumn{2}{l}{$m$ WVSCI } & \multicolumn{2}{c}{ EPT Richness } & \multicolumn{2}{c}{ E Richness } & \multicolumn{2}{c}{$\%$ E (no B) } & \multicolumn{2}{c}{$\%$ Dominant } \\
& $\mathrm{r}$ & $\mathrm{p}$-value & $\mathrm{r}$ & $\mathrm{p}$-value & $\mathrm{r}$ & $\mathrm{p}$-value & $\mathrm{r}$ & $\mathrm{p}$-value & $\mathrm{r}$ & $\mathrm{p}$-value \\
\hline TP & $\mathbf{- 0 . 7 6}$ & $\mathbf{0 . 0 1 0}$ & -0.43 & 0.211 & -0.22 & 0.542 & -0.50 & 0.139 & 0.59 & 0.073 \\
WQ PC1 & $\mathbf{- 0 . 6 7}$ & $\mathbf{0 . 0 3 5}$ & -0.53 & 0.113 & -0.60 & 0.068 & $\mathbf{- 0 . 7 9}$ & $\mathbf{0 . 0 0 6}$ & 0.54 & 0.104 \\
WQ PC2 & 0.25 & 0.489 & 0.24 & 0.512 & 0.37 & 0.290 & 0.08 & 0.832 & -0.38 & 0.279 \\
\hline
\end{tabular}


Table 11: Correlations between physical habitat variables and $m$ WVSCI, EPT richness, E richness, \%E excluding Baetidae (B), and \%dominant along the mining gradient. Correlation coefficients ( $\mathrm{r}$ ) and $\mathrm{p}$-values are displayed. Bolded values are significant at $\alpha=0.05$. LWD=large woody debris, $\mathrm{RF}=$ retentive features, $\mathrm{MSW}=$ mean stream width, $\mathrm{DRF}=$ distance to retentive feature, $\mathrm{DFC}=$ distance to fish cover, $\mathrm{BEHI}=\mathrm{Bank}$ Erosion Hazard Index, USM=Unified Stream Method, RVHA=Rapid Visual Habitat Assessment, CV=coefficient of variation.

\begin{tabular}{|c|c|c|c|c|c|c|c|c|c|c|}
\hline & \multicolumn{2}{|c|}{$m \mathrm{WVSCI}$} & \multicolumn{2}{|c|}{ EPT Richness } & \multicolumn{2}{|c|}{ E Richness } & \multicolumn{2}{|c|}{$\% \mathrm{E}($ no $\mathrm{B})$} & \multicolumn{2}{|c|}{$\%$ Dominant } \\
\hline & $\mathrm{r}$ & p-value & $\mathrm{r}$ & p-value & $\mathrm{r}$ & $\mathrm{p}$-value & $\mathrm{r}$ & $\mathrm{p}$-value & $\mathrm{r}$ & $\mathrm{p}$-value \\
\hline MSW & -0.03 & 0.915 & -0.34 & 0.251 & -0.31 & 0.311 & -0.38 & 0.200 & 0.26 & 0.398 \\
\hline Mean Depth & -0.36 & 0.234 & -0.54 & 0.057 & -0.47 & 0.108 & -0.58 & 0.039 & 0.54 & 0.055 \\
\hline CV Depth & 0.22 & 0.470 & 0.19 & 0.532 & 0.05 & 0.863 & 0.31 & 0.310 & -0.54 & 0.060 \\
\hline $\mathrm{LWD} / \mathrm{m}$ & -0.20 & 0.515 & 0.15 & 0.626 & 0.34 & 0.263 & 0.39 & 0.188 & 0.01 & 0.970 \\
\hline DFC/MSW & 0.23 & 0.448 & 0.49 & 0.091 & 0.37 & 0.217 & 0.34 & 0.258 & -0.38 & 0.204 \\
\hline Retentiveness & 0.02 & 0.944 & 0.04 & 0.888 & 0.17 & 0.585 & 0.57 & 0.044 & -0.48 & 0.098 \\
\hline$\%$ RVHA & 0.07 & 0.813 & 0.09 & 0.759 & 0.09 & 0.763 & 0.41 & 0.169 & 0.08 & 0.802 \\
\hline USM & 0.11 & 0.710 & 0.35 & 0.245 & 0.31 & 0.305 & 0.42 & 0.151 & -0.34 & 0.252 \\
\hline BEHI & 0.27 & 0.371 & 0.18 & 0.555 & 0.11 & 0.732 & 0.04 & 0.895 & -0.25 & 0.412 \\
\hline$\%$ Cobble & 0.19 & 0.526 & 0.05 & 0.881 & 0.04 & 0.890 & 0.36 & 0.234 & -0.36 & 0.224 \\
\hline$\%$ Boulder & 0.17 & 0.571 & -0.04 & 0.907 & -0.04 & 0.888 & 0.44 & 0.138 & -0.55 & 0.050 \\
\hline$\%$ Bedrock & 0.77 & 0.002 & 0.64 & 0.018 & 0.71 & 0.007 & 0.85 & $<0.001$ & -0.55 & 0.051 \\
\hline \% Canopy & 0.03 & 0.926 & 0.08 & 0.787 & 0.27 & 0.368 & 0.38 & 0.203 & -0.16 & 0.594 \\
\hline Habitat PC1 & 0.11 & 0.716 & 0.24 & 0.427 & 0.22 & 0.466 & 0.54 & 0.058 & -0.55 & 0.052 \\
\hline Habitat PC2 & -0.17 & 0.575 & 0.06 & 0.859 & 0.15 & 0.624 & 0.28 & 0.353 & -0.08 & 0.792 \\
\hline
\end{tabular}


Table 12: Correlations between water quality variables and $m$ WVSCI, EPT richness, E richness, $\%$ E excluding Baetidae (B), and \%dominant along the mining gradient. Correlation coefficients $(\mathrm{r})$ and $\mathrm{p}$-values are displayed. Bolded values are significant at $\alpha=0.05$. $\mathrm{DO}=\mathrm{dissolved}$ oxygen, $\mathrm{TP}=$ total phosphorus, and all elements and compounds are listed using their chemical abbreviations and formulas (e.g. $\mathrm{Al}=\mathrm{Aluminum}$ and $\mathrm{SO}_{4}=$ Sulfate).

\begin{tabular}{|c|c|c|c|c|c|c|c|c|c|c|}
\hline & \multicolumn{2}{|c|}{$m \mathrm{WVSCI}$} & \multicolumn{2}{|c|}{ EPT Richness } & \multicolumn{2}{|c|}{ E Richness } & \multicolumn{2}{|c|}{$\% \mathrm{E}($ no B $)$} & \multicolumn{2}{|c|}{$\%$ Dominant } \\
\hline & $\mathrm{r}$ & $\mathrm{p}$-value & $\mathrm{r}$ & $\mathrm{p}$-value & $\mathrm{r}$ & $\mathrm{p}$-value & $\mathrm{r}$ & p-value & $\mathrm{r}$ & $\mathrm{p}$-value \\
\hline Alkalinity & -0.70 & 0.008 & -0.64 & 0.019 & -0.69 & 0.010 & -0.86 & $<0.001$ & 0.70 & 0.008 \\
\hline Acidity & 0.44 & 0.130 & 0.29 & 0.341 & 0.41 & 0.164 & 0.58 & 0.040 & -0.51 & 0.079 \\
\hline $\mathrm{pH}$ & 0.00 & 0.992 & -0.31 & 0.299 & -0.08 & 0.792 & -0.05 & 0.884 & 0.13 & 0.685 \\
\hline DO & 0.27 & 0.381 & 0.67 & 0.012 & 0.60 & 0.032 & 0.46 & 0.111 & -0.48 & 0.095 \\
\hline Conductivity & -0.61 & 0.027 & -0.66 & 0.014 & -0.73 & 0.004 & -0.79 & 0.001 & 0.64 & 0.019 \\
\hline $\mathrm{Al}$ & -0.37 & 0.216 & -0.61 & 0.026 & -0.69 & 0.009 & -0.36 & 0.227 & 0.00 & 0.994 \\
\hline $\mathrm{Ba}$ & -0.26 & 0.385 & -0.14 & 0.645 & -0.16 & 0.614 & -0.33 & 0.270 & 0.36 & 0.226 \\
\hline $\mathrm{Ca}$ & -0.47 & 0.105 & -0.42 & 0.153 & -0.55 & 0.049 & -0.66 & 0.014 & 0.52 & 0.069 \\
\hline $\mathrm{Cl}$ & -0.50 & 0.082 & -0.66 & 0.015 & -0.63 & 0.020 & -0.72 & 0.005 & 0.46 & 0.113 \\
\hline $\mathrm{Co}$ & -0.01 & 0.986 & 0.24 & 0.428 & 0.18 & 0.554 & 0.08 & 0.799 & -0.10 & 0.751 \\
\hline $\mathrm{Cr}$ & 0.02 & 0.956 & 0.29 & 0.345 & 0.27 & 0.376 & 0.10 & 0.735 & -0.03 & 0.924 \\
\hline $\mathrm{Cu}$ & -0.21 & 0.491 & -0.16 & 0.592 & -0.24 & 0.424 & -0.16 & 0.607 & -0.03 & 0.924 \\
\hline $\mathrm{Fe}$ & -0.43 & 0.146 & -0.58 & 0.039 & -0.67 & 0.012 & -0.42 & 0.159 & 0.06 & 0.836 \\
\hline $\mathrm{Mg}$ & -0.47 & 0.105 & -0.35 & 0.237 & -0.50 & 0.081 & -0.67 & 0.013 & 0.54 & 0.059 \\
\hline $\mathrm{Mn}$ & -0.59 & 0.035 & -0.60 & 0.030 & -0.60 & 0.030 & -0.37 & 0.220 & 0.21 & 0.495 \\
\hline $\mathrm{Na}$ & -0.45 & 0.125 & -0.46 & 0.118 & -0.59 & 0.035 & -0.73 & 0.005 & 0.53 & 0.063 \\
\hline $\mathrm{Ni}$ & -0.16 & 0.603 & 0.00 & 0.997 & -0.02 & 0.948 & -0.06 & 0.844 & -0.05 & 0.873 \\
\hline $\mathrm{Se}$ & 0.37 & 0.211 & 0.19 & 0.526 & 0.12 & 0.702 & 0.17 & 0.587 & -0.22 & 0.463 \\
\hline $\mathrm{Zn}$ & -0.16 & 0.597 & -0.23 & 0.443 & -0.35 & 0.244 & -0.12 & 0.704 & -0.13 & 0.664 \\
\hline $\mathrm{SO} 4$ & -0.57 & 0.044 & -0.60 & 0.031 & -0.71 & 0.006 & -0.76 & 0.002 & 0.62 & 0.025 \\
\hline $\mathrm{NO} 2$ & -0.33 & 0.266 & -0.51 & 0.073 & -0.61 & 0.026 & -0.45 & 0.128 & 0.02 & 0.958 \\
\hline NO3 & -0.39 & 0.184 & -0.13 & 0.760 & 0.04 & 0.907 & -0.30 & 0.325 & 0.61 & 0.028 \\
\hline $\mathrm{NH} 3$ & -0.27 & 0.369 & -0.33 & 0.268 & -0.30 & 0.312 & -0.19 & 0.527 & 0.19 & 0.534 \\
\hline
\end{tabular}


Table 12: Continued

\begin{tabular}{lllllllllll}
\hline & \multicolumn{2}{l}{$m$ WVSCI } & \multicolumn{2}{c}{ EPT Richness } & \multicolumn{2}{c}{ E Richness } & \multicolumn{2}{c}{ \% E (no B) } & \multicolumn{2}{c}{$\%$ Dominant } \\
& $\mathrm{r}$ & $\mathrm{p}$-value & $\mathrm{r}$ & $\mathrm{p}$-value & $\mathrm{r}$ & $\mathrm{p}$-value & $\mathrm{r}$ & $\mathrm{p}$-value & $\mathrm{r}$ & $\mathrm{p}$-value \\
\hline TP & $\mathbf{- 0 . 6 0}$ & $\mathbf{0 . 0 3 0}$ & -0.51 & 0.075 & $\mathbf{- 0 . 6 6}$ & $\mathbf{0 . 0 1 5}$ & $\mathbf{- 0 . 5 7}$ & $\mathbf{0 . 0 4 4}$ & 0.12 & 0.698 \\
WQ PC1 & $\mathbf{- 0 . 6 3}$ & $\mathbf{0 . 0 2 0}$ & $\mathbf{- 0 . 6 0}$ & $\mathbf{0 . 0 3 0}$ & $\mathbf{- 0 . 7 0}$ & $\mathbf{0 . 0 0 8}$ & $\mathbf{- 0 . 7 8}$ & $\mathbf{0 . 0 0 2}$ & $\mathbf{0 . 5 9}$ & $\mathbf{0 . 0 3 3}$ \\
WQ PC2 & -0.18 & 0.550 & -0.11 & 0.728 & -0.18 & 0.558 & -0.07 & 0.816 & -0.11 & 0.714 \\
\hline
\end{tabular}


Table 13: Correlations between water quality variables and total richness, EPT richness, and $P$ richness across the large combined sites. Correlation coefficients ( $r$ ) and p-values are displayed. Bolded values are significant at $\alpha=0.05$. Spaces held by a "." indicate correlations where one variable did not vary among study sites. $\mathrm{DO}=$ dissolved oxygen, $\mathrm{TP}=$ total phosphorus, and all elements and compounds are listed using their chemical abbreviations and formulas (e.g. Al=Aluminum and $\mathrm{SO}_{4}=$ Sulfate).

\begin{tabular}{llllllll}
\hline & \multicolumn{2}{l}{ Total Richness } & \multicolumn{2}{c}{ EPT Richness } & \multicolumn{2}{l}{ P Richness } \\
& r & p-value & r & p-value & r & p-value \\
\hline Alkalinity & -0.42 & 0.175 & -0.35 & 0.265 & -0.27 & 0.396 \\
Acidity & - &. & - & $\cdot$ &. &. \\
pH & -0.43 & 0.166 & -0.43 & 0.166 & -0.28 & 0.377 \\
DO & $\mathbf{0 . 7 6}$ & $\mathbf{0 . 0 0 4}$ & $\mathbf{0 . 7 6}$ & $\mathbf{0 . 0 0 4}$ & $\mathbf{0 . 7 4}$ & $\mathbf{0 . 0 0 6}$ \\
Conductivity & -0.46 & 0.129 & -0.44 & 0.151 & -0.40 & 0.194 \\
Al & -0.30 & 0.337 & -0.54 & 0.073 & -0.49 & 0.109 \\
Ba & 0.09 & 0.778 & 0.19 & 0.560 & 0.30 & 0.341 \\
Ca & -0.41 & 0.186 & -0.44 & 0.148 & -0.49 & 0.103 \\
Cl & -0.51 & 0.092 & -0.44 & 0.157 & -0.36 & 0.257 \\
Co & 0.08 & 0.818 & 0.13 & 0.678 & 0.12 & 0.704 \\
Cr & 0.08 & 0.796 & 0.11 & 0.734 & 0.04 & 0.913 \\
Cu & 0.16 & 0.616 & 0.20 & 0.528 & 0.13 & 0.688 \\
Fe & -0.27 & 0.400 & -0.40 & 0.199 & -0.47 & 0.122 \\
Mg & -0.38 & 0.230 & -0.46 & 0.133 & -0.54 & 0.073 \\
Mn & -0.16 & 0.612 & -0.30 & 0.343 & -0.37 & 0.237 \\
Na & -0.40 & 0.120 & -0.30 & 0.347 & -0.19 & 0.561 \\
Ni & 0.16 & 0.616 & 0.20 & 0.528 & 0.13 & 0.688 \\
Se & -0.20 & 0.537 & -0.19 & 0.554 & -0.42 & 0.171 \\
Zn & 0.11 & 0.735 & 0.08 & 0.817 & -0.02 & 0.955 \\
SO4 & -0.45 & 0.147 & -0.48 & 0.115 & -0.49 & 0.106 \\
NO2 & -0.52 & 0.082 & -0.55 & 0.067 & -0.71 & 0.010 \\
NO3 & -0.44 & 0.148 & -0.46 & 0.136 & -0.45 & 0.141 \\
NH3 & 0.16 & 0.619 & 0.33 & 0.293 & 0.15 & 0.652 \\
TP & -0.08 & 0.816 & -0.05 & 0.872 & -0.11 & 0.738 \\
WQ PC1 & -0.49 & 0.107 & -0.50 & 0.102 & -0.50 & 0.099 \\
WQ PC2 & 0.07 & 0.828 & 0.02 & 0.961 & -0.10 & 0.770 \\
\hline & & & & & &
\end{tabular}


Table 14: Correlations between physical habitat variables and total richness, EPT richness, and $P$ richness across the large combined sites. Correlation coefficients ( $r$ ) and p-values are displayed. Bolded values are significant at $\alpha=0.05$. LWD=large woody debris, $R F=$ retentive features, $M S W=$ mean stream width, $\mathrm{DRF}=$ distance to retentive feature, $\mathrm{DFC}=$ distance to fish cover, $\mathrm{BEHI}=\mathrm{Bank}$ Erosion Hazard Index, USM=Unified Stream Method, RVHA=Rapid Visual Habitat Assessment, CV=coefficient of variation.

\begin{tabular}{lllllll}
\hline & \multicolumn{2}{l}{ Total Richness } & \multicolumn{2}{c}{ EPT Richness } & \multicolumn{2}{c}{ P Richness } \\
& r & p-value & r & p-value & r & p-value \\
\hline MSW & -0.39 & 0.212 & -0.36 & 0.257 & -0.44 & 0.150 \\
Gradient & -0.24 & 0.457 & -0.23 & 0.477 & -0.29 & 0.367 \\
Mean Depth & -0.53 & 0.080 & -0.47 & 0.128 & -0.31 & 0.334 \\
CV Depth & -0.35 & 0.260 & -0.26 & 0.421 & -0.28 & 0.383 \\
LWD/m & 0.16 & 0.629 & 0.24 & 0.447 & 0.45 & 0.143 \\
RF/m & $\mathbf{- 0 . 6 7}$ & $\mathbf{0 . 0 1 8}$ & -0.50 & 0.098 & -0.33 & 0.303 \\
DRF/MSW & $\mathbf{0 . 6 5}$ & $\mathbf{0 . 0 2 2}$ & $\mathbf{0 . 6 0}$ & $\mathbf{0 . 0 3 8}$ & 0.53 & 0.078 \\
DFC/MSW & 0.31 & 0.335 & 0.34 & 0.286 & 0.21 & 0.513 \\
Retentiveness & -0.43 & 0.166 & -0.42 & 0.170 & -0.25 & 0.430 \\
\%RVHA & -0.20 & 0.544 & -0.21 & 0.522 & -0.18 & 0.587 \\
USM & -0.05 & 0.875 & 0.15 & 0.641 & 0.41 & 0.185 \\
BEHI & $\mathbf{- 0 . 6 1}$ & $\mathbf{0 . 0 3 6}$ & -0.46 & 0.132 & -0.31 & 0.322 \\
\% Clay/Silt & $\mathbf{- 0 . 6 3}$ & $\mathbf{0 . 0 3 0}$ & -0.47 & 0.123 & -0.45 & 0.146 \\
\% Sand & 0.02 & 0.943 & -0.14 & 0.673 & -0.06 & 0.847 \\
\% Gravel & -0.34 & 0.279 & -0.23 & 0.470 & 0.02 & 0.955 \\
\% Cobble & -0.14 & 0.673 & -0.08 & 0.796 & 0.12 & 0.714 \\
\% Boulder & 0.04 & 0.896 & 0.00 & 0.990 & 0.11 & 0.725 \\
\% Bedrock & 0.32 & 0.307 & 0.33 & 0.301 & 0.07 & 0.819 \\
\% Canopy & 0.25 & 0.431 & 0.28 & 0.379 & 0.36 & 0.247 \\
Habitat PC1 & 0.05 & 0.875 & 0.14 & 0.665 & 0.29 & 0.360 \\
Habitat PC2 & $\mathbf{- 0 . 5 8}$ & $\mathbf{0 . 0 4 7}$ & -0.51 & 0.094 & -0.33 & 0.290 \\
\hline & & & & & &
\end{tabular}


Table 15: Correlations between water quality variables and total abundance (\#) and \%EPT excluding Baetidae (B) across the small combined sites. Correlation coefficients (r) and p-values are displayed. Bolded values are significant at $\alpha=0.05$. Spaces held by a "." indicate correlations where one variable did not vary among study sites. $\mathrm{DO}=$ dissolved oxygen, $\mathrm{TP}=$ total phosphorus, and all elements and compounds are listed using their chemical abbreviations and formulas (e.g. $\mathrm{Al}=A$ Aluminum and $\mathrm{SO}_{4}=$ Sulfate).

\begin{tabular}{lllll}
\hline & \multicolumn{2}{l}{ Total \# } & \multicolumn{2}{l}{ \% EPT (no B) } \\
& $\mathrm{r}$ & $\mathrm{p}$-value & $\mathrm{r}$ & $\mathrm{p}$-value \\
\hline Alkalinity & 0.59 & 0.122 & -0.69 & 0.061 \\
Acidity & $\cdot$ & $\cdot$ & $\cdot$ &. \\
pH & -0.26 & 0.539 & -0.26 & 0.533 \\
DO & -0.28 & 0.495 & 0.54 & 0.166 \\
Conductivity & 0.51 & 0.202 & -0.60 & 0.120 \\
Al & 0.00 & 1.000 & $<0.0001$ & 1.000 \\
Ba & 0.51 & 0.195 & -0.60 & 0.114 \\
Ca & 0.42 & 0.307 & -0.49 & 0.222 \\
Cl & 0.32 & 0.437 & -0.26 & 0.530 \\
Co & -0.66 & 0.077 & 0.40 & 0.332 \\
Cr & 0.60 & 0.120 & $\mathbf{- 0 . 7 8}$ & $\mathbf{0 . 0 2 3}$ \\
Cu & 0.10 & 0.810 & 0.15 & 0.729 \\
Fe & 0.00 & 1.000 & $<0.0001$ & 1.000 \\
Mg & 0.44 & 0.281 & -0.35 & 0.398 \\
Mn & 0.00 & 1.000 & $<0.0001$ & 1.000 \\
Na & 0.57 & 0.137 & -0.71 & 0.050 \\
Ni &. &. &. &. \\
Se & 0.12 & 0.778 & 0.32 & 0.436 \\
Zn & 0.14 & 0.742 & 0.19 & 0.653 \\
SO4 & 0.47 & 0.243 & -0.50 & 0.206 \\
NO2 & -0.07 & 0.876 & 0.49 & 0.215 \\
NO3 & -0.23 & 0.578 & 0.04 & 0.926 \\
NH3 & -0.70 & 0.055 & 0.12 & 0.779 \\
TP & 0.36 & 0.377 & -0.29 & 0.479 \\
WQ PC1 & 0.41 & 0.318 & -0.48 & 0.225 \\
WQ PC2 & 0.05 & 0.917 & 0.52 & 0.184 \\
\hline & & & &
\end{tabular}


Table 16: Correlations between physical habitat variables and total abundance and \%EPT excluding Baetidae (B) across the small combined sites. Correlation coefficients (r) and p-values are displayed. Bolded values are significant at $\alpha=0.05$. $L W D=$ large woody debris, $R F=$ retentive features, $M S W=$ mean stream width, DRF=distance to retentive feature, $\mathrm{DFC}=$ distance to fish cover, $\mathrm{BEHI}=\mathrm{Bank}$ Erosion Hazard Index, USM=Unified Stream Method, RVHA=Rapid Visual Habitat Assessment, CV=coefficient of variation.

\begin{tabular}{lllll}
\hline & Total \# & & \multicolumn{2}{c}{ \%EPT (no B) } \\
& r & p-value & r & p-value \\
\hline MSW & 0.53 & 0.173 & -0.42 & 0.296 \\
Gradient & 0.12 & 0.781 & 0.35 & 0.400 \\
Mean Depth & 0.32 & 0.438 & -0.27 & 0.522 \\
CV Depth & -0.38 & 0.351 & 0.15 & 0.723 \\
LWD/m & -0.06 & 0.880 & 0.34 & 0.418 \\
RF/m & 0.16 & 0.699 & 0.07 & 0.871 \\
DRF/MSW & -0.33 & 0.422 & 0.25 & 0.559 \\
DFC/MSW & -0.54 & 0.165 & 0.21 & 0.615 \\
Retentiveness & -0.12 & 0.777 & 0.60 & 0.115 \\
\%RVHA & 0.13 & 0.751 & 0.16 & 0.710 \\
USM & 0.23 & 0.581 & 0.13 & 0.769 \\
BEHI & 0.10 & 0.824 & -0.07 & 0.873 \\
\% Clay/Silt & -0.11 & 0.800 & -0.36 & 0.381 \\
\% Sand & $\mathbf{0 . 7 1}$ & $\mathbf{0 . 0 4 8}$ & -0.25 & 0.549 \\
\% Gravel & 0.60 & 0.119 & -0.57 & 0.142 \\
\% Cobble & -0.14 & 0.737 & 0.32 & 0.435 \\
\% Boulder & $\mathbf{- 0 . 7 4}$ & $\mathbf{0 . 0 3 8}$ & 0.64 & 0.086 \\
\% Bedrock & -0.01 & 0.979 & 0.15 & 0.725 \\
\% Canopy & $\mathbf{- 0 . 7 3}$ & $\mathbf{0 . 0 4 0}$ & 0.58 & 0.133 \\
Habitat PC1 & -0.57 & 0.140 & 0.70 & 0.054 \\
Habitat PC2 & 0.28 & 0.499 & -0.02 & 0.963 \\
\hline
\end{tabular}


Table 17: Results of Multivariate Analysis of Variance (MANOVA) tests used to identify multivariate differences between the mined, developed, large combined, and small combined sites with respect to physical habitat, water chemistry, and macroinvertebrate community structure. Bolded values indicate significant differences at $\alpha=0.05$.

\begin{tabular}{lll}
\hline & F & p-value \\
\hline Physical Habitat & $\mathbf{2 . 1 3}$ & $\mathbf{0 . 0 0 3}$ \\
Water Chemistry & $\mathbf{3 . 0 2}$ & $<\mathbf{0 . 0 0 1}$ \\
Community Metrics & $\mathbf{2 . 7 6}$ & $<\mathbf{0 . 0 0 1}$ \\
\hline
\end{tabular}


Table 18: Means and standard errors (SE) for physical habitat variables across all sites and individual site types. Bolded variables and ANOVA results indicate significant differences $(\mathrm{p}<0.05)$ between the mined, developed, small combined, and large combined site types $(\mathrm{d} . \mathrm{f} .=3$, 35 for all analyses). All ANOVAs were conducted using transformed data. LWD=large woody debris, RF=retentive features, MSW=mean stream width, $\mathrm{DRF}=$ distance to retentive feature, $\mathrm{DFC}=$ distance to fish cover, $\mathrm{BEHI}=$ Bank Erosion Hazard Index, USM=Unified Stream Method, RVHA=Rapid Visual Habitat Assessment, CV=coefficient of variation.

\begin{tabular}{|c|c|c|c|c|c|c|c|c|}
\hline \multirow[b]{2}{*}{ Habitat Variables } & \multirow{2}{*}{$\begin{array}{l}\text { Mined } \\
\text { Mean (SE) }\end{array}$} & \multirow{2}{*}{$\begin{array}{l}\text { Developed } \\
\text { Mean (SE) }\end{array}$} & \multirow{2}{*}{$\begin{array}{l}\text { Small Combined } \\
\text { Mean (SE) }\end{array}$} & \multirow{2}{*}{$\begin{array}{l}\text { Large Combined } \\
\text { Mean (SE) }\end{array}$} & \multirow{2}{*}{$\begin{array}{l}\text { Reference } \\
\text { Mean (SE) }\end{array}$} & \multirow{2}{*}{$\begin{array}{l}\text { All Sites } \\
\text { Mean (SE) }\end{array}$} & \multicolumn{2}{|c|}{ ANOVA Results } \\
\hline & & & & & & & $\mathrm{F}$ & $\mathrm{p}$-value \\
\hline MSW (m) & $2.80(0.281)$ & $3.28(0.858)$ & $2.60(0.283)$ & $9.98(1.084)$ & $2.20(0)$ & $4.92(0.627)$ & 25.75 & $<0.0001$ \\
\hline Gradient (\%) & $3.06(0.530)$ & $2.51(0.500)$ & $2.59(0.577)$ & $1.09(0.066)$ & $2.4(0.100)$ & $2.25(0.233)$ & 6.25 & 0.002 \\
\hline Mean Depth (m) & $0.07(0.009)$ & $0.08(0.010)$ & $0.08(0.017)$ & $0.25(0.023)$ & $0.05(0)$ & $0.12(0.015)$ & 21.54 & $<0.0001$ \\
\hline CV Depth & $67.29(6.703)$ & $70.57(6.417)$ & $71.86(8.207)$ & $51.01(4.353)$ & $97.78(32.422)$ & $65.54(3.561)$ & 2.58 & 0.069 \\
\hline \#LWD/m & $0.16(0.052)$ & $0.05(0.013)$ & $0.12(0.074)$ & $0.04(0.010)$ & $0.15(0.103)$ & $0.09(0.022)$ & 1.84 & 0.158 \\
\hline$\# \mathrm{RF} / \mathrm{m}$ & $0.02(0.009)$ & $0.01(0.007)$ & $0.02(0.013)$ & $0.02(0.005)$ & $0.03(0.013)$ & $0.02(0.004)$ & 0.31 & 0.817 \\
\hline DRF/MSW & $12.81(3.431)$ & $36.32(14.934)$ & $34.21(12.657)$ & $4.78(1.925)$ & $6.77(2.459)$ & $18.93(4.325)$ & 4.96 & 0.006 \\
\hline DFC/MSW & $10.57(6.660)$ & $23.22(13.665)$ & $18.05(7.496)$ & $0.46(0.062)$ & $5.54(1.065)$ & $11.29(3.619)$ & 9.38 & $<0.001$ \\
\hline Retentiveness & $9.55(1.760)$ & $4.63(0.905)$ & $6.88(1.817)$ & $6.50(1.184)$ & $13.00(0)$ & $7.34(0.758)$ & 1.84 & 0.158 \\
\hline \% RVHA & $60.23(3.674)$ & $51.19(2.541)$ & $45.19(5.510)$ & $51.79(1.842)$ & $64.75(0.250)$ & $53.28(1.810)$ & 3.26 & 0.033 \\
\hline USM & $1.08(0.068)$ & $0.77(0.034)$ & $0.94(0.100)$ & $0.78(0.027)$ & $1.01(0.145)$ & $0.90(0.035)$ & 6.42 & 0.001 \\
\hline BEHI & $27.69(1.805)$ & $34.56(2.555)$ & $28.69(1.953)$ & $29.01(2.254)$ & $29.14(5.810)$ & $29.68(1.083)$ & 1.80 & 0.166 \\
\hline$\%$ Clay/Silt & $2.80(0.801)$ & $1.38(0.706)$ & $6.56(5.856)$ & $3.24(1.060)$ & $1.50(1.500)$ & $3.32(1.183)$ & 0.56 & 0.648 \\
\hline$\%$ Sand & $17.76(2.783)$ & $4.00(1.732)$ & $14.83(4.412)$ & 28.18 (3.109) & $8.50(3.500)$ & $17.10(1.983)$ & 12.62 & $<0.0001$ \\
\hline$\%$ Gravel & $40.80(5.937)$ & $35.75(7.060)$ & $28.59(5.066)$ & $33.80(3.487)$ & $22.00(4.000)$ & $34.47(2.565)$ & 0.73 & 0.536 \\
\hline$\%$ Cobble & $22.50(3.341)$ & $23.13(3.753)$ & $20.37(3.705)$ & $13.57(1.871)$ & $32.50(0.500)$ & $20.08(1.601)$ & 2.17 & 0.109 \\
\hline$\%$ Boulder & $12.31(3.549)$ & $24.38(7.964)$ & $18.89(6.077)$ & $4.00(0.693)$ & $23.00(5.000)$ & $14.04(2.415)$ & 3.86 & 0.017 \\
\hline$\%$ Bedrock & $3.83(2.209)$ & $11.38(6.086)$ & $10.76(5.446)$ & $17.20(6.257)$ & $12.50(0.500)$ & $10.99(2.527)$ & 1.22 & 0.316 \\
\hline \% Canopy & $83.51(2.359)$ & $58.99(6.159)$ & $69.58(7.722)$ & $53.51(5.664)$ & $85.94(1.146)$ & 67.35 (3.197) & 7.02 & $<0.001$ \\
\hline Habitat PC1 & $1.17(0.628)$ & $0.79(0.412)$ & $1.07(0.547)$ & $-2.74(0.180)$ & $2.53(0.155)$ & $-0.13(0.361)$ & 18.17 & $<0.0001$ \\
\hline Habitat PC2 & $0.81(0.602)$ & $-1.47(0.675)$ & $-0.679(1.062)$ & $0.585(0.365)$ & $0.61(0.030)$ & $-0.03(0.347)$ & 2.69 & 0.061 \\
\hline
\end{tabular}


Table 19: Results of the Tukey's HSD tests used for pair-wise comparisons of the habitat variables found to significantly differ ( $\mathrm{p}<0.05$ ) between the mined (M), developed (D), small combined (CS), and large combined (CL) sites. Comparisons denoted by an asterisk $(*)$ represent significant pair-wise comparisons $(\mathrm{p}<0.05)$. P-values are provided in parentheses for all significant comparisons.

\begin{tabular}{|c|c|c|c|c|c|c|}
\hline Pair & $\mathrm{CS}-\mathrm{CL}$ & D-CL & $\mathrm{M}-\mathrm{CL}$ & D-CS & $\mathrm{M}-\mathrm{CS}$ & M-D \\
\hline MSW (m) & $*(<0.0001)$ & $*(0.0001)$ & $*(0.0001)$ & - & . & . \\
\hline Gradient (\%) & $*(0.020)$ & $*(0.020)$ & $*(0.002)$ & . & . & . \\
\hline Mean Depth (m) & $*(<0.0001)$ & $*(<0.0001)$ & $*(<0.0001)$ & . & . & . \\
\hline DRF/MSW & $*(0.016)$ & $*(0.015)$ & . & . & . & . \\
\hline DFC/MSW & $*(<0.001)$ & $*(0.001)$ & $*(0.007)$ & . & . & . \\
\hline$\%$ RVHA & . & . & . & . & $*(0.022)$ & . \\
\hline USM & . & . & $*(0.003)$ & . & . & $*(0.006)$ \\
\hline$\%$ Sand & $*(0.031)$ & $*(<0.0001)$ & . & $*(0.031)$ & . & $*(0.001)$ \\
\hline$\%$ Boulder & . & $*(0.016)$ & . & . & . & . \\
\hline \% Canopy & . & . & $*(<0.001)$ & . & . & $*(0.015)$ \\
\hline Habitat PC1 & $*(<0.0001)$ & $*(<0.0001)$ & $*(0.0001)$ & . & . & . \\
\hline
\end{tabular}


Table 20: Means and standard errors (SE) for water quality variables across all sites and individual site types. Bolded ANOVA results indicate significant differences ( $\mathrm{p}<0.05$ ) between the mined, developed, small combined, and large combined site types (d.f. $=3$, 35 for all analyses). All ANOVAs were conducted using transformed data. $\mathrm{DO}=$ dissolved oxygen, Cond=conductivity, $\mathrm{TP}=$ total phosphorus, and all elements and compounds are listed using their chemical abbreviations and formulas (e.g. $\mathrm{Al}=\mathrm{Aluminum}$ and $\mathrm{SO}_{4}=\mathrm{Sulfate}$ ).

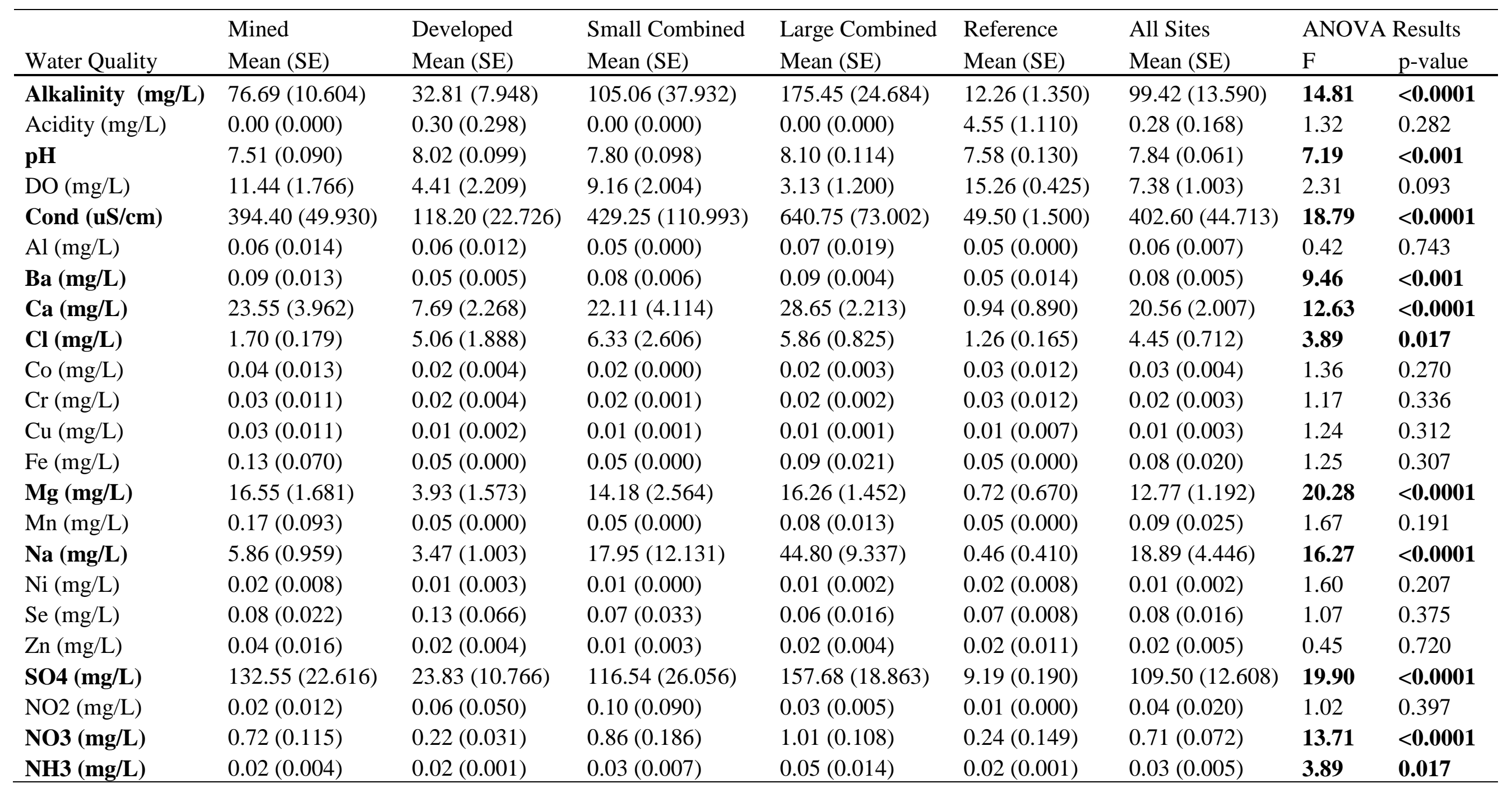


Table 20: Continued

\begin{tabular}{|c|c|c|c|c|c|c|c|c|}
\hline \multirow[b]{2}{*}{ Water Quality } & \multirow{2}{*}{$\begin{array}{l}\text { Mined } \\
\text { Mean (SE) }\end{array}$} & \multirow{2}{*}{$\begin{array}{l}\text { Developed } \\
\text { Mean (SE) }\end{array}$} & \multirow{2}{*}{$\begin{array}{l}\text { Small Combined } \\
\text { Mean (SE) }\end{array}$} & \multirow{2}{*}{$\begin{array}{l}\text { Large Combined } \\
\text { Mean (SE) }\end{array}$} & \multirow{2}{*}{$\begin{array}{l}\text { Reference } \\
\text { Mean (SE) }\end{array}$} & \multirow{2}{*}{$\begin{array}{l}\text { All Sites } \\
\text { Mean (SE) }\end{array}$} & \multicolumn{2}{|c|}{ ANOVA Results } \\
\hline & & & & & & & $\mathrm{F}$ & p-value \\
\hline $\mathrm{TP}(\mathrm{mg} / \mathrm{L})$ & $0.06(0.022)$ & $0.06(0.011)$ & $0.03(0.005)$ & $0.04(0.009)$ & $0.02(0.000)$ & $0.05(0.007)$ & 1.62 & 0.201 \\
\hline WQ PC1 & $0.35(0.513)$ & $-2.62(0.625)$ & $0.44(0.582)$ & $2.29(0.364)$ & $-6.90(1.188)$ & $6.34 \mathrm{E}-09(0.432)$ & 15.46 & $<0.0001$ \\
\hline WQ PC2 & $1.09(1.051)$ & $0.06(0.627)$ & $-1.12(0.122)$ & $-0.58(0.443)$ & $1.74(1.807)$ & $2.68 \mathrm{E}-09(0.358)$ & 1.71 & 0.170 \\
\hline
\end{tabular}


Table 21: Results of the Tukey's HSD tests used for pair-wise comparisons of the water chemistry variables found to significantly differ $(\mathrm{p}<$ 0.05 ) between the mined (M), developed (D), small combined (CS), and large combined (CL) sites. Comparisons denoted by an asterisk (*) represent significant pair-wise comparisons $(\mathrm{p}<0.05)$. P-values are provided in parentheses for all significant comparisons. All elements and compounds are listed using their chemical abbreviations and formulas (e.g. $\mathrm{Ba}=\mathrm{Barium}$ and $\mathrm{SO}_{4}=\mathrm{Sulfate}$ ).

\begin{tabular}{|c|c|c|c|c|c|c|}
\hline Pair & CS-CL & $\mathrm{D}-\mathrm{CL}$ & $\mathrm{M}-\mathrm{CL}$ & D-CS & M-CS & M-D \\
\hline Alkalinity & $*(0.042)$ & $*(<0.0001)$ & $*(0.006)$ & $*(0.006)$ & . & $*(0.010)$ \\
\hline $\mathrm{pH}$ & . & . & $*(<0.001)$ & . & . & $*(0.010)$ \\
\hline Conductivity & . & $*(<0.0001)$ & . & $*(<0.001)$ & . & $*(<0.0001)$ \\
\hline $\mathrm{Ba}$ & . & $*(<0.0001)$ & . & $*(0.003)$ & . & $*(0.001)$ \\
\hline $\mathrm{Ca}$ & . & $*(<0.0001)$ & . & $*(0.001)$ & . & $*(<0.001)$ \\
\hline $\mathrm{Cl}$ & . & . & $*(0.009)$ & . & . & . \\
\hline $\mathrm{Mg}$ & . & $*(<0.0001)$ & . & $*(<0.0001)$ & . & $*(<0.0001)$ \\
\hline $\mathrm{Na}$ & $*(0.003)$ & $*(<0.0001)$ & $*(<0.0001)$ & . & . & . \\
\hline $\mathrm{SO} 4$ & . & $*(<0.0001)$ & . & $*(<0.0001)$ & . & $*(<0.0001)$ \\
\hline NO3 & . & $*(<0.0001)$ & . & $*(<0.001)$ & . & $*(0.001)$ \\
\hline NH3 & . & $*(0.045)$ & $*(0.023)$ & . & . & . \\
\hline PC1 & . & $*(<0.0001)$ & $*(0.028)$ & $*(0.002)$ & . & $*(0.001)$ \\
\hline
\end{tabular}


Table 22: Means and standard errors (SE) for habitat variables across all sites and individual site types. Bolded ANOVA results indicate significant differences $(\mathrm{p}<0.05)$ between the mined, developed, small combined, and large combined site types (d.f. $=3$, 35 for all analyses). All ANOVAs were conducted using transformed data. $m \mathrm{WVSCI}=$ modified West Virginia stream condition index, E=Ephemeroptera, $\mathrm{P}=\mathrm{Plecoptera}$, $\mathrm{T}=$ Trichoptera, and $\mathrm{B}=$ Baetidae.

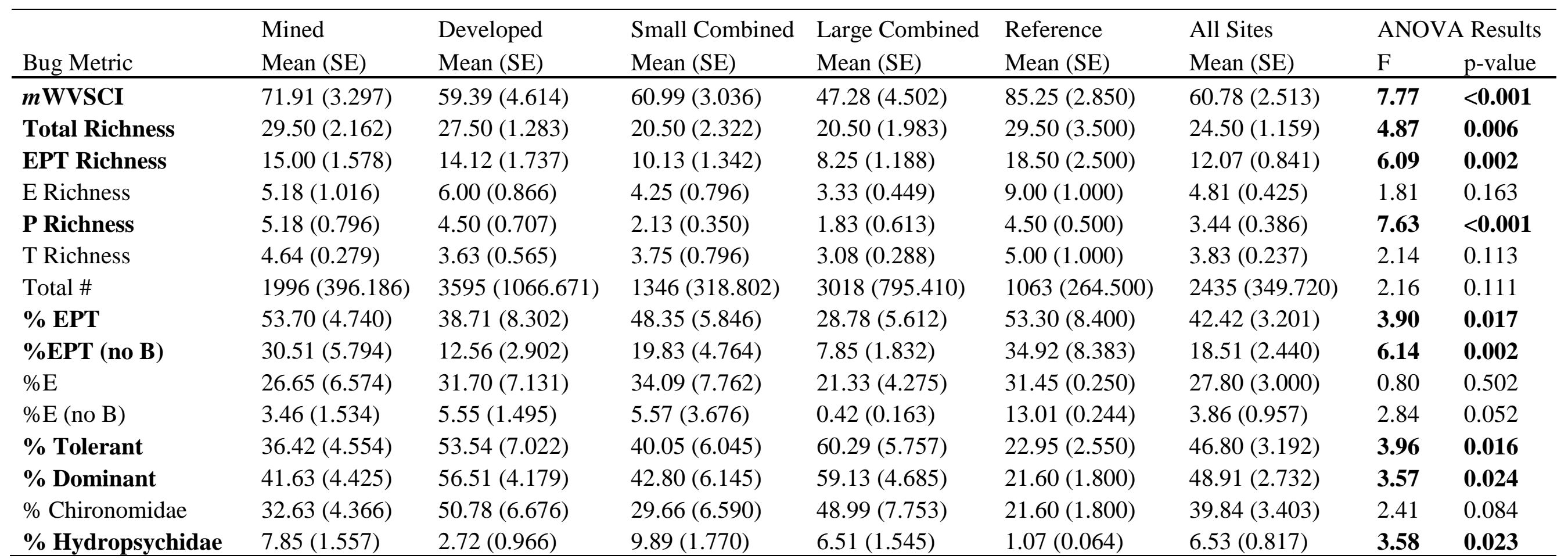


Table 23: Results of the Tukey's HSD tests used for pair-wise comparisons of the macroinvertebrate community metrics found to significantly differ ( $\mathrm{p}<0.05$ ) between the mined (M), developed (D), small combined (CS), and large combined (CL) sites. Comparisons denoted by an asterisk $\left(^{*}\right)$ represent significant pair-wise comparisons. P-values are provided in parentheses for all significant comparisons. $m \mathrm{WVSCI}=$ modified West Virginia stream condition index, E=Ephemeroptera, $\mathrm{P}=$ Plecoptera, $\mathrm{T}=$ Trichoptera, and $\mathrm{B}=\mathrm{B}$ aetidae.

\begin{tabular}{|c|c|c|c|c|c|c|}
\hline Pair & CS-CL & $\mathrm{D}-\mathrm{CL}$ & $\mathrm{M}-\mathrm{CL}$ & $\mathrm{D}-\mathrm{CS}$ & M-CS & M-D \\
\hline$m \mathrm{WVSCI}$ & $*(0.050)$ & . & $*(<0.001)$ & . & . & . \\
\hline Total Richness & . & . & $*(0.022)$ & . & $*(0.039)$ & . \\
\hline EPT Richness & . & $*(0.014)$ & $*(0.003)$ & . & . & . \\
\hline P Richness & . & $*(0.006)$ & $*(<0.001)$ & . & . & . \\
\hline$\%$ EPT & . & . & $*(0.014)$ & . & . & . \\
\hline$\%$ EPT (no B) & . & . & $*(0.001)$ & . & . & $*(0.044)$ \\
\hline$\%$ Tolerant & . & . & $*(0.018)$ & . & . & . \\
\hline$\%$ Dominant & . & . & $*(0.046)$ & . & . & . \\
\hline$\%$ Hydropsychidae & . & . & & $*(0.018)$ & . & . \\
\hline
\end{tabular}


Table 24: Results of partial Mantel tests run on the macroinvertebrate community, water quality (WQ), and physical habitat datasets in response to \% mining, parcel density (PD), and spatial location (x- and $\mathrm{y}$ coordinates) across the mined, developed, small combined, and reference sites. Bolded values indicate statistically significant correlations $(\mathrm{p}<0.05)$. Vertical bars $(\mid)$ are read as "removing the effect of".

\begin{tabular}{llll}
\hline Dataset & Landscape Variable & Mantel r & p-value \\
\hline Community & PD|Mining & $\mathbf{0 . 2 6}$ & $\mathbf{0 . 0 3 6}$ \\
& Mining|PD & 0.06 & 0.221 \\
& PD|Mining+Space & $\mathbf{0 . 2 6}$ & $\mathbf{0 . 0 3 5}$ \\
& Mining|PD+Space & 0.08 & 0.125 \\
& Space|PD+Mining & -0.13 & 0.925 \\
Water Quality & & & \\
& PD|Mining & -0.09 & 0.828 \\
& Mining|PD & $\mathbf{0 . 3 1}$ & $\mathbf{0 . 0 0 4}$ \\
& PD|Mining+Space & -0.09 & 0.812 \\
& Mining|PD+Space & $\mathbf{0 . 2 6}$ & $\mathbf{0 . 0 1 0}$ \\
& Space|PD+Mining & $\mathbf{0 . 2 9}$ & $\mathbf{0 . 0 0 4}$ \\
& & & \\
Physical Habitat & PD|Mining & $\mathbf{0 . 3 8}$ & $\mathbf{0 . 0 3 6}$ \\
& Mining|PD & -0.09 & 0.924 \\
& PD|Mining+Space & $\mathbf{0 . 3 8}$ & $\mathbf{0 . 0 2 5}$ \\
& Mining|PD+Space & -0.09 & 0.899 \\
& Space|PD+Mining & 0.02 & 0.407 \\
\hline
\end{tabular}


Table 25: Results of partial correlation analysis used to determine the relative influence of total \% mining and parcel density $\left(\# / \mathrm{km}^{2}\right)$ on WQ PC1 and Habitat PC2. Bolded values indicated significant correlations ( $p<0.05)$.

\begin{tabular}{lllll}
\hline & \multicolumn{2}{l}{ Mining } & \multicolumn{2}{c}{ Parcel Density } \\
& $\mathrm{r}$ & $\mathrm{p}$-value & $\mathrm{r}$ & $\mathrm{p}$-value \\
\hline WQ PC1 & $\mathbf{0 . 6 8}$ & $<\mathbf{0 . 0 0 0 1}$ & 0.34 & 0.063 \\
Habitat PC2 & 0.17 & 0.380 & $\mathbf{- 0 . 3 8}$ & $\mathbf{0 . 0 3 5}$ \\
\hline
\end{tabular}


Table 26: Results of ANCOVAs used to determine how community metrics varied with respect to site type, combined index (CI) scores, and their interaction. F-values, $p$-values, and degrees of freedom (d.f.) are presented. Bolded p-values represent significant relationships at $\alpha=0.05$. $m \mathrm{WVSCI}=$ modified West Virginia Stream Condition Index, E=Ephemeroptera, P=Plecoptera, T=Trichoptera, and B=Baetidae.

\begin{tabular}{llllllllll}
\hline & \multicolumn{3}{l}{ Site Type } & \multicolumn{3}{c}{ CI Score } & \multicolumn{3}{c}{ Type x CI Score Interaction } \\
& d.f. & F-value & p-value & d.f. & F-value & p-value & d.f. & F-value & p-value \\
\hline$m$ WVSCI & 2 & 4.23 & $\mathbf{0 . 0 2 6}$ & 1 & 8.27 & $\mathbf{0 . 0 0 8}$ & 2 & 2.10 & 0.143 \\
EPT richness & 2 & 5.66 & $\mathbf{0 . 0 0 9}$ & 1 & 12.01 & $\mathbf{0 . 0 0 2}$ & 2 & 1.07 & 0.360 \\
E richness & 2 & 1.97 & 0.161 & 1 & 10.29 & $\mathbf{0 . 0 0 4}$ & 2 & 0.49 & 0.618 \\
\%E (no B) & 2 & 1.11 & 0.344 & 1 & 3.33 & $\mathbf{0 . 0 8 0}$ & 2 & $\mathbf{9 . 4 6}$ & $<\mathbf{0 . 0 0 1}$ \\
\%Dominant & 2 & 1.31 & 0.286 & 1 & 4.49 & $\mathbf{0 . 0 4 4}$ & 2 & 1.27 & 0.300 \\
\hline
\end{tabular}


Table 27: Results of ANCOVAs used to determine how community metrics varied with respect to site type, conductivity (Cond), and their interaction. F-values, $\mathrm{p}$-values, and degrees of freedom (d.f.) are presented. Bolded $\mathrm{p}$-values represent significant relationships at $\alpha=0.05$. $m$ WVSCI=modified West Virginia Stream Condition Index, E=Ephemeroptera, $\mathrm{P}=$ Plecoptera, T=Trichoptera, and B=Baetidae.

\begin{tabular}{llllllllll}
\hline & \multicolumn{3}{l}{ Site Type } & \multicolumn{3}{c}{ Cond } & \multicolumn{3}{c}{ Site Type x Cond Interaction } \\
& d.f. & F-value & p-value & d.f. & F-value & p-value & d.f. & F-value & p-value \\
\hline$m$ WVSCI & 2 & 3.99 & $\mathbf{0 . 0 3 1}$ & 1 & 8.75 & $\mathbf{0 . 0 0 7}$ & 2 & 0.83 & 0.449 \\
EPT Richness & 2 & 5.25 & $\mathbf{0 . 0 1 2}$ & 1 & 11.21 & $\mathbf{0 . 0 0 3}$ & 2 & 0.07 & 0.935 \\
E Richness & 2 & 2.43 & 0.108 & 1 & 19.76 & $<\mathbf{0 . 0 0 1}$ & 2 & 0.002 & 0.998 \\
\%E (no B) & 2 & 1.21 & 0.317 & 1 & 25.47 & $\mathbf{< 0 . 0 0 0 1}$ & 2 & 0.35 & 0.705 \\
\%Dominant & 2 & 1.32 & 0.284 & 1 & 6.91 & $\mathbf{0 . 0 1 4}$ & 2 & 0.12 & 0.889 \\
\hline
\end{tabular}


Table 28: Results of ANCOVAs used to determine how community metrics varied with respect to site types, \%Rapid Visual Habitat Assessment (RVHA), and their interaction. F-values, p-values, and degrees of freedom (d.f.) are presented. Bolded p-values represent significant relationships at $\alpha=0.05$. $m$ WVSCI=modified West Virginia Stream Condition Index, E=Ephemeroptera, $\mathrm{P}=$ Plecoptera, $\mathrm{T}=$ Trichoptera, and $\mathrm{B}=\mathrm{Baetidae}$.

\begin{tabular}{llllllllll}
\hline & \multicolumn{3}{l}{ Site Type } & \multicolumn{3}{c}{ RVHA } & \multicolumn{3}{c}{ Site Type x RVHA Interaction } \\
& d.f. & F-value & p-value & d.f. & F-value & p-value & d.f. & F-value & p-value \\
\hline$m$ WVSCI & 2 & 3.61 & $\mathbf{0 . 0 4 2}$ & 1 & 2.02 & 0.167 & 2 & 2.51 & 0.102 \\
EPT Richness & 2 & 3.81 & $\mathbf{0 . 0 3 6}$ & 1 & 0.05 & 0.833 & 2 & 0.64 & 0.536 \\
E Richness & 2 & 1.43 & 0.259 & 1 & 0.14 & 0.713 & 2 & 0.57 & 0.576 \\
\%E (no B) & 2 & 0.67 & 0.520 & 1 & 1.76 & 0.197 & 2 & 0.86 & 0.435 \\
\%Dominant & 2 & 1.64 & 0.214 & 1 & $\mathbf{1 2 . 5 8}$ & $\mathbf{0 . 0 0 2}$ & 2 & 1.15 & 0.333 \\
\hline
\end{tabular}


Table 29: Maximum probability of a change point (PCP) associated with each macroinvertebrate community metric for each site type as identified by Bayesian Change Point (BCP) analysis. The maximum PCP is given along with the associated landscape metric score at which each max PCP occurred. Bolded values indicate possible change points with probabilities $\geq 0.300$. $m \mathrm{WVSCI}=$ modified West Virginia stream condition index, $\mathrm{E}=$ Ephemeroptera, $\mathrm{P}=\mathrm{Plecoptera}, \mathrm{T}=$ Trichoptera, and $\mathrm{B}=\mathrm{B}$ aetidae.

\begin{tabular}{|c|c|c|c|c|c|c|c|c|}
\hline & \multicolumn{2}{|c|}{ Residential Gradient } & \multicolumn{2}{|c|}{ Mining Gradient } & \multicolumn{2}{|c|}{ All Combined } & \multicolumn{2}{|c|}{ Small Combined } \\
\hline & $\max$ PCP & Parcel Density & $\max \mathrm{PCP}$ & $\%$ Mining & $\max \mathrm{PCP}$ & CI Score & $\max \mathrm{PCP}$ & CI Score \\
\hline$m \mathrm{WVSCI}$ & 0.020 & 11.30 & 0.002 & 29.44 & 0.042 & 31.38 & 0.004 & 18.18 \\
\hline Total Richness & 0.000 & NA & 0.006 & 32.59 & 0.040 & 19.52 & 0.010 & 21.27 \\
\hline E Richness & 0.072 & 43.60 & 0.362 & 26.18 & 0.048 & 21.27 & 0.022 & 21.27 \\
\hline P Richness & 0.020 & 43.60 & 0.032 & 32.59 & 0.394 & 18.98 & 0.068 & 21.27 \\
\hline$\% \mathrm{EPT}$ & 0.044 & 43.60 & 0.008 & 47.70 & 0.162 & 31.38 & 0.016 & 25.02 \\
\hline \%EPT (no B) & 0.402 & 1.25 & 0.132 & 29.44 & 0.732 & 46.18 & 0.112 & 25.87 \\
\hline$\% \mathrm{E}$ & 0.024 & 14.36 & 0.058 & 47.70 & 0.146 & 31.38 & 0.090 & 25.02 \\
\hline$\% \mathrm{E}($ no $\mathrm{B})$ & 0.884 & 14.36 & 0.454 & 26.18 & 1.000 & 46.18 & 0.968 & 35.24 \\
\hline \%Tolerant & 0.036 & 16.58 & 0.028 & 47.70 & 0.046 & 31.38 & 0.012 & 26.83 \\
\hline
\end{tabular}


Table 30: Maximum probability of a change point (PCP) associated with each macroinvertebrate community metric resulting from a conductivity gradient across each site type. The maximum PCP is given along with the associated conductivity at which each max PCP occurred. Bolded values indicate potential change points with probabilities $\geq 0.300$. $m W V S C I=$ modified West Virginia stream condition index, E=Ephemeroptera, $\mathrm{P}=$ Plecoptera, $\mathrm{T}=$ Trichoptera, and $\mathrm{B}=$ Baetidae.

\begin{tabular}{|c|c|c|c|c|c|c|c|c|}
\hline & \multicolumn{2}{|l|}{ Mined } & \multicolumn{2}{|c|}{ Developed } & \multicolumn{2}{|c|}{ All Combined } & \multicolumn{2}{|c|}{ Small Combined } \\
\hline & $\max \mathrm{PCP}$ & Conductivity & $\max \mathrm{PCP}$ & Conductivity & $\max \mathrm{PCP}$ & Conductivity & $\max$ PCP & Conductivity \\
\hline$m$ WVSCI & 0.004 & 104 & 0.170 & 58 & 0.190 & 555 & 0.002 & 481 \\
\hline Total Richness & 0.018 & 684 & 0.000 & NA & 0.010 & 374 & 0.010 & 285 \\
\hline EPT Richness & 0.056 & 170 & 0.034 & 250 & 0.180 & 374 & 0.026 & 285 \\
\hline E Richness & 0.654 & 104 & 0.026 & 250 & 0.364 & 437 & 0.170 & 285 \\
\hline P Richness & 0.022 & 170 & 0.024 & 250 & 0.316 & 374 & 0.032 & 168 \\
\hline T Richness & 0.002 & 287 & 0.018 & 69 & 0.020 & 374 & 0.026 & 481 \\
\hline Total \# & 0.022 & 104 & 0.106 & 69 & 1.000 & 975 & 0.048 & 481 \\
\hline$\%$ EPT & 0.008 & 384 & 0.054 & 58 & 0.328 & 481 & 0.012 & 481 \\
\hline$\%$ EPT (no B) & 0.086 & 287 & 0.212 & 58 & 0.864 & 168 & 0.092 & 168 \\
\hline$\% \mathrm{E}$ & 0.068 & 684 & 0.036 & 58 & 0.192 & 477 & 0.032 & 444 \\
\hline$\% \mathrm{E}($ no B $)$ & 0.966 & 104 & 0.252 & 69 & 1.000 & 168 & 0.970 & 168 \\
\hline$\%$ Tolerant & 0.036 & 104 & 0.468 & 58 & 0.696 & 481 & 0.052 & 481 \\
\hline$\%$ Dominant & 0.040 & 104 & 0.210 & 51 & 0.018 & 374 & 0.006 & 232 \\
\hline$\%$ Chironomidae & 0.024 & 346 & 0.432 & 58 & 0.260 & 555 & 0.112 & 481 \\
\hline \%Hydropsychidae & 0.142 & 51 & 0.284 & 83 & 0.538 & 555 & 0.044 & 494 \\
\hline
\end{tabular}




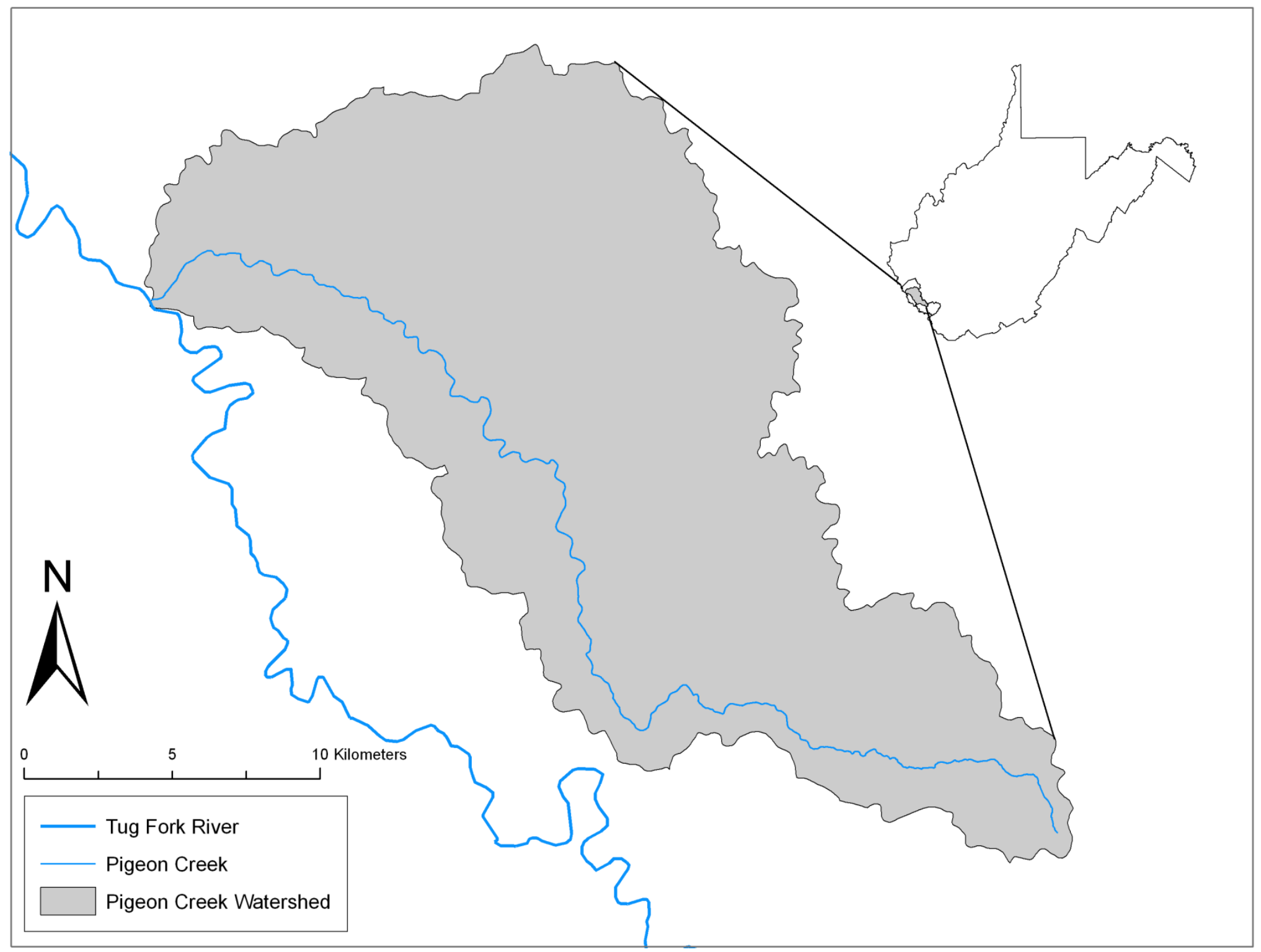

Figure 1: Location of Pigeon Creek within West Virginia. 


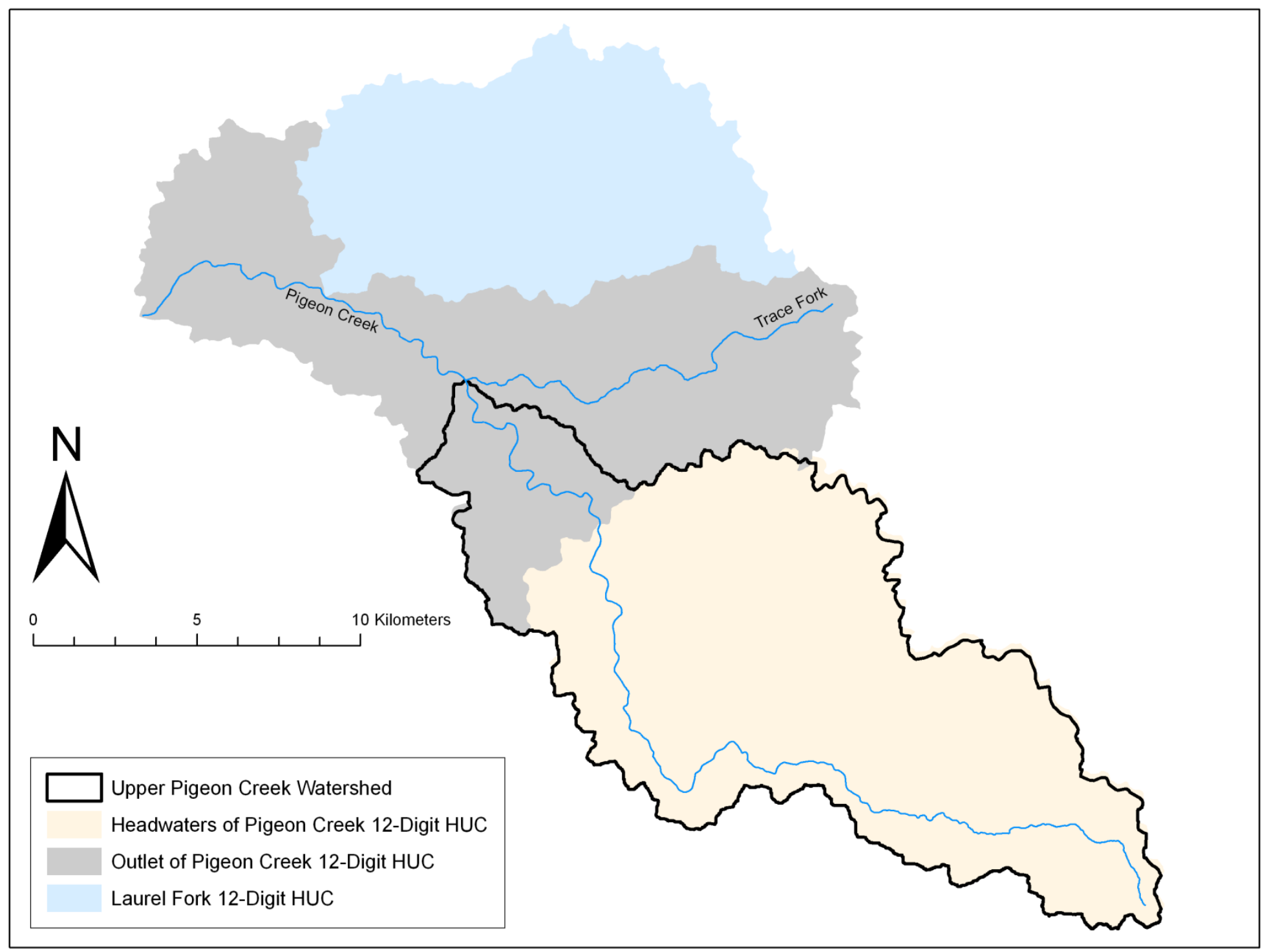

Figure 2: The Upper Pigeon Creek watershed (study basin) with respect to the Pigeon Creek watershed and its component 12-Digit HUCs. 


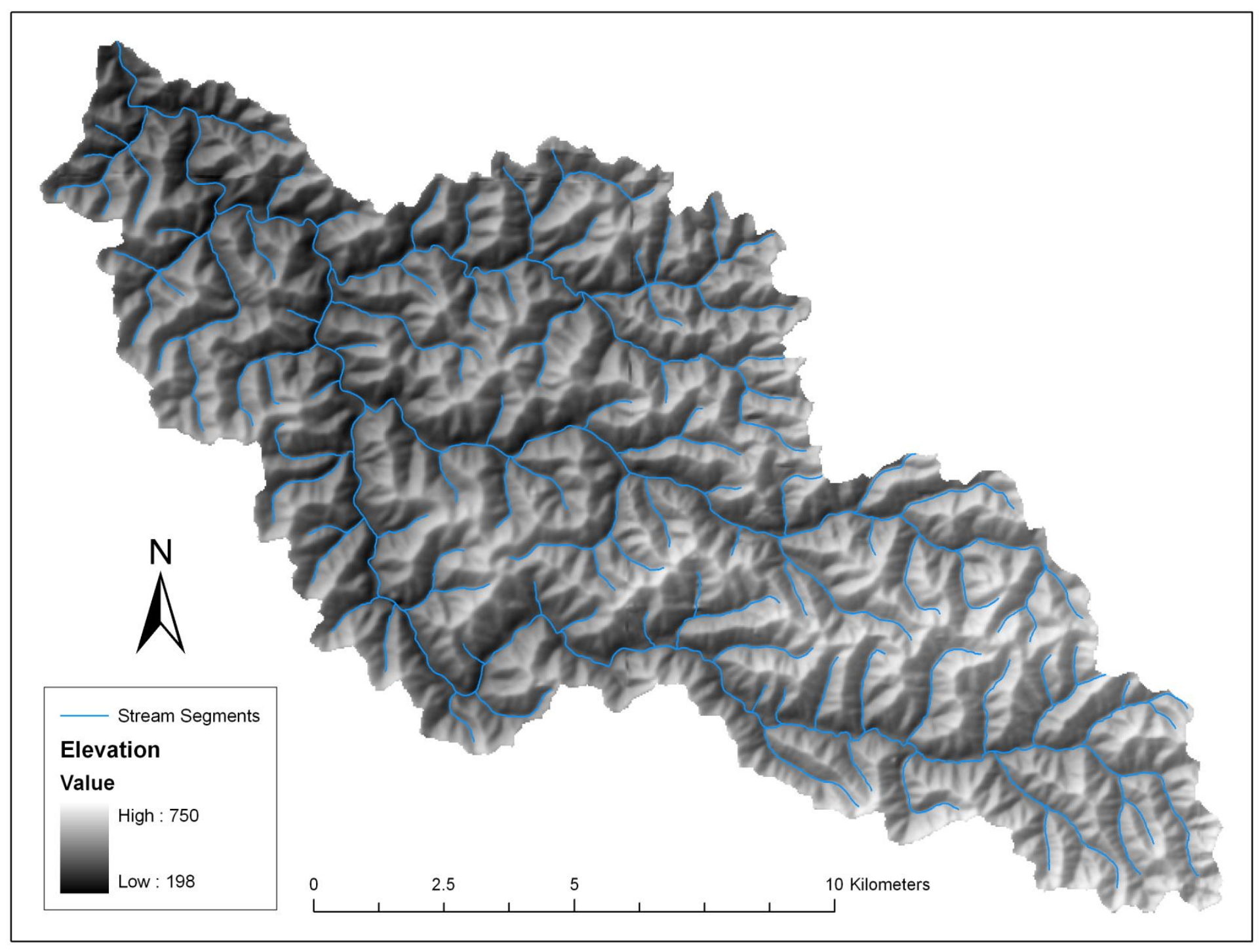

Figure 3: Topography of the Upper Pigeon Creek watershed. 


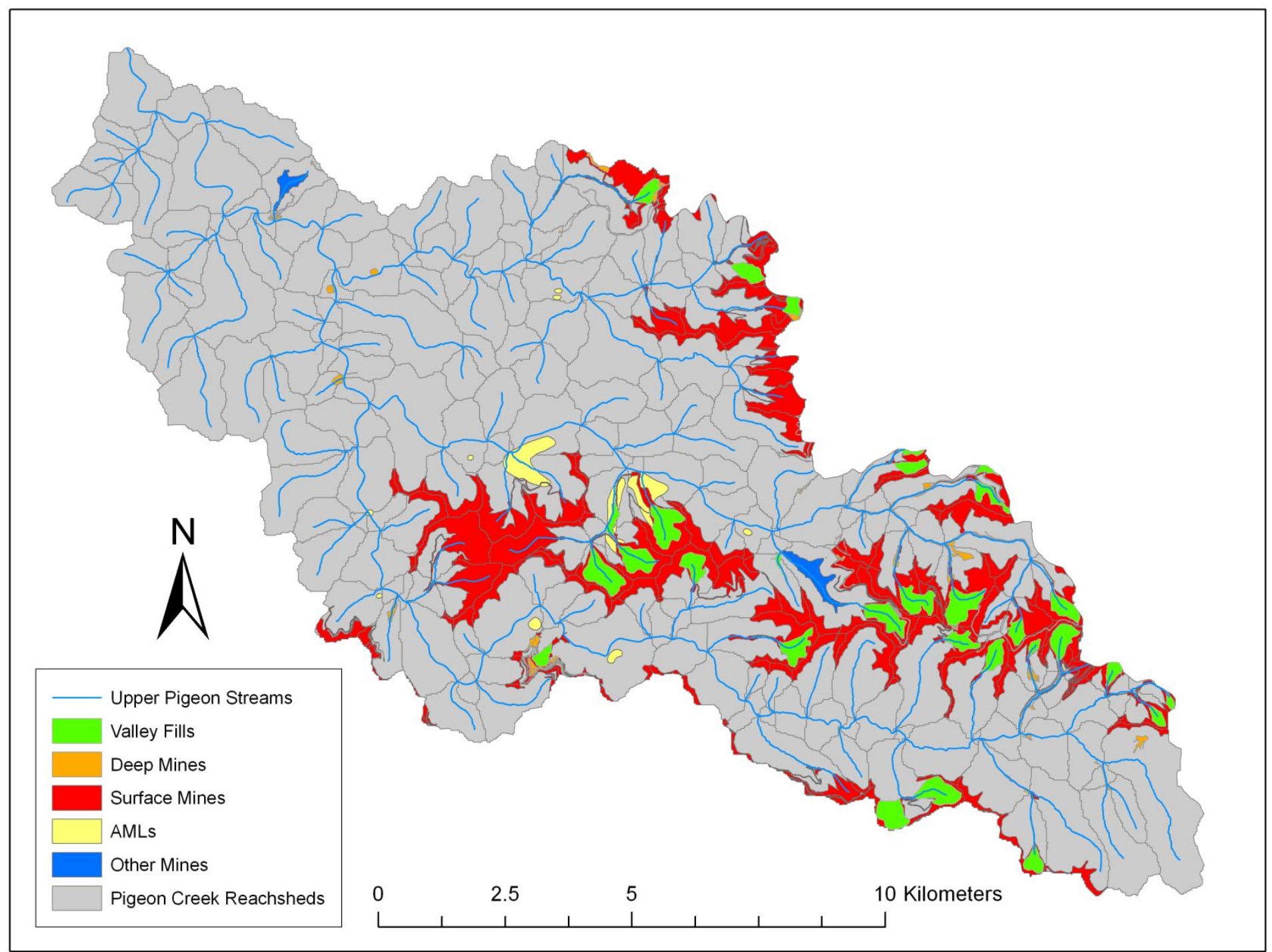

Figure 4: Mining within the Upper Pigeon Creek watershed. AML=Abandoned Mine Land. 


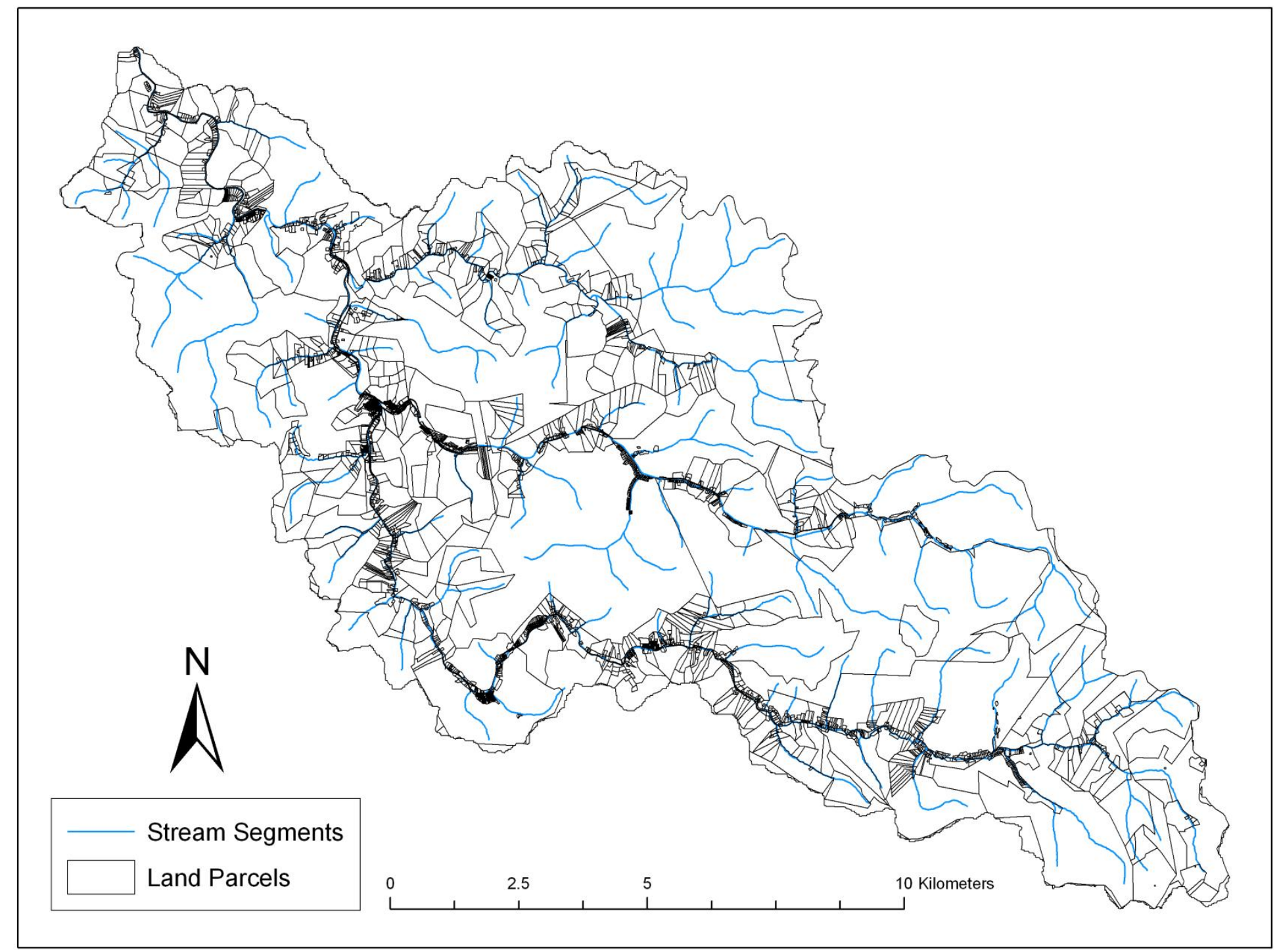

Figure 5: Land Parcels within the Upper Pigeon Creek watershed. 


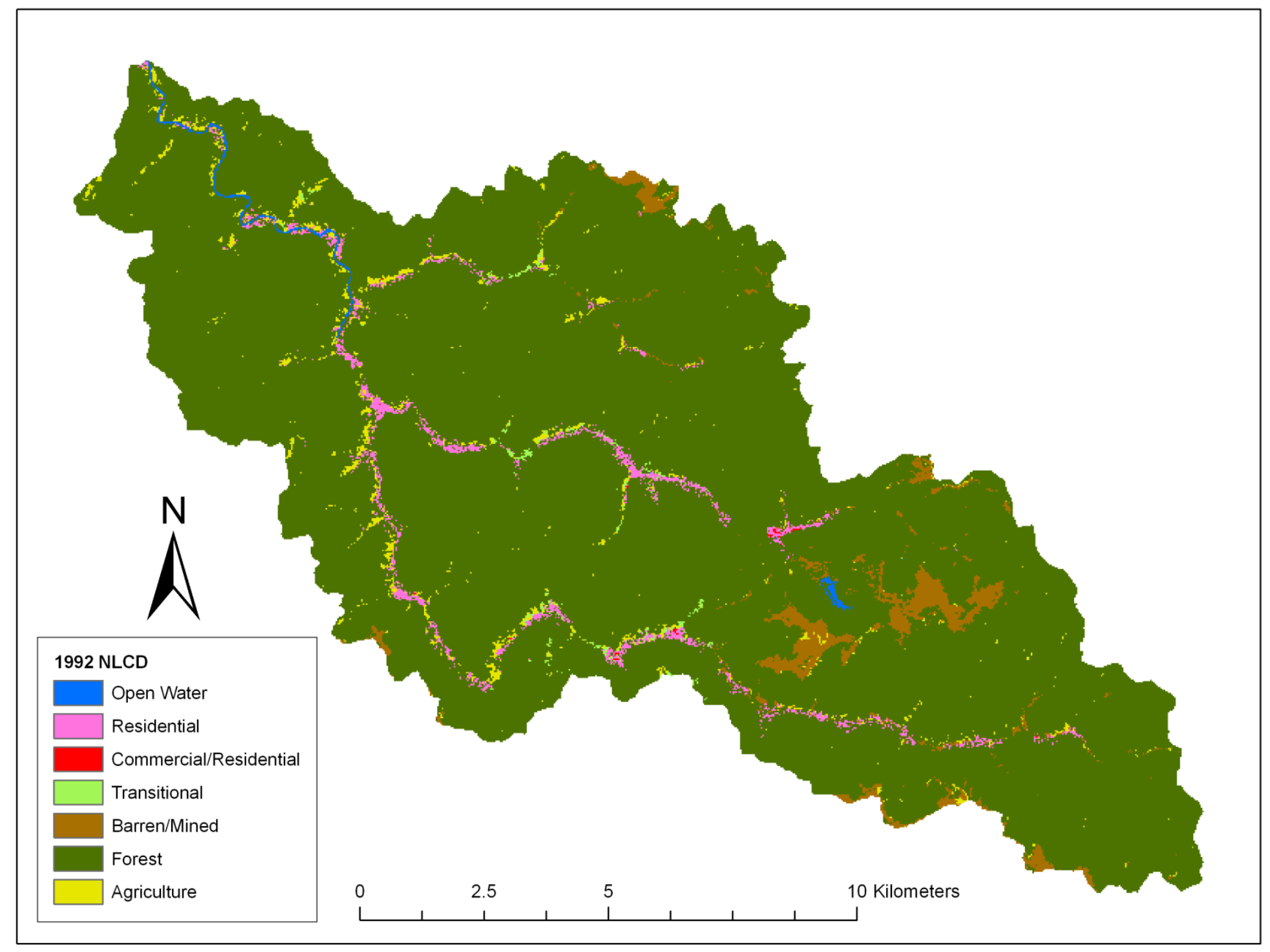

Figure 6: Land use throughout the Upper Pigeon Creek watershed as defined by the 1992 National Land Cover Dataset (NLCD). 


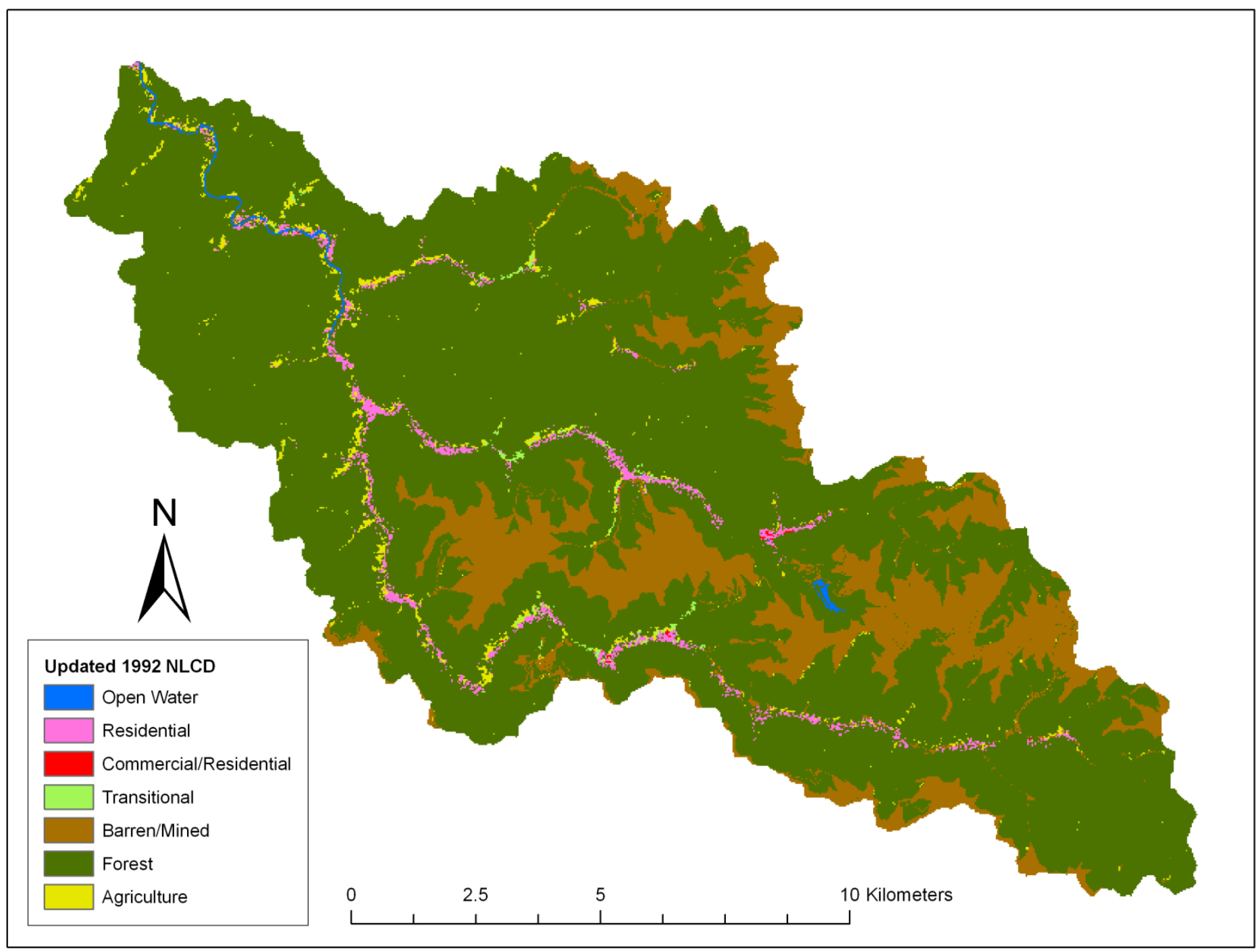

Figure 7: Land use within the Upper Pigeon Creek watershed as defined by the 1992 National Land Cover Dataset (NLCD) following the replacement of previously forested area by recent large-scale surface mining. 


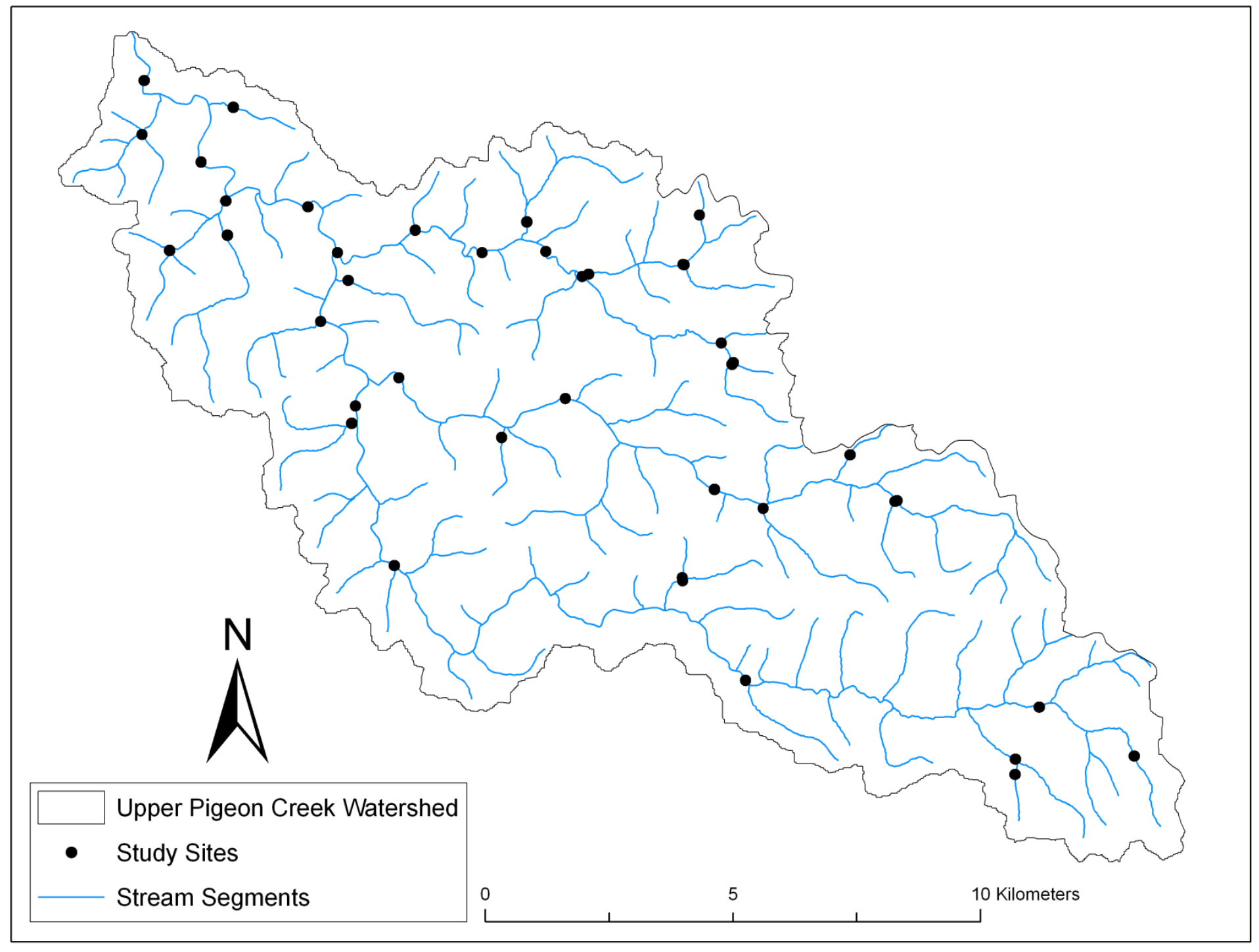

Figure 8: Study sites throughout the Upper Pigeon Creek watershed. 


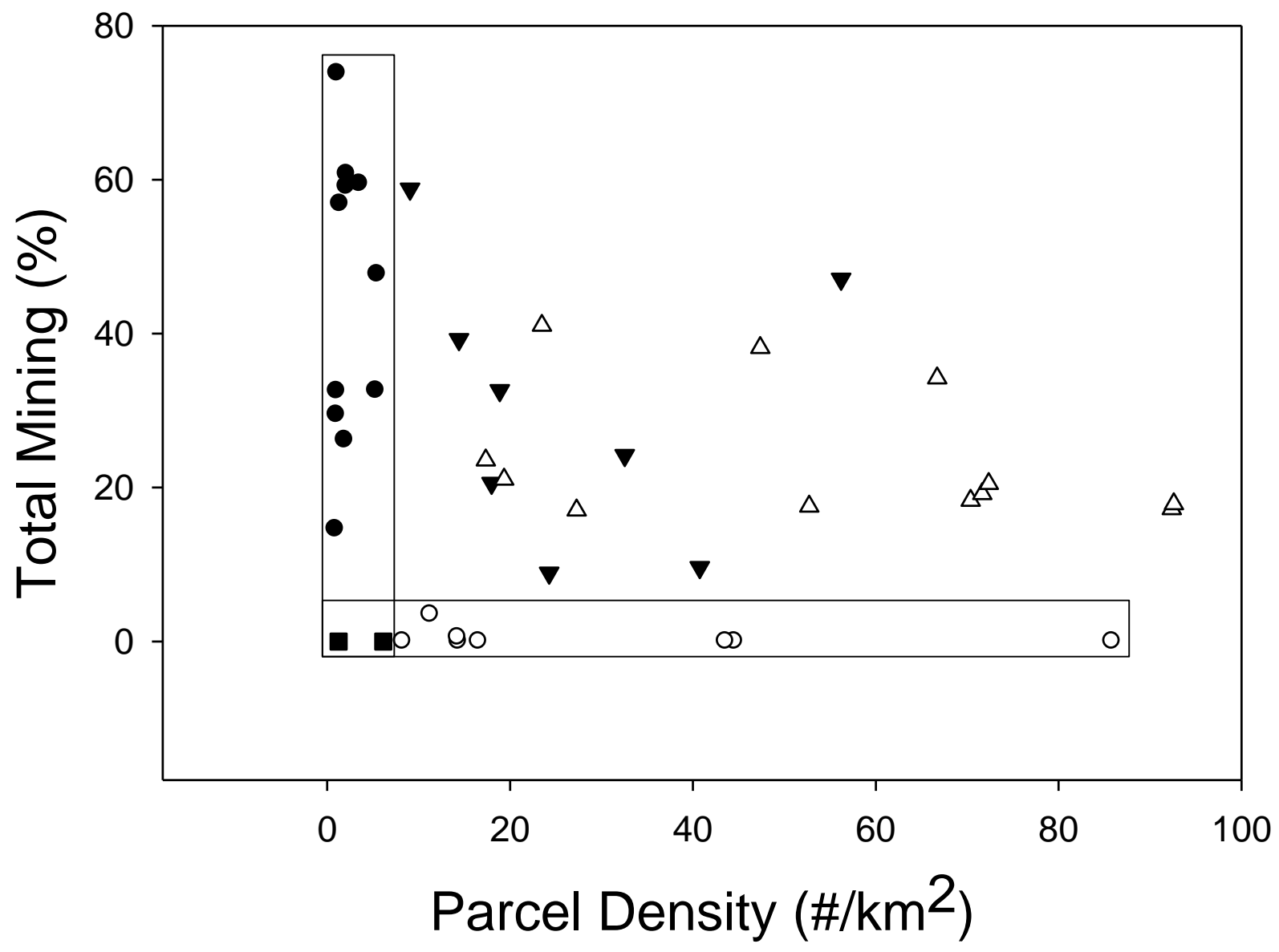

- Mined

- Developed

$\nabla$ Combined Small

$\triangle$ Combined Large

- Reference

Figure 9: Scatter plot of study sites with respect to their influence from mining and residential development (parcel density). Sites falling within the boxes represent the mining and residential gradients. Reference sites were included in both gradients to represent optimal conditions. 


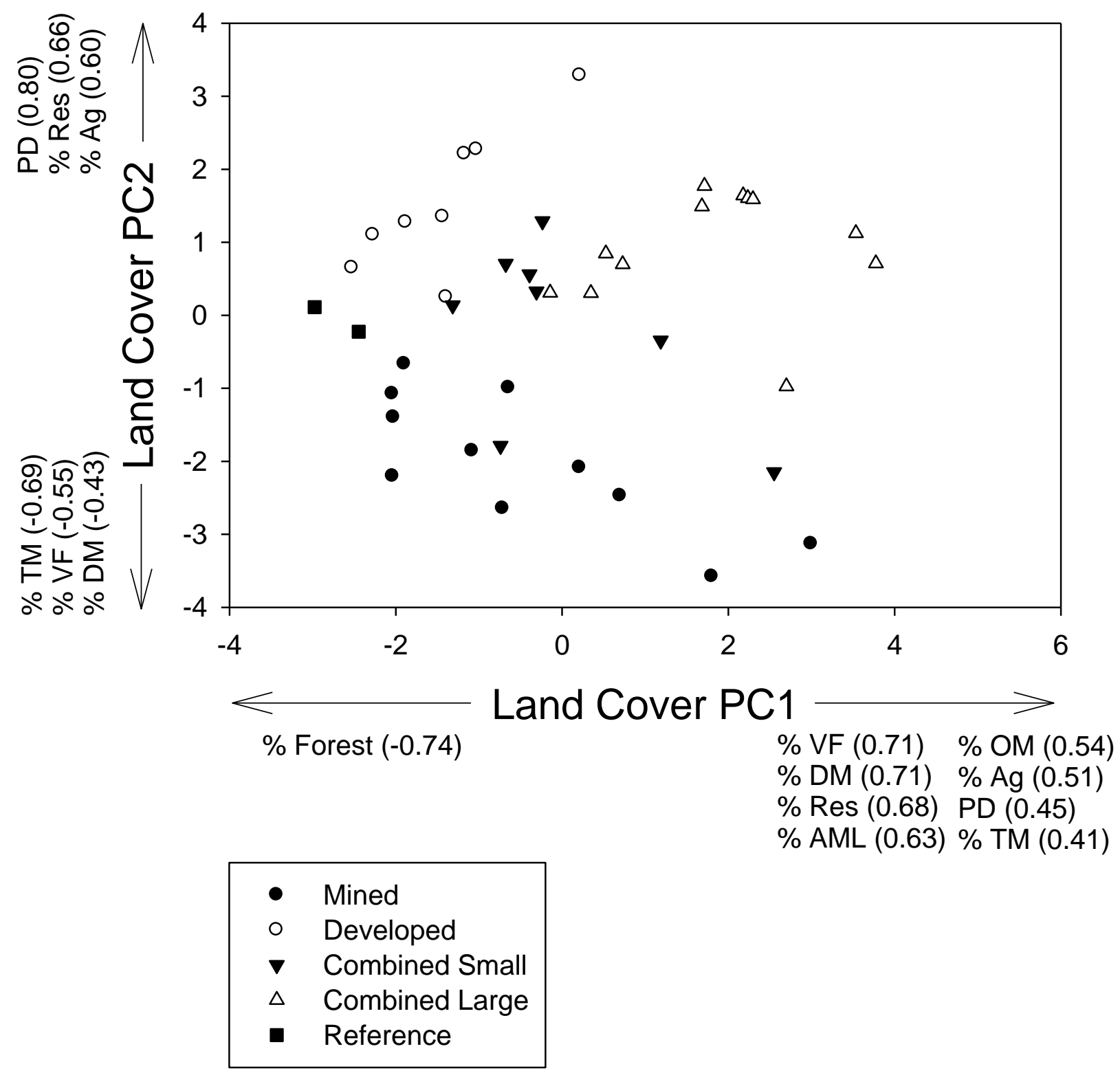

Figure 10: Scatter plot of the first two landscape principal components (PCs). Sites are labeled by site type. Variables significantly loading onto a given PC (loadings $\geq|0.4|$ ) are annotated along each axis. Arrows indicate the direction of increase for each variable. $\mathrm{TM}=$ total mining, $\mathrm{VF}=$ valley fills, $\mathrm{DM}=\mathrm{deep}$ mines, $\mathrm{AML}=$ abandoned mine lands, $\mathrm{OM}=$ other mining, $\mathrm{PD}=$ parcel density, $\mathrm{Ag}=$ agriculture, and Res=Residential. 


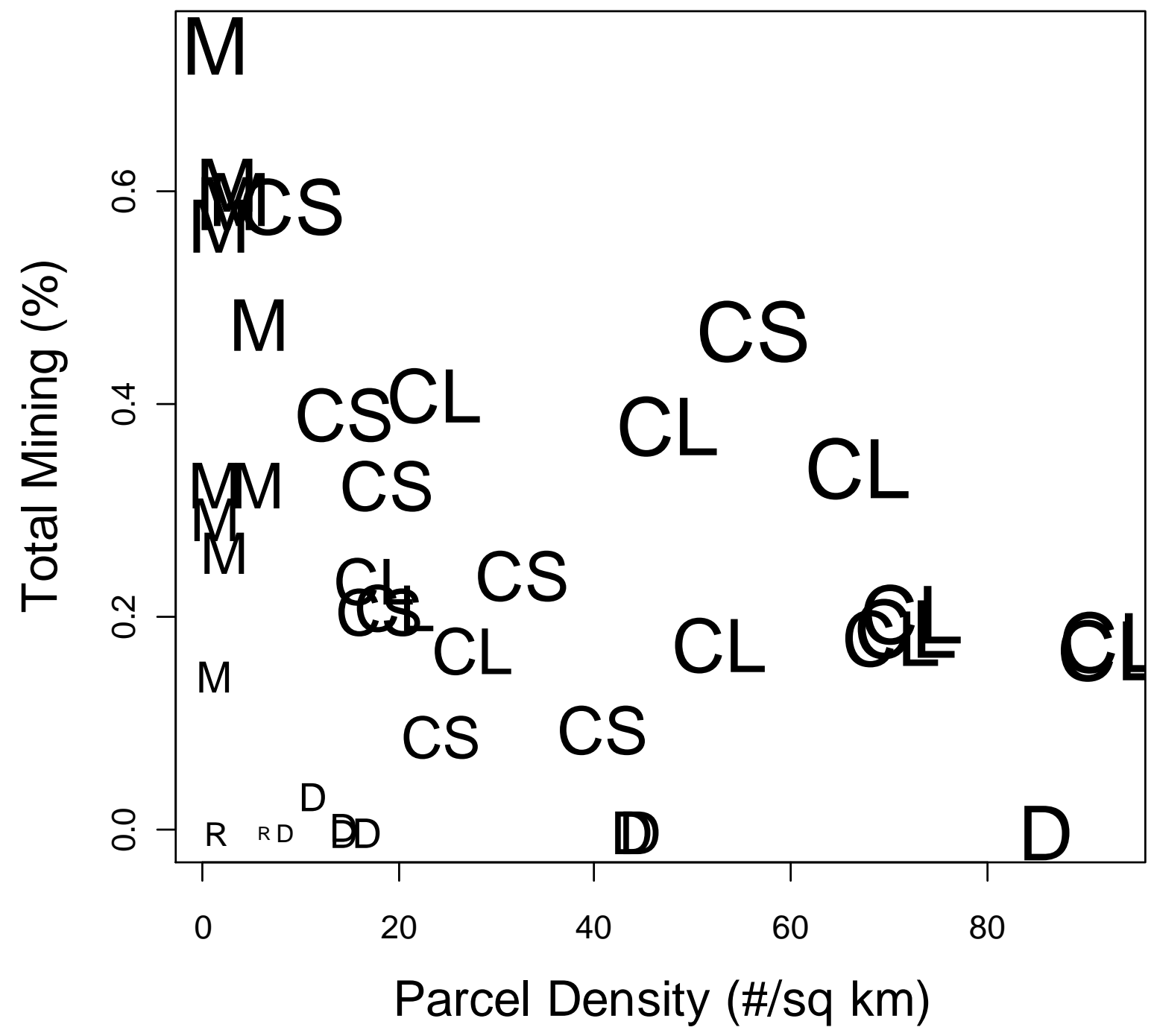

Figure 11: Scatter plot of the 41 study sites with respect to their influence from total $\%$ mining and parcel density. The size of each character is relative to the combined index value associated with each site. Sites are labeled based on their type: $\mathrm{M}=$ mined, $\mathrm{D}=$ developed, $\mathrm{CS}=$ combined small, and $\mathrm{CL}=$ combined large. 


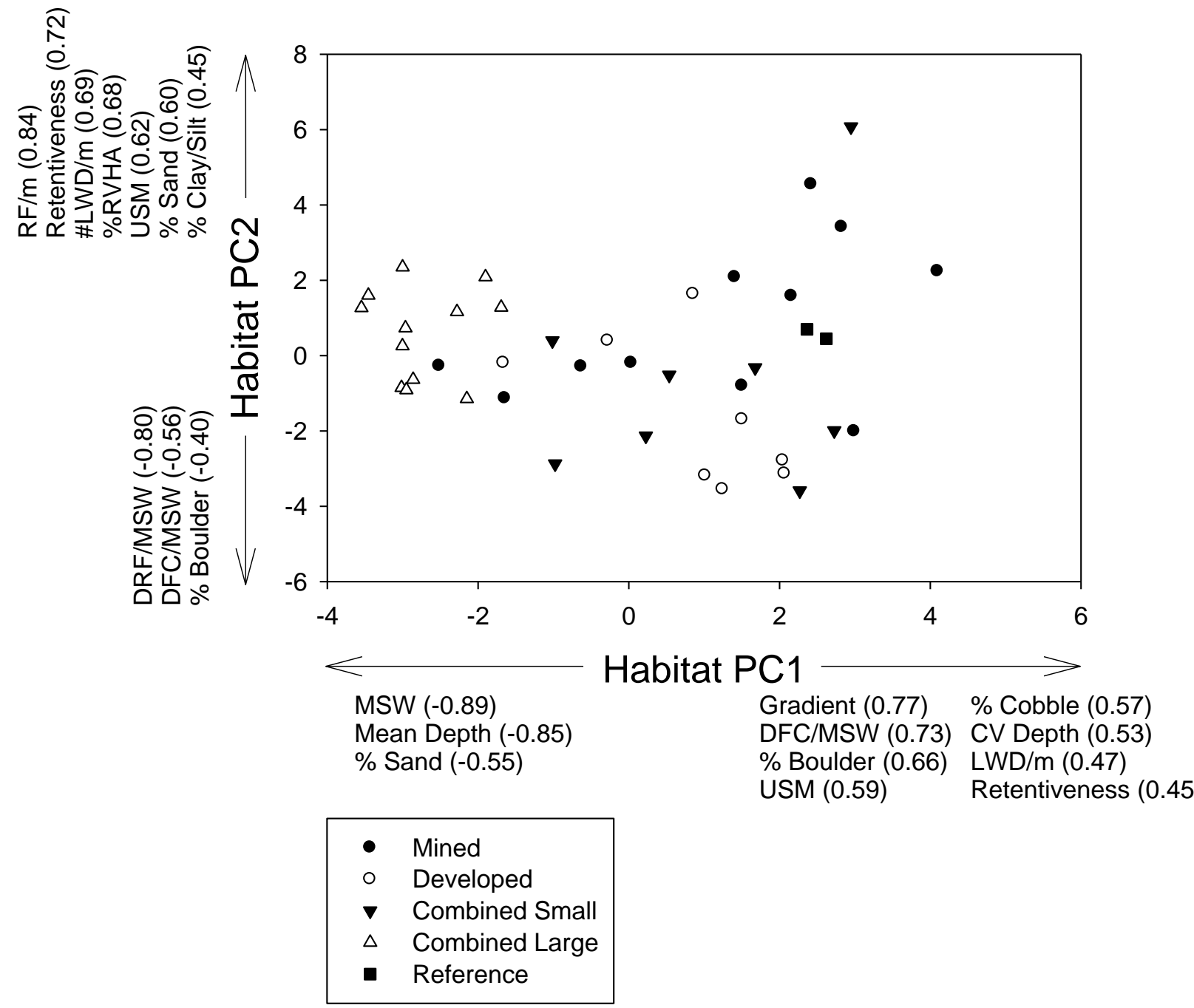

Figure 12: Scatter plot of the first two physical habitat principal components (PCs). Sites are labeled by site type. Variables significantly loading onto a given PC (loadings $\geq|0.4|$ ) are annotated along each axis. Arrows indicate the direction of increase for each variable. MSW=mean stream width, RVHA=Rapid Visual Habitat Assessment, DFC=distance to fish cover, DRF=distance to retentive feature, USM=Unified Stream Method, LWD=large woody debris, $\mathrm{RF}=$ retentive feature, $\mathrm{CV}=$ coefficient of variation. 


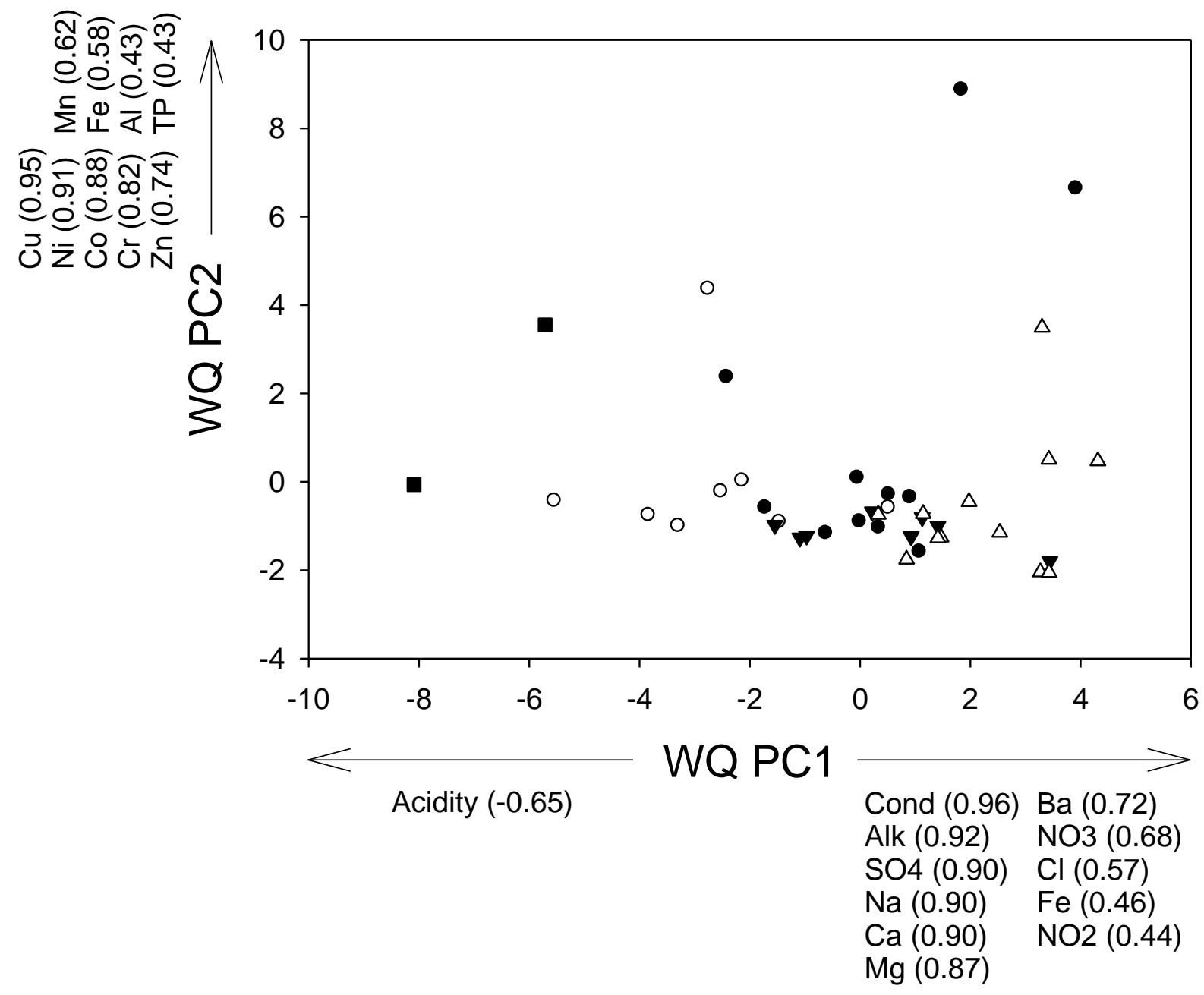

Figure 13: Scatter plot of the first two water chemistry principal components (PCs) created using spring 2008 water chemistry data. Sites are labeled based on site type. Variables significantly loading onto a given PC (loadings $\geq|0.4|$ ) are annotated along each axis. Arrows indicate the direction of increase for each variable. $\mathrm{TP}=$ total phosphorus, $\mathrm{Alk}=$ alkalinity, $\mathrm{Cond}=$ conductivity, and all elements and compounds are listed using their chemical abbreviations and formulas (eg. $\mathrm{Al}=\mathrm{Aluminum}$ and $\mathrm{SO}_{4}=\mathrm{Sulfate}$ ). 


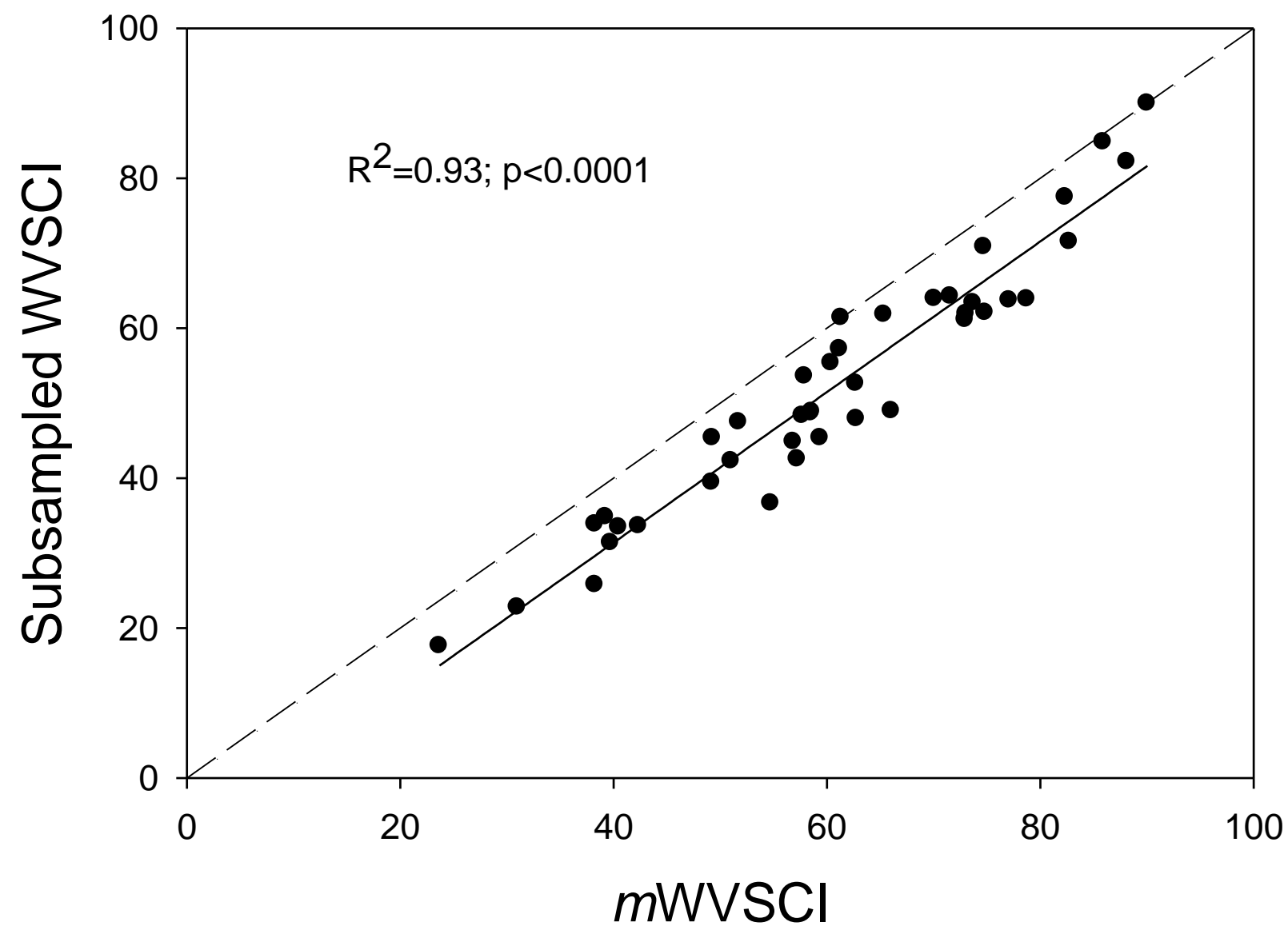

Figure 14: Relationship between the modified West Virginia Stream Condition Index ( $m$ WVSCI) and WVSCI scores calculated using a 200-individual subsample. The dashed guideline represents a perfect relationship between $m$ WVSCI and the subsampled WVSCI. The difference between the actual relatiomship and the guideline represents the overestimation of $m$ WVSCI by 8.81 points. 


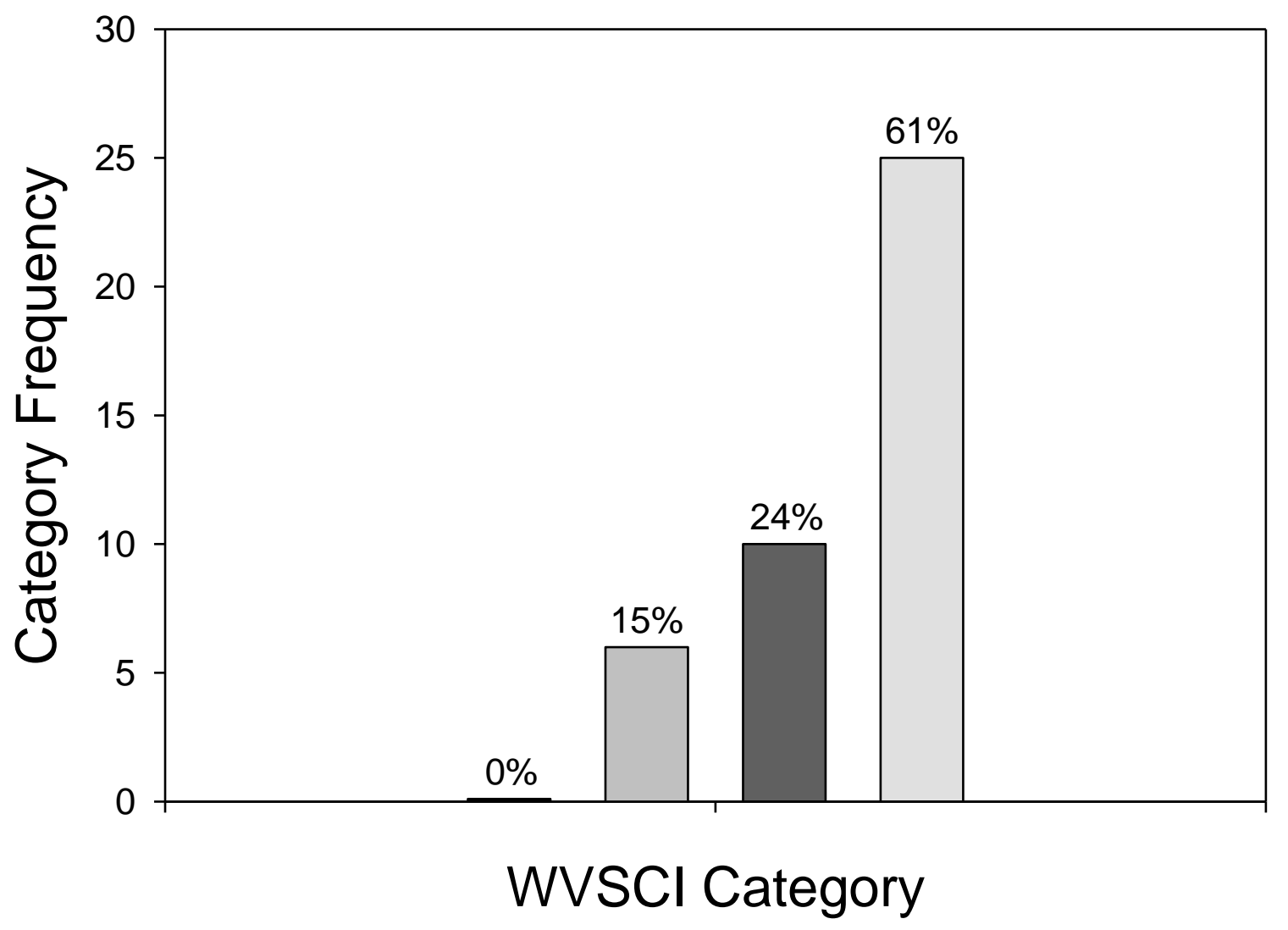

$\square$ Excellent
$\square$ Good
$\square$ Marginal
$\square$ Poor

Figure 15: Frequency distribution of West Virginia Stream Condition Index (WVSCI) categories throughout the study area. Modified West Virginia Stream Condition Index ( $m$ WVSCI) scores were adjusted to approximate WVSCI scores by subtracting 8.81 points. Adjusted $m$ WVSCI scores of $>84.9=$ Excellent, $84.9-70.0=$ Good, 69.9-55.0 $=$ Moderate, and $<55=$ Poor. The relative abundance of each category across the study area is presented. 


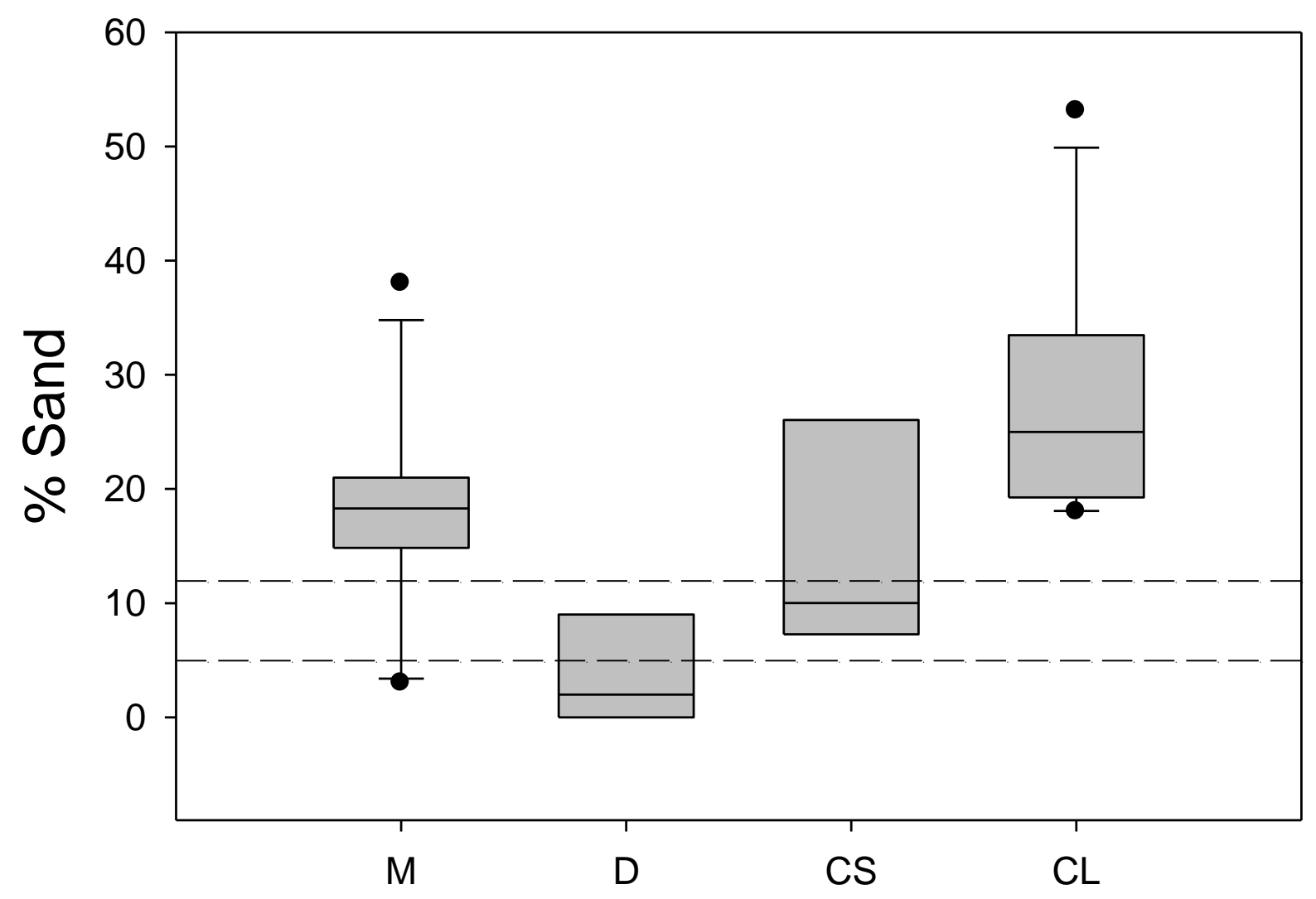

Figure 16: Box plot comparing \%sand across all site types. 95\% confidence intervals are presented. The horizontal bar within each box represents the mean score for each respective site type. The dashed lines represent \%sand measures for the two reference sites. $\mathrm{M}=$ mined, $\mathrm{D}=$ developed, $\mathrm{CS}=$ small combined, and $\mathrm{CL}=$ large combined. 


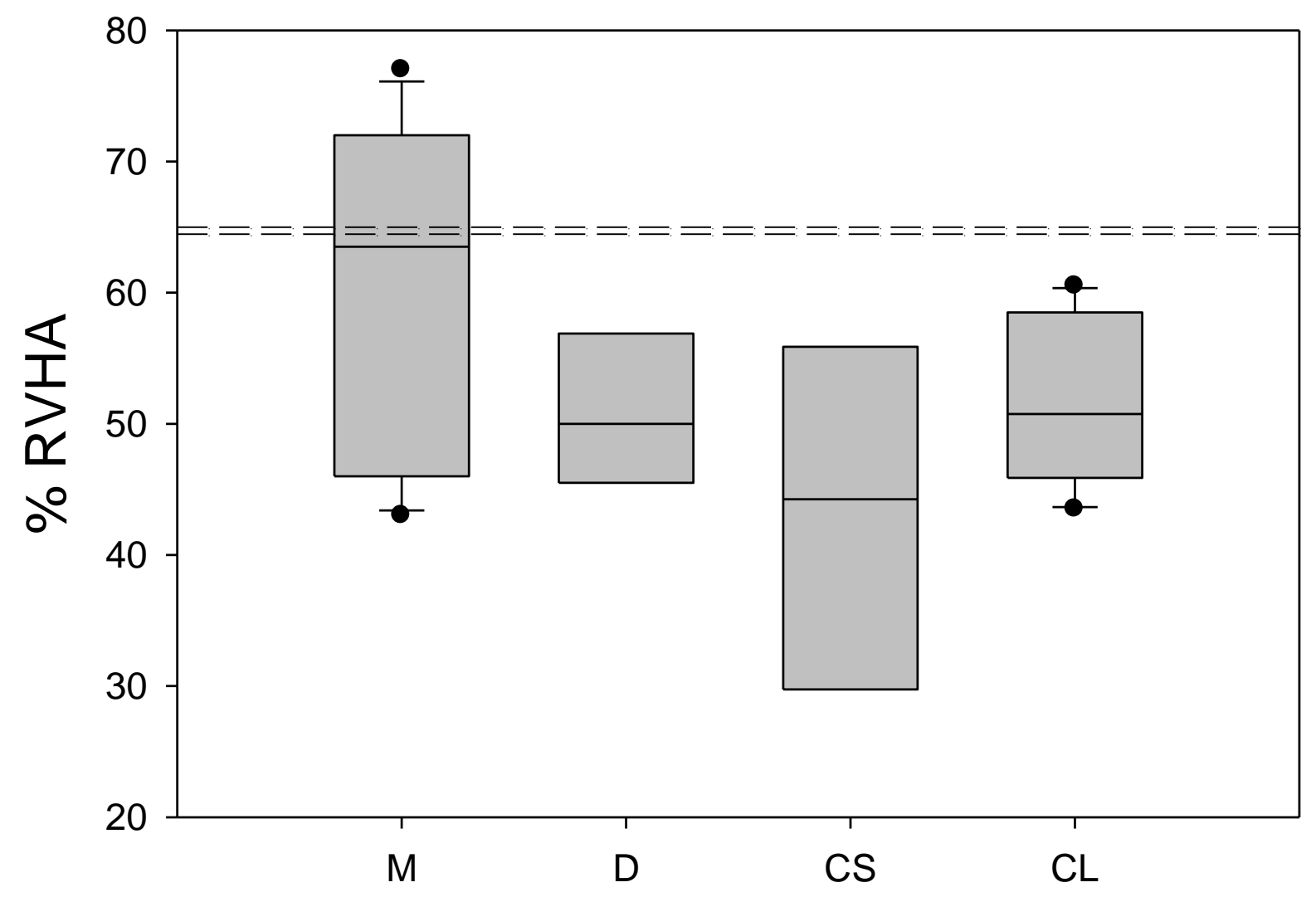

Figure 17: Box plot comparing \%Rapid Visual Habitat Assessment (RVHA) scores across all site types. 95\% confidence intervals are presented. The horizontal bar within each box represents the mean score for each respective site type. The dashed lines represent \%RVHA scores for the two reference sites. $\mathrm{M}=$ mined, $\mathrm{D}=$ developed, $\mathrm{CS}=$ small combined, and $\mathrm{CL}=$ large combined. 


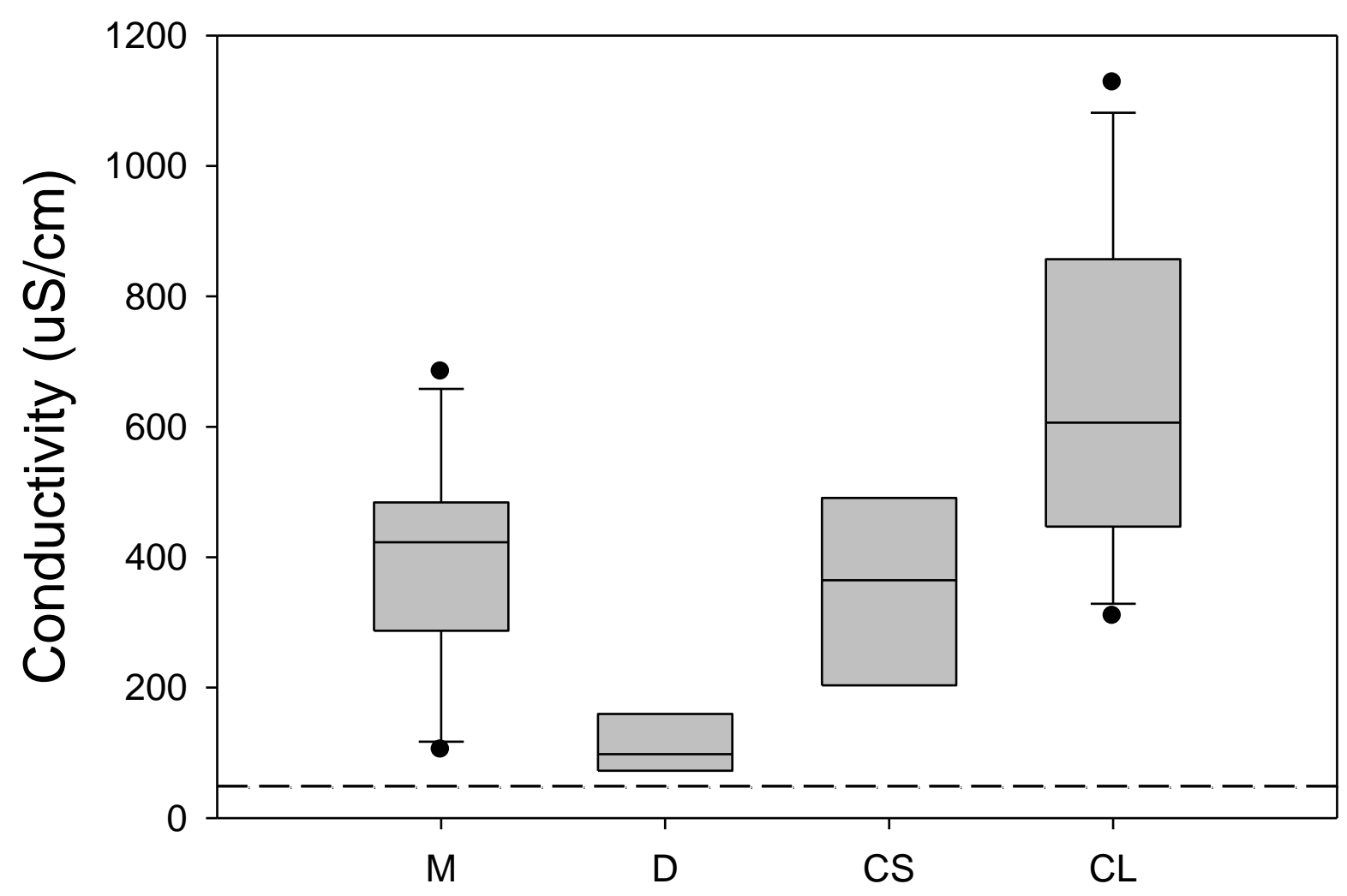

Figure 18: Box plot comparing conductivity values across all site types. 95\% confidence intervals are presented. The horizontal bar within each box represents the mean score for each respective site type. The dashed lines represent conductivity values for the two reference sites. M=mined, $\mathrm{D}=$ developed, $\mathrm{CS}=$ small combined, and $\mathrm{CL}=$ large combined. 


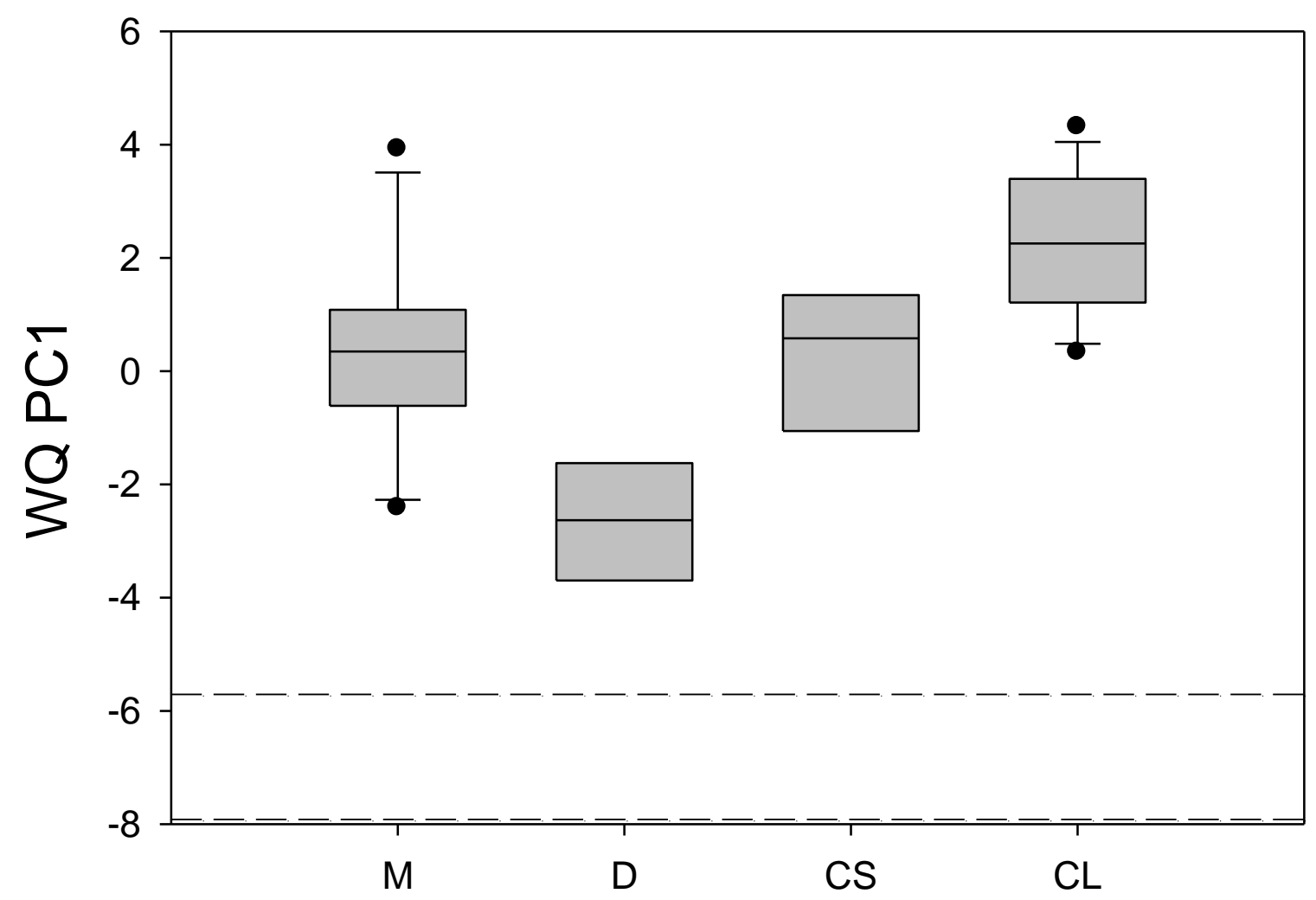

Figure 19: Box plot comparing water quality principal component 1 (WQ PC1) scores across all site types. $95 \%$ confidence intervals are presented. The horizontal bar within each box represents the mean score for each respective site type. The dashed lines represent WQ PC1 values for the two reference sites. $\mathrm{M}=$ mined, $\mathrm{D}=$ developed, $\mathrm{CS}=$ small combined, and $\mathrm{CL}=$ large combined. 


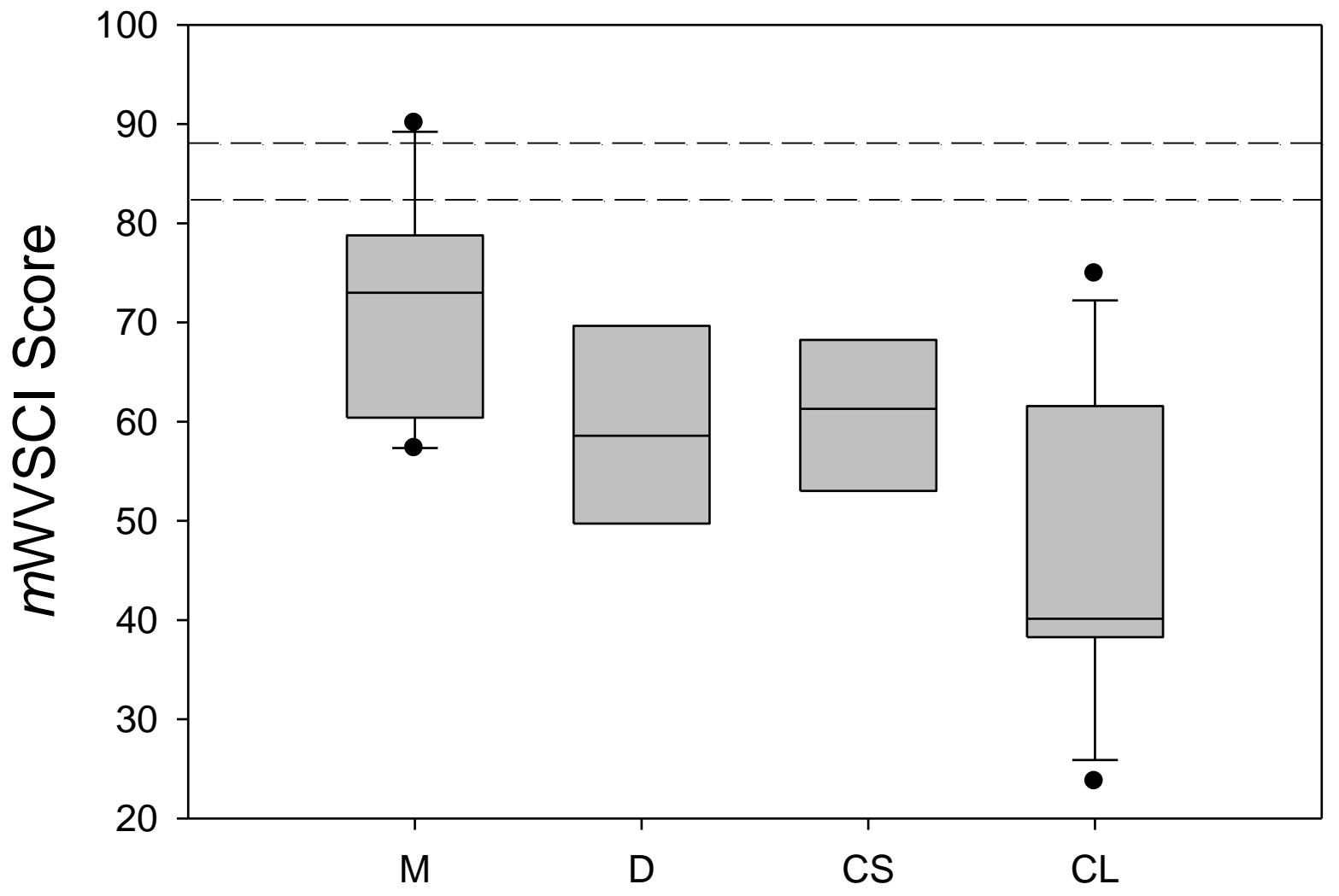

Figure 20: Box plot comparing modified West Virginia Stream Condition Index ( $m$ WVSCI) scores across all site types. 95\% confidence intervals are presented. The horizontal bar within each box represents the mean score for each respective site type. The dashed lines represent $m \mathrm{WVSCI}$ scores for the two reference sites. $\mathrm{M}=$ mined, $\mathrm{D}=$ developed, $\mathrm{CS}=$ small combined, and $\mathrm{CL}=$ large combined. 


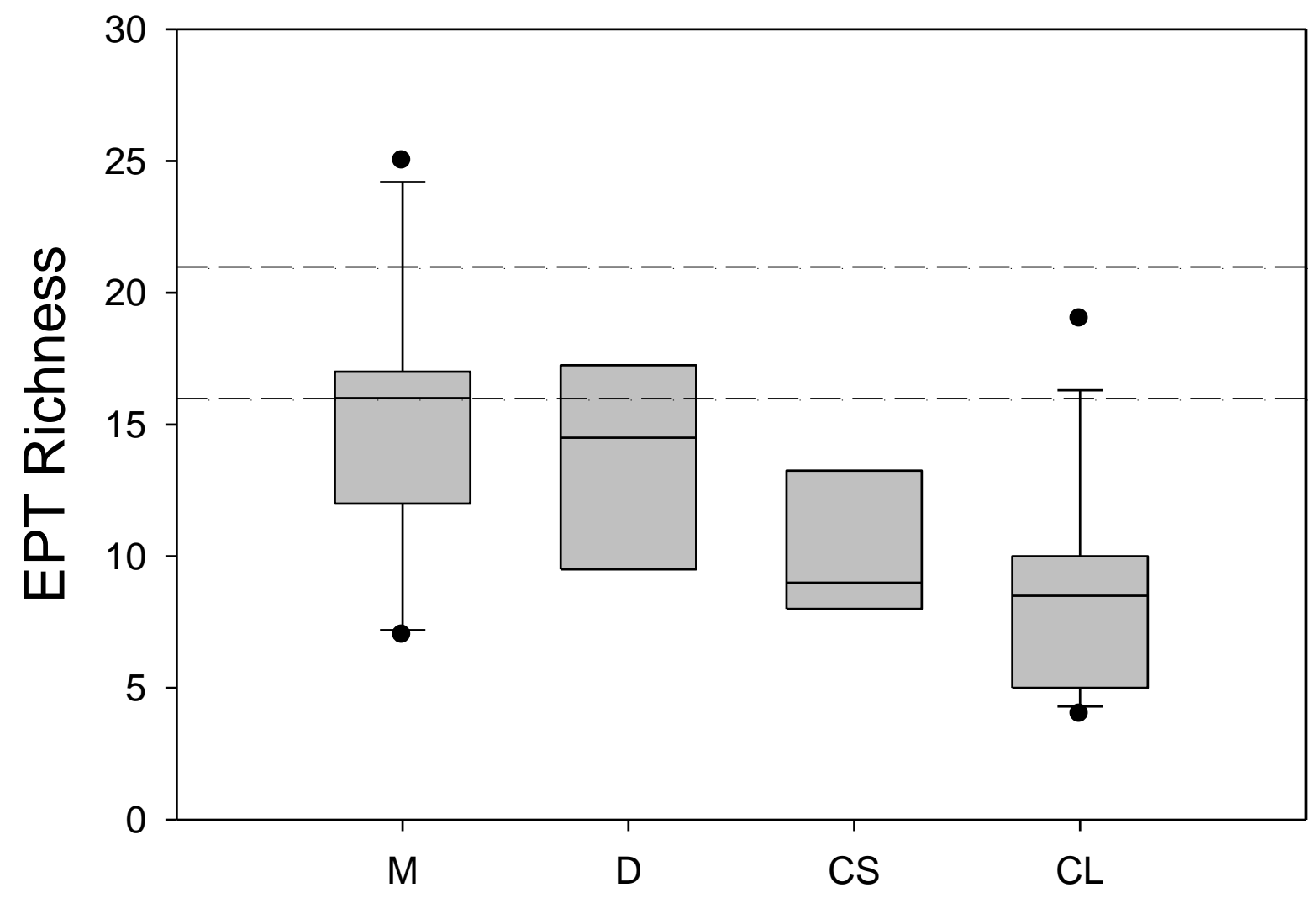

Figure 21: Box plot comparing Ephemeroptera, Plecoptera, and Trichoptera richness (EPT) scores across all site types. 95\% confidence intervals are presented. The horizontal bar within each box represents the mean score for each respective site type. The dashed lines represent EPT scores for the two reference sites. $\mathrm{M}=$ mined, $\mathrm{D}=$ developed, $\mathrm{CS}=$ small combined, and $\mathrm{CL}=$ large combined. 


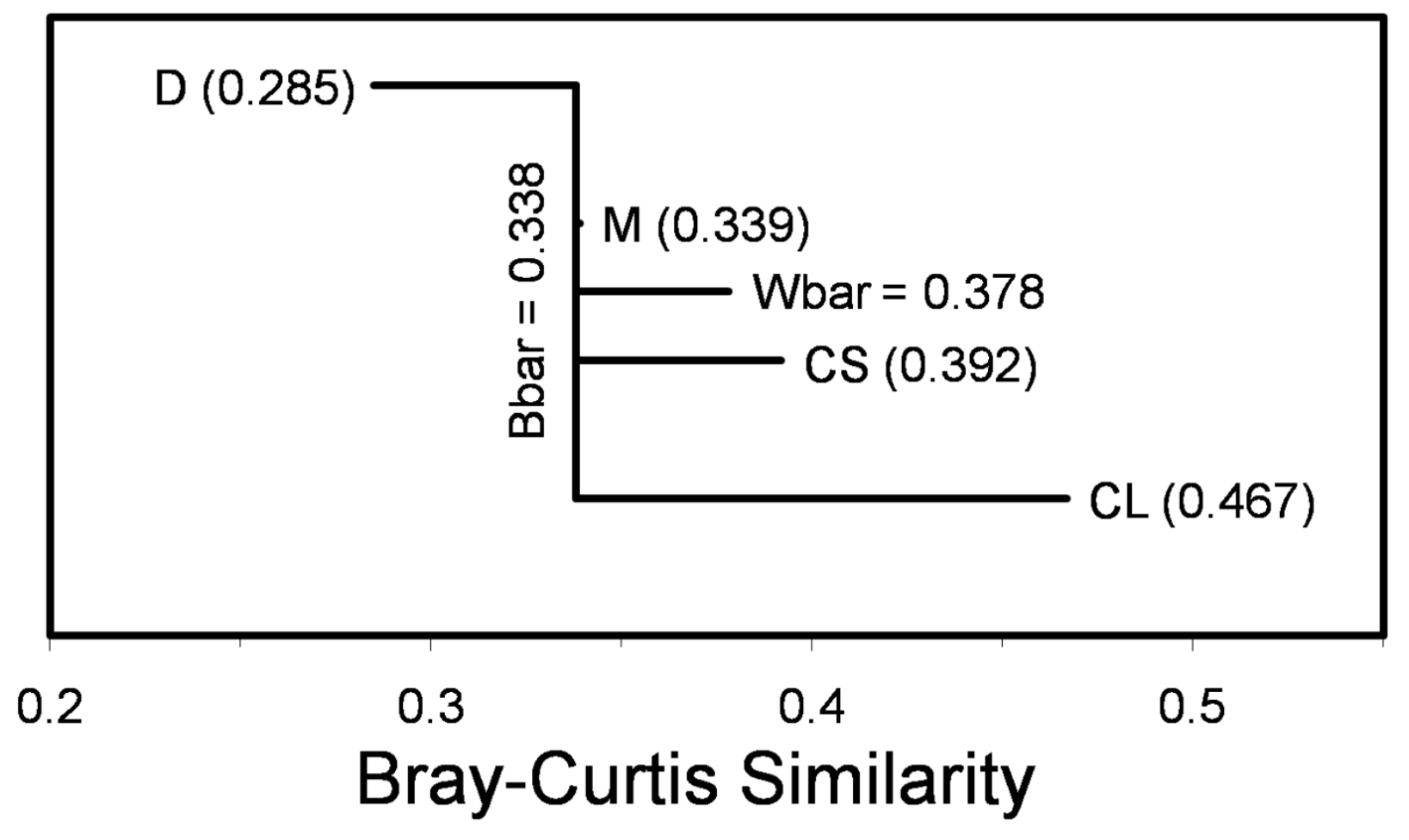

Figure 22: Mean Similarity dendrogram comparing site types based on macroinvertebrate community structure. The vertical bar represents the overall between-group similarity (Bbar), and each branch represents the within-group similarity for each site type. The overall within-group similarity (Wbar) is plotted for comparison. Each branch is labeled with respect to site type and within-group similarity. $\mathrm{D}=$ developed, $\mathrm{M}=$ mined, $\mathrm{CS}=$ combined small, and $\mathrm{CL}=$ combined large. 


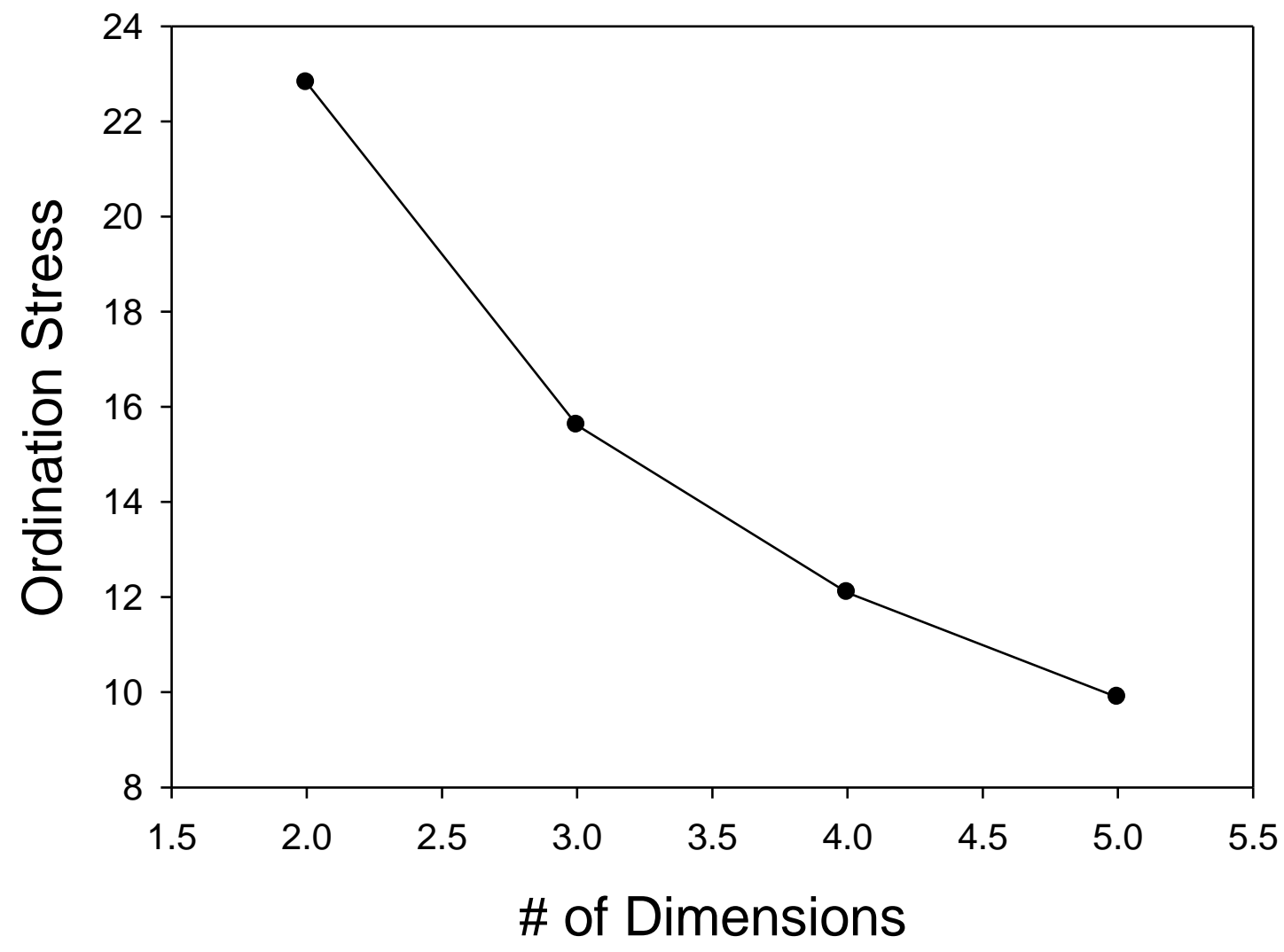

Figure 23: Scree plot used to determine the number of dimensions needed to construct the NMDS ordination. Three dimensions best represented the data without unnecessarily increasing $k$. Three dimensions resulted in a stress of 15.62, which was identified in two convergent solutions after 9 runs. 


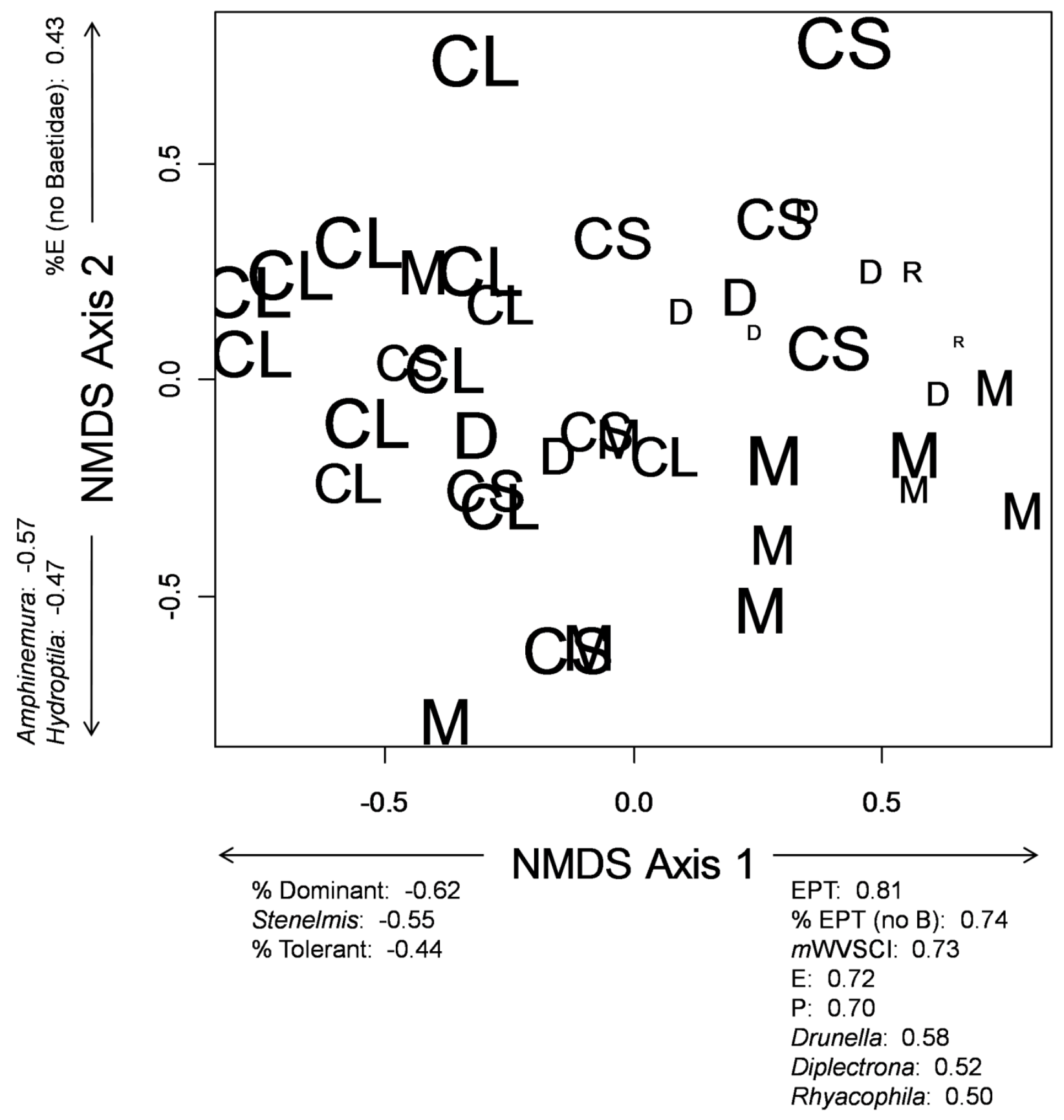

Figure 24: Non-Metric Multidimensional Scaling (NMDS) ordination of sites based on genus-level macroinvertebrate community data. NMDS scores from Axis 1 (x-axis) and Axis 2 (y-axis) are plotted. Taxa abundances and community metrics with high Spearman rank correlations $(\mathrm{p}<0.05)$ are annotated along each axis. Arrows indicate the direction of increase for each variable. Sites are labeled based on their type: $\mathrm{M}=$ mined, $\mathrm{D}=$ developed, $\mathrm{CS}=$ small combined, $\mathrm{CL}=$ large combined, and $\mathrm{R}=$ reference. Character size is relative to the CI score for each site. 


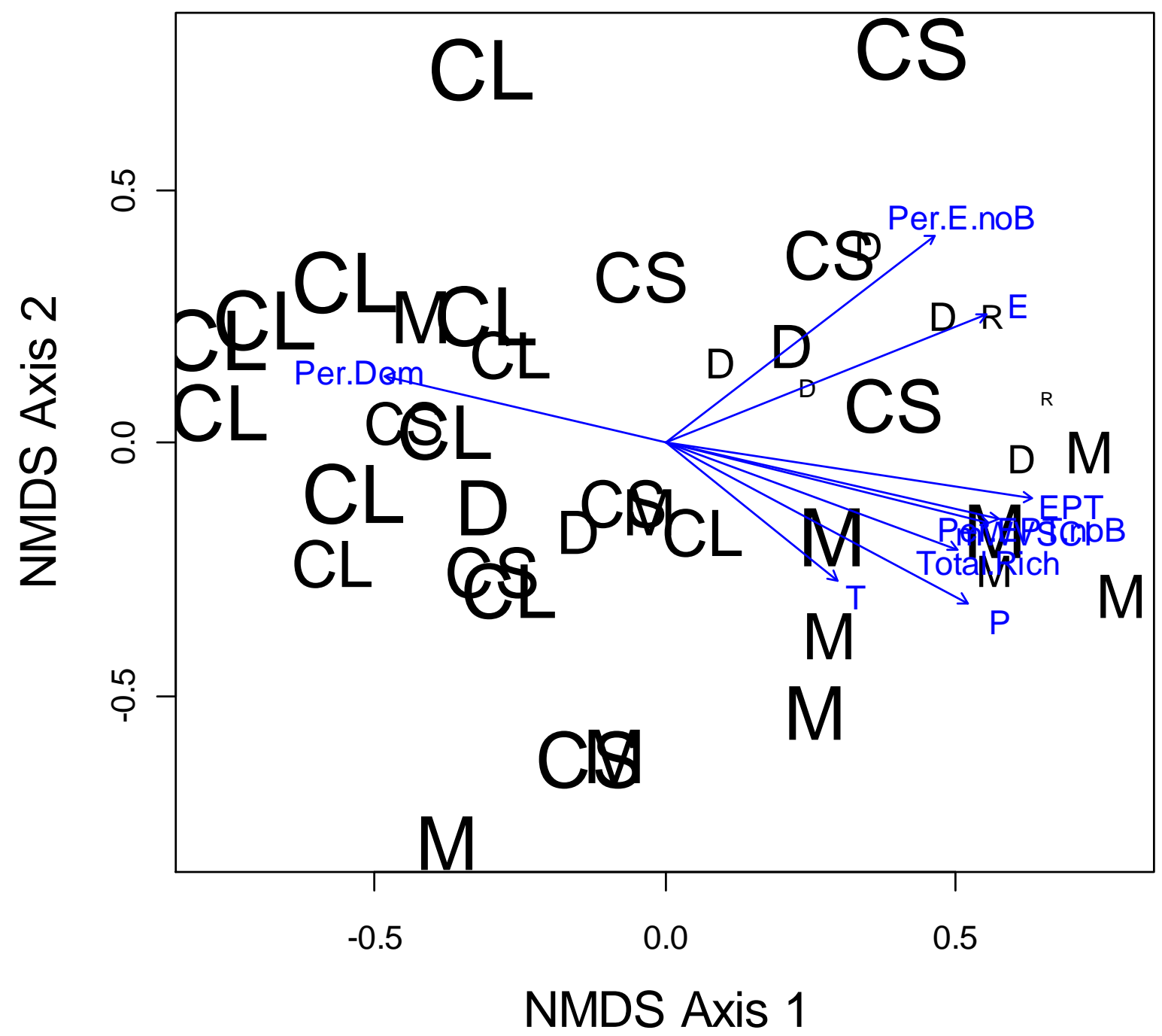

Figure 25: Non-Metric Multidimensional Scaling (NMDS) biplot separating sites based on genus-level macroinvertebrate community data. Individual community metrics were environmentally fitted to the NMDS ordination. Only metrics significantly correlated with the NMDS ordination $(p<0.0001)$ were plotted. The arrows indicate the direction of increase for each variable. The length of each arrow indicates the strength of the relationship between the ordination and the variable of interest. Sites are labeled based on their type: $\mathrm{M}=$ mined, $\mathrm{D}=$ developed, $\mathrm{CS}=$ small combined, $\mathrm{CL}=$ large combined, and $\mathrm{R}=$ reference. Character size is relative to the $\mathrm{CI}$ score for each site. Per.Dom $=\%$ Dominant, Per.E.noB=\%Ephemeroptera excluding Baetidae, E=Ephemeroptera richness, $\mathrm{P}=\mathrm{Plecoptera}$ richness, $\mathrm{T}=$ Trichoptera richness, EPT=Ephemeroptera, Plecoptera, and Trichoptera richness, Per.EPT.noB=\%EPT excluding Baetidae, $m$ WVSCI=modified West Virginia Stream Condition Index, Total.Rich= Total Richness. 


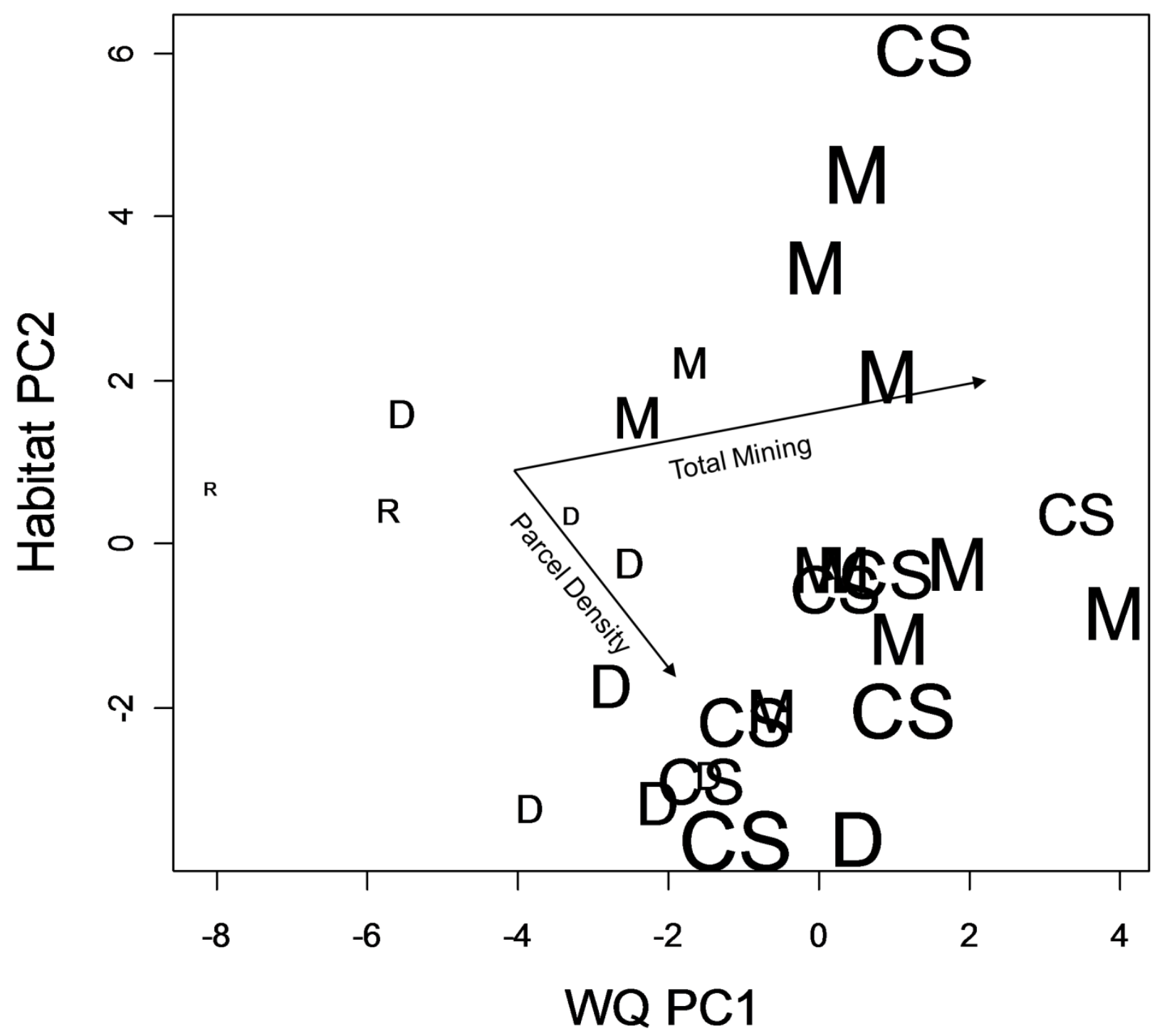

Figure 26: Scatter plot between WQ Principal Component (PC) 1 and Habitat PC2. The arrows represent results of partial correlation analysis used to determine the influence of total mining (\%) and parcel density $\left(\# / \mathrm{km}^{2}\right)$ on both the WQ and habitat PCs. The length and direction of each arrow indicate the strength of the correlations between each landscape variable and each PC, while removing the effect of the competing predictor variable (i.e. landscape variable). Sites are labeled by site type, and the size of each character is relative to the CI score for each. $\mathrm{M}=$ mined, $\mathrm{D}=$ developed, $\mathrm{CS}=$ combined small, and $\mathrm{R}=$ reference. 

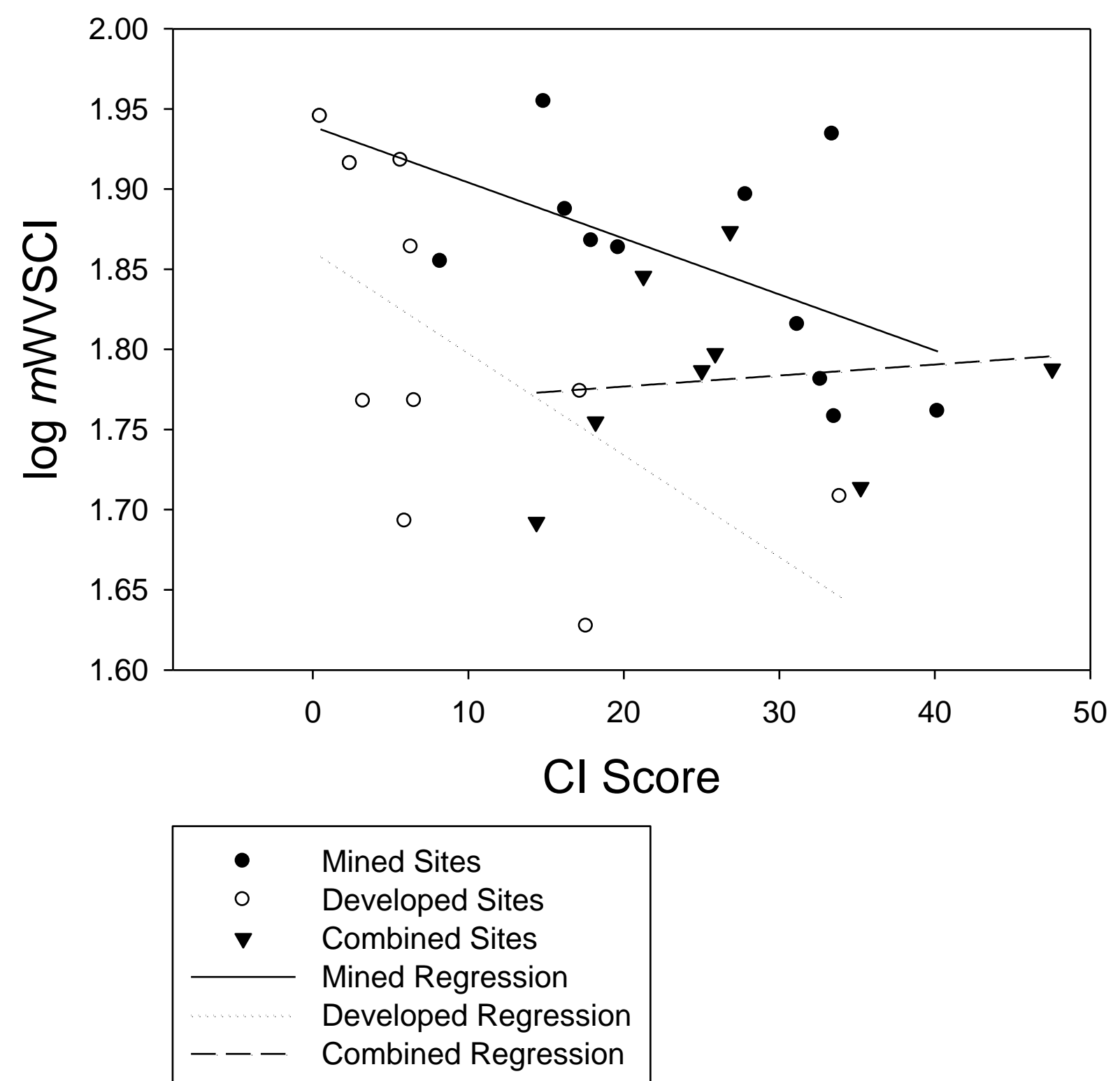

Figure 27: Relationship between the modified West Virginia Stream Condition Index ( $m$ WVSCI) and combined index (CI) score for each site type. Only small combined sites were used in the ANCOVA analysis to ensure study site independence. 

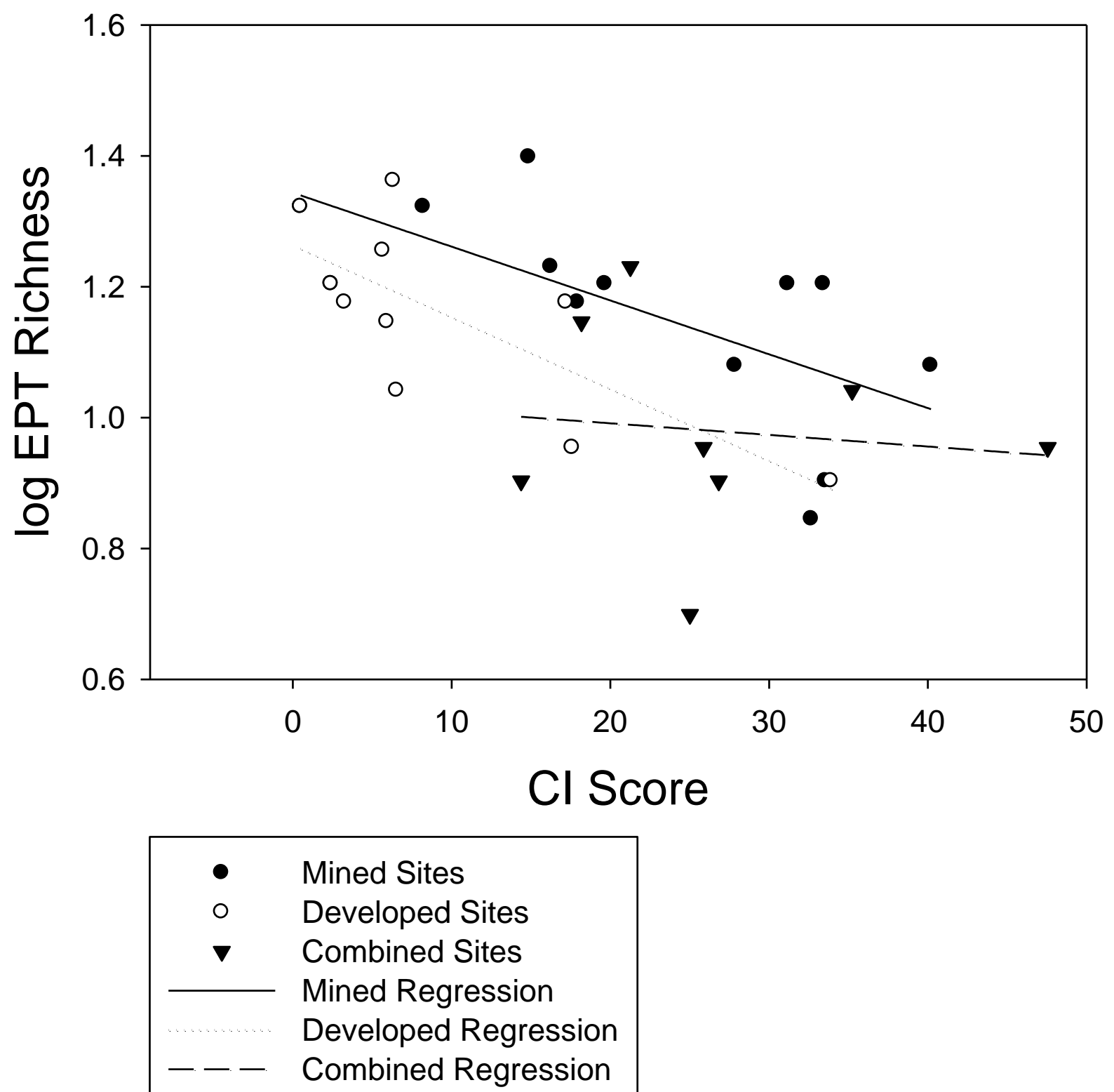

Figure 28: Relationship between Ephemeroptera, Plecoptera, and Trichoptera (EPT) richness and combined index (CI) score for each site type. Only small combined sites were used in the ANCOVA analysis to ensure study site independence. 


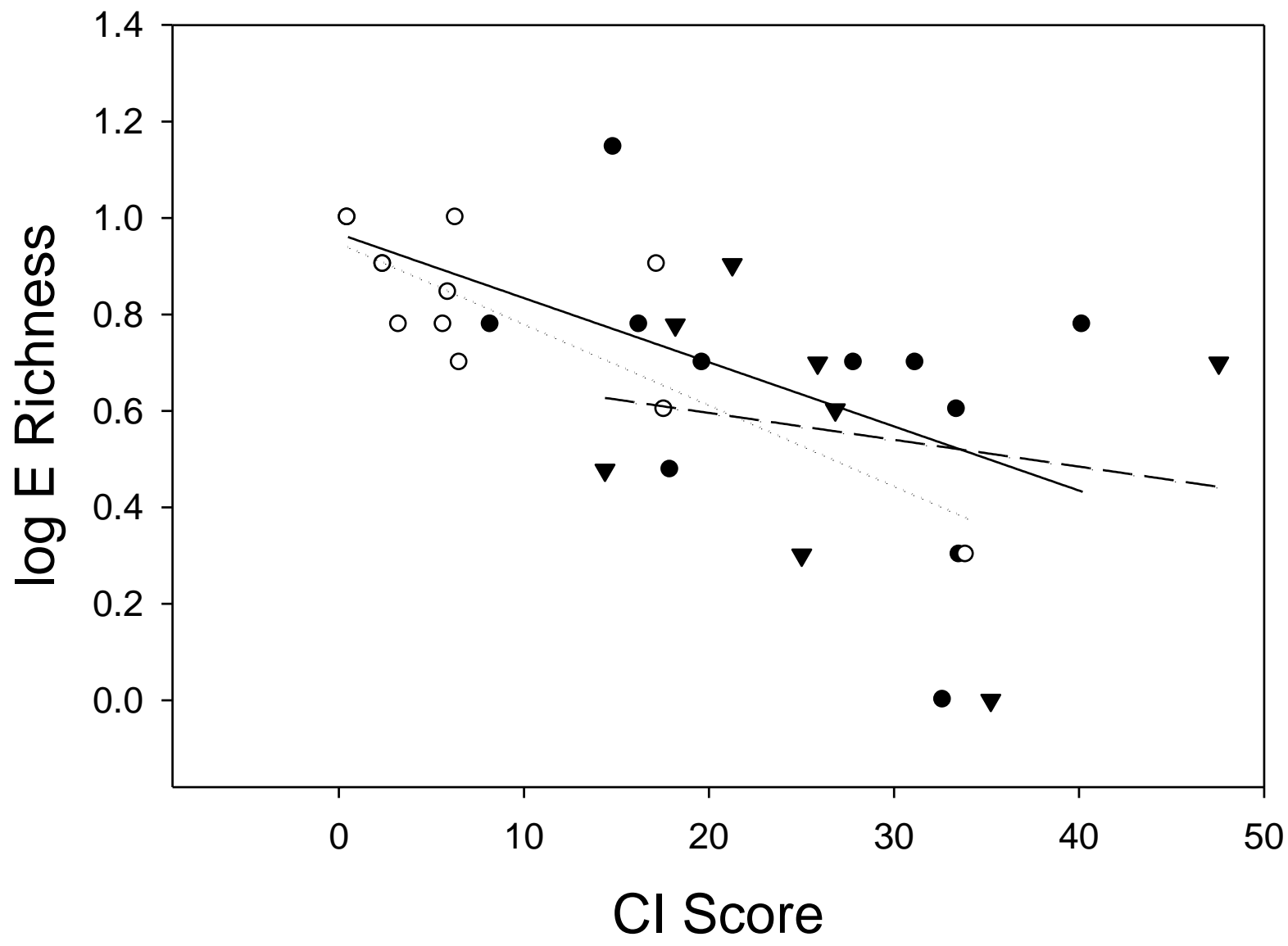

\begin{tabular}{cl}
\hline$\bullet$ & Mined Sites \\
$\circ$ & Developed Sites \\
$\boldsymbol{\nabla}$ & Combined Sites \\
\hdashline$\ldots . . . .$. & Mined Regression \\
$\ldots-$ & Developed Regression \\
\hline- & Combined Regression
\end{tabular}

Figure 29: Relationship between Ephemeroptera (E) richness and CI score for each site type. Only small combined sites were used in the ANCOVA analysis to ensure study site independence. 

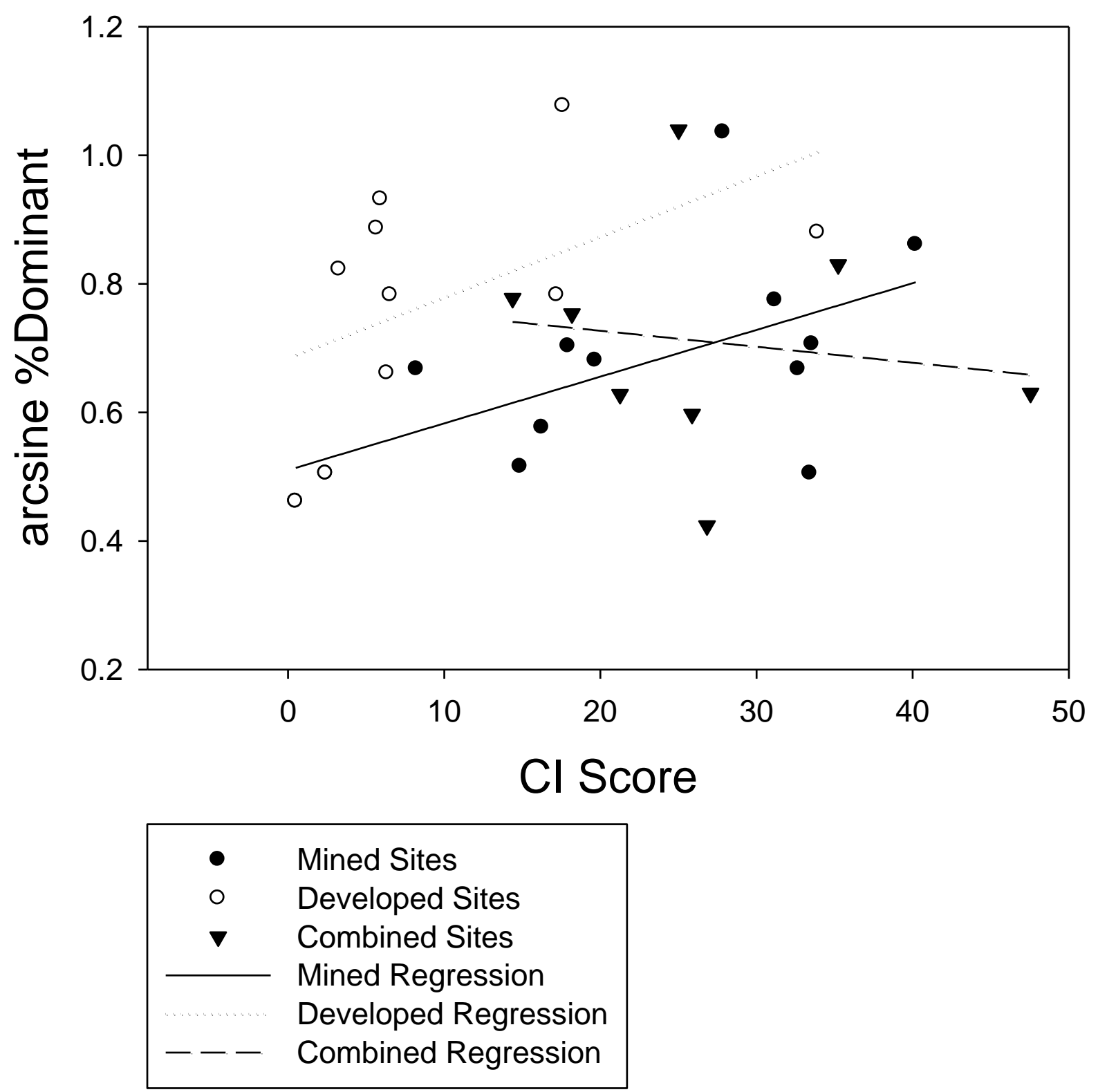

Figure 30: Relationship between \%dominant and combined index (CI) score for each site type. Only small combined sites were used in the ANCOVA analysis to ensure study site independence. 

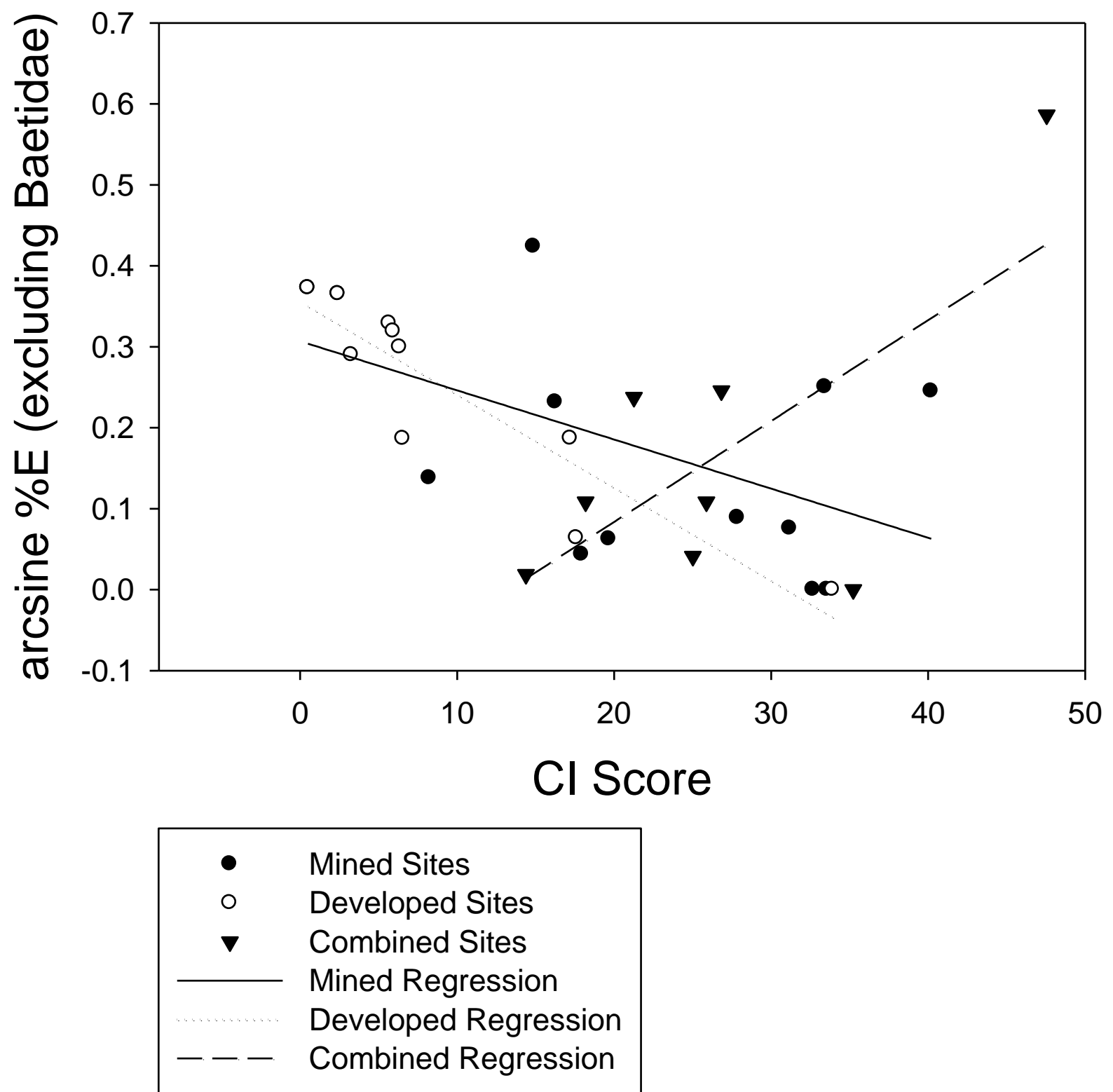

Figure 31: Relationship between \%E excluding Baetidae and combined index (CI) score for each site type. Only small combined sites were used in the ANCOVA analysis to ensure study site independence. 

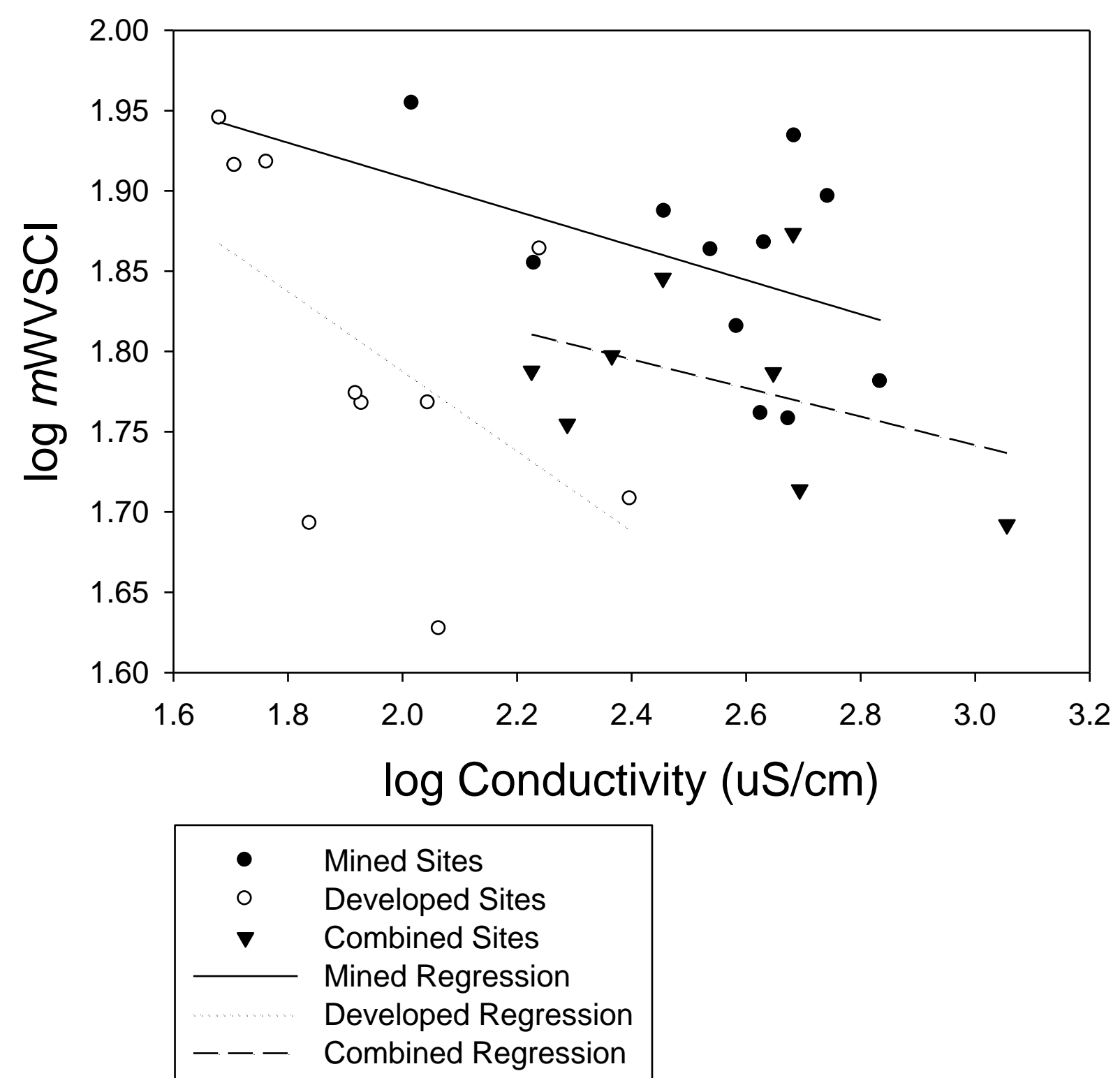

Figure 32: Relationship between the modified West Virginia Stream Condition Index ( $m$ WVSCI) and conductivity for each site type. Only small combined sites were used in the ANCOVA analysis to ensure study site independence. 

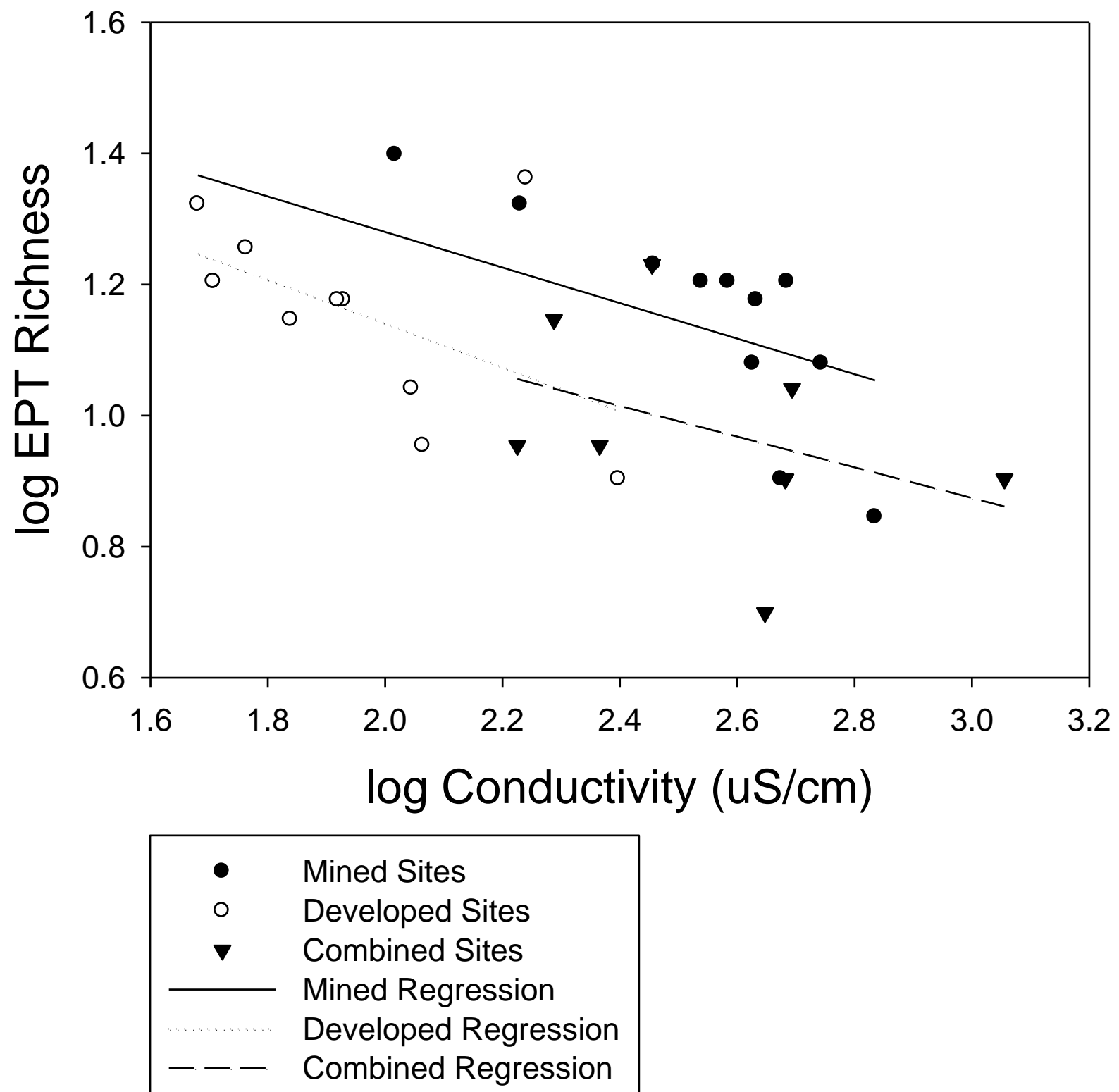

Figure 33: Relationship between Ephemeroptera, Plecoptera, and Trichoptera (EPT) richness and conductivity for each site type. Only small combined sites were used in the ANCOVA analysis to ensure study site independence. 

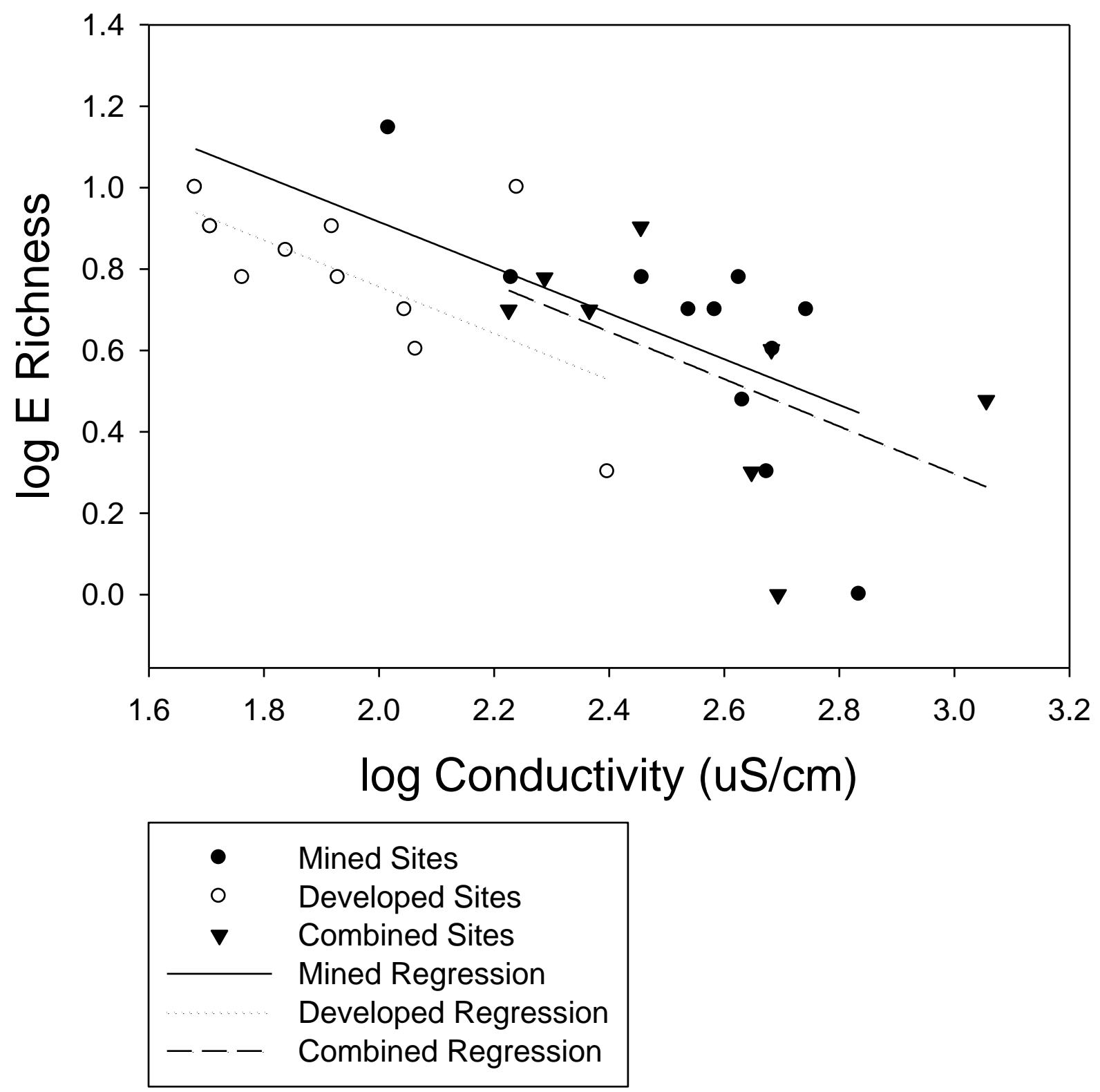

Figure 34: Relationship between Ephemeroptera (E) richness and conductivity for each site type. Only small combined sites were used in the ANCOVA analysis to ensure study site independence. 

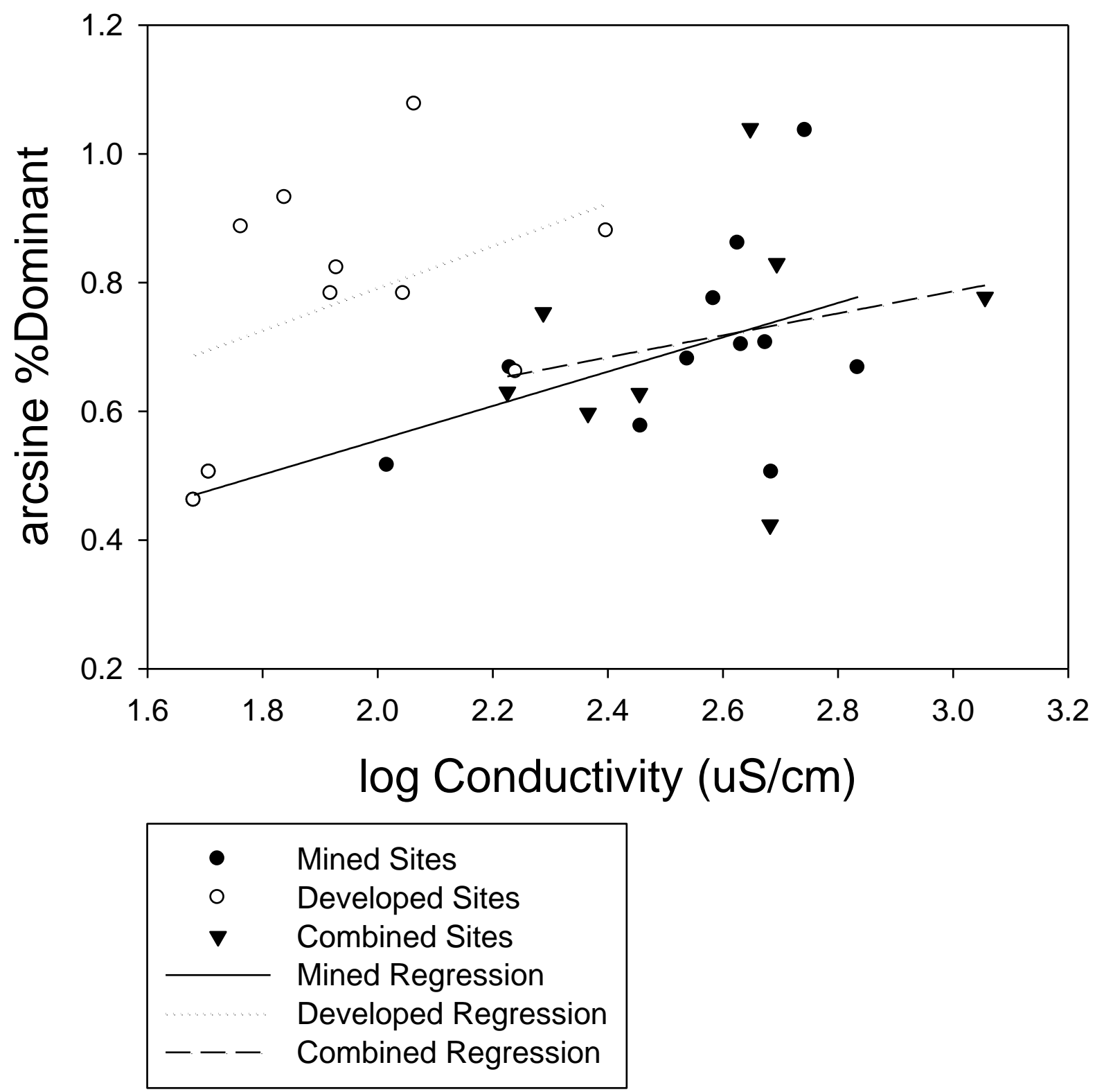

Figure 35: Relationship between \%dominant and conductivity for each site type. Only small combined sites were used in the ANCOVA analysis to ensure study site independence. 

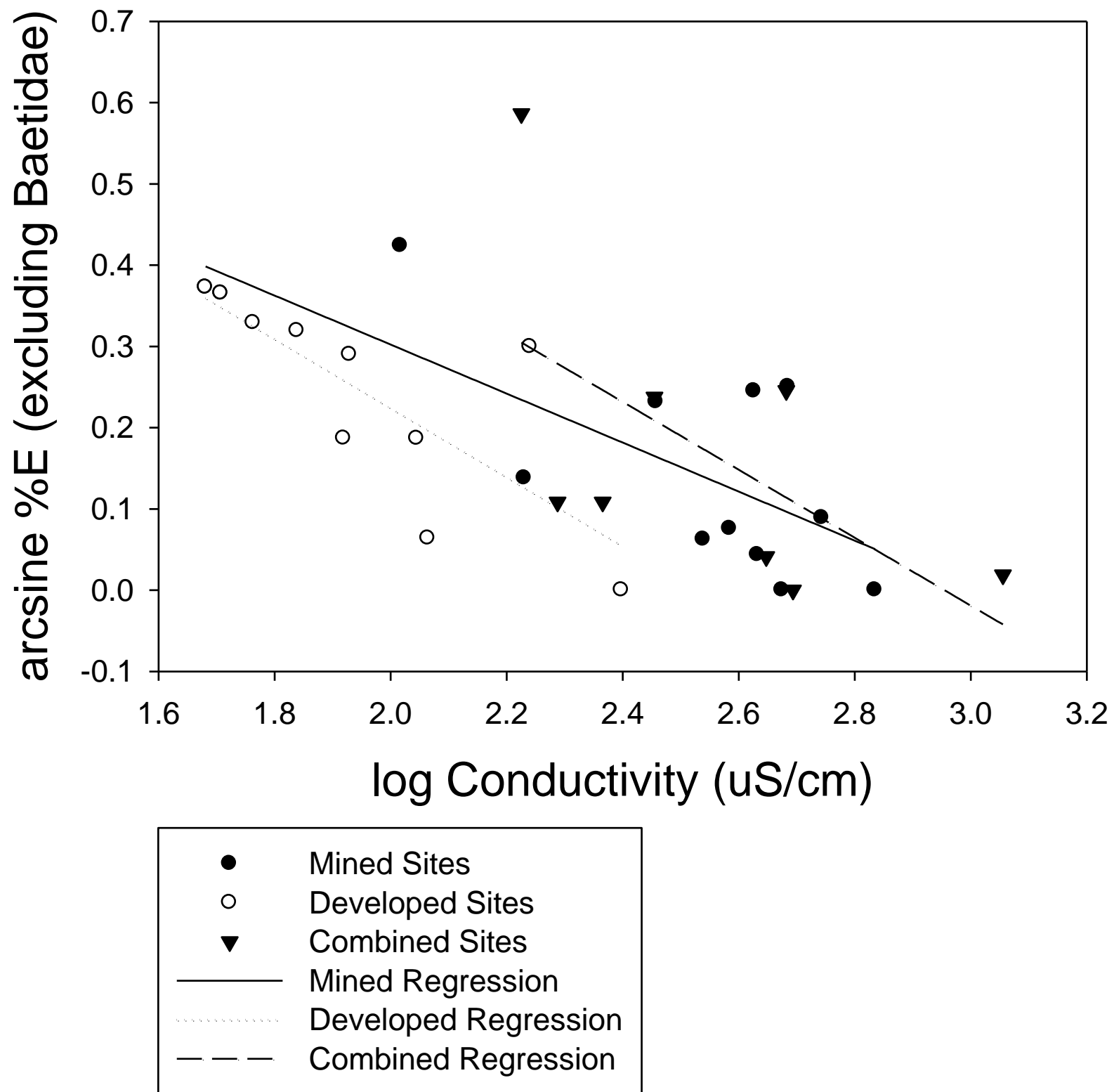

Figure 36: Relationship between \%E excluding Baetidae and conductivity for each site type. Only small combined sites were used in the ANCOVA analysis to ensure study site independence. 

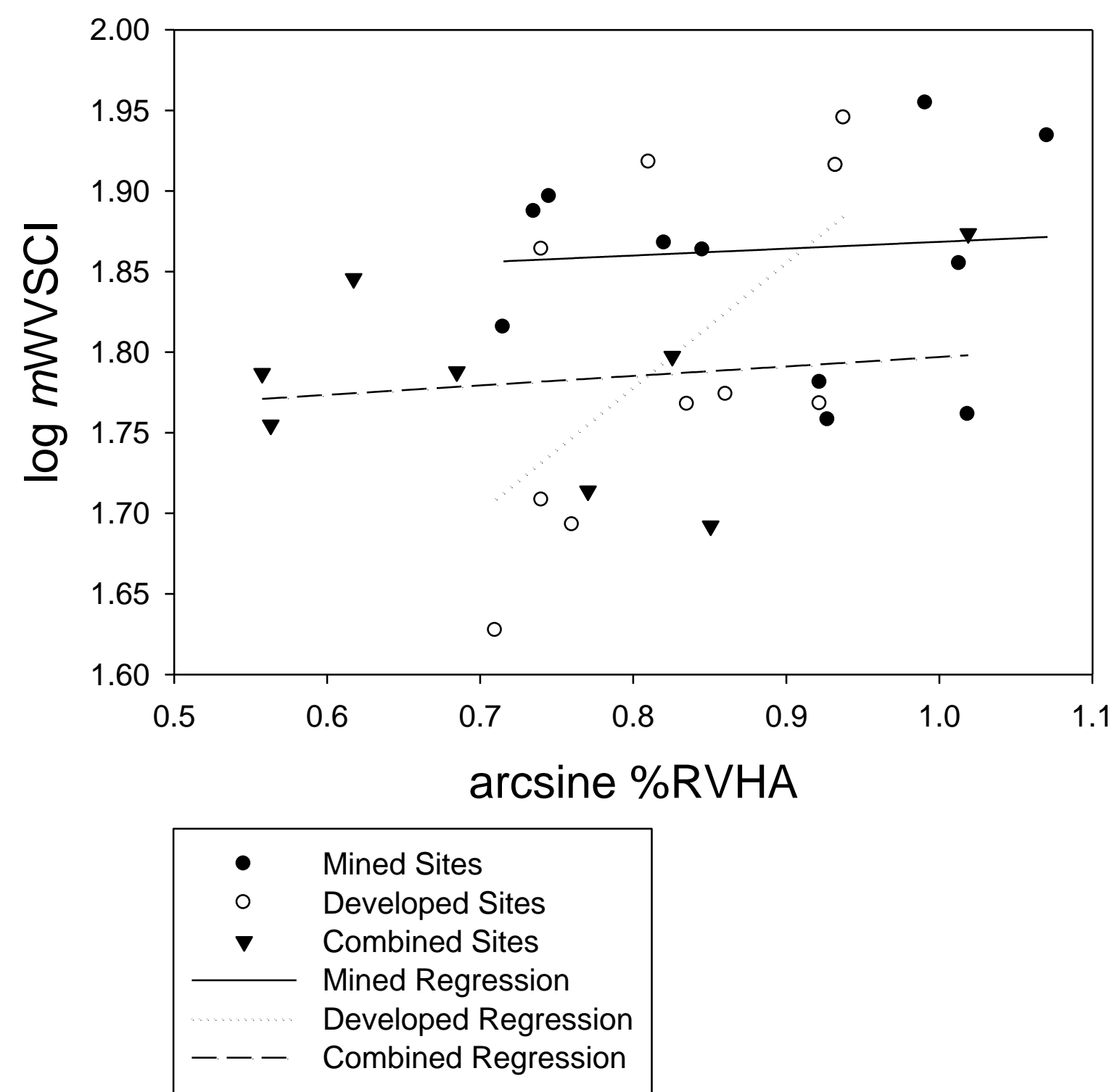

Figure 37: Relationship between the modified West Virginia Stream Condition Index ( $m$ WVSCI) and \% Rapid Visual Habitat Assessment (RVHA) for each site type. Only small combined sites were used in the ANCOVA analysis to ensure study site independence. 


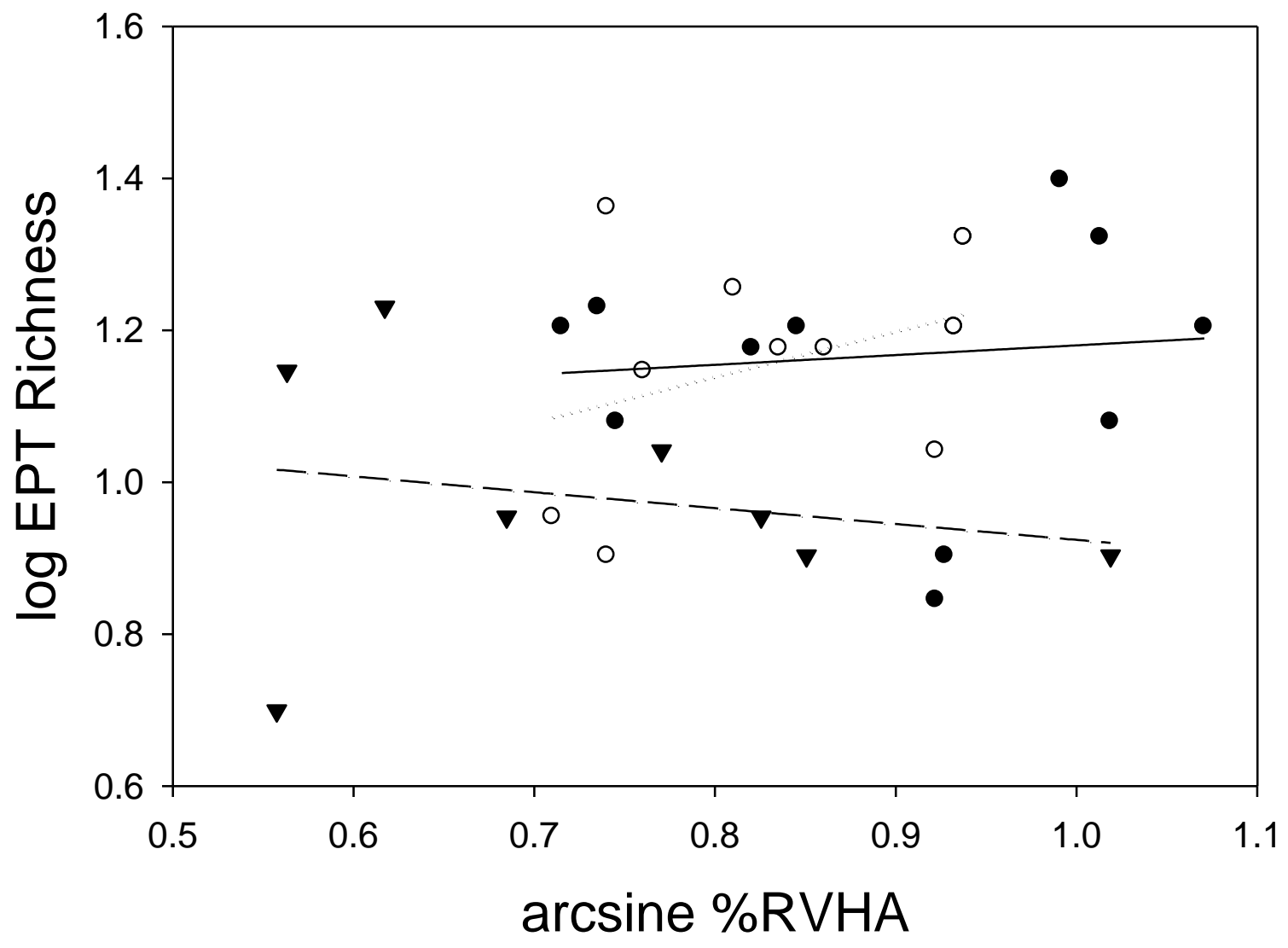

\begin{tabular}{rl|}
\hline$\bullet$ & Mined Sites \\
$\circ$ & Developed Sites \\
$\boldsymbol{\nabla}$ & Combined Sites \\
\hdashline & Mined Regression \\
\hdashline$-\ldots . . .$. & Developed Regression \\
-- & Combined Regression
\end{tabular}

Figure 38: Relationship between Ephemeroptera, Plecoptera, and Trichoptera (EPT) richness and $\%$ Rapid Visual Habitat Assessment (RVHA) for each site type. Only small combined sites were used in the ANCOVA analysis to ensure study site independence. 


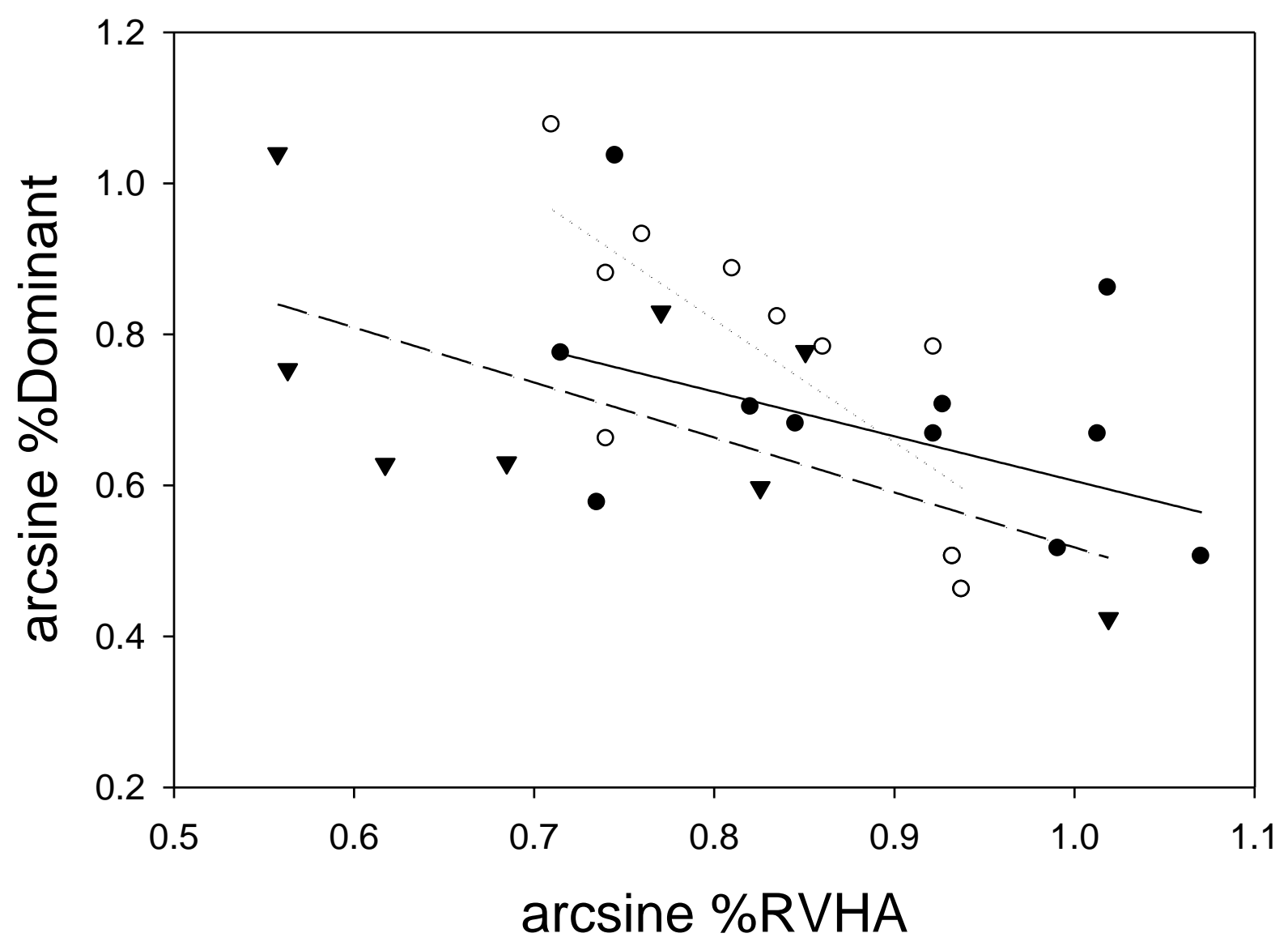

\begin{tabular}{cl}
\hline$\bullet$ & Mined Sites \\
$\circ$ & Developed Sites \\
$\boldsymbol{\nabla}$ & Combined Sites \\
\hline$\ldots . . . . . .$. & Mined Regression \\
--- & Developed Regression \\
\hline
\end{tabular}

Figure 39: Relationship between \%dominant and \%Rapid Visual Habitat Assessment (RVHA) for each site type. Only small combined sites were used in the ANCOVA analysis to ensure study site independence. 

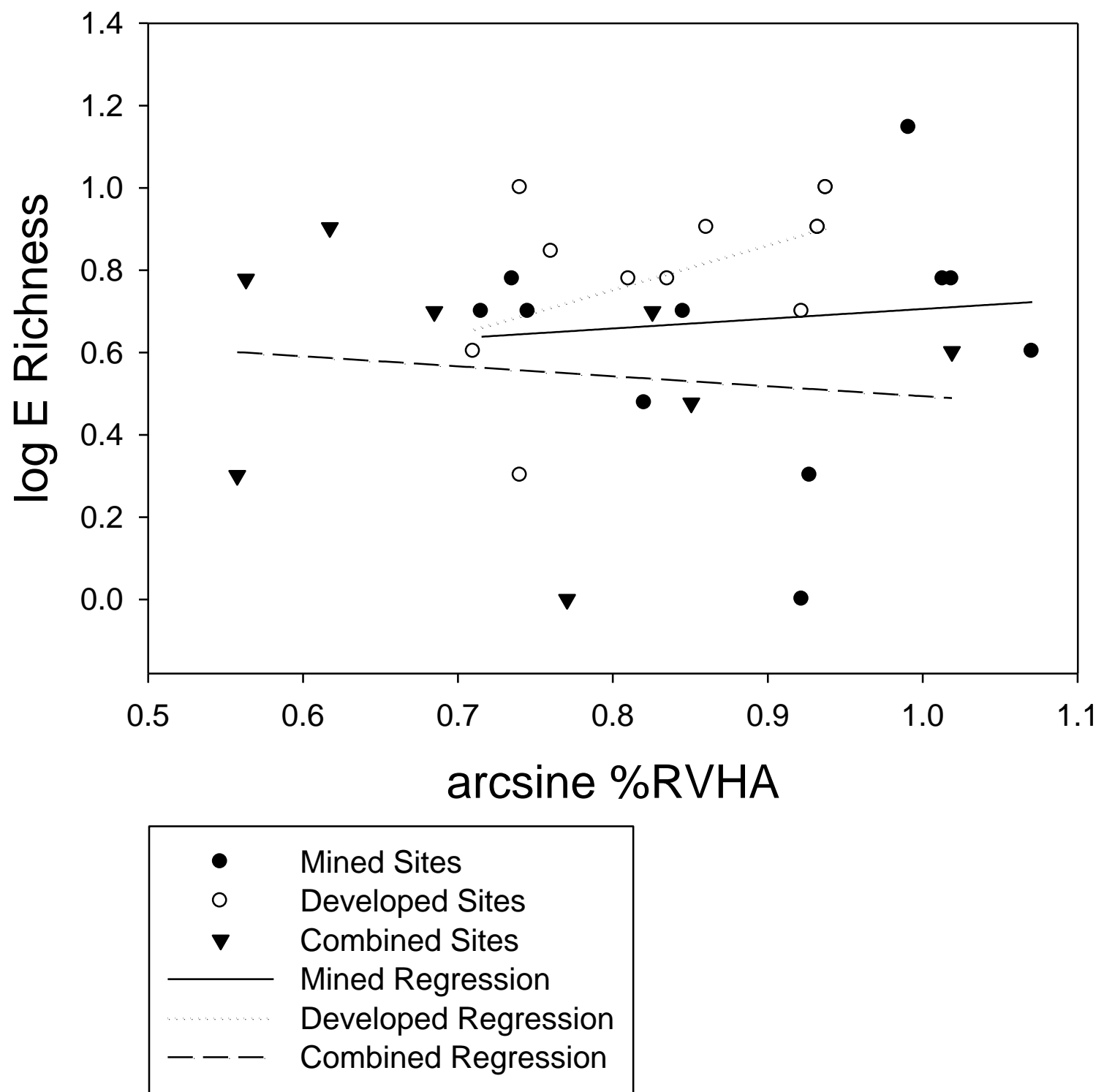

Figure 40: Relationship between Ephemeroptera (E) richness and \%Rapid Visual Habitat Assessment (RVHA) for each site type. Only small combined sites were used in the ANCOVA analysis to ensure study site independence. 

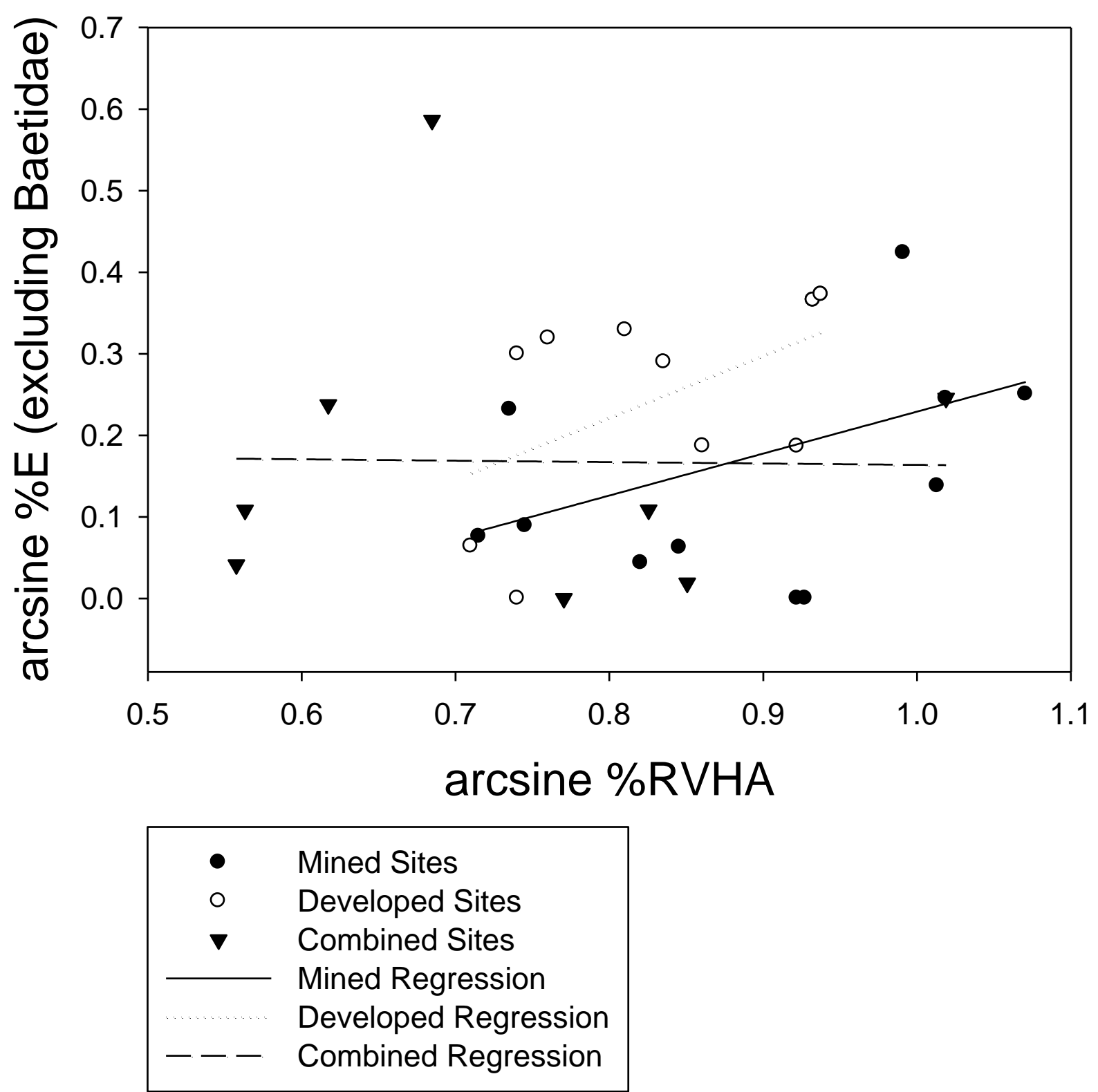

Figure 41: Relationship between \%E excluding Baetidae and \%Rapid Visual Habitat Assessment (RVHA) for each site type. Only small combined sites were used in the ANCOVA analysis to ensure study site independence. 


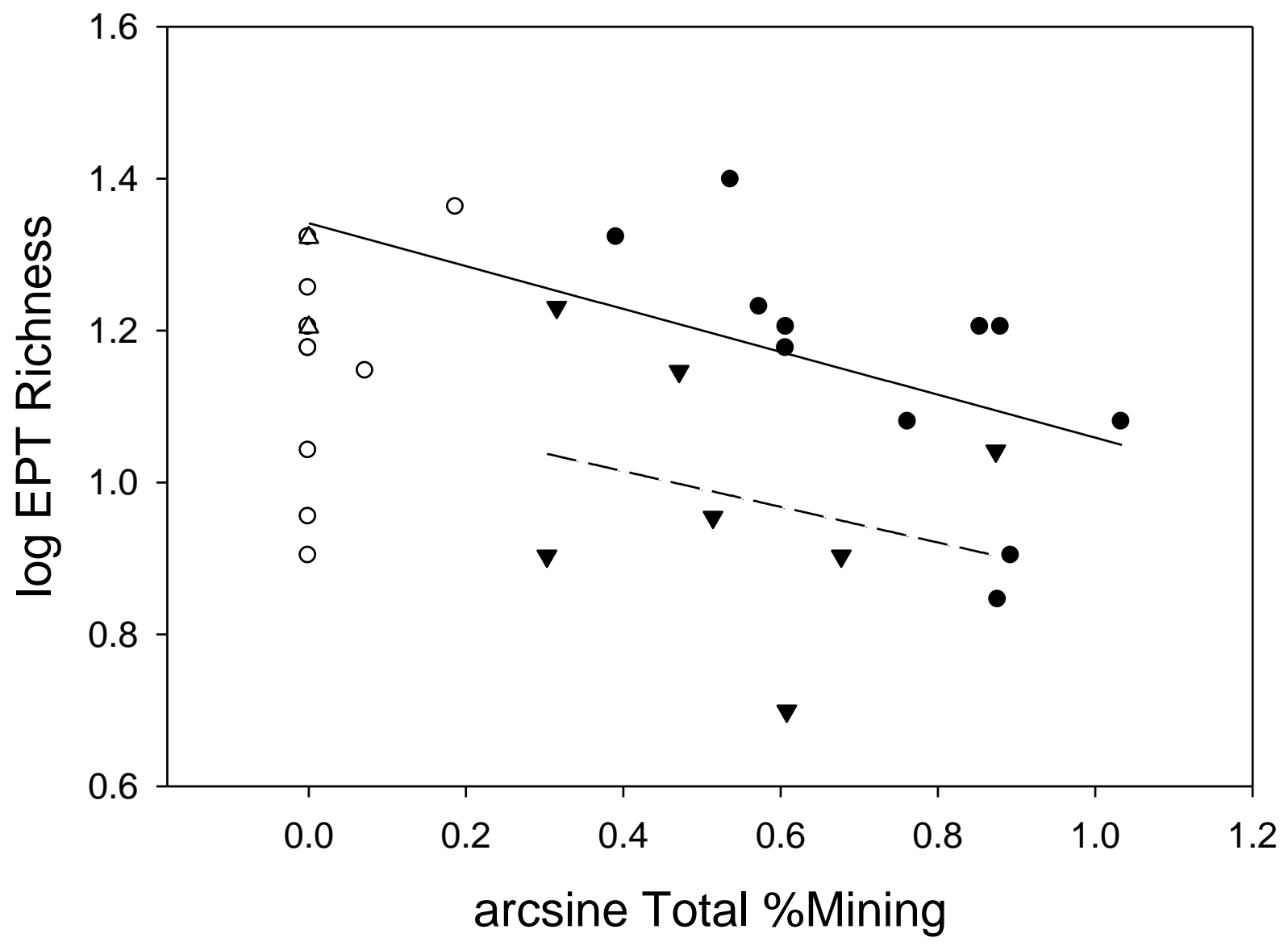

\begin{tabular}{|cl|}
\hline$\bullet$ & Mined Sites \\
$\circ$ & Developed Sites \\
$\boldsymbol{\nabla}$ & Combined Sites \\
$\Delta$ & Reference Sites \\
\hline$-\ldots$ & Mined Regression \\
\hline- & Combined Regression
\end{tabular}

Figure 42: Multiple scatter plot showing the correlation between total \%mining and EPT richness for each site type. Linear regressions were constructed for the mined and combined sites to help identify and visualize differences in EPT richness across the two site types. 


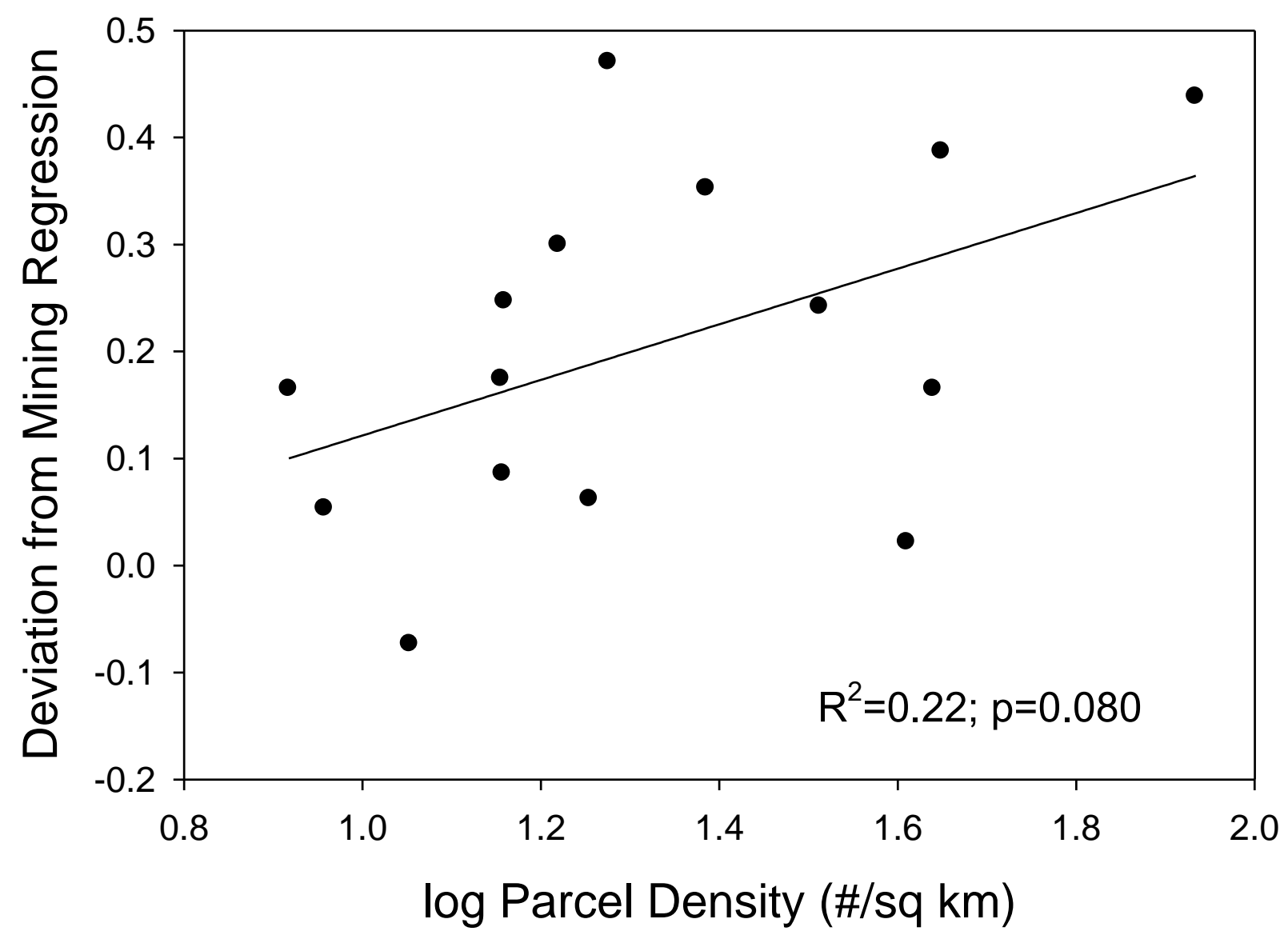

Figure 43: Relationship between parcel density and the deviation of the developed and combined sites from the mining regression. The $\mathrm{R}^{2}$ and $\mathrm{p}$-value are presented. 

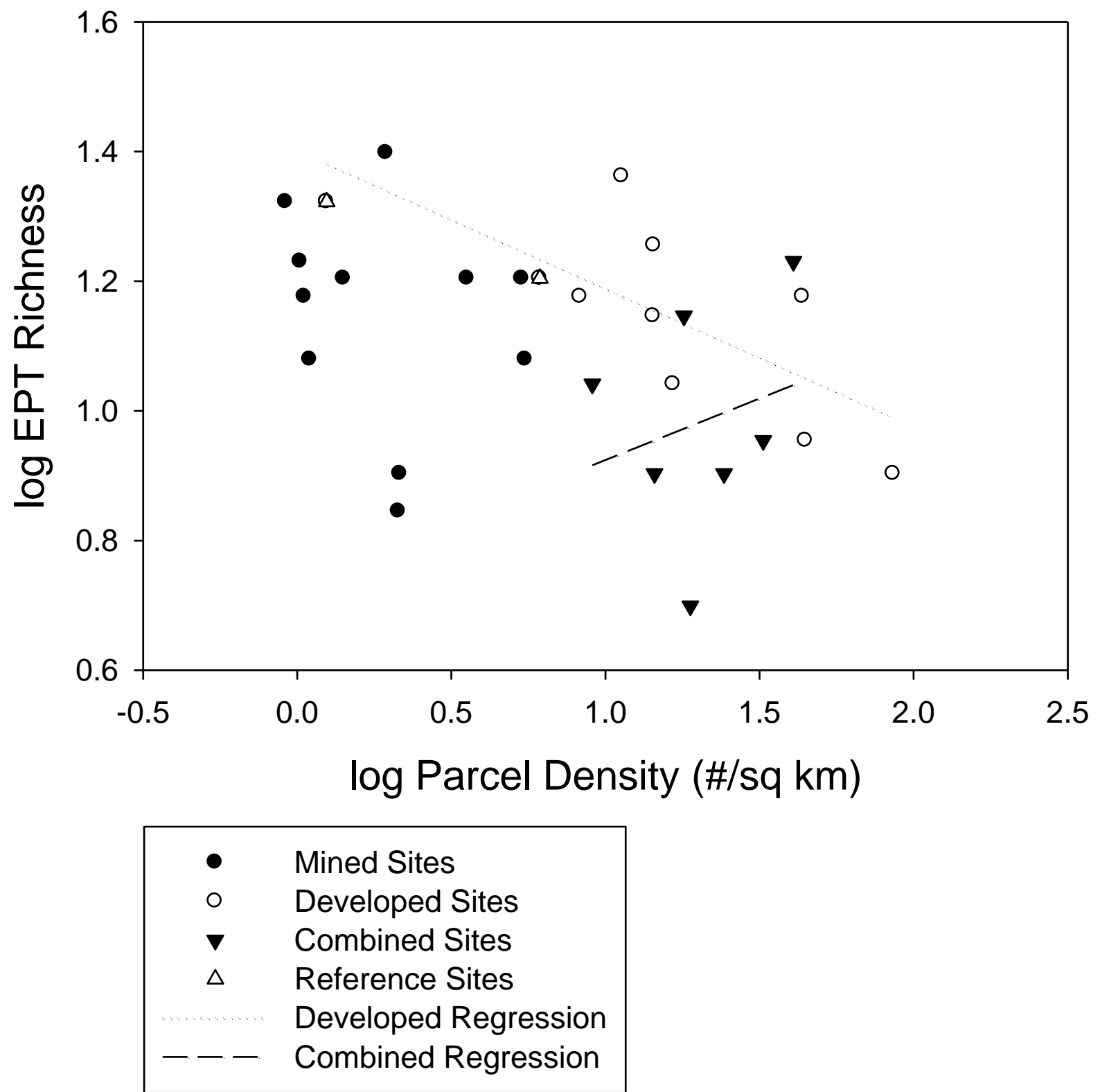

Figure 44: Multiple scatter plot showing the correlation between parcel density and EPT richness for each site type. Linear regressions were constructed for the developed and combined sites to help identify and visualize differences in EPT richness across the two site types. 


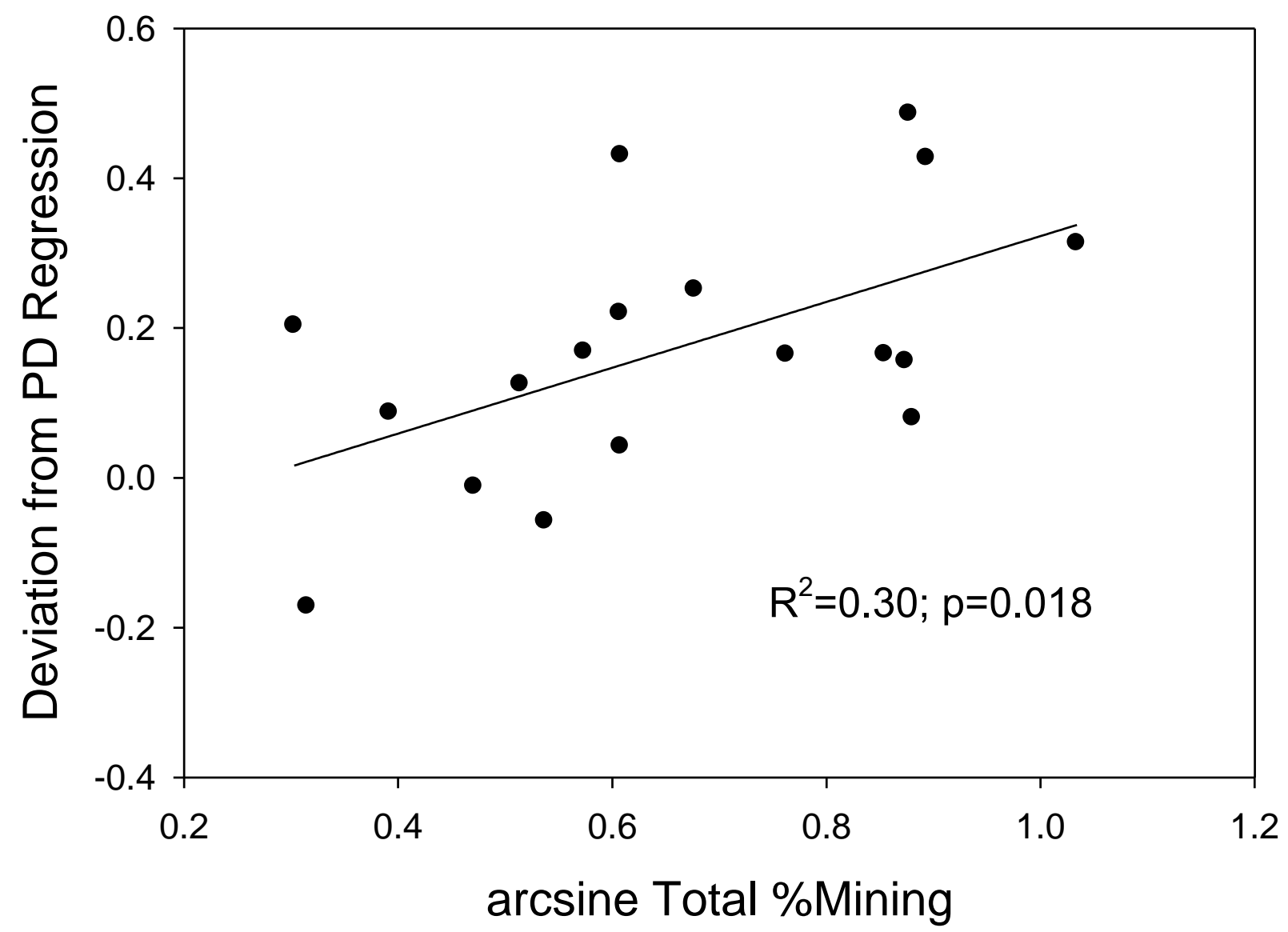

Figure 45: Relationship between total \%mining and the deviation of the mined and combined sites from the developed regression. The $\mathrm{R}^{2}$ and $\mathrm{p}$-value are presented. 


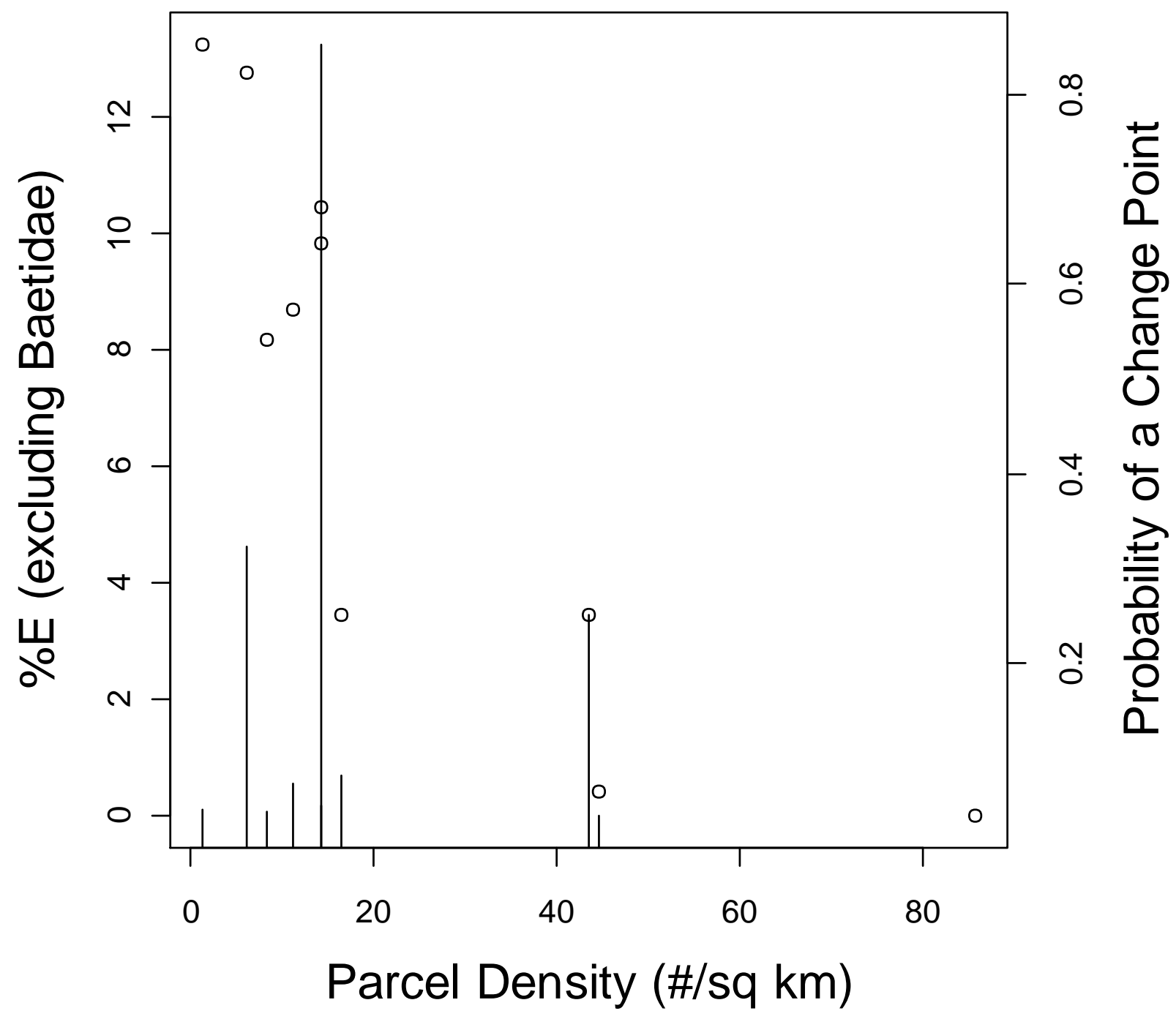

Figure 46: Results of Bayesian Change Point (BCP) analysis for the correlation between $\%$ Ephemeroptera excluding Baetidae and parcel density along the residential gradient. Hollow circles represent sites along the gradient. Vertical bars represent the probability of a change point for each site. 


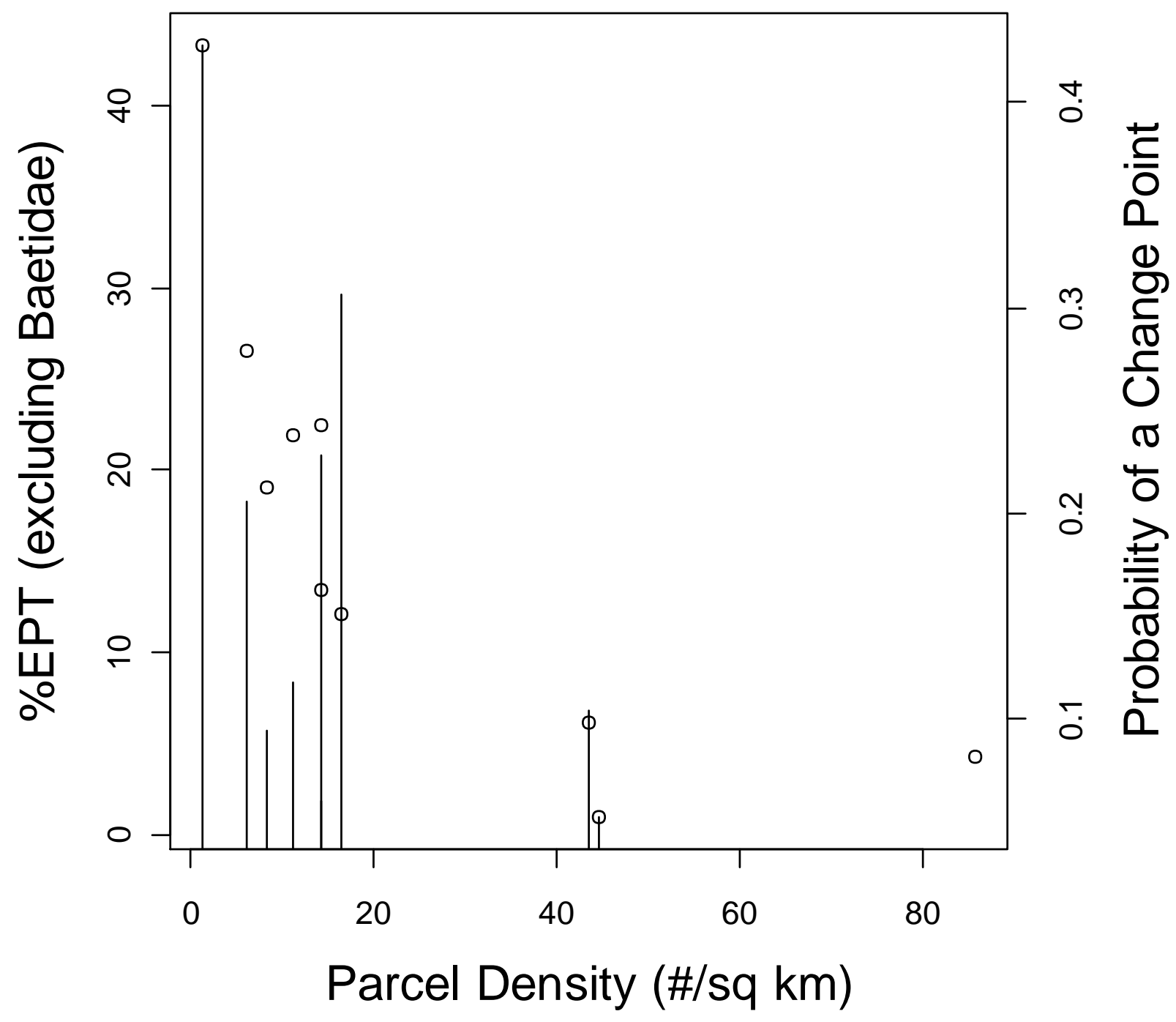

Figure 47: Results of Bayesian Change Point (BCP) analysis for the correlation between \%EPT excluding Baetidae and parcel density along the residential gradient. Hollow circles represent sites along the gradient. Vertical bars represent the probability of a change point for each site. 


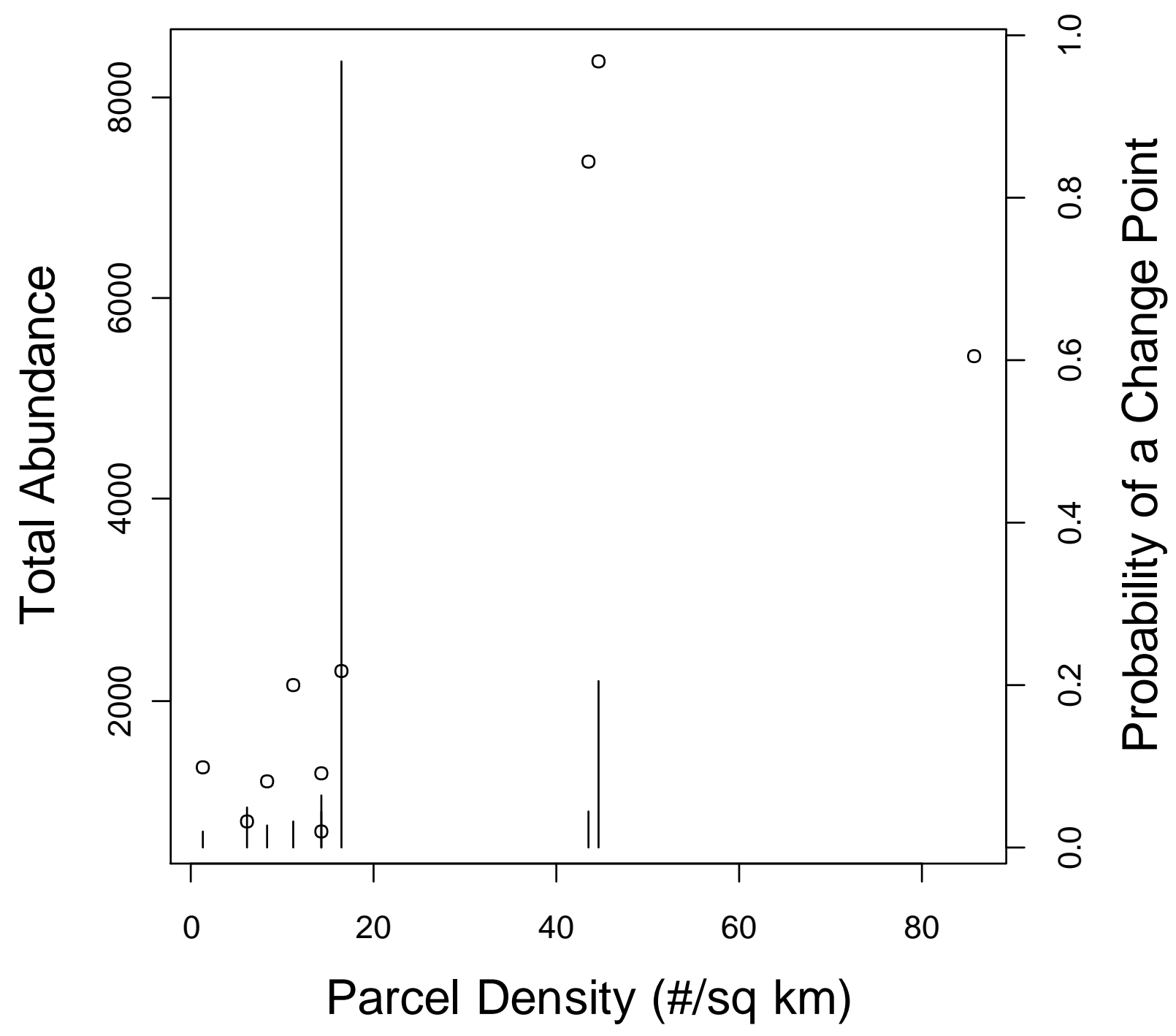

Figure 48: Results of Bayesian Change Point (BCP) analysis for the correlation between total abundance and parcel density along the residential gradient. Hollow circles represent sites along the gradient. Vertical bars represent the probability of a change point for each site. 


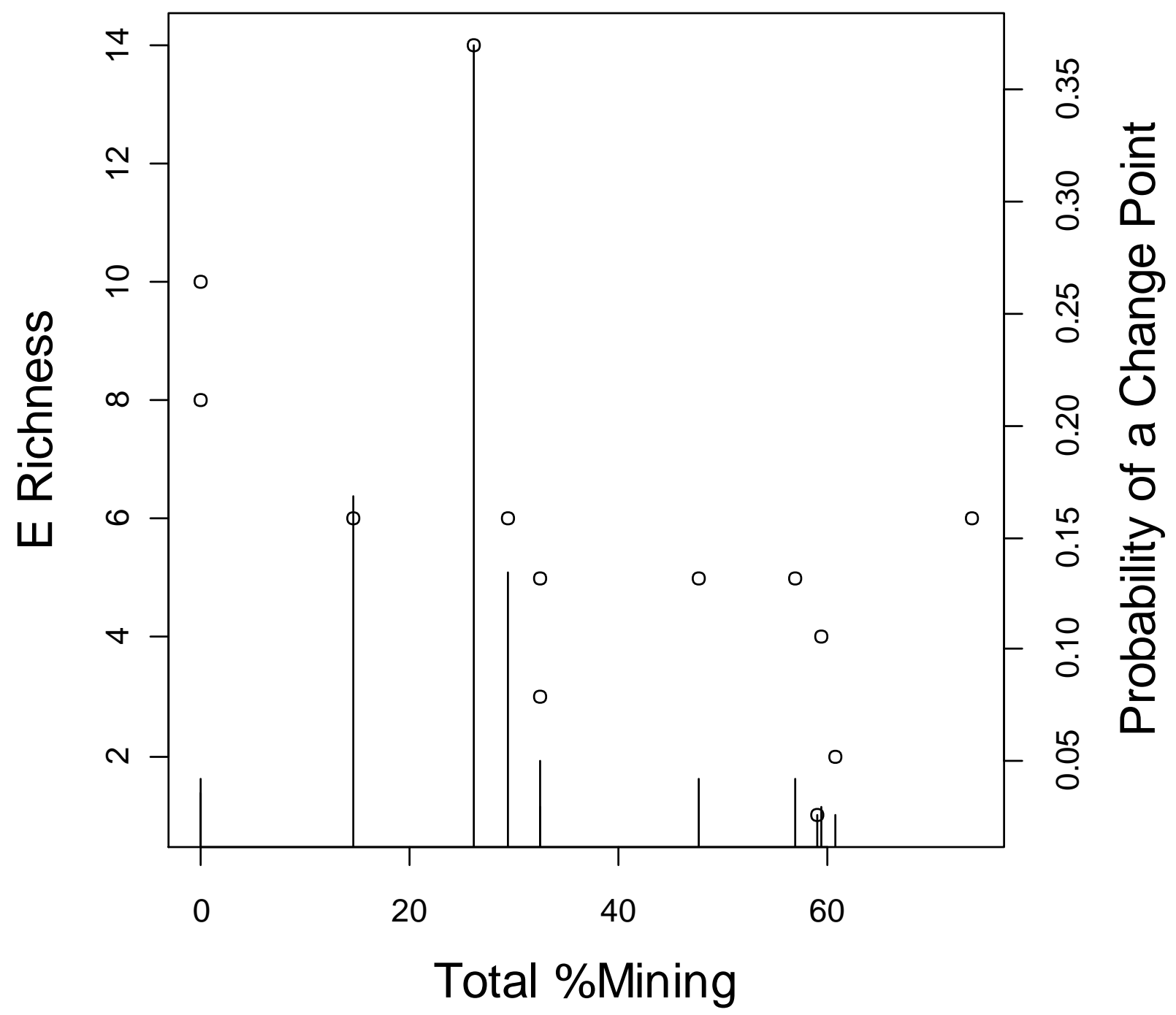

Figure 49: Results of Bayesian Change Point (BCP) analysis for the correlation between Ephemeroptera (E) richness and total mining along the mining gradient. Hollow circles represent sites along the gradient. Vertical bars represent the probability of a change point for each site. 


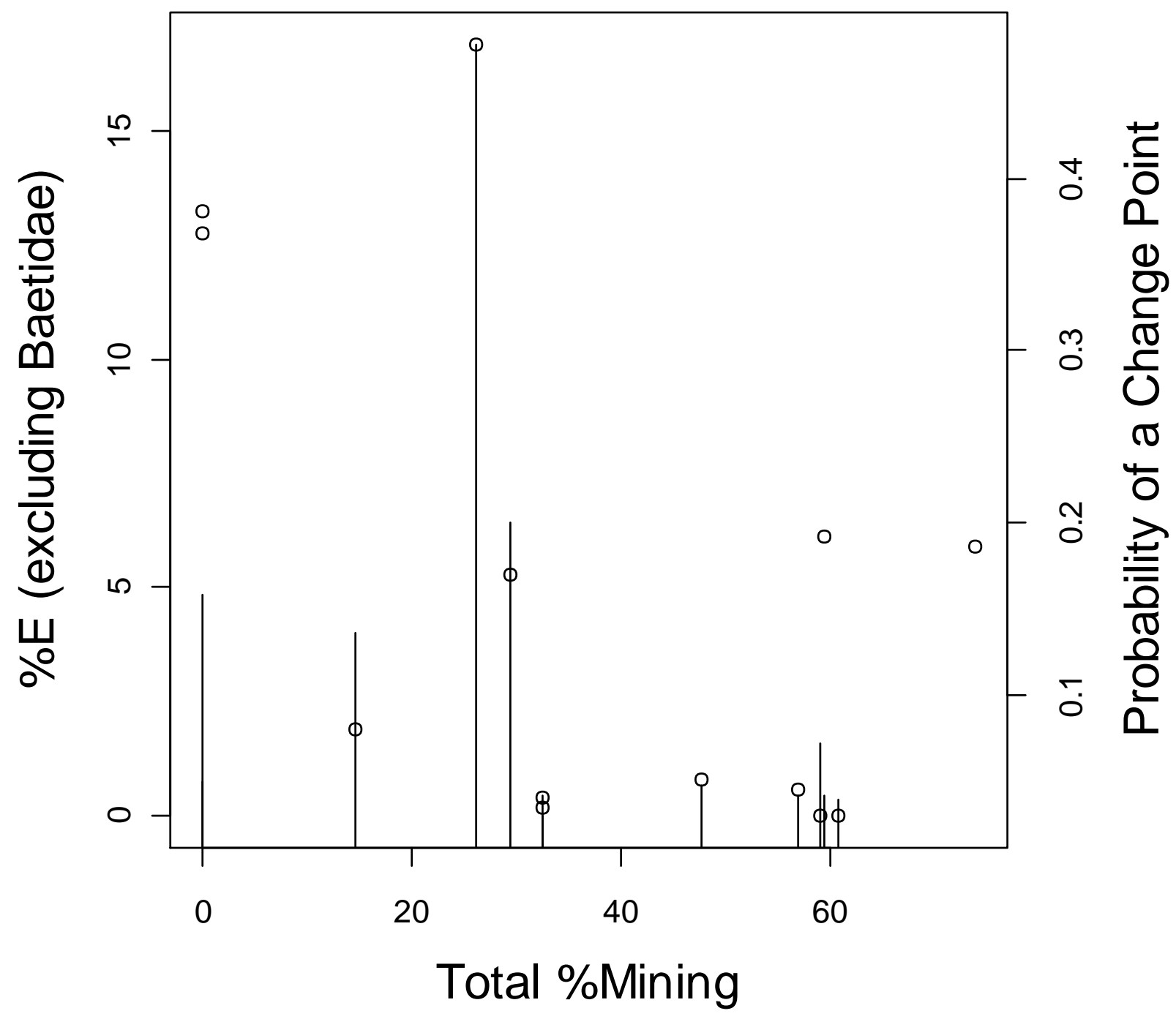

Figure 50: Results of Bayesian Change Point (BCP) analysis for the correlation between $\%$ Ephemeroptera excluding Baetidae and total mining along the mining gradient. Hollow circles represent sites along the gradient. Vertical bars represent the probability of a change point for each site. 


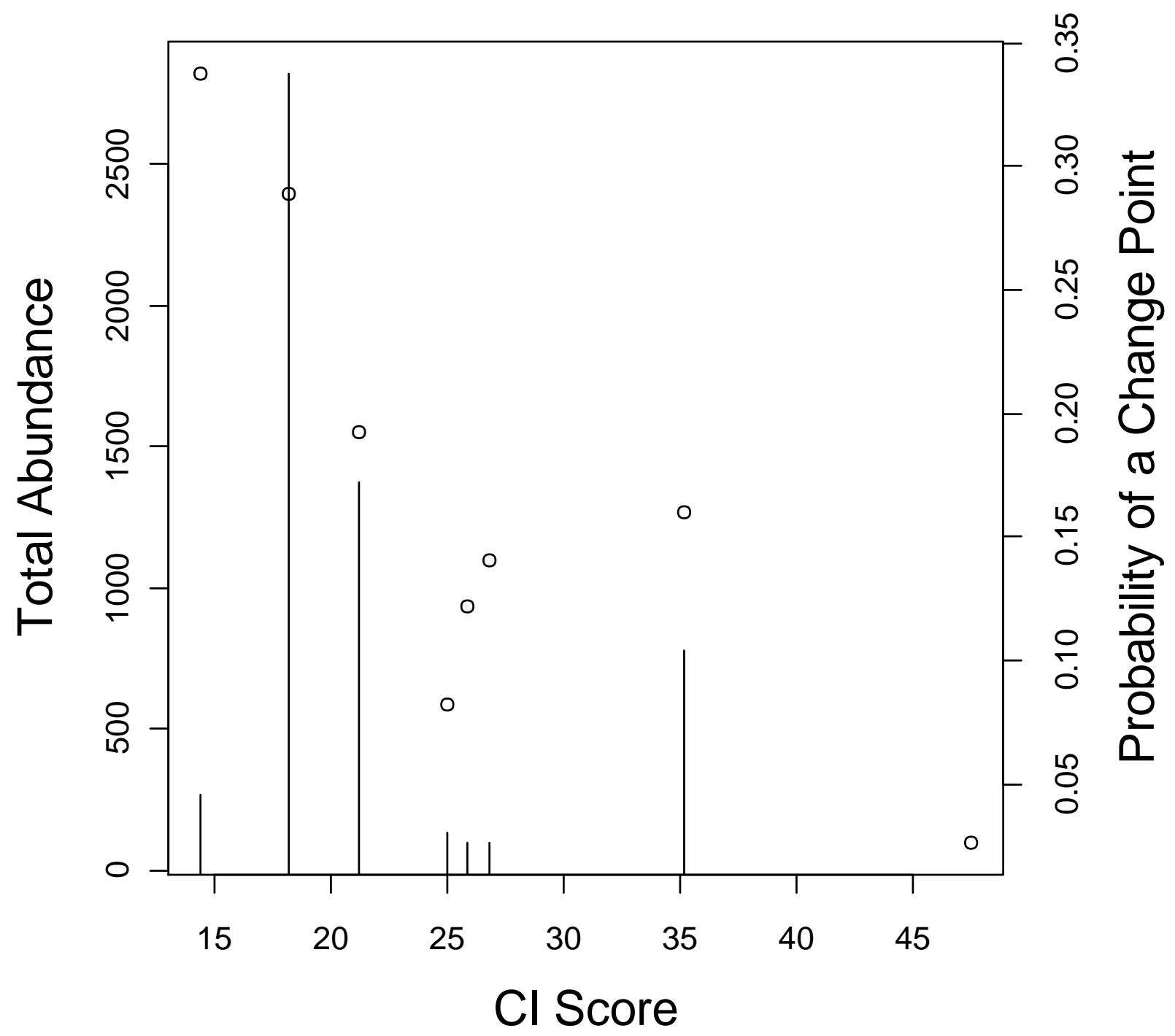

Figure 51: Results of Bayesian Change Point (BCP) analysis for the correlation between total abundance and combined index (CI) score across the small combined sites. Hollow circles represent sites along the gradient. Vertical bars represent the probability of a change point for each site. 


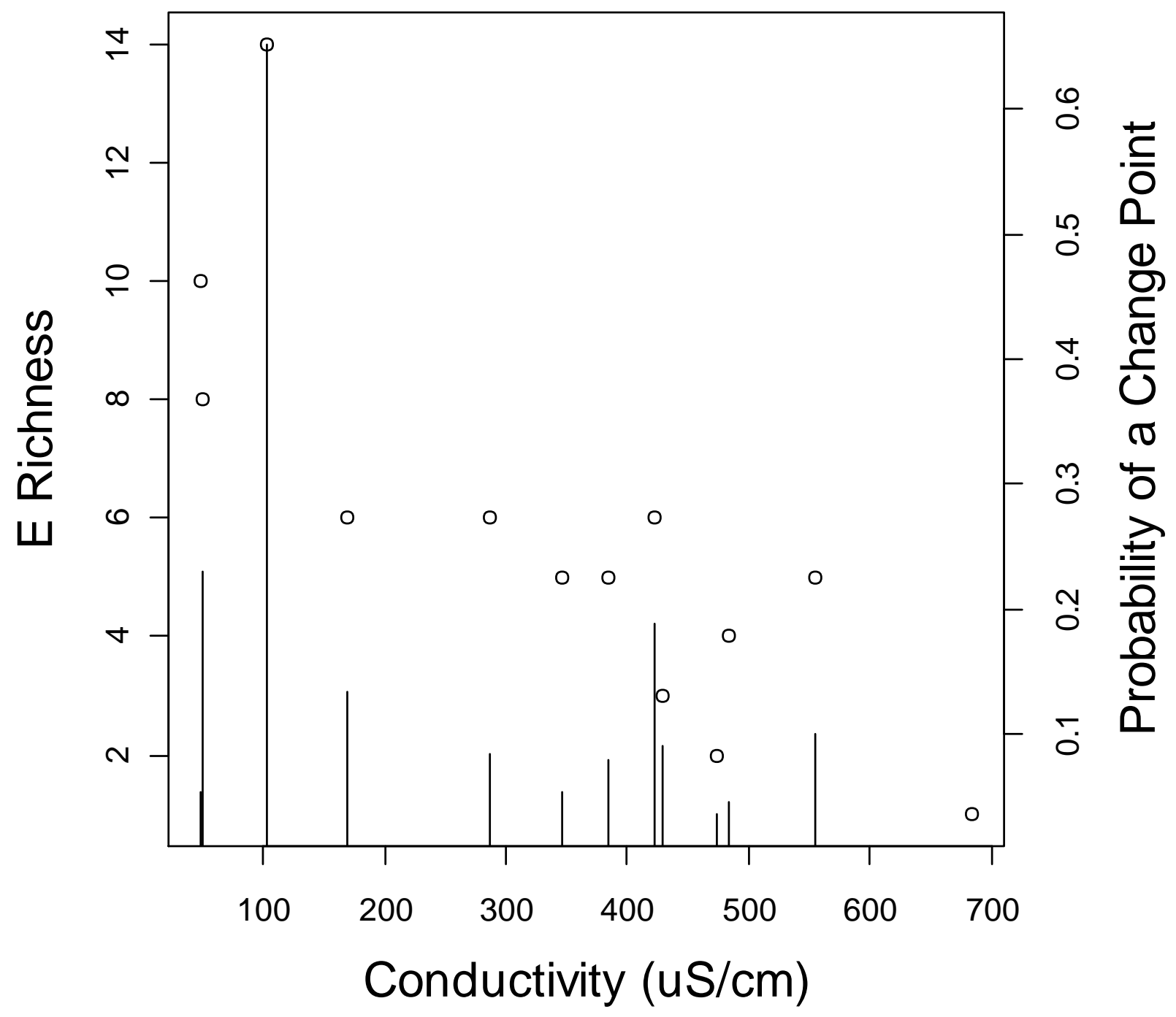

Figure 52: Results of Bayesian Change Point (BCP) analysis for the correlation between Ephemeroptera (E) richness and conductivity along the mining gradient. Hollow circles represent sites along the gradient. Vertical bars represent the probability of a change point for each site. 


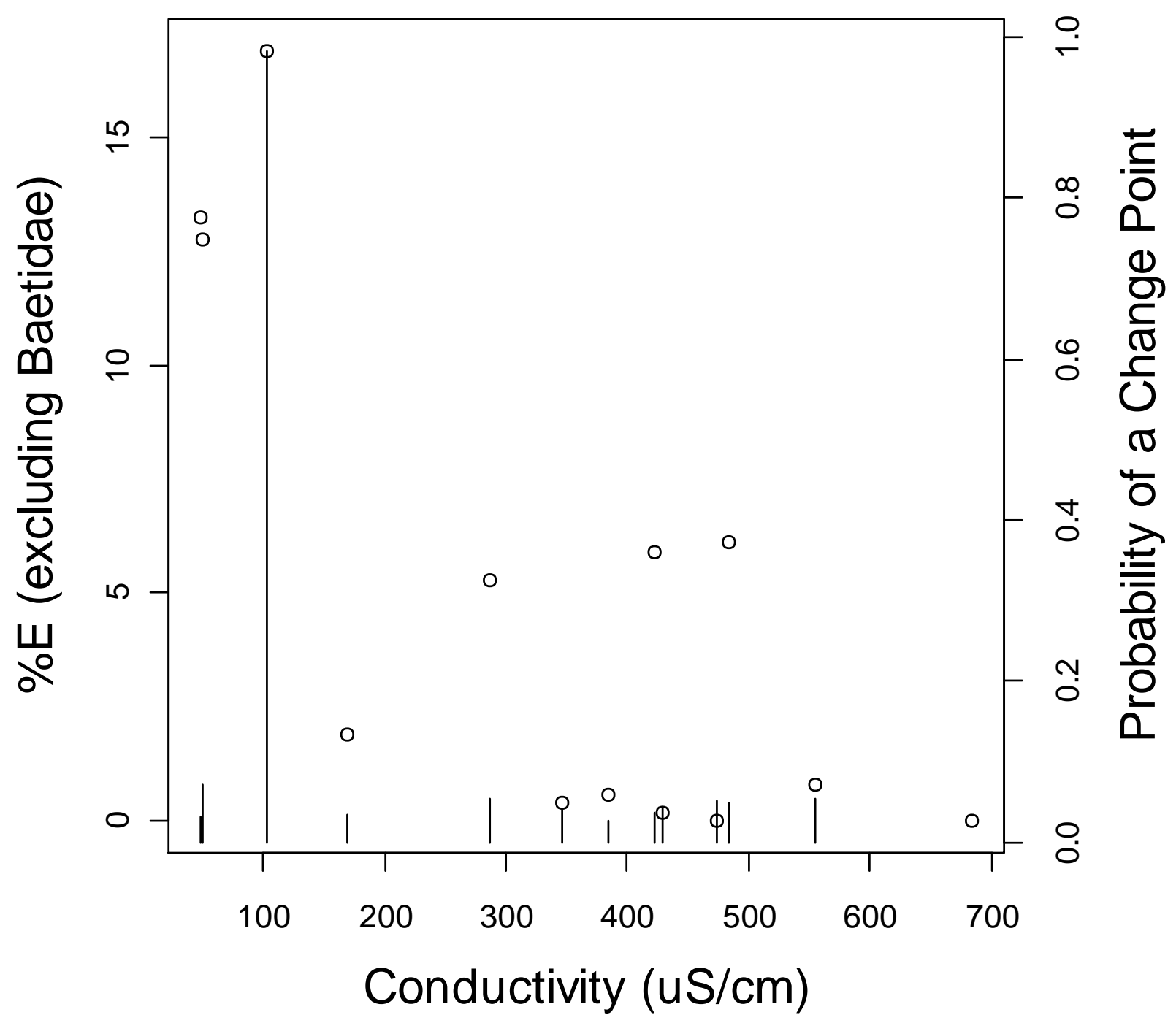

Figure 53: Results of Bayesian Change Point (BCP) analysis for the correlation between \%E excluding Baetidae and conductivity along the mining gradient. Hollow circles represent sites along the gradient. Vertical bars represent the probability of a change point for each site. 


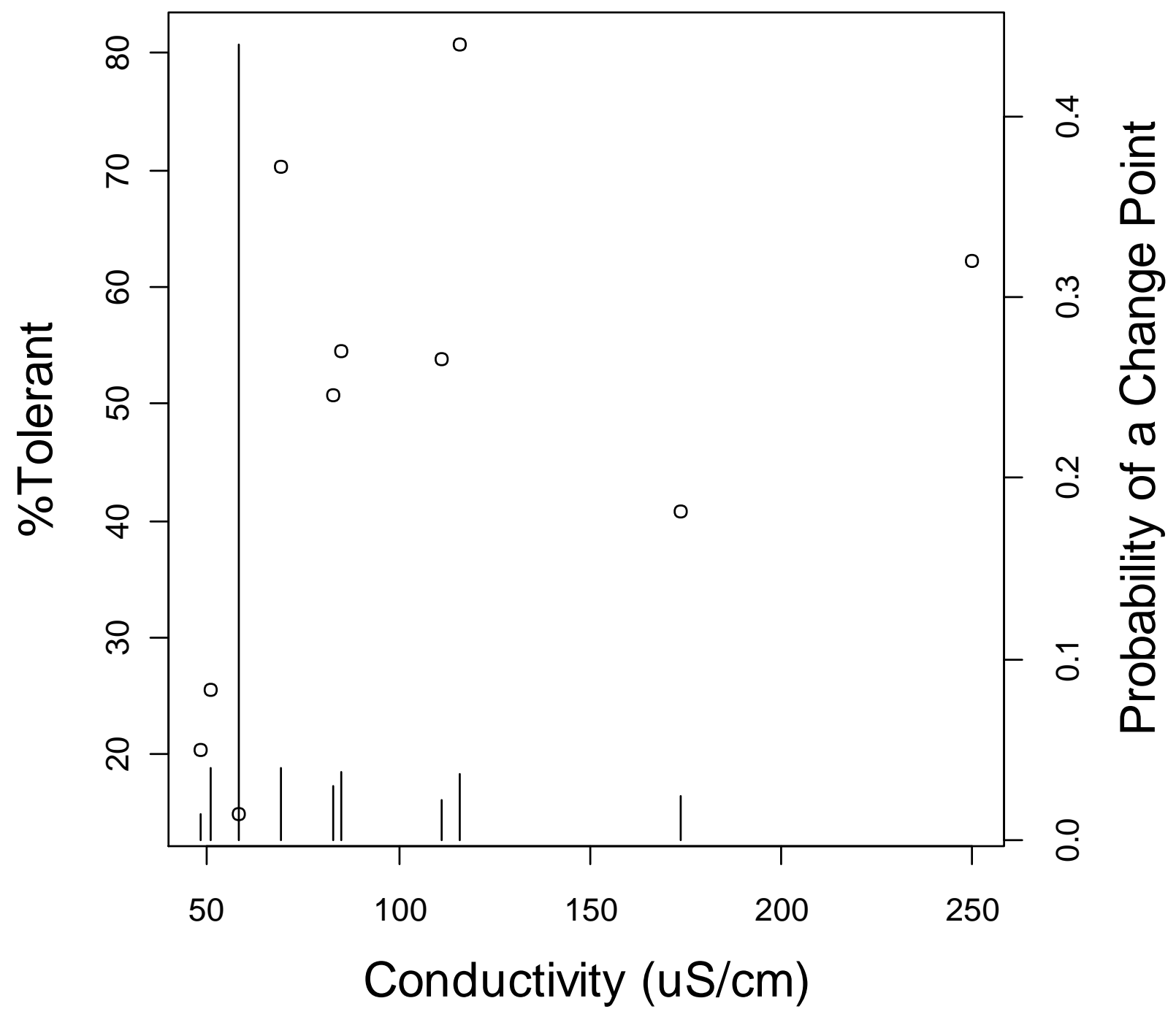

Figure 54: Results of Bayesian Change Point (BCP) analysis for the correlation between \%tolerant and conductivity along the residential gradient. Hollow circles represent sites along the gradient. Vertical bars represent the probability of a change point for each site. 


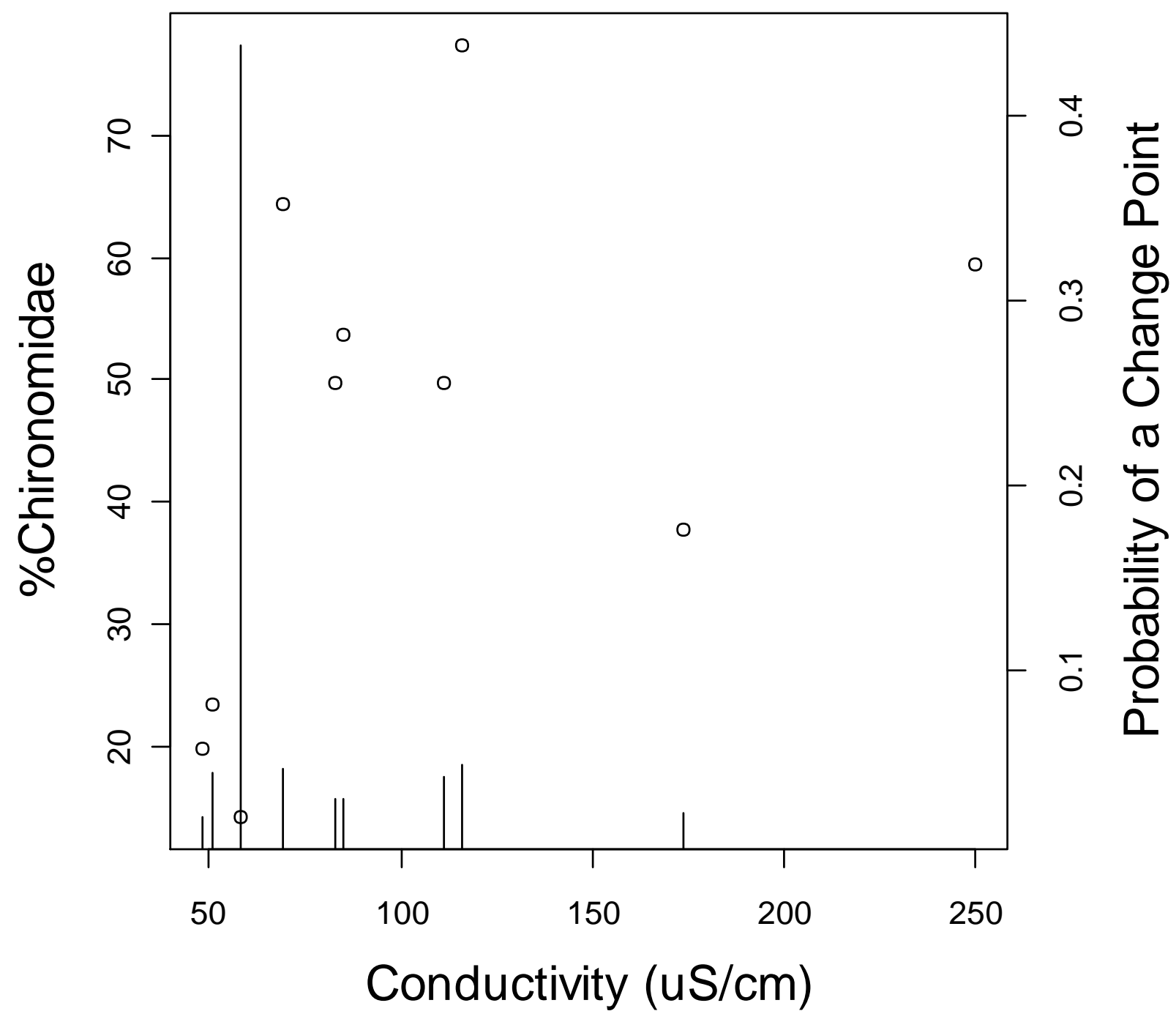

Figure 55: Results of Bayesian Change Point (BCP) analysis for the correlation between \%Chironomidae and conductivity along the residential gradient. Hollow circles represent sites along the gradient. Vertical bars represent the probability of a change point for each site. 


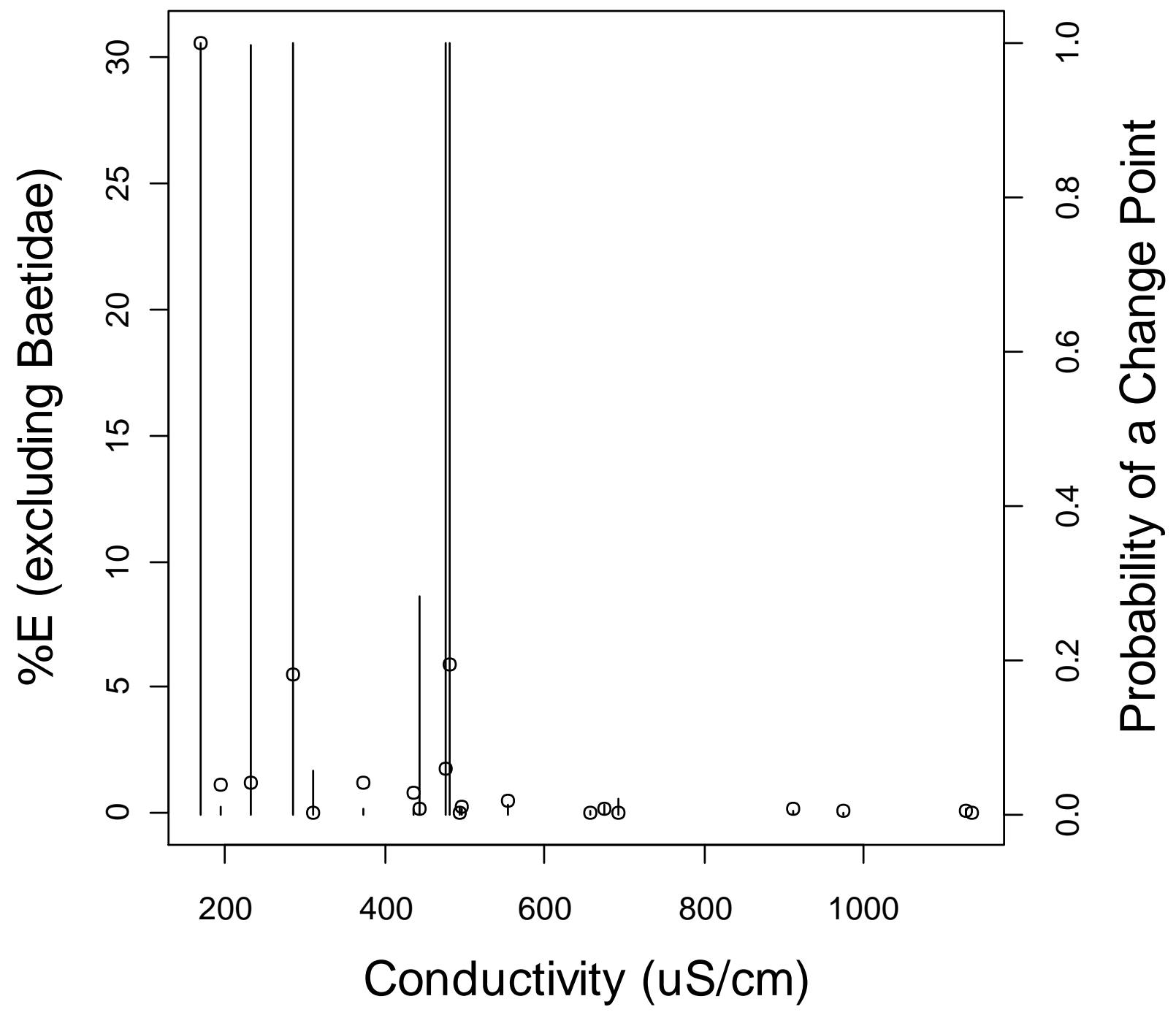

Figure 56: Results of Bayesian Change Point (BCP) analysis for the correlation between \%E excluding Baetidae and conductivity across all combined sites. Hollow circles represent sites along the gradient. Vertical bars represent the probability of a change point for each site. 


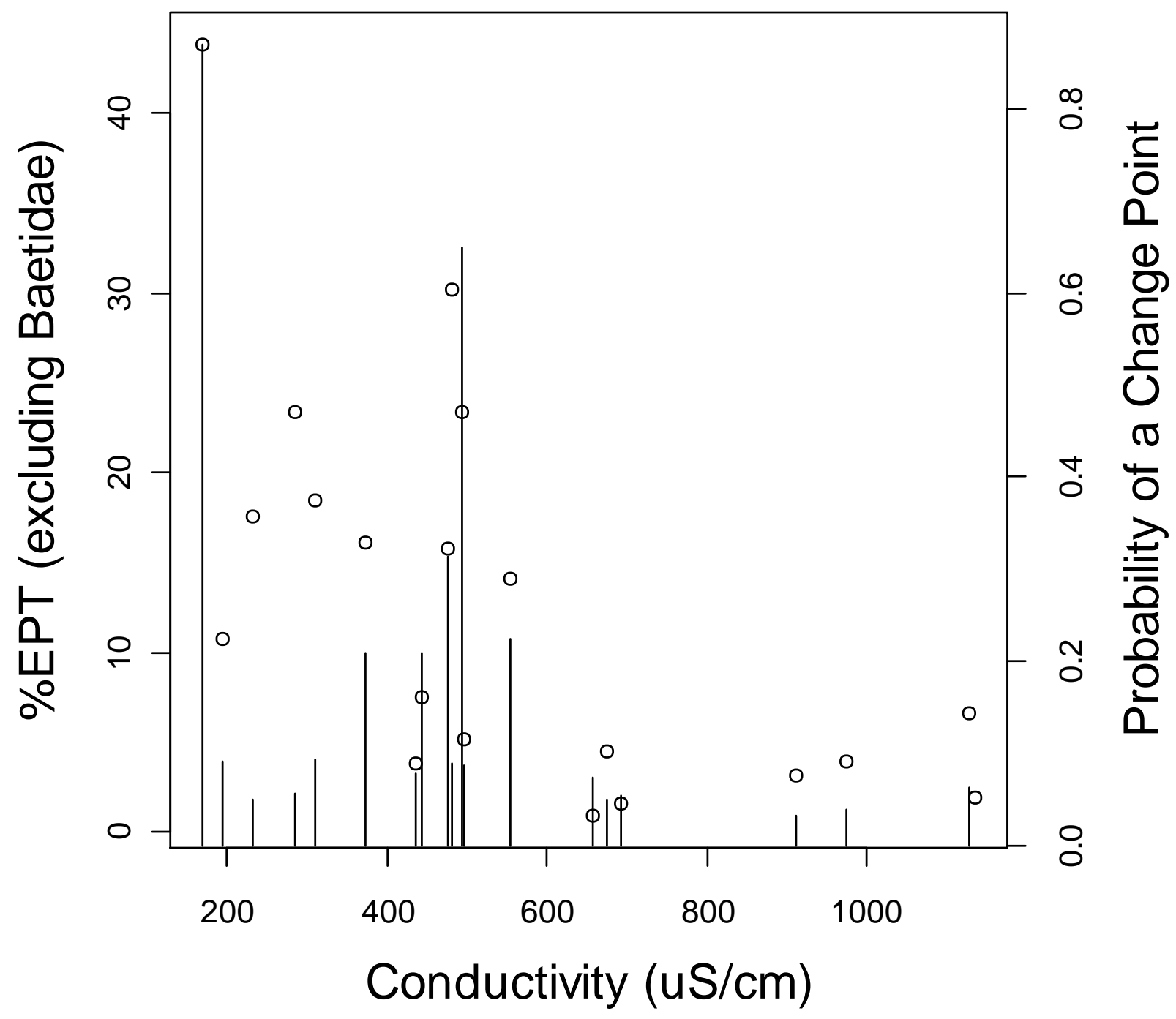

Figure 57: Results of Bayesian Change Point (BCP) analysis for the correlation between \%EPT excluding Baetidae and conductivity across all combined sites. Hollow circles represent sites along the gradient. Vertical bars represent the probability of a change point for each site. 


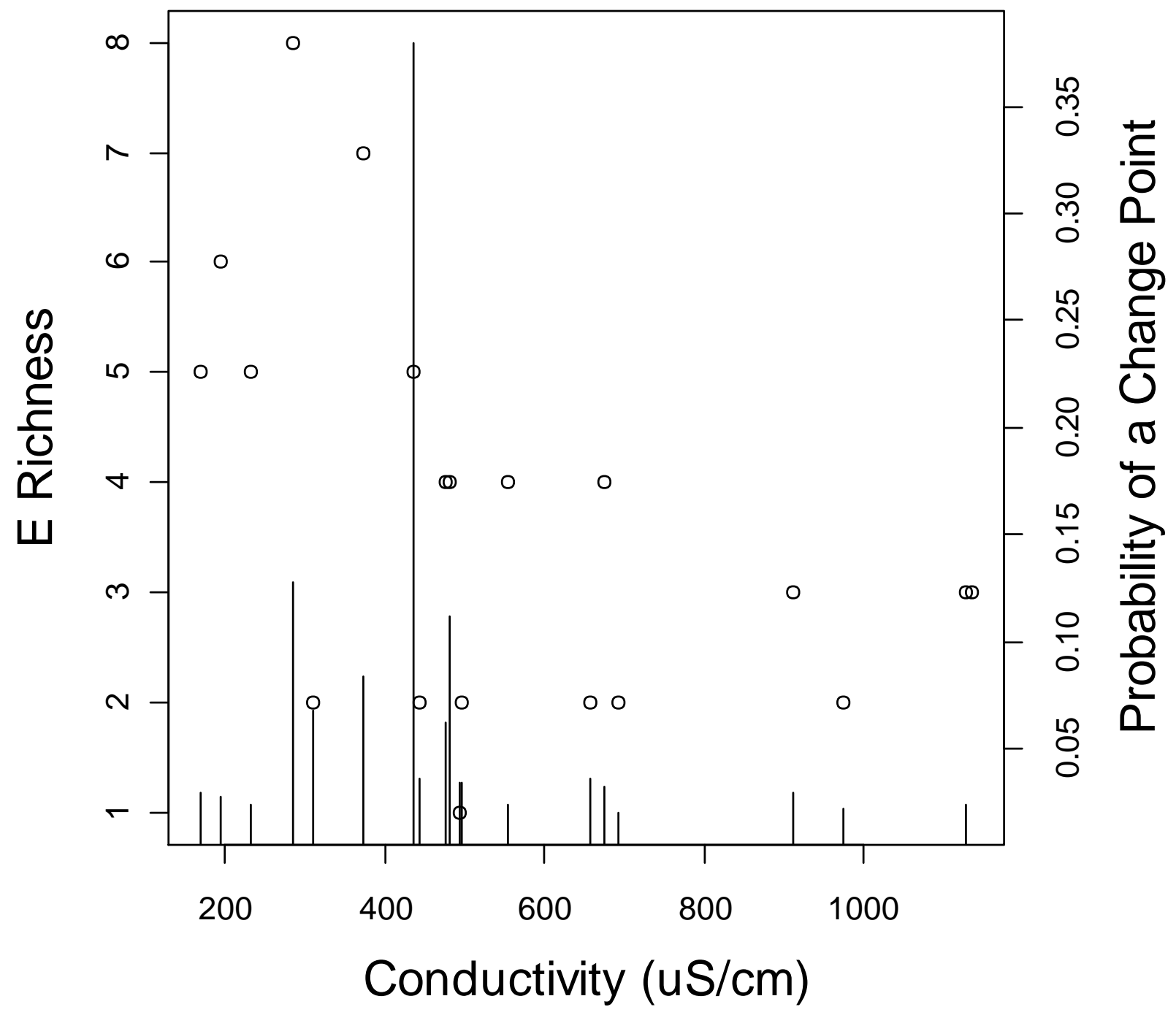

Figure 58: Results of Bayesian Change Point (BCP) analysis for the correlation between Ephemeroptera (E) richness and conductivity across all combined sites. Hollow circles represent sites along the gradient. Vertical bars represent the probability of a change point for each site. 


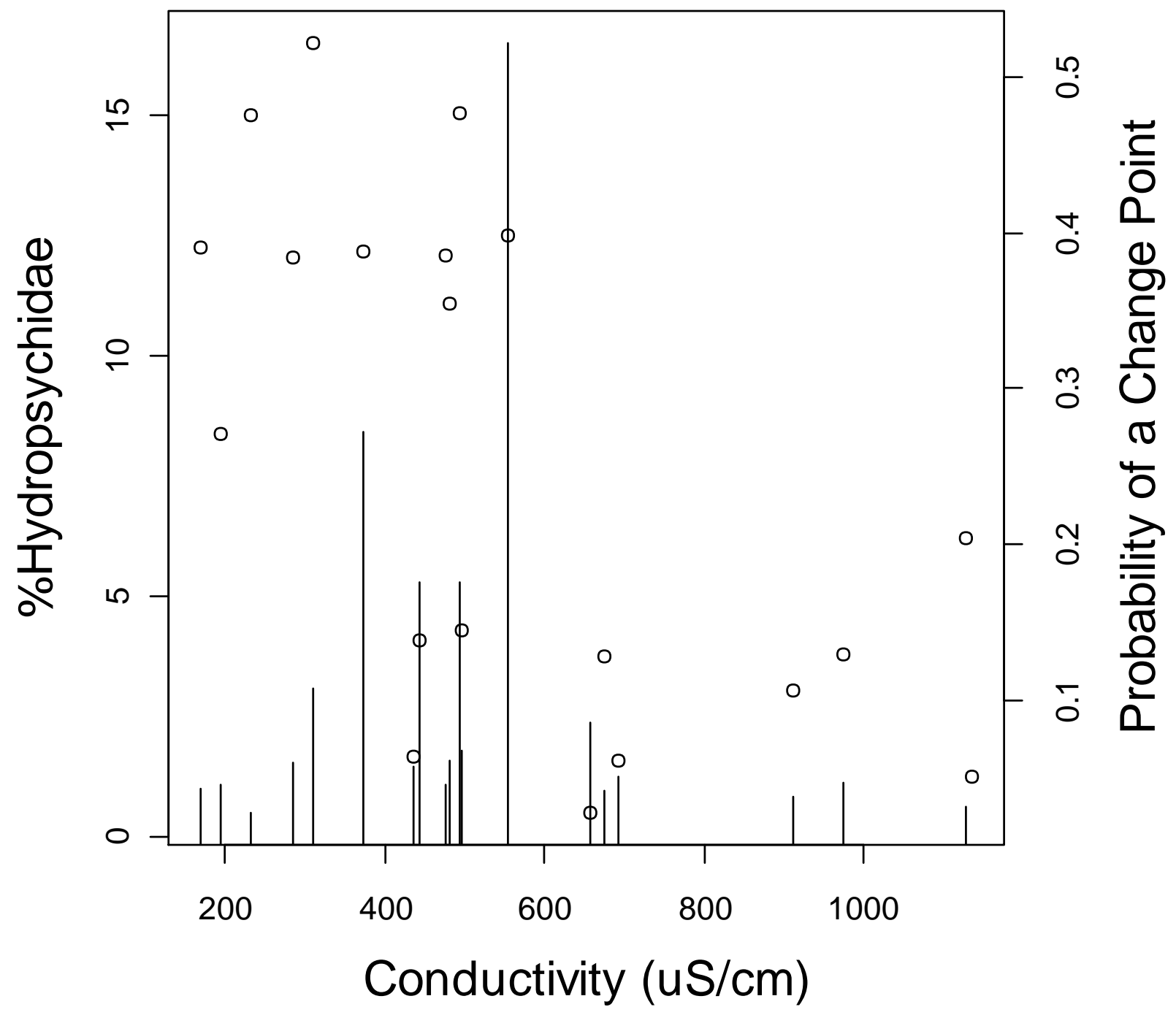

Figure 59: Results of Bayesian Change Point (BCP) analysis for the correlation between $\%$ Hydropsychidae and conductivity across all combined sites. Hollow circles represent sites along the gradient. Vertical bars represent the probability of a change point for each site. 


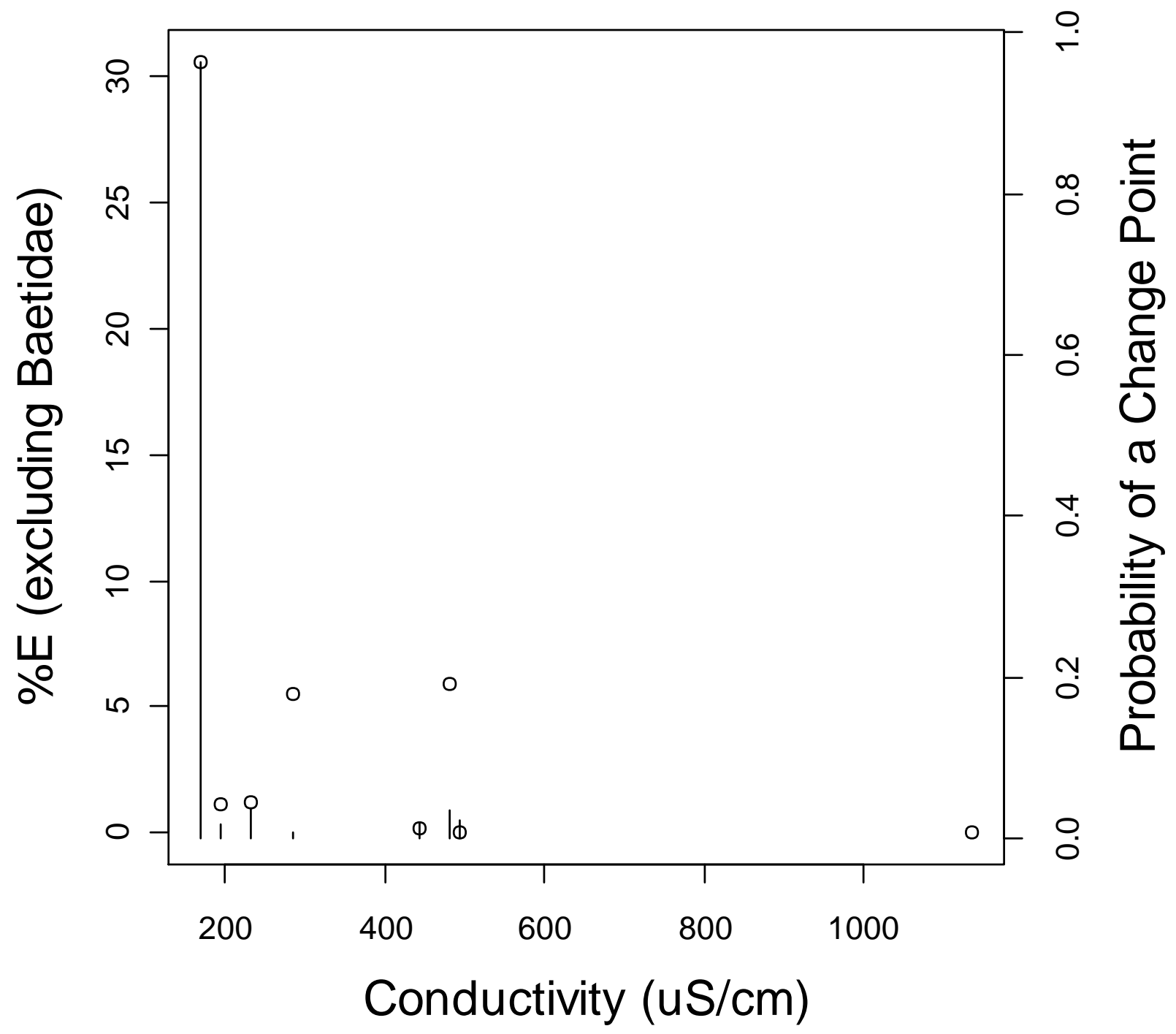

Figure 60: Results of Bayesian Change Point (BCP) analysis for the correlation between \%E excluding Baetidae and conductivity across the small combined sites. Hollow circles represent sites along the gradient. Vertical bars represent the probability of a change point for each site.

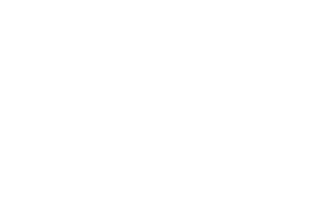

